\title{
Historische Anatomieleichen der Universität Göttingen - Zur Morbidität einer Bevölkerungsgruppe des 19. Jahrhunderts
}

\author{
DISSERTATION \\ zur Erlangung des mathematisch-naturwissenschaftlichen Doktorgrades \\ "Doctor rerum naturalium" \\ der Georg-August-Universität Göttingen \\ im Basisprogramm Biologie \\ der Georg-August University School of Science (GAUSS)
}

vorgelegt von

Maria Feicke

aus Karl-Marx-Stadt, jetzt Chemnitz

Göttingen, 2019

\section{Band 1}




\section{Betreuungsausschuss}

Prof. Dr. P. Kappeler, Abteilung Verhaltensökologie und Soziobiologie, Deutsches Primatenzentrum; Abteilung Soziobiologie und Anthropologie, Johann-Friedrich-Blumenbach Institut für Zoologie und Anthropologie, Georg-August-Universität Göttingen

Prof. Dr. Dr. M. Schultz, AG Paläopathologie, Institut für Anatomie und Embryologie, Zentrum für Anatomie, Universitätsmedizin Göttingen; Abteilung Biologie, Institut für Biologie und Chemie, Universität Hildesheim

Dr. S. Hummel, Abteilung Historische Anthropologie und Humanökologie, Johann-FriedrichBlumenbach Institut für Zoologie und Anthropologie, Georg-August-Universität Göttingen

\section{$\underline{\text { Mitglieder der Prüfungskommission }}$}

Referent: Prof. Dr. P. Kappeler, Abteilung Verhaltensökologie und Soziobiologie, Deutsches Primatenzentrum; Abteilung Soziobiologie und Anthropologie, Johann-Friedrich-Blumenbach Institut für Zoologie und Anthropologie, Georg-August-Universität Göttingen

Korreferent: Prof. Dr. Dr. M. Schultz, AG Paläopathologie, Institut für Anatomie und Embryologie, Zentrum für Anatomie, Universitätsmedizin Göttingen; Abteilung Biologie, Institut für Biologie und Chemie, Universität Hildesheim

Weitere Mitglieder der Prüfungskommission:

Prof. Dr. J. Ostner, Abteilung Verhaltensökologie, Johann-Friedrich-Blumenbach Institut für Zoologie und Anthropologie, Georg-August-Universität Göttingen

Prof. Dr. A. Stumpner, Abteilung Zelluläre Neurobiologie, Johann-Friedrich-Blumenbach Institut für Zoologie und Anthropologie, Georg-August-Universität Göttingen

Dr. S. Hummel, Abteilung Historische Anthropologie und Humanökologie, Johann-FriedrichBlumenbach Institut für Zoologie und Anthropologie, Georg-August-Universität Göttingen

PD Dr. S. Bradler, Abteilung Evolution und Biodiversität der Tiere, Johann-FriedrichBlumenbach Institut für Zoologie und Anthropologie, Georg-August-Universität Göttingen 
Diese Arbeit wurde angefertigt in der Abteilung Historische Anthropologie und Humanökologie des Johann-Friedrich-Blumenbach Institutes für Zoologie und Anthropologie der Georg-August-Universität Göttingen im Rahmen des Projektes: „Historische Anatomieleichen der Universität Göttingen - Ein fachübergreifender Ansatz zur Deskription der Morbidität sozial schwacher Bevölkerungsgruppen des 19. Jahrhunderts“. Das Projekt wurde gefördert vom Ministerium für Wissenschaft und Kultur (MWK) des Landes Niedersachsen, Förderkennzeichen: 76202-20-7/14. Projektleiterin: Dr. Susanne Hummel. 


\section{Inhaltsverzeichnis}

1 Einleitung ....................................................................... 1

2 Fundgut und Materialien ....................................................

2.1 Fundumstände und Bergung der Skelette ......................................................... 7

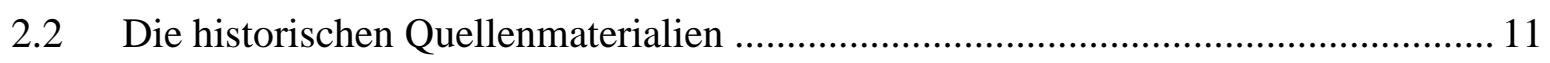

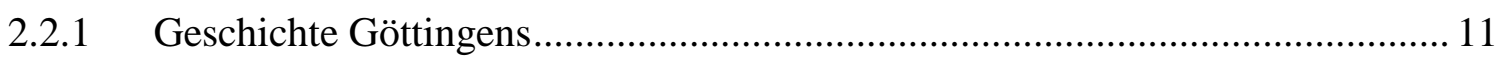

2.2.2 Die Universitätsmedizin Göttingens ...................................................... 13

2.2.3 Der Friedhof und die katholische Gemeinde in Göttingen .............................. 14

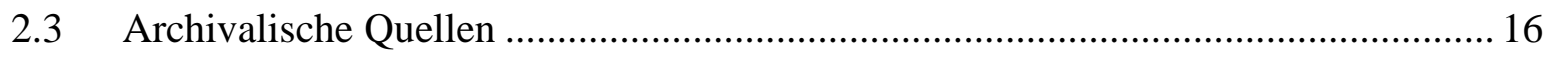

3 Untersuchungsmethoden ............................................... 17

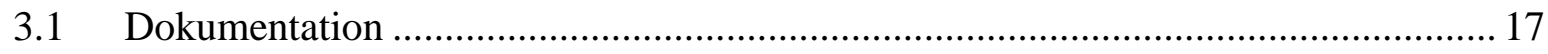

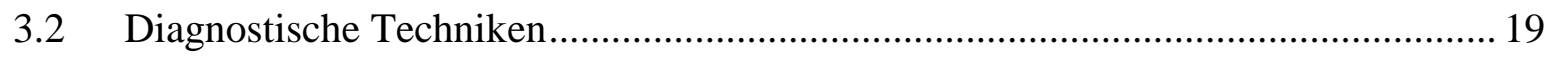

3.2.1 Makroskopie, Lupenmikroskopie und Endoskopie....................................... 20

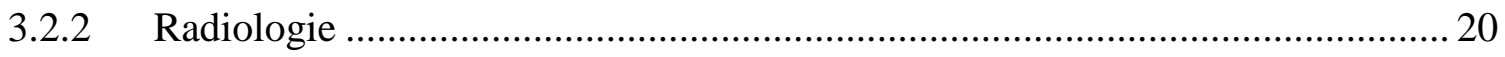

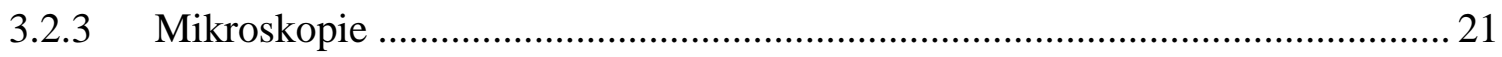

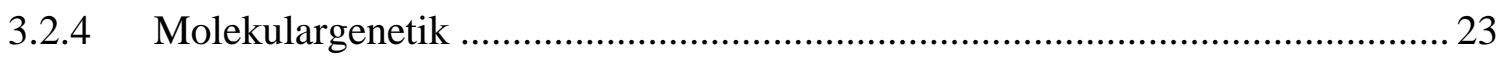

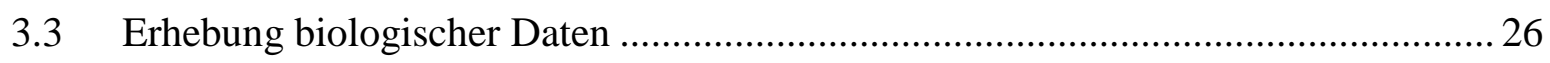

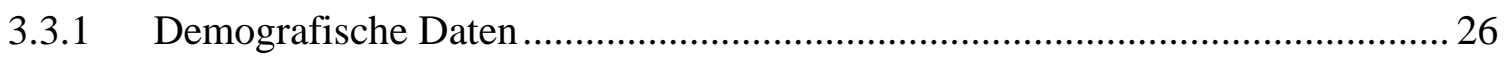

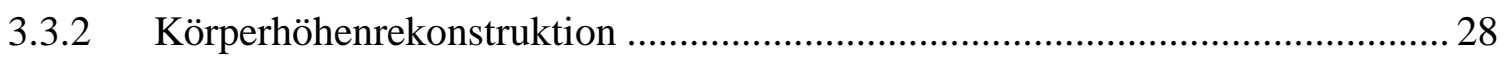

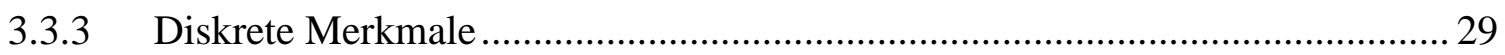

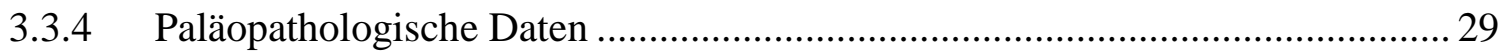

3.3.4.1 Unspezifische Stressmarker ............................................................. 29

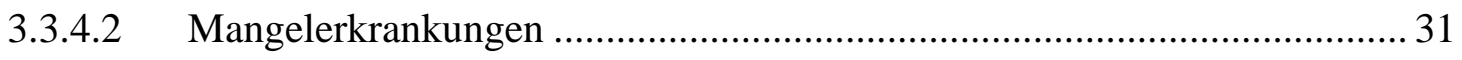

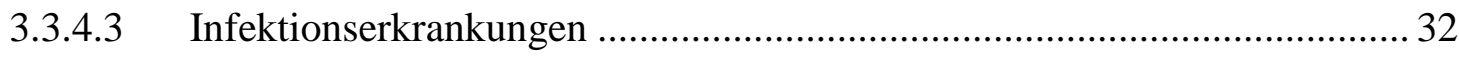




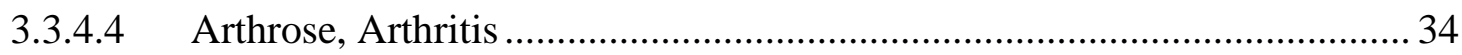

3.3.4.5 Erkrankungen der Zähne und Kiefer..................................................... 38

3.3.4.6 Weitere Erkrankungen und Veränderungen.............................................. 39

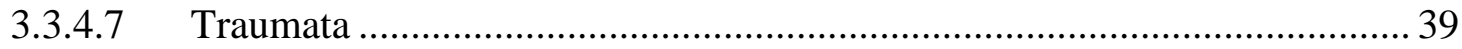

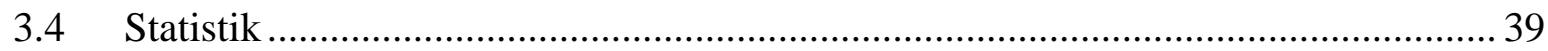

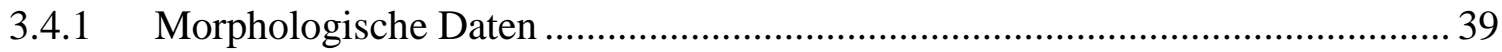

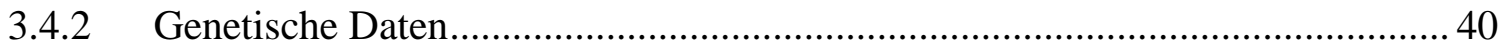

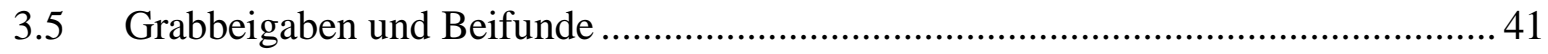

3.6 Bewertung der historischen Daten............................................................ 41

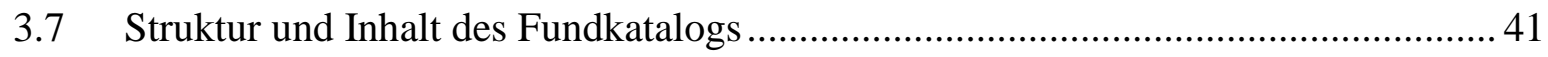

4 Befunde und Ergebnisse ...............................................................43

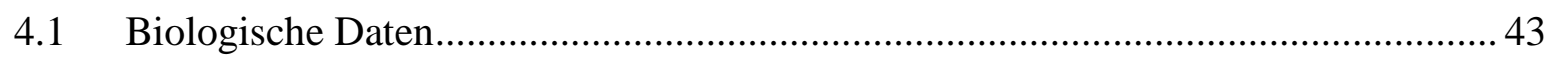

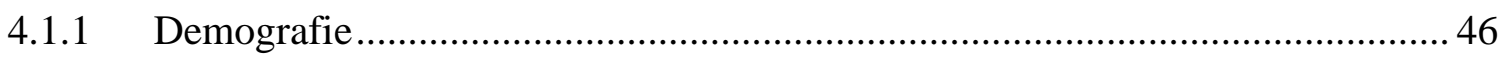

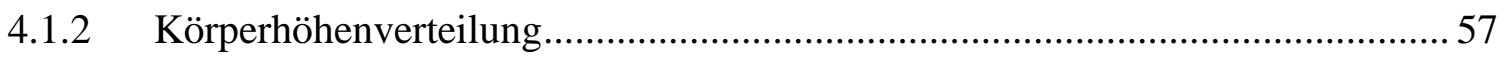

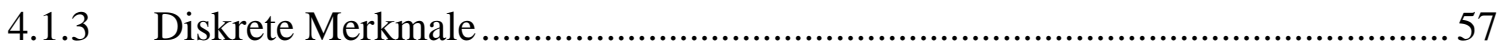

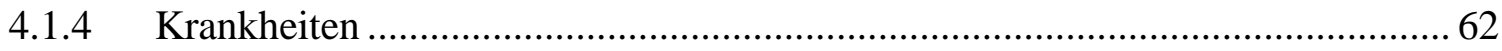

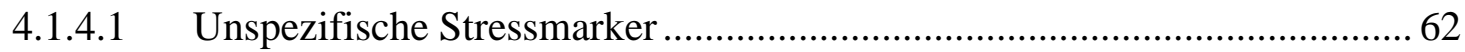

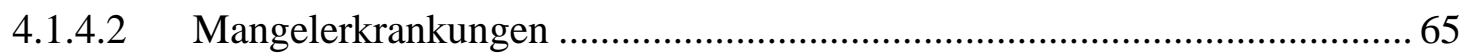

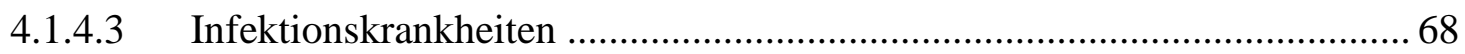

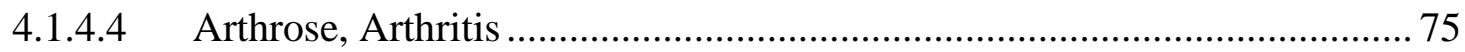

4.1.4.5 Erkrankungen der Zähne und Kiefer...................................................... 91

4.1.4.6 Weitere Erkrankungen und Veränderungen............................................ 94

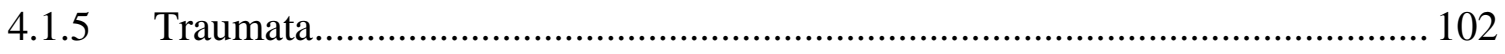

4.1.6 Vergleich von Allelfrequenzen ................................................................ 106

4.2 Grabbeigaben, Beifunde und Sozialstatus ............................................................. 107

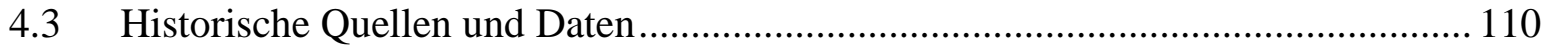

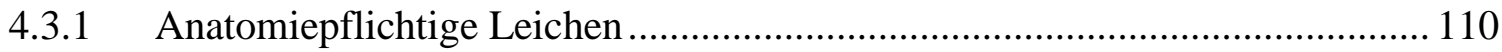


4.3.2 Meldescheine bei Todesfällen

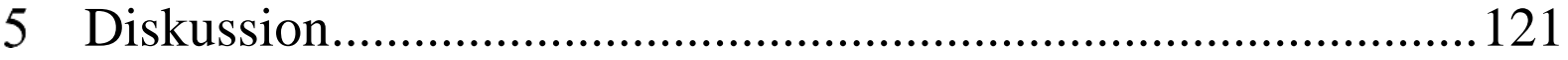

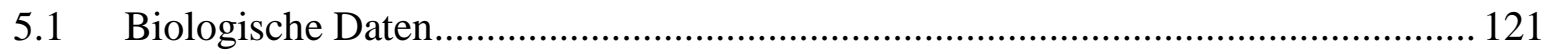

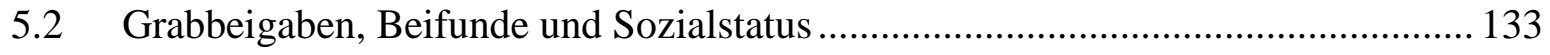

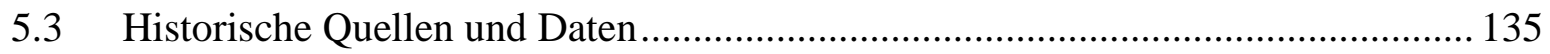

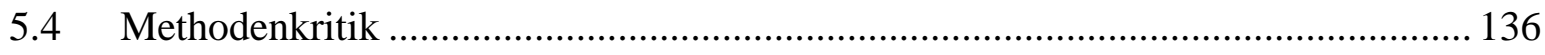

6 Zusammenfassung ............................................................... 141

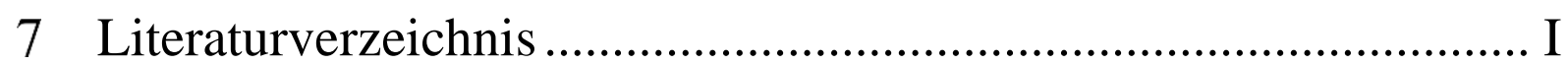

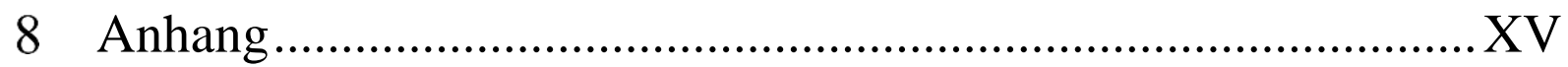

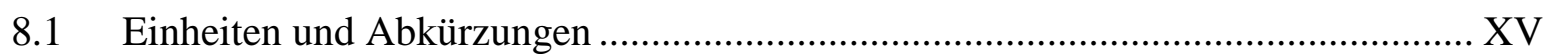

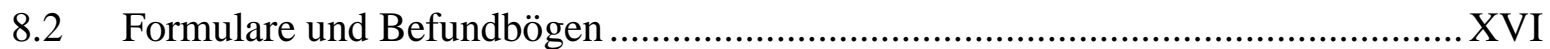

8.3 Ergebnisse Molekulargenetischer Untersuchungen.............................................XXI

8.4 Ergebnisse statistischer Untersuchungen pathologischer Veränderungen ........... XXVI

8.5 Daten auf der beigelegten CD/Band 2 .................................................... XXXIII 
"I profess to learn and to teach anatomy not from books but from dissections, not from the tenets of philosophers but from the fabric of nature."

— William Harvey (1628) — 


\section{Einleitung}

\section{Einleitung}

In dem Fach Historische Anthropologie wird mittels unterschiedlicher naturwissenschaftlicher Methoden das Leben eines Einzelnen oder gar einer ganzen Population rekonstruiert. Kulturelle Veränderungen, Migration, Konflikte, Epidemien, Klima und Umwelt haben von jeher einen enormen Einfluss auf den Menschen gehabt. Sowohl psychisch als auch physisch findet mit jeder Veränderung auch eine Anpassung an die neuen Umweltbedingungen statt. Anthropologen können mithilfe menschlicher Überreste, in Form von Knochen und Zähnen, und der daraus gewonnenen biologischen Basisdaten (z. B. Alter, Geschlecht) ein Individuum in einen gesellschaftlichen und sozialen Kontext einordnen. Die Fachdisziplin Paläopathologie beschäftigt sich vorrangig mit Erkrankungen unserer Vorfahren. Die Verknüpfung der Daten aus beiden Fachbereichen vermittelt einen umfassenden Eindruck über Lebensumstände und den Gesundheitszustand einer Population. Bei anthropologischen und paläopathologischen Untersuchungen kann auf ein ausgedehntes Methodenrepertoire zurückgegriffen werden. Makroskopische Untersuchungen zu Art und Häufigkeit von Erkrankungen werden sowohl durch die Endoskopie, Radiologie, Licht- und Rasterelektronenmikroskopie als auch die Molekulargenetik unterstützt. In dieser Arbeit wird evaluiert, ob die menschlichen Überreste zweier Bevölkerungsgruppen aus Göttingen Rückschlüsse auf deren Lebensumstände und soziale Stellung zulassen.

\section{Einfluss des sozialen Status}

Die Zugehörigkeit zu einer sozial niedrigen Schicht ist sehr eng an Morbidität und Mortalität geknüpft (Illsley und Baker 1991). Unter bestimmten Umständen spielt auch die Anfälligkeit des einzelnen Individuums gegenüber Krankheitserregern eine Rolle.

Im Vergleich zur einkommensstarken Bevölkerung haben Menschen der niedrigsten Einkommensgruppe heutzutage ein um 2,4 bzw. 2,7-fach erhöhtes Mortalitätsrisiko (Lampert et al. 2007). Als Folge sterben Menschen der niedrigsten Einkommensschicht im Vergleich zu Menschen der höchsten Einkommensschicht mehr als doppelt so häufig vor ihrem 65 . Lebensjahr. Ergänzend kommt hinzu, dass Menschen höherer Einkommensschichten nicht nur eine höhere Lebenserwartung haben, sondern diese auch in einem besseren Gesundheitszustand verbringen. Diese Phänomene der sozialen Ungleichheit existieren europaweit (Lampert und Kroll 2014) und letztlich sogar weltweit. Im Gegensatz dazu haben Menschen mit einem geringen Einkommen nicht nur eine niedrigere Lebenserwartung, sondern auch ein erhöhtes 


\section{Einleitung}

Risiko für Erkrankungen (Lampert und Kroll 2010). Bei diesen Erkrankungen handelt es sich konkret um Herz-Kreislauf-Erkrankungen, Atemwegserkrankungen und Stoffwechselstörungen. Die daraus resultierenden langanhaltenden Gesundheitsprobleme führen wiederum zu einer eingeschränkten Alltagsbewältigung. Zusätzlich erhalten Personen, welche in Armut leben, vergleichsweise weniger soziale Unterstützung und neigen häufiger zu gesundheitsriskanten Verhaltensweisen (Lampert und Kroll 2010).

Tendenziell besteht mit steigendem Einkommen vor allem für Männer die Aussicht auf ein längeres Leben in Gesundheit (Lampert et al. 2007). Frauen mit niedrigem Einkommen scheinen vor allem deswegen eine niedrigere Lebenserwartung zu haben, weil sie stark unter der psychischen Belastung finanzieller Knappheit leiden und ihnen sozialen Kontakte fehlen (Kroh et al. 2012). Im Allgemeinen reagieren Frauen offenbar stärker als Männer auf positive und negative Umwelteinflüsse (Cronkite und Moos 1984). So sind Frauen zum Beispiel empfänglicher für soziale Ressourcen, z. B. familiären Rückhalt. Des Weiteren stellte sich heraus, dass Menschen mit einem geringen Selbstwertgefühl im Durchschnitt häufiger mit Depressionen zu kämpfen haben (Kroh et al. 2012). Bei den Männern der niedrigen Einkommensschicht sind geringe Bildung und physisch belastende Arbeit die Hauptfaktoren für ein erhöhtes Mortalitätsrisiko (Kroh et al. 2012). Unabhängig vom Geschlecht wird bereits im Säuglingsalter der Grundstein für die Zukunft gelegt. Wird ein Kind in eine entsprechend niedrige soziale Schicht hinein geboren, besteht ein erhöhtes Risiko für Krankheiten im Kindesalter, aber auch im Erwachsenenalter (Dragano 2007).

Kritische Stimmen merken an, dass die typischen, auf Klassen basierenden Untersuchungen nur limitiert aussagefähig sind (Illsley und Baker 1991). Das Problem bei auf Sozialklassen basierenden Systemen ist die Tatsache, dass sich die Klassen über die Zeit ständig in ihrer Größe und Zusammensetzung verändern. Um die Studien aussagekräftiger zu gestalten, müsste man den Interaktionen zwischen Alter, Geschlecht und der Todesursache mehr Beachtung schenken. Außerdem beeinflussen möglicherweise Ereignisse wie zum Beispiel Totgeburten oder plötzliche Kindstode Statistiken dahin gehen, dass fälschlicherweise der Eindruck entsteht, dass Individuen sozial niedriger Schichten eine durchschnittlich geringere Lebenserwartung haben.

Bei Menschen zwischen dem 45 - 64 Lebensjahr sind die Todesursachen oft Herzkrankheiten oder Krebs. Des Weiteren sind beispielsweise Herz-Kreislauf-Erkrankungen nicht nur ein Resultat von Armut, sondern auch von Ernährungsgewohnheiten, übermäßigem Konsum von Fleisch, gesättigtem Fett, Tabak, Alkohol und fehlender Bewegung (Illsley und Baker 1991) in 


\section{Einleitung}

Kombination mit genetischen Faktoren. Daher sind die Todesursachen oft eine Reflextion des Lebensstils und des Konsumverhaltens. Der Begriff der sozialen Schicht ist umstritten und nicht unkritisch zu bewerten, da gerade die horizontalen, nicht berufsbedingten Ungleichheiten zwischen Geschlechtern, Altersgruppen, der regionalen Herkunft u. v. m. die Heterogenität sozialer Lebenslagen in einer Schicht verstärken (Möller-Leimkühler 1999). Bei Untersuchungen über den Zusammenhang zwischen der sozialen Ungleichheit und psychischen Erkrankungen wird vor allem Bezug auf die Indikatoren Sozialstatus und Geschlecht genommen. Ein geringes Einkommen kann auch Folge einer psychischen Erkrankung sein (Möller-Leimkühler 1999). Die vertikalen sozialen Ungleichheiten spiegeln sich in Faktoren wie Bildung, Einkommen und Vermögen, Ansehen und Macht wieder.

Allein negative Emotionen, wie Depressionen und Angst, können eine Vielzahl von Gesundheitsproblemen nach sich ziehen, da sie das Immunsystem aktiv beeinflussen (KiecoltGlaser et al. 2002). Die nachhaltige Produktion von entzündungsfördernden Zytokinen kann direkt durch negative Emotionen und stressige Erlebnisse stimuliert werden. Des Weiteren führen negative Emotionen zu einer verlängerten Infektions- und zu einer verspäteten Heilungsphase (Kiecolt-Glaser et al. 2002).

Extreme Armut, gekoppelt mit minderwertiger Nahrung, schlechten Wohnverhältnissen sowie inadäquate medizinische Versorgung, haben pathologische Auswirkungen auf den menschlichen Körper. Allerdings sind in jeder der Schichten einer Sozialhierarchie Verbindungen zwischen dem sozioökonomischen Status und der Gesundheit zu finden (Adler et al. 1994).

\section{Das Skelett als Informationsquelle}

Der Knochen, als zug- und druckfestes Organ, ist Teil des passiven Stütz- und Bewegungsapparates und schützt die inneren Organe. Da sowohl proliferative als auch resorptive Prozesse am Knochen zeitlebens stattfinden und durch verschiedenste Faktoren und Krankheiten beeinflusst werden, sind Hinweise auf Belastungen unterschiedlichster Art deutlich sichtbar. Angeborene aber auch erworbene Erkrankungen können die Entwicklung beschleunigen, verzögern oder zeitweise bzw. endgültig zum Stillstand bringen (Brossmann et al. 1982). Da Knochen allerdings nur die Fähigkeit haben mit einer gewissen Plastizität zu reagieren, muss in jedem Fall eine Differentialdiagnostik durchgeführt werden. Im Folgenden werden die wichtigsten Faktoren geschildert, die die entscheidenden Daten für die 


\section{Einleitung}

Interpretation und Rekonstruktion eines Menschlebens oder aber dem Leben einer ganzen Population liefern.

Anhand des Geschlechterverhältnisses kann die Zusammensetzung einer Population näher beschrieben werden. Ein Männer- oder Frauenüberschuss kann auf eine hohe Sterblichkeitsrate bei einem der beiden Geschlechter hinweisen. So sind zum Beispiel während des Krieges allgemein mehr männliche Leichen zu erwarten. Der morphologische Unterschied zwischen den Geschlechtern, vor allem in Hinsicht auf die Robustizität, ist stark populationsabhängig und kann in seiner Deutlichkeit intra- und interspezifisch variieren. Individuelle Anforderungen im Alltag, vor allem in Gruppen mit traditionellen Rollenbildern und Aufgabenverteilungen, können ebenso einen Einfluss auf die Robustizität des Körpers haben. Folglich muss für eine zu untersuchende Skelettserie zu Beginn der Bearbeitung auf regionale, kulturelle und habituelle Kontexte geachtet werden.

Die Altersverteilung einer Population lässt sich anhand der Sterbealter aller Individuen erstellen. Diese Verteilung gibt wiederum Auskunft über die generelle Lebenserwartung der untersuchten Population. Die Lebenserwartung und die Kindersterblichkeit vermitteln die generellen Lebensbedingungen einer Population. Ein gehäuftes Auffinden von weiblichen Skeletten in der Altersklasse 20 - 40 Jahre kann beispielsweise auf die tödlichen Komplikationen bei Schwangerschaften und/oder Geburten zurückzuführen sein. Eine ungleichmäßige oder untypische Altersverteilung kann im Zusammenhang mit Sonderbestattungen bestimmter Individuen, z. B. Kindern, stehen. Darüber hinaus können die Anforderungen des Alltags deutlich das Aussehen des Körpers und, für diese Arbeit am interessantesten, des Skeletts beeinflussen. Die Knochen eines Individuums, welches permanent körperlich tätig ist, weisen eine Zunahme von Kollagenfasern und eine deutlich dickere Compacta der Langknochen auf. Zudem kommt es zu einer erhöhten Abnutzung der Gelenksflächen. Die Auswirkungen körperlicher Belastung auf die Knochenbinnenstruktur und Gelenke führen zu einem verminderten oder erhöhten biologischen Altem. Zu beachten ist, dass bei morphologischen und mikroskopischen Methoden nur ein biologisches Alter für ein Individuum, nicht aber ein chronologisches Alter, festgestellt werden kann. Eine Ausnahme bildet die Auszählung der Zuwachsringe im Zahnzement.

Die Körperhöhe eines Menschen setzt sich zum einen aus der genetischen Veranlagung und zum anderen aus den Lebensumständen, zum Beispiel Ernährung, Hygiene und vielen mehr, zusammen. Bereits im 19. Jahrhundert war Sozialreformern bewusst, dass es eine Beziehung zwischen der Körperhöhe eines Menschen und seinem sozialen Status gibt (Komlos 1990). Es 


\section{Einleitung}

wurde vermutet, da die Nahrungsmittelaufnahme vom realen Einkommen abhing und das Einkommen positiv (die Arbeitsintensität negativ) mit dem sozioökonomischen Status korrelierte, müsste die Körperhöhe ein guter Indikator für die Gesundheit sein und ebenfalls mit dem sozialen Status korrelieren. Wenn sich die allgemeinen Lebensbedingungen im Zuge der Industrialisierung verbessern, wie es zum Beispiel seit Mitte des 19. Jahrhunderts in Europa der Fall ist, nimmt auch die durchschnittliche Körperhöhe zu. Der Trend der beschleunigten ontogenetischen Entwicklung wird im anthropologischen Kontext säkulare Akzeleration genannt. Laut Rösing et al. (2005) nahm die Körperhöhe zwischen Mitte des 19. Jahrhunderts bis heute in Europa um $16-18 \mathrm{~cm}$ zu. Für rezente Populationen sollten entsprechend veränderte und an die Proportionen angepasste Formeln für die Berechnung der Körperhöhe genutzt werden.

Die Lebensumstände in Form von örtlichen Faktoren spielen bei der Bewertung von Skelettfunden eine ebenso große Rolle wie zeitliche Faktoren. Beispielsweise können die ökologischen Bedingungen des Ortes die Ernährung maßgeblich beeinflussen. Sind fruchtbare Äcker und Wiesen, genügend Niederschlag und Sonnenschein in der Region vorhanden, kann eine umfangreiche Landwirtschaft und Viehzucht betrieben werden. Gleichermaßen sind die historische, soziale und kulturelle Zugehörigkeit eines Individuums wesentliche Faktoren bei der Interpretation naturwissenschaftlich erhobener Daten. Ereignisse wie Kriege, Epidemien, wirtschaftlicher Aufschwung oder politischer Umschwung können dabei nicht minder große Einflüsse auf die Existenz haben wie Naturkatastrophen oder Individualschicksale.

Bei der Untersuchung von menschlichen Überresten ist darauf zu achten, ob Abweichungen von der Regelanatomie intravital, peri- oder postmortal entstanden sind. Wird dies nicht beachtet, könnten falsche Rückschlüsse gezogen werden.

Wie bereits dargestellt sind die Art und Häufung eines Krankheitsbefundes, die Schwere der Gelenkabnutzung und die Qualität des Heilungsprozesses neben den biologischen Basisdaten gute Indikatoren für Lebensumstände, wie Ernährung, Hygiene und Belastung. Daher sollten Abweichungen von der Regelanatomie, zumindest indirekt, auch als Indikator für die soziale Stellung nutzbar sein. Miszkiewicz und Mahoney (2016) konnten an Skeletten aus dem mittelalterlichen England nachweisen, dass sich die Mikrostruktur der Oberschenkeldiaphysen von Individuen zweier verschiedener sozialer Schichten voneinander unterscheidet. 


\section{Einleitung}

\section{Zielsetzung der Arbeit}

In dieser Arbeit wird das im Jahre 2011 auf dem ersten katholischen Friedhof Göttingens geborgene Skelettkollektiv auf die Verbindung von sozialer Zugehörigkeit mit Morbidität untersucht. Das neuzeitliche Kollektiv besteht aus den menschlichen Überresten von 159 Individuen und lässt sich in zwei Gruppen einteilen. Im Vordergrund steht eine Gruppe (n = 39), welche im Bereich des Schädels und vereinzelt am postcranialen Skelett Spuren von Sektionen aufweist. Sie wurden vermutlich in der Medizinischen Fakultät der Universität Göttingen seziert und werden im Verlauf der Arbeit als „Anatomieleichen“ bezeichnet. Die zweite Gruppe $(n=120)$ weist keinerlei Anzeichen einer Leichenöffnung auf. Sie werden im Weiteren „Regelbestattungen“ genannt. In dieser Arbeit werden beide Gruppen eingehend mittels medizinisch-naturwissenschaftlicher Methoden untersucht und miteinander verglichen. Folgende sind die Kernpunkte dieser Arbeit:

- Erstellung eines ausführlichen Fundkatalogs über die biologischen Basisdaten sowie Krankheitsbefunde und habituelle Veränderungen der Skelette.

- Analyse des Einflusses des sozialen Standes eines Individuums auf das Skelett und damit verbundene Erkrankungen.

- Interpretation der biologischen Datenlage und Zusammenführung mit historischen Quellen über die Akquise und den Umgang mit Leichen in der Anatomie.

Hypothese: Aufgrund der Annahme, dass Menschen der sozial niedrigsten Schichten im 18. und 19. Jahrhundert nach ihrem Tod in der Anatomie seziert wurden, wird erwartet, dass die Skelette dieser Anatomieleichen infolge der schlechteren Lebensbedingungen eine höhere Morbiditätsfrequenz als die Vergleichsgruppe aufweisen. 


\section{Fundgut und Materialien}

\subsection{Fundumstände und Bergung der Skelette}

2011 wurden auf dem zentralen Campusgelände der Georg-August-Universität Göttingen im Rahmen von Bauarbeiten für ein neues Universitätsgebäude menschliche Überreste freigelegt. Die Ausgrabung dieser menschlichen Knochen wurde im Zeitraum vom 13. Juli bis 30. September 2011 durch die Grabungsfirma Arcontor Projekt GmbH unter der Leitung der Stadtarchäologie Göttingen durchgeführt. Die Grabungsarbeiten wurden dokumentiert. Es ist eine annähernde West-Ost-Ausrichtung der Begräbnisse erkennbar. Die Schädel lagen im Westen und die Füße im Osten. Das Gesetz zur Denkmalspflege ließ nur eine Teilbergung der Skelette zu, welche durch die Bauarbeiten unwiederbringlich zerstört worden wären. Weitere Skelette befinden sich noch immer im Erdreich des angrenzenden Areals.

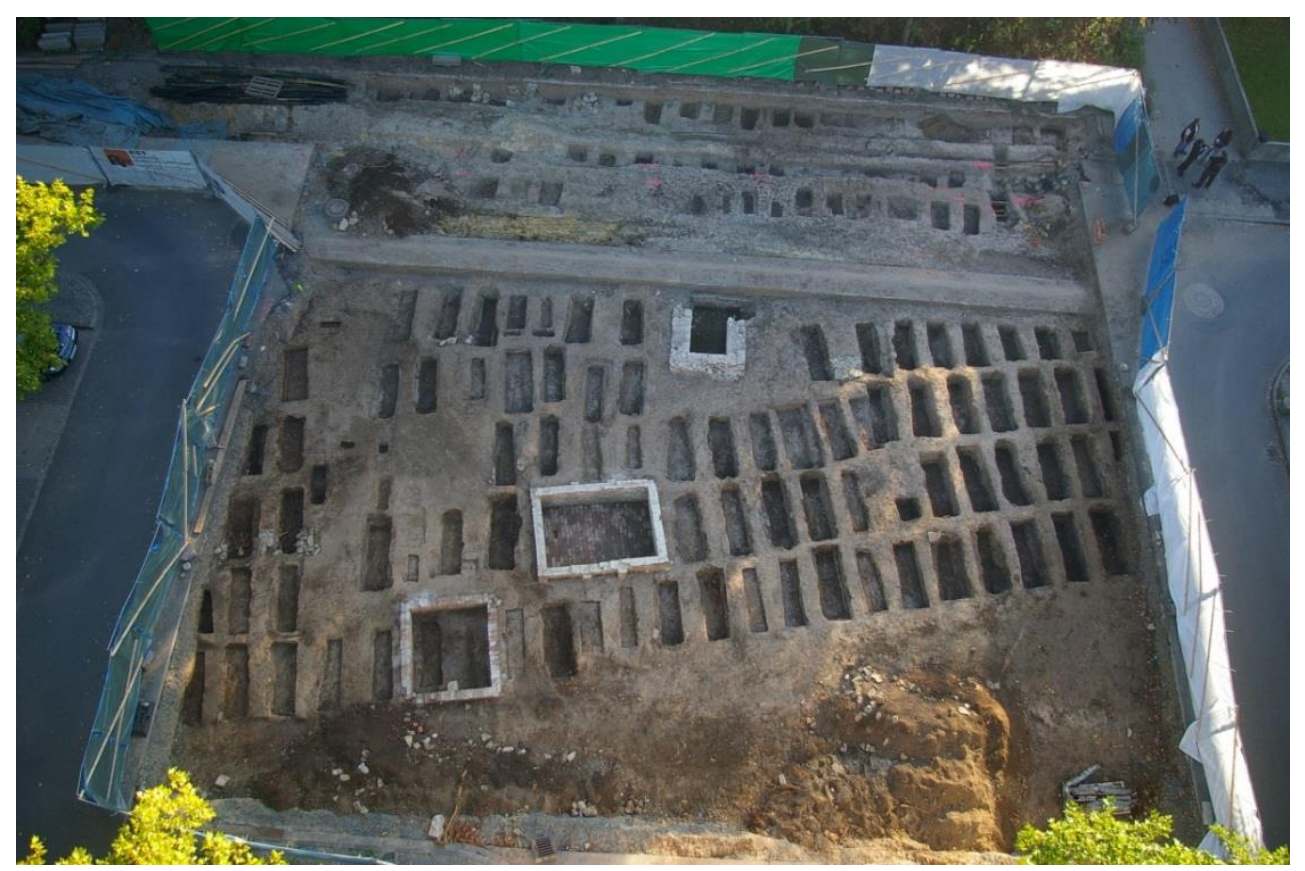

Abb. 1: Übersichtsaufnahme des Grabungsareals (30.09.11 Blickrichtung Osten). Foto Fa. Arcontor Projekt $\mathrm{GmbH}$.

Das ergrabene Areal (Abbildung 1) von $600 \mathrm{~m}^{2}$ ist Teil des südwestlichen Randbereiches der Friedhofsanlage $\left(4000 \mathrm{~m}^{2}\right)$ der katholischen Pfarrgemeinde St. Michael Göttingen, Bistum Hildesheim. Die Belegungsdauer ist zeitlich zwischen 1851 und 1888 einzuordnen. Damit gilt dieser Friedhof als erster katholischer Friedhof Göttingens. Bei der geborgenen Skelettserie handelt es sich um 159 Skelette erwachsener und subadulter Individuen, die durch die Grabungsfirma fortlaufend nummeriert wurden und zu der Fundstellennummer 50/10 gehören. Die Grabgruben sind überwiegend eng beieinanderliegende Reihenbegräbnisse und sind 
lediglich durch zwei Grüfte, welche der Bestattung von wohlhabenden und angesehenen Bürgern dienten (siehe Abbildung 1 mittig und unten) sowie Fundamentreste einer kleinen Kapelle (siehe Abbildung 1 oben) unterbrochen. Bei der Kapelle handelt es sich um die Marienkapelle (Ströbl 2015). Doppelbestattungen kamen vereinzelt vor. In Ausnahmefällen wurden Knochen oder ganze Skelette zusammen mit einer regelhaften Bestattung in einem Grab beerdigt. Die Gräber an der östlichen Grabungsgrenze sind bereits durch frühere Baumaßnahmen, zur Legung von Kabelschächten, gestört worden.

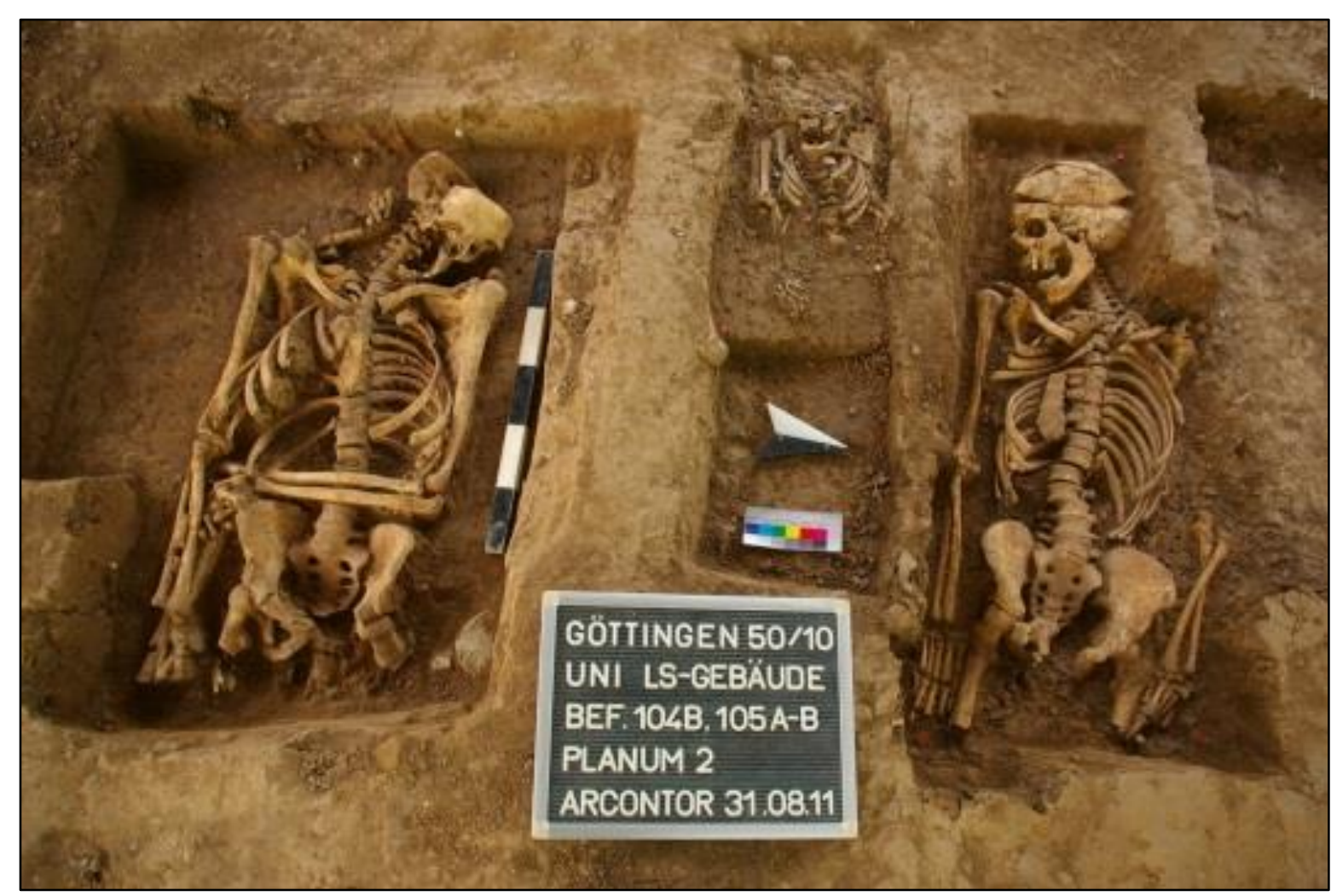

Abb. 2: Bestattung von Anatomieleichen. Fundnummern 104B, 105A-B. Geöffnete Calvaria bei beiden erwachsenen Individuen. Foto Fa. Arcontor Projekt GmbH.

Ein besonderes Augenmerk bei den Untersuchungen liegt auf den menschlichen Überresten mit Sägespuren im Bereich des Craniums und/oder des postcranialen Skelettes, wie sie in Abbildung 2 zu sehen sind. Diese Spuren sind vermutlich durch Sektionen in der Medizinischen Fakultät der Universität Göttingen, im Rahmen der Ausbildung von Studenten, entstanden.

Während der Grabung zeigte sich, dass es keine räumliche Trennung zwischen den regelbestatteten Individuen und den Anatomieleichen auf der Friedhofsanlage gab. Die Knochen aller Individuen wurden der Abteilung für Historische Anthropologie und Humanökologie des Johann-Friedrich-Blumenbach-Instituts für Zoologie und Anthropologie für weiterführende Untersuchungen übergeben. 
Die überwiegend morphologischen Voruntersuchungen im Rahmen von Abschlussarbeiten (Jugert 2012, Klatt 2012, Frischalowski 2012, Heptner 2012) konnten einen ersten vagen Eindruck über die Skelettserie vermitteln. Die gute Qualität der DNA-Erhaltung wurde ebenfalls in mehreren Abschlussarbeiten (Dicks 2012, Schröder 2012, Trede 2016) durch molekulargenetische Analysen belegt.

In den Gräbern wurden mitunter Grabbeigaben und Beifunde gefunden (z. B. Abbildung 3 bis 5) und der Stadtarchäologie übergeben.
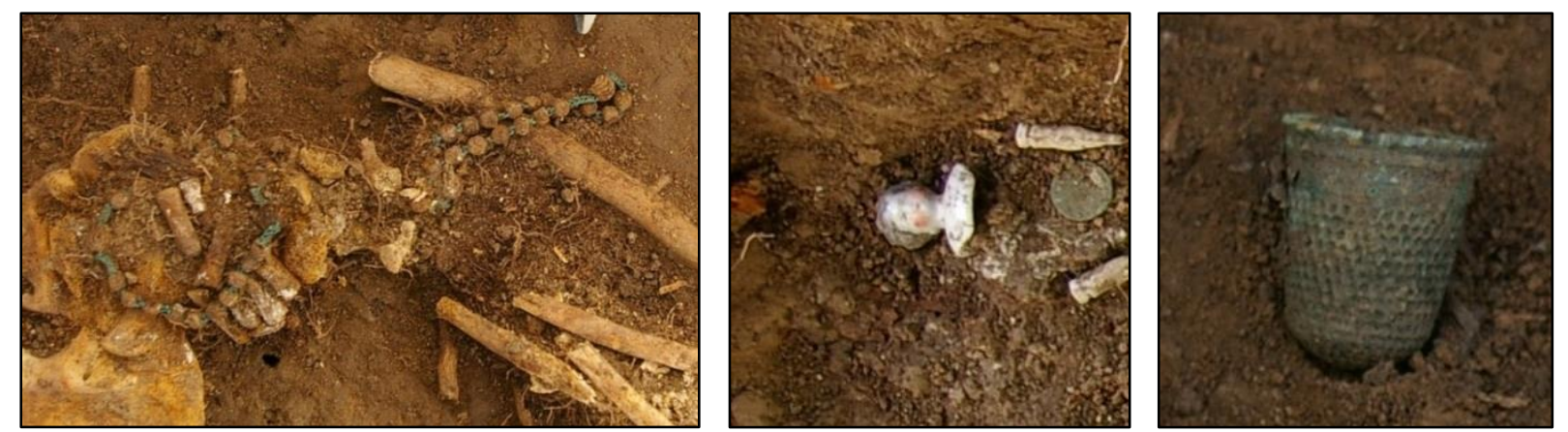

Abb. 3 bis 5: Von links nach rechts: Rosenkranz, Porzellanpüppchen, Fingerhut. Foto Fa. Arcontor Projekt $\mathrm{GmbH}$.

Der Erhaltungszustand der Skelette, die im Bereich des Campus der Universität Göttingen ergraben wurden, ist insgesamt sehr unterschiedlich. Zwar wird der menschliche Körper relativ schnell durch körpereigene Enzyme während der Autolyse abgebaut, jedoch dauern die folgenden anaeroben Fäulnis- und aeroben Verwesungsprozesse bis zur vollständigen Skelettierung mehrere Monate bis Jahre an. Die Abbauprozesse unterliegen verschiedensten Faktoren. So können Faktoren wie Liegedauer, Sauerstoffangebot, Temperatur, Mikroorganismen, Flora, Fauna, Pilzbefall, Feuchtigkeit, Boden-pH und Grabtiefe den Vorgang beschleunigen oder verlangsamen. Auch die Konstitution, das Gewicht und die gesamte körperliche Verfassung eines Menschen haben einen großen Einfluss auf die Geschwindigkeit der Fäulnis- und Verwesungsprozesse und damit auf den Erhalt der Knochen zum Bergungszeitpunkt. Eine große Anzahl von Skeletten ist gut und vollständig erhalten (siehe Abbildung 6). Voruntersuchungen haben ergeben, dass dies auch auf den DNA-Erhalt zutrifft. In diesen Fällen war eine sehr detaillierte Untersuchung des genetischen Fingerabdrucks möglich. Einige Skelette sind allerdings durch die Oberflächendegradierung, die Bildung von Brushit und Insektenbefall schlecht oder unvollständig erhalten (siehe Abbildung 7). Im Rahmen von DNA-Analysen zeigten diese Skelettelemente oder Zähne auch einen schlechten DNA-Erhalt. 


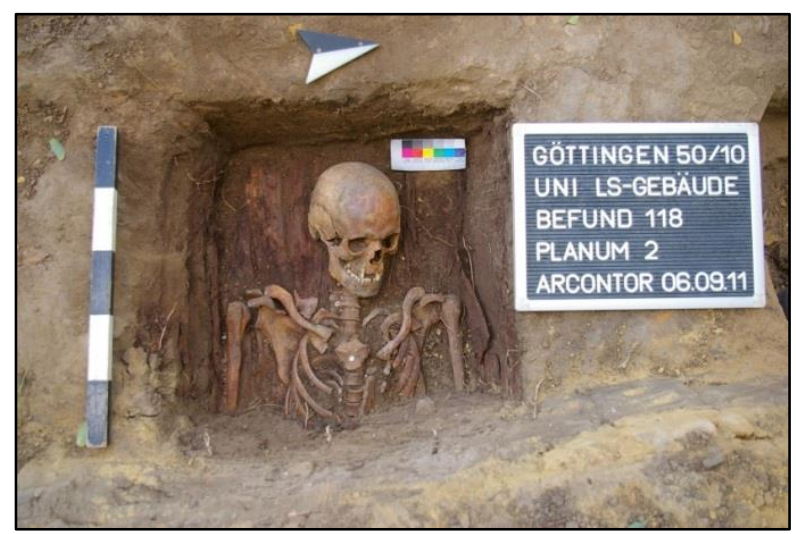

Abb. 6: Gut erhaltenes Skelett. Fundnummer 118. Foto Fa. Arcontor Projekt GmbH.

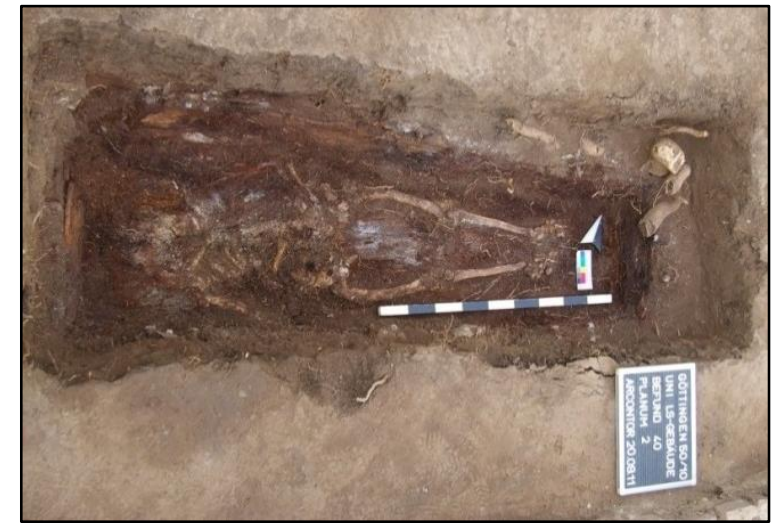

Abb. 7: Schlecht erhaltenes Skelett. Fundnummer 40. Foto Fa. Arcontor Projekt GmbH.

Der gute Knochen- und DNA-Erhalt vieler Individuen könnte der kurzen Liegezeit und dem in und um Göttingen vorkommenden, kalkhaltigen Boden geschuldet sein. Durch den leicht basischen pH-Wert wird die Knochenstruktur und die darin enthaltene DNA weniger schnell angegriffen und zersetzt. Einige Skelette sind allerdings stark degradiert und zeigen Anzeichen von Brushitbildung. Es ist bekannt, dass das Friedhofsgelände auf ehemaligen Gartengrundstücken (Wehking 1992) errichtet wurde. Gartenerde hat meist einen sauren pHWert und kann somit den Vorgang der Diagenese menschlicher Überreste beschleunigen sowie zur Bildung von Brushit führen. Bei einem $\mathrm{pH}-$ Wert von unter sieben entsteht Octacalciumphosphat. Das dafür nötige Calcium stammt aus dem Knochen. Sinkt der pH-Wert unter sechs, entsteht Brushit $\left(\mathrm{CaHPO}_{4}+2 \mathrm{H}_{2} \mathrm{O}\right)$ (Herrmann 1981). Dadurch wird der Knochen meist sehr spröde und vergeht unter Einwirkung von Feuchtigkeit schneller im Boden (Herrmann und Newesely 1982).

Es konnte eine Mindestanzahl von 159 Individuen ermittelt werden. Darunter befinden sich allerdings nicht nur vollständig erhaltene Skelette, sondern auch einzelne Knochenfragmente, die in Einzelfällen als Beifunde in einem Grab neben einem vollständig erhaltenen Skelett entdeckt wurden. In der Tabelle 3 (siehe Kapitel 4.1.1 Demografie) ist der Erhaltungszustand für jedes Individuum vermerkt. Viele am westlichen Grabungsrand gefundene Skelette sind stark fragmentiert aufgrund früherer Bauarbeiten. Häufig sind vor allem Kinderknochen infolge ihrer Grazilität nur schlecht erhalten. Mehrfach sind einzelne Knochenelemente in Gräbern gefunden wurden, welche während einer Sektion anderen Individuen entnommen wurden. So fand man im Grab 4 (1) beispielsweise ein zusätzliches Stück Schienen- und Wadenbein. Sie gehörten nicht zu dem bestatteten Individuum, da das Skelett unter der Fundnummer 4 (1) vollständig ist. Hier ist zu vermuten, dass in der Anatomie präparierte Knochen nachträglich einer Regelbestattung beigelegt wurden. 


\subsection{Die historischen Quellenmaterialien}

\subsubsection{Geschichte Göttingens}

Für die Einordnung der menschlichen Überreste in einen gesellschaftlichen und geschichtlichen Kontext wurden medizinisch-naturwissenschaftliche Methoden sowie historisches Quellenmaterial herangezogen. Folgende Informationen über die Bewohner der Stadt Göttingen zum Zeitpunkt der Friedhofsbelegung sind bekannt.

953 n. Chr. das erste Mal erwähnt (Fahlbusch 1957), wurde dem Dorf Gutingi bereits Anfang des 13. Jahrhunderts das Stadtrecht zugesprochen. Das welfische Fürstenhaus sorgte für eine kurze wirtschaftliche Stärkung der ganzen Stadt (Wehking 1992), indem sie sich unter anderem für die Gründung der Universität 1734 einsetzte. Sie wurde nach dem Stifter Georg August II, König von Großbritannien und Herzog von Braunschweig-Lüneburg, benannt (Fahlbusch 1957). Allerdings gingen Anfang des 19. Jahrhunderts mit der industriellen Revolution eine sehr starke Zunahme des Bevölkerungswachstums und der Niedergang alter Gewerbe einher. Diese Entwicklungen traf die Stadt Göttingen sehr hart, die von jeher deutlich mehr durch den Handwerks- und Dienstleistungssektor, als durch Industrie geprägt war (Sachse 1987). So gingen beispielsweise zwei große Arbeitgeber in Göttingen, ein Tuchhersteller und eine Textilmanufaktur, in Konkurs (Römling 2012) und viele Arbeiter wurden arbeitslos. 1837 kam es zur Vertreibung der Göttinger Sieben und damit zu einem "geistigen Aderlass“ (Römling 2012), der dem Ansehen der Stadt sehr schadete. Kurz darauf folgte eine deutschlandweite Hungerkrise, verursacht durch die Kartoffelfäule 1845 (Herrmann 2010). Die Oberschicht in Göttingen, der es zu diesem Zeitpunkt noch sehr gut ging, bestand hauptsächlich aus Professoren, Kaufleuten und Honoratioren. Jedoch die zwei größten sozialen Schichten, die Unter- und Mittelschicht, wurden seit dem 18. Jahrhundert immer größer. Die Arbeitsmärkte waren im 19. Jahrhundert schließlich so übersättigt, dass es zu einer Unterbeschäftigung und Deklassierung der Unterschicht, mit einer anwachsenden Zahl an Tagelöhnern, Beschäftigungslosen und verarmten Handwerkern kam (Sachse 1987). In diesem Zeitraum verstärkten sich die sozialen Spannungen in ganz Deutschland, welche für zahlreiche Menschen in Massenarmut, Verelendung und in der Folge in Existenzängsten gipfelten (Koops 2002). Obwohl häufig die ganze Familie zum Erwerb beitrug, reichte das Einkommen oft nicht an das Existenzminimum heran. Die Bevölkerungszahl sowie die Armut nahmen zeitgleich zu, so auch die damit verbundene Nahrungsmittelknappheit, vor allem in den sozial niederen Schichten. Auch die Bewohner der Universitätsstadt Göttingen ereilte dieses Schicksal. 
Die Armut im Göttingen des 19. Jahrhundert war eine massive gesellschaftliche Herausforderung. Zahlreiche Menschen unterschiedlichen Alters mussten auf Armenunterstützung in Form von Seelsorge oder auf materielle Unterstützung zurückgreifen. Die Verarmung war vor allem für die weibliche Bevölkerung ein großes Problem. Frauen erlernten meist keinen Beruf, daher waren sie lediglich für schlecht bezahlte Arbeiten qualifiziert (Schallmann 2014). Dieser Umstand machte sie finanziell von ihren Ehemännern anhängig. Allerdings weisen die Statistiken, welche sich mit dem Thema Armut auseinandersetzen, einige Schwächen auf. Unter anderem war der Anteil sozial schwacher Frauen in Göttingen ein wenig höher, da eine beachtliche Anzahl an Männern die Stadt bei Arbeitsmangel verließ oder durch Arbeitsunfälle, bei schweren körperlichen Arbeiten, in jungen Jahren verstarb. Ein weiteres Problem war häufig der Alkoholismus in der männlichen Bevölkerung und ein damit verbundener vorzeitiger Tod (Schallmann 2014). Der frühe Tod eines Manns führte wiederum meist zur Verarmung der ganzen Familie. Während es Anfang des 18. Jahrhunderts eine institutionalisierte Armenversorgung durch die Regierung gab, wurde diese im 19. Jahrhundert durch die prohibitive und repressive Bevölkerungspolitik beendet (Sachse 1987). Da eine städtische Armenversorgung schlussendlich nicht ausreichte, übernahmen auch kirchliche Vereine einen Anteil der meist materiellen Versorgung. Die erste offizielle Stätte der katholischen Armenfürsorge in Göttingen befand sich ab 1865 in „Klein Paris“ (heute Turmstaße), ein Bezirk vorrangig mit Wohnraum für die sozial Schwächeren der Stadt. Bei dem Haus in „Klein Paris“ handelte es sich um eine Schenkung von Ernst-Friedrich Vollmer, Mitglied der katholischen Gemeinde St. Michael. Später wurde in unmittelbarer Nähe der katholische Stift „Alt-Mariahilf“ gegründet (Schallmann 2014). Eine große emotionale Belastung vieler in Armut Lebender war zusätzlich die Gewissheit, dass sie sich nach ihrem Tod keine Beerdigung leisten würden können. Die gängige Praxis in solchen Fällen war ab dem 18. Jahrhundert, dass die Verstorbenen der sozial niederen Schichten häufig für Lehrzwecke in die anatomischen Institute von Universitäten verbracht und seziert wurden. Anschließend übernahm die Universität die Bestattungskosten für den sezierten Leichnam. Auch in Göttingen war dies, geregelt durch Gesetze, ein übliches Vorgehen. 


\subsubsection{Die Universitätsmedizin Göttingens}

An der Georg-August-Universität Göttingen wurden schon ein Jahr nach ihrer Gründung im Jahr 1734 die ersten Sektionen durch den als Professor für Anatomie berufenen Wilhelm Albrecht durchgeführt. Die ersten zwei Sektionen männlicher Leichen fanden noch im Turm am Albanitor statt (Zimmermann 2009). Allerdings starb Wilhelm Albrecht im Jahr darauf und Albrecht von Haller (Abbildung 8) wurde dessen Nachfolger von 1736 bis 1753. Die ersten öffentlichen Sektionen hielt er $1737 \mathrm{ab}$ und erregte damit den Unmut der Göttinger Bevölkerung. In seiner 17-jährigen Amtszeit sezierte er jedes Semester zwischen 30 bis 40 Kadaver (Zimmermann 2009) und wurde zu einer treibenden Kraft im medizinischen Fachbereich, vor allem der Physiologie. Haller setzte sich darüber hinaus umfassend für den Aufbau der Universität ein, verbesserte Unterrichtsmethoden und half maßgeblich beim Bau des Botanischen Gartens sowie des anatomischen Theaters (1738). 1753 verließ Haller die Universität Göttingen nach einer längeren Auseinandersetzung mit dem Dekan Johann Friedrich Brendel $(* 1712 ; \uparrow 1758)$. Es folgten mehrere kurzfristige Anstellungen von Nachfolgern und zeitweise blieb der Anatomielehrstuhl vakant. Erst mit Johann Friedrich Blumenbach (Abbildung 9), bedeutender Anatom und Begründer der Anthropologie, erlebte die Medizinische Fakultät einen Aufschwung (Zimmermann 2009) und gewann durch dessen große Präparatesammlung wesentlich an Bedeutung.

1852 - 1885 wurde Jakob Henle (Abbildung 10) an den Lehrstuhl für Anatomie und Physiologie (Abbildung 11) berufen und führte das Werk von Albrecht von Haller, vor allem hinsichtlich der praxisbezogenen Anatomieforschung, fort. Interessant ist der Umstand, dass Henles Wirken mit der Belegung des $\mathrm{zu}$ untersuchenden katholischen Friedhofes zusammenfiel. Daher ist davon auszugehen, dass die an der Georg-August-Universität Göttingen gefundenen Skelette mit

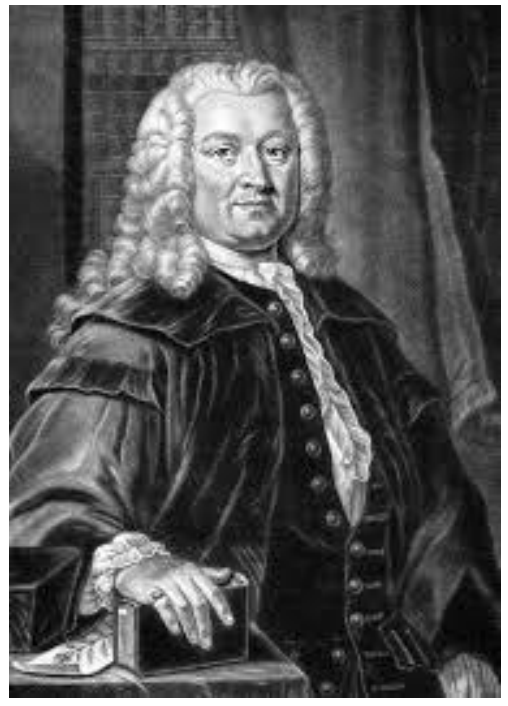

Abb. 8: A. v. Haller *1708; $\uparrow 1777$ (Quelle: Burgerbibliothek Bern o. D.).

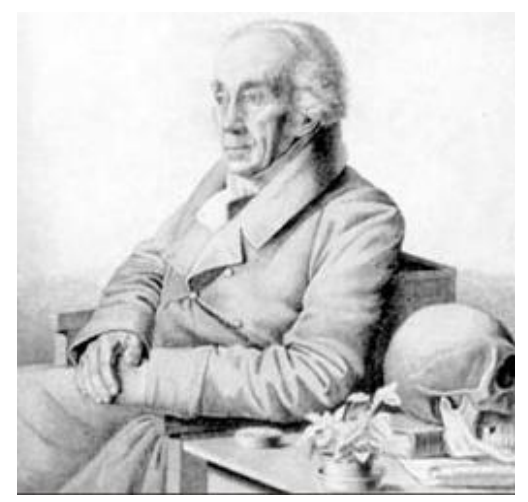

Abb. 9: J. F. Blumenbach *1752; $\dagger 1840$ (Quelle: Anatomie UMG o. D.).

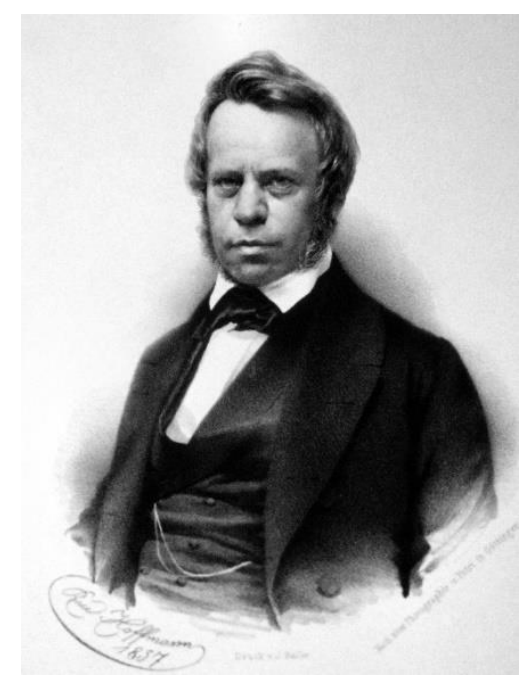

Abb. 10: J. Henle *1809; †1885 (Quelle: Hoffmann 1857). 
den Sektionsspuren vermutlich Anatomieleichen waren und von Henle beziehungsweise seinen Schülern zu Lehr- und Forschungszwecken seziert wurden. 1855 verfasst er das Handbuch der systematischen Anatomie des Menschen. Dieses Werk zeigt vor allem getreue Abbildungen seiner präparatorischen Arbeiten. Er hatte ein weitläufiges Forschungsinteresse, gilt als Erstbeschreiber der Henle'schen Schleife in der Nebennierenrinde und formulierte mit seinem Schüler Robert Koch die sogenannten Henle-Koch-Postulate über die Grundregelung zur Definition von Krankheitserregern.

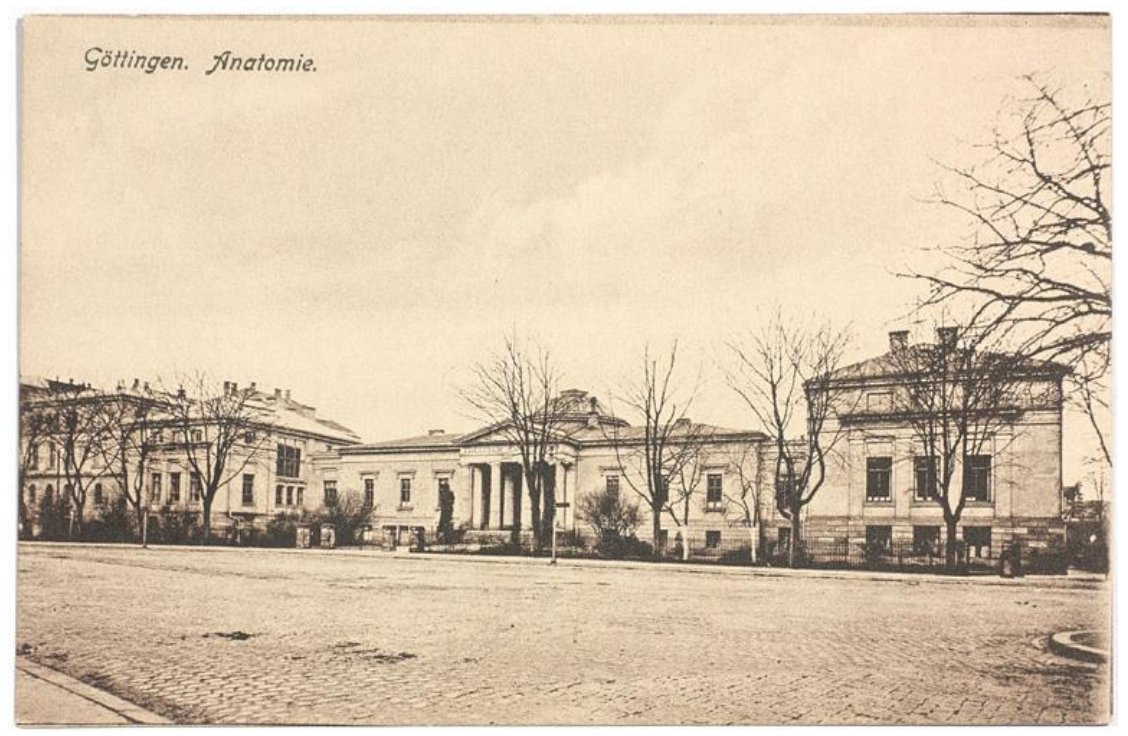

Abb. 11: Anatomie Göttingen 1829 - 1945 (Zimmermann 2009 S. 24).

\subsubsection{Der Friedhof und die katholische Gemeinde in Göttingen}

Mit der Einführung der Reformation in Göttingen galt die Stadt ab 1529/1530 als evangelisch und sämtliche kirchlichen Ämter wurden ausschließlich mit protestantischen Geistlichen besetzt. Kurze Phasen der Etablierung der katholischen Kirche wurden oft schnell wieder unterdrückt (Wehking 1992). Erst mit Gründung der Universität 1735, welche zwar öffentlich als evangelische Universität geführt wurde, aber Studenten jeglicher Religionen willkommen hieß, kamen auch Anhänger des katholischen Glaubens wieder nach Göttingen und bildeten ab Mitte des 18. Jahrhunderts eine Gemeinde.

Die katholische Gemeinde in Göttingen erwählte den Erzengel Michael zu ihrem Schutzpatron. Vermutlich ist die Wahl des Patrons auf dessen kämpferischen Charakter zurückzuführen, da die kleine Gemeinde anfangs mit Anfeindungen der protestantischen Umgebung zu kämpfen hatte (Wehking 1992). Der Name kommt vom hebräischen Mi-ka-el, wörtlich übersetzt bedeutet es „Wer (ist) wie Gott?“. Dieser Erzengel gilt als Anführer der himmlischen 
Heerscharen, gleichzeitig ist er im Volksglauben der „Seelenwäger“, der die guten und schlechten Taten zu Lebzeiten protokolliert und im Tode vorlegt.

Bereits im Frühherbst 1789 erfolgte die Einweihung der ersten Kirche der katholischen St. Michael Gemeinde. Jedoch erst im Sommer 1825 wurde die Göttinger Missionsstation durch den Erzbischof zur Pfarrei erhoben und dem Konsistorium Hildesheim unterstellt (Wehking 1992). 1849 erhielt die katholische Gemeinde eine Schenkung des Katholiken Ernst Vollmer, welcher dafür eintrat, auf einem alten Gartengrundstück zwischen dem Sültebecksgraben und der Weender Chaussee einen katholischen Friedhof zu errichten (Abbildung 12 und 13). Dies sollte zum einen verhindern, dass verstorbene Gemeindemitglieder auf dem Stadtfriedhof begraben werden und zum anderen der Sicherung seines eigenen Seelenheils dienen (Wehking 1992). Bis zur Einweihung im Sommer 1851 dauerte es allerdings weitere zwei Jahre. 1864 und 1871 wurde das Grundstïck jeweils noch einmal erweitert. Allerdings war der Friedhof schnell vollständig belegt und musste bereits 1888 geschlossen werden. Lediglich die letzten gekauften Stellen wurden noch bis 1910 besetzt. Andere Gemeindemitglieder sollten auf dem Zentralfriedhof beigesetzt werden. In den 1960er Jahren wurden die verfallenen Grabsteine schließlich beseitigt, um Platz für universitäre Einrichtungen zu schaffen.

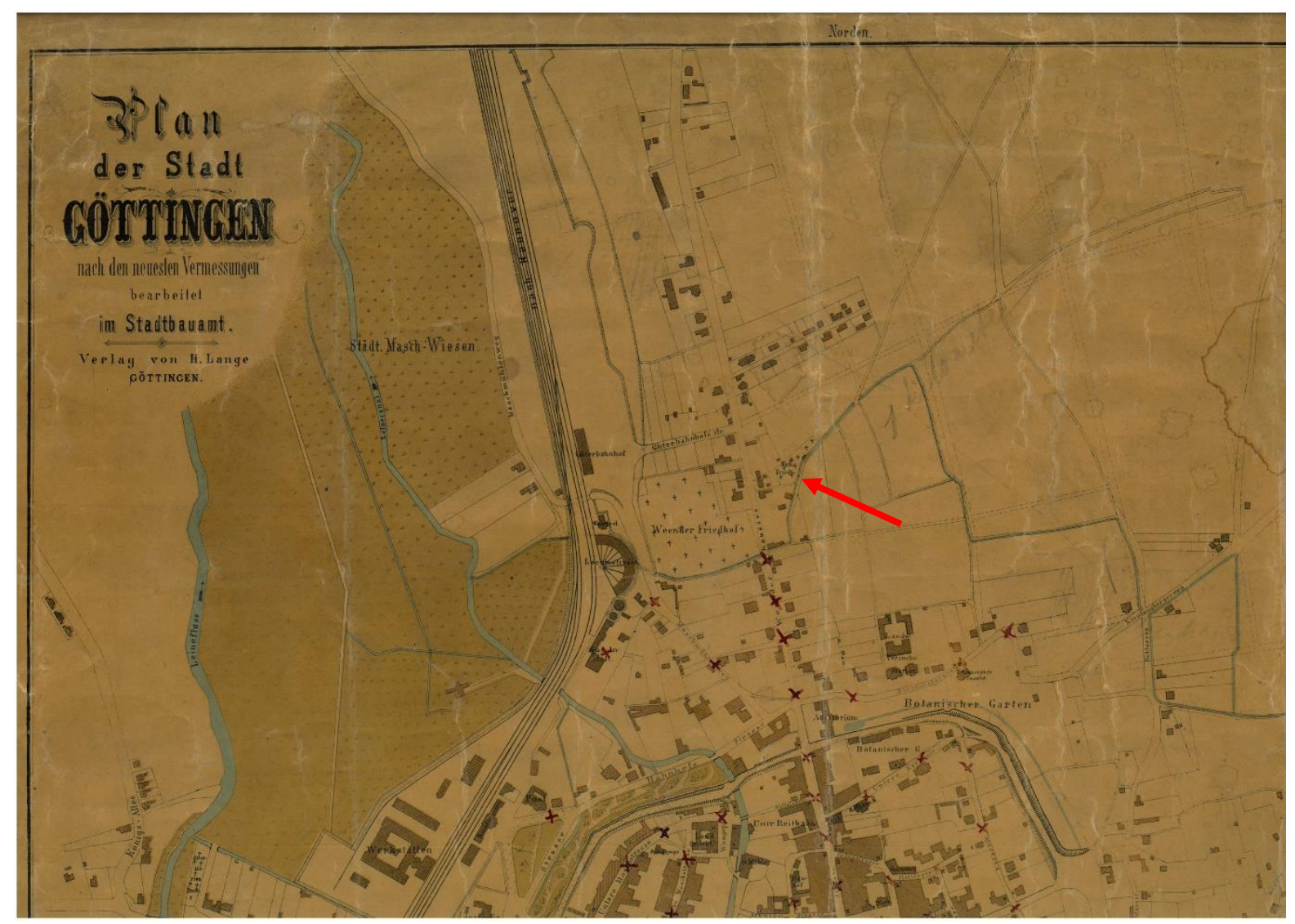

Abb. 12: Stadtplan von Göttingen um 1880. Roter Pfeil zeigt die Lage des katholischen Friedhofs (Stadtarchiv Göttingen, Signatur: D - Karten und Pläne, V a 47,2; Titel: Stadtplan Göttingen; Laufzeit: um 1880). 


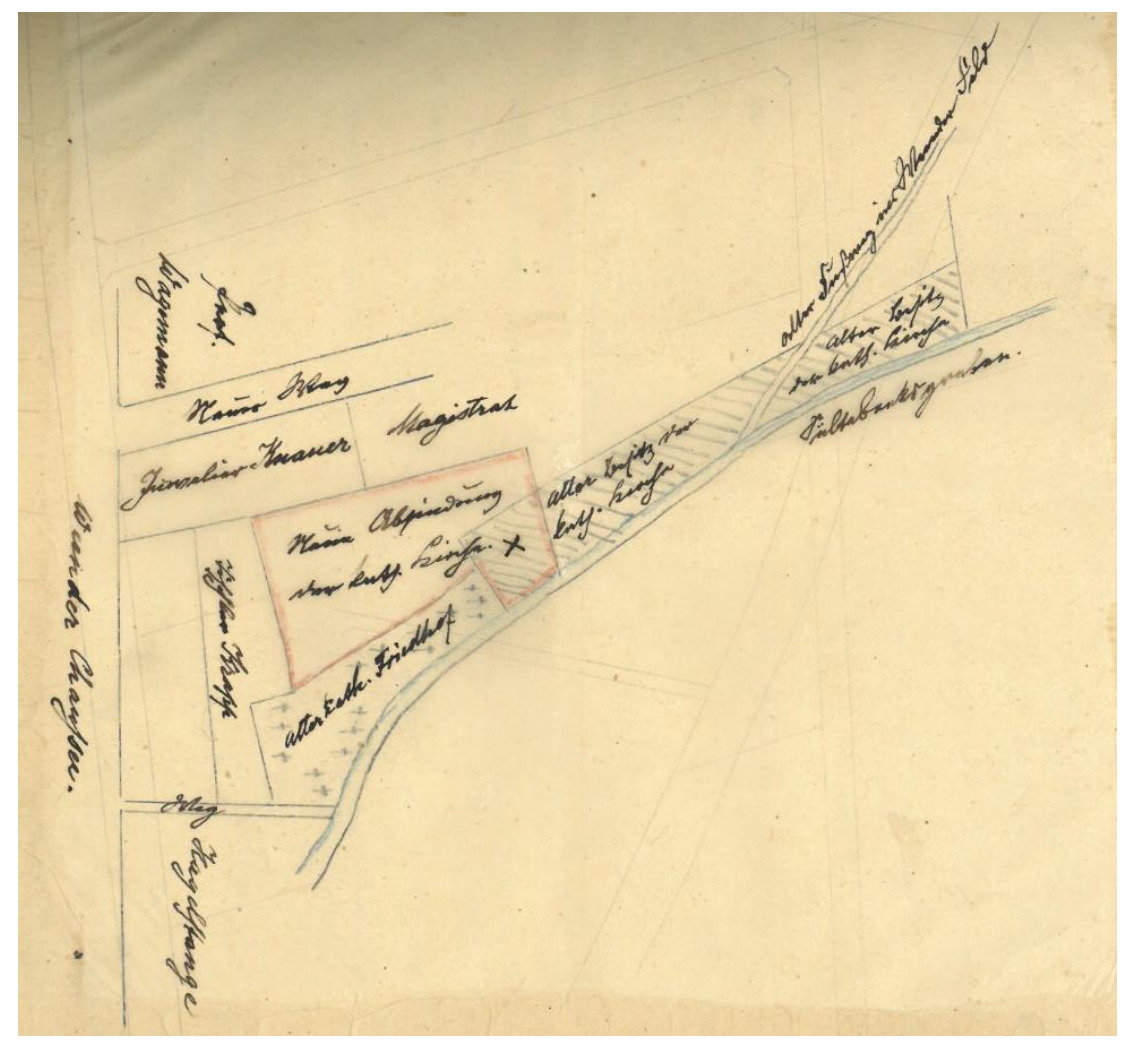

Abb. 13: Lageplan des katholischen Friedhofs 2. Hälfte des 19. Jahrhunderts (Stadtarchiv Göttingen, Signatur: AHR I J Fach 3 Nr. 2 Bd. 2; Titel: Katholischer Friedhof; Laufzeit: 1849 - 1889; Blatt 33).

\subsection{Archivalische Quellen}

Erste Begutachtungen der Totenbücher des Bistums Hildesheim nahm Droste (2015) vor. Diese ergaben, dass die Dokumentation in diesem Zeitraum sehr lückenhaft war und es keinen Belegungsplan des ersten katholischen Friedhofs gibt.

Im Verlauf dieser Arbeit wurde in den Landesarchiven Hannover und Wolfenbüttel sowie im Kirchenarchiv Hildesheim nach Unterlagen gesucht, welche Auskunft über den Umgang mit Verstorbenen geben können. Dabei lag ein großes Augenmerk auf Erlässen zur Abgabe von Leichen an die Anatomie der Universität Göttingen und Einzelnachweisen in Form von Meldescheinen und Briefwechseln. 


\section{Untersuchungsmethoden}

In Voruntersuchungen bereits erhobene biologische Basisdaten, wie Geschlecht, Alter und Körperhöhe, wurden in einem ersten Schritt überprüft und um fehlende Daten ergänzt. Anhand der Geschlechts- und Altersverteilung lassen sich die demografischen Strukturen einer Bevölkerung zu einem spezifischen Zeitpunkt annähernd beschreiben. Für die Gruppe der Anatomieleichen sind diese Rückschlüsse nur eingeschränkt möglich. Die Verfügbarkeit menschlicher Körper und Auswahl entscheidet über die somit mehr oder weniger zufällige Zusammensetzung der Gruppe. Obwohl es sich bei den Anatomieleichen um Einzelschicksale handelt, lassen sich die meisten Individuen jedoch der ärmeren Gesellschaftsschicht zuordnen. Ergänzt wurden die Basisdaten durch Daten über Veränderungen am Knochen in Form von Abweichungen von der Regelanatomie, wie zum Beispiel irregulärer Knochenaufbau bzw. abbau. Durch eine Interpretation der Datenlage sind Rückschlüsse auf den Gesundheitszustand der katholischen Bevölkerung der St. Michael Gemeinde Ende des 19. Jahrhunderts möglich. Im Folgenden werden die angewendeten Kriterien, Verfahren und Methoden erläutert. Alle benutzten Abkürzungen sind im Abkürzungsverzeichnis Kapitel 8.1 aufgeführt.

\subsection{Dokumentation}

Die Skelettfunde wurden bereits während der Ausgrabung durch die Firma Acontor Projekt $\mathrm{GmbH}$ fotografisch dokumentiert und in einem Lageplan verzeichnet. Eine weitere Dokumentation sämtlicher Skelette fand in einer Abschlussarbeit (Jugert 2012) statt. Dafür schraffierte Jugert die Abbildung eines Skelettumrisses je nach Erhaltungszustand der einzelnen Skelettelemente.

Der makroskopisch beurteilte Erhaltungszustand der untersuchten Knochen wurde nach Jungklaus (2010, nach Karolyi 1971) in die Kategorien sehr gut, gut, mittel, schlecht und sehr schlecht eingeordnet (siehe Tabelle 1 mit den Abbildungen 14 bis 18). Zeigen sich an unterschiedlichen Knochenelementen eines Skeletts verschiedene Grade der Erhaltung, wird ein mittlerer Wert angegeben. 
Tab. 1: Erhaltungszustand der Knochen in Bezug auf Vollständigkeit. Der Maßstab entspricht $5 \mathrm{~cm}$.

Sehr gut erhalten:

Am Knochen sind

keinerlei Dekompositions-

spuren erkennbar.

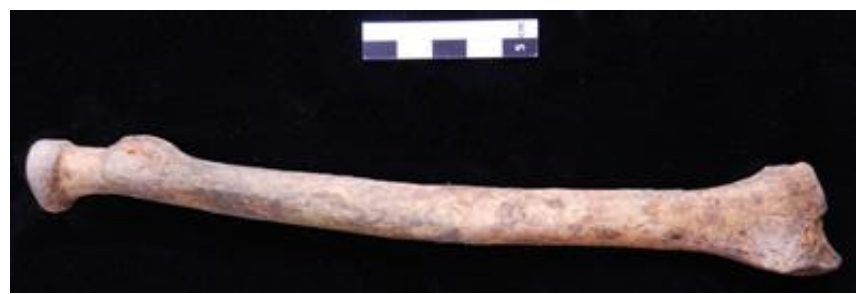

Abb. 14: Rechter Radius, anteriore Ansicht. Fundnummer 2.

Gut erhalten:

Am Knochen sind wenige

Dekompositionsspuren zu

erkennen.

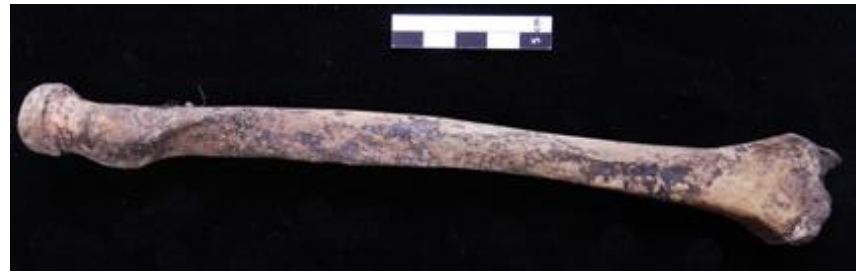

Abb. 15: Linker Radius, anteriore Ansicht. Fundnummer 9.

Mäßig erhalten:

Fortgeschrittene

Dekompositionsspuren

erkennbar.

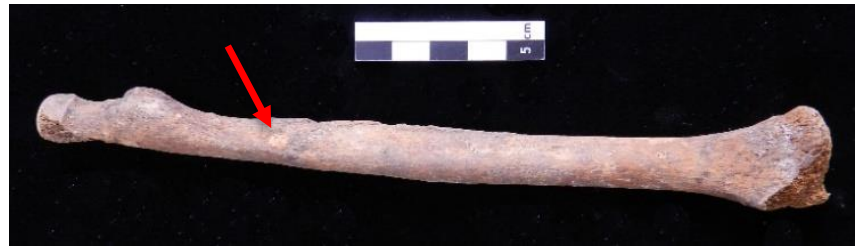

Abb. 16: Rechter Radius, anteriore Ansicht. Fundnummer 10.

Schlecht erhalten:

Diagenese großflächig an

den Epiphysen und der

Knochenoberfläche zu

erkennen.

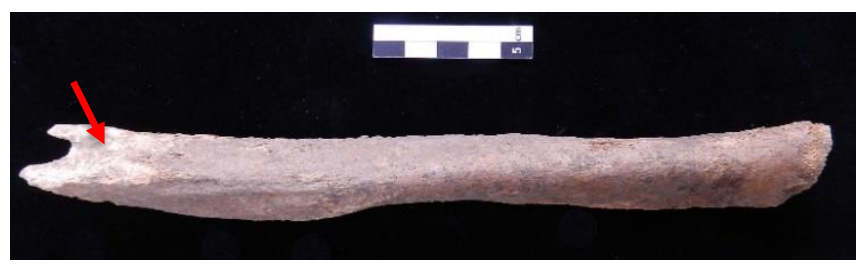

Abb. 17: Rechter Humerus, anteriore Ansicht. Fundnummer 18. Der dargestellte Knochen ist unvollständig.

Sehr schlecht erhalten:

Der Knochen ist stark

durch Diagenese zerstört.

Es ist wenig bis gar keine

Knochenoberfläche mehr vorhanden.

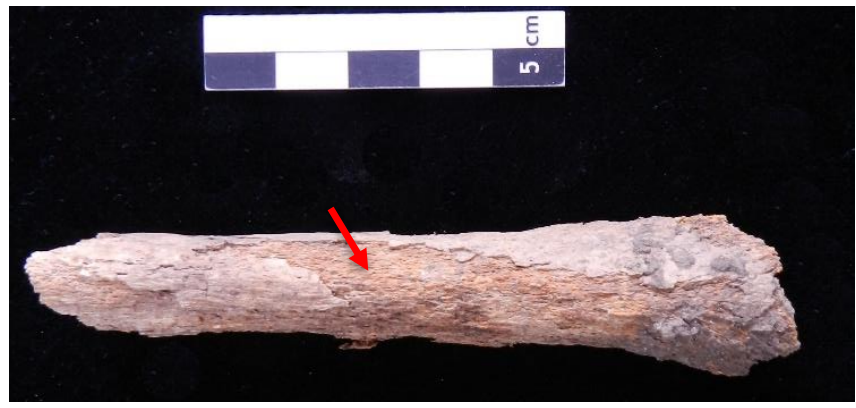

Abb. 18: Radius, anteriore Ansicht. Fundnummer 1. Der dargestellte Knochen ist unvollständig. 
Für die Erfassung von Unregelmäßigkeiten oder Auffälligkeiten unterschiedlichster Art am Skelett wurden in dieser hier vorliegenden Arbeit Befundbögen ausgefüllt. Um den Grad der Veränderung durch Arthrose in den großen Körpergelenken und der Wirbelsäule aufzunehmen, wurde der Befundbogen nach Schultz (1988b) verwendet. Für die Dokumentation der ecto- und endocranialen Oberflächen am Schädel wurden zwei Erhebungsbögen der Arbeitsgruppe Paläopathologie der Universitätsmedizin Göttingen (UMG) verwendet. Durch unterschiedliche Farben und Schraffuren (siehe Tabelle 2) wurden Unregelmäßigkeiten und/oder Auffälligkeiten in den Befundbögen zum Schädel gekennzeichnet. Alle verwendeten Befundbögen sind im Anhang unter dem Kapitel 8.2 Formulare und Befundbögen abgebildet.

Tab. 2: Beschriftung der Schädelskizze nach den Regularien der Arbeitsgruppe Paläopathologie der UMG.

\begin{tabular}{|c|c|c|}
\hline Farbe & & Makroskopische Veränderung \\
\hline rot & & $\begin{array}{ll}\text { - } & \text { von der Norm abweichende Gefäßimpressionen } \\
\text { - } & \text { Reste eines epiduralen Hämatoms }\end{array}$ \\
\hline grün & $\begin{array}{l}\text { schraffiert } \\
\text { gepunktet }\end{array}$ & 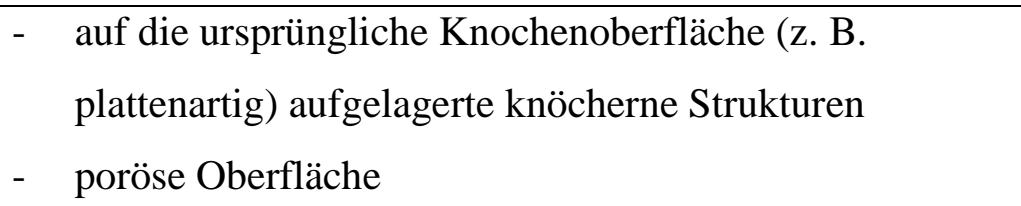 \\
\hline hellblau & & $\begin{array}{l}\text { - } \text { nicht gefäßbedingte Impressionen, z. B. Foveolae } \\
\text { granulares }\end{array}$ \\
\hline dunkelblau & & $\begin{array}{l}\text { - für tuberkulöse Meningitis typische grübchenförmige } \\
\text { oder muldenförmige Impressionen }\end{array}$ \\
\hline schwarz & $\begin{array}{l}\text { schraffiert } \\
\text { gepunktet oder } \\
\text { flächig }\end{array}$ & $\begin{array}{l}\text { - } \text { raue, narbige, unregelmäßige Oberfläche } \\
\text { - dem Knochen nicht aufgelagerte Knochenneubildungen, } \\
\text { z. B. Exostosen und tumorartige Gebilde }\end{array}$ \\
\hline
\end{tabular}

In Einzelfällen wurden pathologische Veränderungen oder Abweichungen von der Regelanatomie fotografisch dokumentiert. Die verwendete Kamera ist eine Nikon Coolpix P500 mit 36-fachem optischem Zoom. Die eingestellten Parameter umfassen Kontrast, Helligkeit und Tonwert.

\subsection{Diagnostische Techniken}

Für die Untersuchung und Einschätzung von pathologischen Veränderungen am Skelett benötigt es neben anatomischen Kenntnissen des menschlichen Körpers auch langjährige Erfahrung in diesem Fachgebiet. Neben der einschlägigen Literatur (beispielsweise Ortner 2003, Aufderheide und Rodriguez-Martin 1998, Ortner und Putschar 1981) wurde stetig 
Rücksprache mit dem Anatomen Prof. Dr. Dr. Schultz (UMG) gehalten. Für die Untersuchungen der menschlichen Überreste wurden verschiedene naturwissenschaftliche Verfahren, z. B. Morphologie, Radiologie und Mikroskopie genutzt, um ein möglichst vollständiges Bild über den Krankheitsverlauf des einzelnen Individuums und den Gesundheitszustand ganzer Population rekonstruieren zu können.

\subsubsection{Makroskopie, Lupenmikroskopie und Endoskopie}

$\mathrm{Zu}$ Beginn der Arbeit wurden die Skelette jeweils in ihrer anatomischen Anordnung ausgelegt und vollständig makroskopisch und lupenmikroskopisch untersucht. Durch pathologische Prozesse verursachte Knochenveränderungen wurden auf eigens dafür vorgesehenen Untersuchungsbögen (Schultz 1988b, AG Paläopathologie UMG, eigener Bogen) festgehalten. Krankhafte Veränderungen sind vor weiteren Bearbeitungsschritte fotografisch dokumentiert worden. Wegen ihrer schweren Zugänglichkeit wurden die endocranialen Räume vollständig erhaltener Schädel mittels eines Endoskops auf pathologische Veränderungen untersucht. Es handelte sich im wesentlich um die pneumatisierten Räume des Os temporale und der Nasennebenhöhlen. Es handelt sich um ein digitales Endoskop der Firma Schweitzer, Baujahr 2009, mit Kaltlichtquelle und Spiegelrohr. Die endoskopischen Untersuchungen wurden in der AG Paläopathologie am Zentrum für Anatomie der Universitätsmedizin Göttingen durchgeführt.

\subsubsection{Radiologie}

Ausgewählte Skelettelemente, mit makroskopisch und/oder lupenmikroskopisch festgestellten Abweichungen von der Regelanatomie, wurden zur differentialdiagnostischen Absicherung einer Röntgendiagnose unterzogen. Die Untersuchungen fanden in der AG Paläopathologie am Zentrum für Anatomie der Universitätsmedizin Göttingen statt. Mittels Röntgentechnik wurde die Knochendichte in den jeweiligen Bereichen der Skelettelemente abgebildet, ohne den Knochen zu beschädigen oder zu zerstören. Es können beispielsweise Harris-Linien in den Tibiae und damit verbundene Wachstumsstörungen durch Röntgenaufnahmen sichtbar gemacht werden, aber auch Knochenumbauvorgänge im Bereich der Markhöhle und der Compacta. Im Vordergrund stehen osteoblastische und/oder osteoklastische Prozesse. Durch die Röntgendiagnostik können Strukturen erkennbar gemacht werden, die weder durch äußerliche Sichtbetrachtungen noch durch Knochendünnschliffe sichtbar wären. Bei dem Untersuchungsgerät handelt es sich um ein Vollschutzröntgengerät Hewlett Packard Faxitron 
des Typs 43805N mit einem Digital Linear Scanner EZ 320 der Firma NTB. Die Spannung wurde je nach Knochendichte manuell auf 70 - $90 \mathrm{kV}$ und 2,5 mA eingestellt.

\subsubsection{Mikroskopie}

Die mikroskopische Inspektion unterstützt die Wahrnehmung und Beurteilung von Knochenumbauprozessen, die beispielsweise in Folge von Mangelernährung in der Wachstumsphase entstanden sind. Gleichzeitig ermöglicht sie die Differentialdiagnose von trocknem Knochen und Fossilien (Schultz 1999). Bei der Begutachtung mikroskopischer Dünnschliffe muss jedoch darauf geachtet werden, dass Lochdefekte, welche durch Pilze, Algen, Wurzeln oder Bakterien verursacht worden, nicht fälschlicherweise als intravitale Prozesse wahrgenommen werden. Aus den pathologisch veränderten Knochen der Skelette wurden Proben entnommen und Dünnschliffpräparate mit einer Stärke von 50 bzw. $70 \mu \mathrm{m}$ nach Schultz (1988) hergestellt. Diese Präparate wurden einer lichtmikroskopischen Inspektion unterzogen, um Einblicke in die Knochenbinnenstruktur $\mathrm{zu}$ erhalten und um etwaige Abweichungen vom Regelwachstum erkennen und näher beschreiben zu können. Bei dem Untersuchungsgerät handelt es sich um das Polarisationsmikroskop DMR XP der Firma Leica. Die Knochendünnschliffe wurden in polarisiertem Lichtunter Verwendung eines Hilfsobjekts Rot 1. Ordnung (Quarz) als Kompensator bei einer 16 - 400-fachen Vergrößerung betrachtet. Die Fotos der Dünnschliffpräparate wurden mit einer DFC 500 Kamera der Firma Leica aufgenommen.

\section{Herstellung von Dünnschliffpräparaten pathologischer Veränderungen}

Im Folgenden wird die modifizierte Technik zur Einbettung von trockenem Knochen nach Schultz (1988a, 2001) beschrieben. Die Probe wird dabei mit Kunstharz ummantelt und durchdrungen. Das Verfahren nennt sich forcierte Imprägnierung. Für Knochen hat sich Biodur $^{\circledR}$ (E12 und Härter E1) nach der modifizierten Rezeptur von Gunter von Hagens (1979) als geeignetes Einbettungsmedium erwiesen. Die Untersuchung der pathologisch veränderten Knochen fand in der AG Paläopathologie am Zentrum für Anatomie der Universitätsmedizin Göttingen statt.

Das zu untersuchende Knochenstück sollte möglichst eine Länge von ca. $1 \mathrm{~cm}$ haben. Es wird für ca. 24 Stunden in ein Bad des Intermediums Dichlormethan eingelegt. Danach wird das Knochenstück in ein Gemisch aus Biodur ${ }^{\circledR}$ (E1 und E12 im Verhältnis drei zu zehn) gegeben. Durch eine Pumpe mit Ventilen in einem Exsikkator wurde ein kontrolliertes Vakuum 
eingestellt. Der Unterdruck bringt das Dichlormethan im Knochen zum „Sieden“ und der entstehende Dampfdruck führt zum Eindringen des Kunstharzes in die Knochenhohlräume. Nach dreistündigem Unterdruck in Höhe von 5 Torr (Kontrolle mittels eines BennertManometers) wird der Exsikkator wieder belüftet. Der imprägnierte Knochen wird zur vollständigen Aushärtung des Kunststoffes etwa drei Wochen bei Raumtemperatur in einem Wärmeschrank gelagert.

Die ausgehärtete Probe wird mit einer motorbetriebenen Säge der Firma Dr. Steeg und Reuter (Typ 270109) und einer Diamanttrennscheibe (Woco 93/6, 150 x 0,4 mm der Firma Conrad) in Form gesägt, die Oberfläche glatt geschliffen (Schleifpapier 310; 1200; 2000; 4000) und auf Leder mit einer Juwelierpaste poliert. Das bearbeitete Blöckchen wird mit Biodur ${ }^{\circledR}$ auf einen Objektglasträger aufgebracht. Der Schleifvorgang beginnt mit dem Zurechtsägen und -trimmen mittels Diamanttrennscheibe und einer Topfscheibe. Die Stärke wird zu jeder Zeit mit einer Mikrometerschraube geprüft. Anschließend wird manuell, mit Schleifpapier und Polierpaste, die gewünschte Stärke des Präparates herausgearbeitet. Das Deckglas wird mit Biodur ${ }^{\circledR}$ auf der Probe fixiert. Die entstandene Probe sollte im Idealfall eine Stärke zwischen 50 - $70 \mu \mathrm{m}$ haben, um die Knochenstrukturen, z. B. Kollagen, bestmöglich sichtbar zu machen.

\section{Herstellung von Dünnschliffpräparaten zur Alterseinschätzung}

Zusätzlich ist durch die lichtmikroskopische Untersuchung des Zahnzementes und der Knochenbinnenstruktur eine Präzisierung des morphologisch bestimmten Alters möglich. Daher wurden Stücke der Femurdiaphysen und Wurzeln der Canini beider Gruppen zur Untersuchung des Sterbealters der Individuen eingebettet. Grund für diese Art der Untersuchung ist die mögliche Abweichung des kalendarischen Alters zum morphologisch bestimmten biologischen Alter. Abweichungen dieser Art können durch das Einwirken äußerer Umstände auf das Skelettsystem und die Zahnentwicklung entstehen. Für die Vergleichbarkeit der Daten wurden möglichst Femora der gleichen Körperseite und Canini, wenn möglich aus dem Oberkiefer, ausgewählt. Aus der Mitte der Femurdiaphyse wurde eine 3/4 Querscheibe (lateral, anterior und medial) mit einer Breite von 0,5 - $1 \mathrm{~cm}$ entnommen. Die Canini werden im Ganzen eingebettet, aber nur aus dem Bereich der Zahnwurzel wurden Schliffe hergestellt. Die Untersuchung der Dünnschliffpräparate für die Alterseinschätzung fand in der Abt. Historische Anthropologie und Humanökologie des J.-F.-B. Institutes der Georg-AugustUniversität statt. 
Zum Einbetten wurden 12,5 Teile Biodur ${ }^{\circledR}$ und 3,5 Teile Härter als Kunstharzgemisch verwendet. Die in Kunstharz getränkten Proben wurden für mindestens eine Stunde im Exsikkator unter Vakuum gesetzt. Das ausgehärtete Blöckchen mit dem eingeschlossenen Knochen wurde mittels Innenlochsäge (Modell 1600, Leitz, Wetzlar, Deutschland) in 80 - 120 $\mu \mathrm{m}$ (80 - $100 \mu \mathrm{m}$ für Zähne) dicke Schliffe gesägt. Da während des Sägeprozesses mit Wasser gekühlt und Sägestaub entfernt wird, muss der Schliff für mehrere Stunden getrocknet werden. Die Zahnschliffe werden in einem zusätzlichen Schritt im Ultraschallbad gereinigt. Anschließend wird jeder Schliff mit Eukitt ${ }^{\circledR}$ auf dem Objektträger unter einem Objektgläschen fixiert.

\subsubsection{Molekulargenetik}

Individuen, deren Geschlecht morphologisch nicht bestimmbar war, weil die aussagekräftigen Skelettelemente fehlten oder die Individuen aufgrund ihres jungen Alters noch keine geschlechtstypischen Merkmale ausgeprägt hatten, wurden molekulargenetisch untersucht und geschlechtsdeterminiert. Hierfür wurde DNA aus Knochenmaterial oder Zahnwurzeln isoliert und PCR-gestützt amplifiziert. So konnte anhand von Fragmentlängenanalysen der genetische Fingerabdruck inklusive geschlechtsspezifischer Systeme für die fraglichen Individuen erstellt werden. Der genetische Fingerabdruck beinhaltet mehrere Short Tandem Repeat-Systeme (STR-Systeme). Dabei handelt es sich um Sequenzeinheiten, deren Länge sich wiederholt und Fragmentlängen von maximal einigen 100 Basen ergeben. Die Anzahl der Wiederholungen variiert zwischen Menschen. Die Untersuchung mehrerer STR-Systeme und die zweifache Ausprägung jedes Locus durch den diploiden Chromosomensatz ermöglichen eine Vielzahl an Kombinationsmöglichkeiten, die für jedes Individuum statistisch einmalig in der Weltbevölkerung ist (Goodwin et al. 2011). In Einzelfällen wurden molekulargenetische Analysen an Individuen durchgeführt, welche pathologische Veränderungen zeigten, um die Pathogen-DNA zu isolieren. Es wurde versucht, die DNA der krankheitsverursachenden Pathogene für Osteomyelitis und Tuberkulose $\mathrm{zu}$ isolieren, um morphologische oder mikrostrukturelle Befunde der Knochen differentialdiagnostisch abzuklären. Sämtliche molekulargenetische Untersuchungen fanden in der Abt. Historische Anthropologie und Humanökologie des J.-F.-B. Institutes der Georg-August-Universität statt.

Zusätzlich zur Untersuchung des genetischen Fingerabdrucks mittels STR-Typisierung, welcher einen durch Einzigartigkeit authentifizierenden Charakter hat, wurden die Allelfrequenzen beider Gruppen auf Unterschiede untersucht. Dies fand statt, um zu klären, ob 
die Katholiken und die Anatomieleichen einer sozialen Schicht angehören. Konkret sollte die Frage geklärt werden, ob die katholische Bevölkerung in Göttingen so eng mit der armen Bevölkerung in Verbindung steht, dass sie genetisch nicht zu differenzieren sind.

Für die Kontaminationsprävention und die Analysen kamen vielfältig publizierte Standardverfahren zur Anwendung (z. B. Hummel 2003). Um eine Kontamination der Proben durch den Bearbeiter zu vermeiden, wurden während der Probenvorbereitung, DNA-Extraktion und -Amplifikation Schutzkittel, Haube, Mundschutz, Schutzbrille und Einmalhandschuhe getragen. Zusätzlich sind standardmäßig alle genetischen Fingerabdrücke der Mitarbeiter der Abteilung in eine genetische Datenbank aufgenommen worden, um etwaige Kontaminationen identifizieren zu können. Zur Vermeidung von Kontaminationen zwischen den Proben kamen Einwegmaterialien zum Einsatz beziehungsweise wurden verwendete Materialien und Arbeitsflächen vor und nach der Nutzung gründlich mit Seife, destilliertem Wasser und Ethanol gereinigt. Es gibt eine räumliche Trennung zwischen Prä- und Post-PCR-Laboren. Mitgeführte Leerkontrollen sollten auf eventuelle Kontaminationen während aller Prozesse hinweisen. Die Probenvorbereitung beinhaltet die Probenentnahme sowie die Dekontamination mittels sechsprozentiger Natriumhypochlorit-Lösung ( $\mathrm{NaClO}$ ). Darauf folgen das Spülen mittels doppelt destillierten Wassers und das Trocknen der Probe. Anschließend wird die Probe mit 24 Schwingungen pro Sekunde in der Kugelschwingmühle ca. 10 - 20 Sekunden lang zu Knochenbzw. Zahnpulver zermahlen. Für die Extraktion werden 0,25 g Knochen- bzw. Zahnpulver benötigt. Auf diesen Schritt folgen die Lyse und die eigentliche DNA-Extraktion unter zur hilfenahme einer silikatbasierten Methode (Frischalowski et al. 2015). Hier erwies sich die Vakuumextraktion durch das QIAvac-System (QIAGEN) aufgrund der größeren DNAAusbeute als geeignete Methode. Für die Lyse wird das Knochen- bzw. Zahnpulver mit EDTA (Ethylendiamintetraacetat) sowie Proteinase $\mathrm{K}$ versetzt und bei $37{ }^{\circ} \mathrm{C}$ unter Rotation für 18 Stunden inkubiert. EDTA bewirkt bei diesem Schritt eine Decalcifizierung des Hartgewebes und Proteinase K lysiert die organischen Zellbestandteile. In einem weiteren Schritt wird erneut Proteinase $\mathrm{K}$ hinzugefügt und für 2 Stunden bei $56^{\circ} \mathrm{C}$ unter Rotation inkubiert, um die Proteine von der DNA abzulösen. Das Lysat wird mit SDS (Natriumlaurylsulfat) versetzt, bei $65^{\circ} \mathrm{C}$ für 5 Minuten inkubiert und anschließend bei 3.300 rcf abzentrifugiert. Um die DNA aus dem Lysat zu extrahieren, wird das Lysat mit einem Binding Buffer (PB-Buffer, Qiagen) versetzt, welcher die DNA adsorptiv an eine silikatbeschichtete Membran bindet. Mittels Vakuum wird die Flüssigkeit durch das MinEluteTM (Qiagen) gezogen. Anschließend wird die Membran dreimal mit einem Waschpuffer (PE-Buffer, Qiagen) unter kurzer Inkubationszeit gespült und danach 
abzentrifugiert. Abschließend erfolgt die Elution der DNA mit Wasser in drei Schritten mittels Zentrifugation. Das Elutionsvolumen beträgt $60 \mu$, die Extrakte werden bei $-20^{\circ} \mathrm{C}$ gelagert.

Für die Untersuchung der Pathogen-DNA wird die DNA-Extraktion zusätzlich mit einer Phenol-Chloroform-Aufreinigung kombiniert (Flux et al. 2017). Hierfür wird vor der Bindung der DNA an die Silikamembran das Lysat zunächst in Phenol überführt und bei Raumtemperatur invertiert. Bei $56^{\circ} \mathrm{C}$ findet eine Phasentrennung statt. Die wässrige Phase wird anschließend in Chloroform überführt und invertiert. Auch hier findet eine Ruhephase zur Phasentrennung bei $56^{\circ} \mathrm{C}$ statt. Die wässrige Phase wird schließend in dem PB-Puffer überführt und die DNA wie oben beschrieben extrahiert.

Alte DNA liegt degradierungsbedingt in geringen Mengen vor (Hummel 2003). Um die gewünschten Zielsequenzen untersuchen zu können, muss daher eine Vervielfältigung der entsprechenden DNA-Abschnitte erfolgen. Für die Untersuchung der genetischen Fingerabdrücke geschieht dies PCR-gestützt mithilfe eines eigens für alte DNA entwickelten Multiplex-Kits (Heptaplex-Kit, Seidenberg et al. 2012). Die Heptaplex für stark degradierte DNA umfasst miniSTRs mit einer maximalen Fragmentlänge um die 200 bp. Die Primerpaare amplifizieren Amelogenin für die Geschlechtsbestimmung und sechs autosomale STRs: D13S317, D21S11, D18S51, TH01, D5S818 und FGA. Der Reaktionsmix der PCR beinhaltet hierbei einem Teil QIAGEN Multiplex PCR Master Mix plus, Primer in bestimmter Konzentration, DNA (variierende Menge) und Reinstwasser. Das Cycling wurde mit 40 Zyklen durchgeführt.

Für die Untersuchung der Pathogen-DNA wurden Singleplex-Amplifikationen der jeweiligen Genorte vorgenommen. Die untersuchten Genorte des Haupterregers der Osteomyelitis Staphylococcus aureus lauten nuc (Thermonuklease) und fib (Fibrinogen Binding Protein) (Flux et al. 2017). Für Tuberkulose wurden der Genort katG und die Insertionssequenz IS 1081 untersucht (Schüßler 2016). Der Reaktionsmix für die jeweiligen PCRs besteht zu einem Teil aus AmpliTaq Gold®360 Master Mix (Thermo Fisher Scientific), Primer in bestimmter Konzentration, DNA (variierende Menge) und Reinstwasser. Die Zyklenzahl des Cyclings betrug zwischen 40 und 45 Zyklen.

Zur Überprüfung des Amplifikationserfolges werden die Proben nach der PCR in einem 2,5\%igem Agarose Gel elektrophoretisch aufgetrennt (Hummel 2003) und unter UV-Licht fotografiert. Zusätzlich dazu dienen diese Gelelektrophoresen der Abschätzung der Einsatzmenge von PCR-Produkt in anschließende Analysen. 
Die Fragmenlängenanalyse des genetischen Fingerabdrucks erfolgt basengenau mittels Kapillarelektrophorese im 3500 Series Genetic Analyzer (36 Kapillare, POP-7 ${ }^{\mathrm{TM}}$ Polymer, Applied Biosystems $\left.{ }^{\circledR}\right)$. Die Alleldetermination erfolgt Software gestützt mittels GeneMapper5 Software (Applied Biosystem®).

Für die Sequenzanalyse der Pathogen-DNA findet zunächst eine Sequenzier-PCR unter Verwendung von BigDye® Terminators (Applied Biosystems ${ }^{\circledR}$ ) nach dem Protokoll von Flux et al. (2017) statt. Die anschließende basengenaue Sequenzanalyse erfolgt im Genetic Analyzer 3500 Series (Applied Biosystems ${ }^{\circledR}$ ). Die Sequenzauswertung am Computer erfolgt mit der Software SeqA (Applied Biosystem ${ }^{\circledR}$ ) und den Lasergene 10 Core Suite software packages (DNASTAR). Zur Überprüfung auf spezifische Sequenzen wurden eine BLAST-Suche (Zahng et al. 2000, Morgulis et al. 2008) durchgeführt.

Um die Reproduzierbarkeit der Ergebnisse zu gewährleisten, wurden alle Analysen im Doppelansatz durchgeführt.

Die Daten aus den genetischen Untersuchungen stammen aus Zwischenberichten von Frischalowski (unveröffentlicht) und Mazanec (unveröffentlicht).

\subsection{Erhebung biologischer Daten}

\subsubsection{Demografische Daten}

\section{Geschlechtsbestimmung}

Um das Geschlecht eines Individuums zu bestimmen, wurden morphologische Schädel- und Beckenmerkmale am Skelett untersucht. Zur Beurteilung der Skelette wurden die Geschlechtsmerkmale europäischer Populationen (Acsádi und Nemeskéri 1970, Ferembach et al. 1980, Herrmann et al. 1990) herangezogen. In einem ersten Schritt war es erforderlich, sich einen Überblick über die Serie zu verschaffen, um Robustizität und Varianz des Geschlechtsdimorphismus in dieser Population einschätzen zu können. Die Ausprägung des Beckens unterscheidet sich zwischen Frauen und Männern stärker als der Schädel, denn das Becken ist bei Frauen an das Gebären von Kindern angepasst. Das männliche Becken muss diese Funktion nicht erfüllen und ist daher optimal an die bipede Fortbewegung angepasst. Untersucht wurden hier unter anderem die Höhe und Breite des gesamten Beckens sowie der Größe des Beckeneingangs. Im Vergleich zu den Beckenmerkmalen sind die Schädelmerkmale einem schwächeren Selektionsdruck unterlegen. Aufgrund populationsabhängiger 
Unterschiede wird eine morphologische Reihe erarbeitet, um die Ausprägung der Geschlechtsmerkmale innerhalb der Population zu evaluieren.

Die morphologische Geschlechtsbestimmung an Skeletten subadulter Individuen ist sehr ungenau. Geschlechtsmerkmale, wie zum Beispiel die Größe des Arcus pubis und des Angulus subpubicus sowie des Winkels der Incisura ischiadica major, entstehen durch die vermehrte Bildung der Sexualhormone in der Pubertät. Daher sind sie am subadulten Skelett weitgehend gleich bei Jungen und Mädchen. In diesen Fällen können molekulargenetische Analysen das Geschlecht dieser Individuen determinieren.

Weist ein Individuum sowohl männliche als auch weibliche Merkmale in gleichem Verhältnis auf oder ist kein Geschlecht feststellbar, da beispielsweise die aussagekräftigen Knochen nicht vorhanden sind, wurde „ND“ für nicht determinierbar notiert. Für morphologisch eindeutig männliche Individuen wurde „M“ und für weibliche “ $\mathrm{W}$ “ notiert. Weisen die Merkmale des Geschlechtsdimorphismus überwiegend auf ein Geschlecht hin, wurde „EM“ und „EW“ für eher männliches beziehungsweise eher weibliches Individuum notiert. Sind nur wenige Merkmale aussagekräftig, wurde „TM“ und „TW“ für tendenziell männliches beziehungsweise tendenziell weibliches Individuum notiert.

Individuen, die aufgrund starker Degradierung oder fehlender Skelettelemente keinem Geschlecht zugeordnet werden konnten, wurden molekulargenetisch untersucht. Für diese Untersuchung wurde dem Individuum eine Knochen- oder Zahnprobe entnommen. Anhand der Geschlechtschromosomen konnte molekulargenetisch das Geschlecht in etlichen Fällen bestimmt oder verifiziert werden. Diese Methode wurde ebenfalls eingesetzt, wenn Individuen keine eindeutigen geschlechtsspezifischen Merkmale am Skelett ausgebildet hatten oder morphologische Merkmale beider Geschlechter zu finden waren.

\section{Altersbestimmung}

Die Zuordnung zu den Altersklassen fand nach Herrmann et al. (1990) in Anlehnung an Martin (1928) statt und wurde wie folgt verwendet: Infans 1 (Inf 1) = 0. - 6. Lebensjahr, Infans 2 (Inf $2)=6 .-12$. Lebensjahr, Juvenis (juv) $=13 .-18$. bzw. 20. Lebensjahr, Adultas $(\mathrm{ad})=20 .-40$. Lebensjahr, Maturitas $(m a t)=40$. -60 . Lebensjahr und Senium $($ sen $)=60$. Lebensjahr und älter. Die Altersklassen des Erwachsenenalters wurden wiederum jeweils in drei Unterklassen, z. B. früh-, mittel- oder spätadult, mit einem Umfang von ca. sieben Jahren, unterteilt. Ist eine genaue Zuordnung in eine bestimmte Altersklasse nicht möglich, wurde das Alter durch mehrere Altersklassen, z. B. mittel-spätadult, beschrieben. In so einem Fall wird für die 
statistische Auswertung das Alter des Individuums anteilig auf die Altersklassen aufgeteilt. $\mathrm{Zu}$ berücksichtigen ist, dass bei der morphologischen Altersbestimmung nur ein biologisches Alter, beeinflusst durch den Lebensstil und äußeren Umstände, nicht aber ein chronologisches Alter eines Individuums ermittelt werden kann.

Da die Knochen möglichst wenigen invasiven Methoden ausgesetzt werden sollen, fand die Altersbestimmung erwachsener Individuen mittels Beurteilung des Leitmerkmals der Facies symphysialis und des Obliterationszustandes der Nähte des Schädeldaches (Szilvássy 1988, Nemeskéri et al. 1960) statt. In einigen Fällen wurde die Facies sternalis zusätzlich als Merkmal für die Bestimmung des Sterbealters herangezogen (Szilvássy 1977). Zur Altersbestimmung von subadulten Individuen, Infans 1 - 2, wird der Zahnstatus (Schema der Zahnentwicklung Ubelaker 1989) und für juvenile Individuen der Grad des Epiphysenschlusses (Ferembach et al. 1980) herangezogen.

Individuen, von denen nur wenige Knochenelemente erhalten sind, können mithilfe eines Knochen- oder Zahnwurzeldünnschliffs altersbestimmt werden. Diese Methode ist für Skelette jeder Altersklasse anwendbar. Bei der Untersuchung der Zuwachsringe im Zahnzement wurden die gezählten Ringanzahlen mit dem Durchbruchsalter des jeweiligen Zahns addiert und ergaben das chronologische Alter. Das Durchbruchsalter variiert zwischen den Zähnen und auch zwischen den Geschlechtern. Für eine bessere Vergleichbarkeit der Untersuchungsergebnisse wurden ausschließlich männliche Individuen beider Gruppen ausgewählt. Das Durchbruchalter des Dens caninus lautet nach Schumacher und Schmidt (1972, nach Adler 1967) im Durchschnitt für männliche Individuen 11,81 Jahre (Oberkiefer) und 10,80 Jahre (Unterkiefer). Die Beurteilung der Knochendünnschliffe erfolgt nach Großkopf (1990) und die der Zuwachsringe im Zahnzement nach Grosskopf (2004).

\subsubsection{Körperhöhenrekonstruktion}

Für die Rekonstruktion der Körperhöhe eines Individuums sind in erster Linie die Langknochen von Relevanz. Insbesondere die osteometrischen Messstrecken der unteren Langknochen korrelieren mit der Körperhöhe, während die Messstrecken der oberen Langknochen unter Umständen eine größere Varianz aufweisen. Für die Berechnung der Verteilung der Körperhöhe wurden bereits erhobene Daten (Grosskopf unveröffentlichter Katalog) genutzt. Da die zu untersuchenden Skelette aus dem ausgehenden 19. Jahrhundert stammen, sind die mathematischen Schätzformeln von Pearson (1899) für historische Populationen vor der säkularen Akzeleration verwendet worden. Die Formeln für männliche und weibliche 
Individuen beinhalten die Messstrecken F1, H1, T1 und R1 nach Martin (1928). Zu beachten ist, dass mittels Regressionsfunktionen nur die maximale Körperhöhe zu Lebzeiten des Individuums berechnet und um einen Standardfehler ergänzt werden kann. Es handelt sich lediglich um eine Schätzung der Körperhöhe. Laut Herrmann et al. (1990) beträgt der Standardfehler $\pm 2,5 \mathrm{~cm}$. Dieser Fehlerbereich beinhaltet die Werte von $80 \%$ der Bevölkerung. Auf die Körperhöhenrekonstruktion anhand der Wirbelsäule wurde in dieser Arbeit verzichtet, da die Wirbelsäulen häufig nicht vollständig erhalten waren.

\subsubsection{Diskrete Merkmale}

Im folgenden Abschnitt werden die diskreten Merkmale (Anatomische Varianten) sowohl der Regelbestattungen als auch der Anatomieleichen beschrieben. Es handelt sich dabei um kleinere Variationen am Skelett, die sowohl durch exogene Kräfte, als auch genetische Faktoren verursacht werden können. Für morphologische Untersuchungen ist es wichtig, zu bedenken, dass Merkmale, wie zum Beispiel Nahtknochen und Obliteration der Schädelnähte, mit zunehmendem Alter nicht mehr erkennbar sein können. Auch der fehlende Epiphysenschluss im Jugendalter kann dazu führen, dass einige Merkmale nicht deutlich erkennbar sind.

Folgende diskrete Merkmale wurden vermerkt: Sutura metopica, Nahtknochen, Os incae, Os bregmaticum, Foramen sterni, zusätzliche Foramina transversaria, Spondylolyse, Fusionsbereich der Beckenteile im Acetabulumbereich, Spina bifida bzw. unverschlossene Crista mediana, Hyper- und Hypodontie.

\subsubsection{Paläopathologische Daten}

\subsubsection{Unspezifische Stressmarker}

Cribra orbitalia: Einem porös veränderten Orbitadach können unterschiedlichste Ursachen zugrunde liegen, zum Beispiel Anämie, Skorbut, Rachitis, Entzündung (z. B. Ostitis) oder Einblutungen bei traumatischen Geschehen (Schultz 2001, Wapler et al. 2004). Eine postmortale Erosion im Bereich des Augendachs kann mit einer Cribra orbitalia verwechselt werden und ist mittels eines Knochendünnschliffs des entsprechenden Areals in einer lichtmikroskopischen Untersuchung abzuklären. Die Einteilung der Cribra orbitalia in unterschiedliche Schweregrade erfolgt, wie in der Abbildung 19 gezeigt, in Grad 0: keine Veränderung, Grad I: leicht poröse Oberfläche und Grad II: großflächig poröse Oberfläche. 


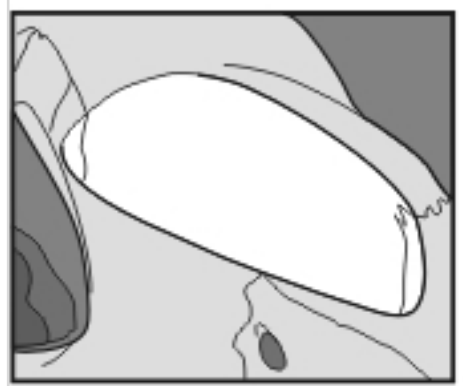

0

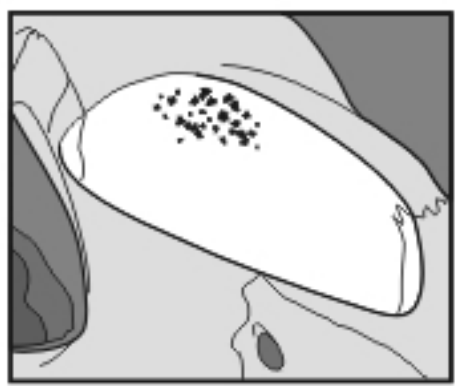

1

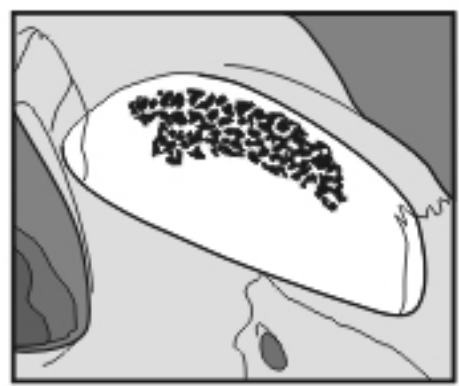

2

Abb. 19: Schweregrade der Cribra orbitalia von Grad 0 (keine Veränderung der Orbita) bis Grad 2 (starke Veränderungen der Orbita). Abbildung von Schultz aus Steckel et al. (2005 S. 13).

Transversale lineare Schmelzhypoplasien: Die meist horizontal verlaufenden Schmelzhypoplasien sind ein weiterer unspezifischer Stressfaktor. Transversale lineare Schmelzhypoplasien sind rillenartige Defekte in der Oberfläche des Zahnschmelzes (Suckling 1989) der Schneidezähne. Sie gelten entweder als nichtspezifische Stressmarker systematisch physiologischer Stresssituationen in der Kindheit (Goodman und Rose 1990) oder deuten auf psychischen Stress hin (Goodman et al. 1980, Schwartz et al. 2006). Perioden von Mangelernährung, (Stoffwechsel-) Erkrankungen und Fieber können die Ameloblastenaktivität beeinträchtigen und führen zu unzureichend mineralisiertem Zahnschmelz (Ogden et al. 2007) und Abweichungen in der Dicke. Nach Schultz (1988b) sind vor allem die transversalen Hypoplasien ein Zeichen einer Mangelernährung und wurden deshalb in diesem Projekt als Indikator herangezogen. Bei der Bewertung der transversalen linearen Schmelzhypoplasien wurde auf das Bewertungsmodell nach Schultz (1988b, Abbildung 20) zurückgegriffen. Dabei gilt Grad 0 als der Normzustand und Grad 1 als eine Variation des Normzustandes. Die weitere Einteilung nach Schultz (1988b) lautet: Grad II: schwach, Grad III: mittel, Grad IV: stark, Grad V: sehr stark.

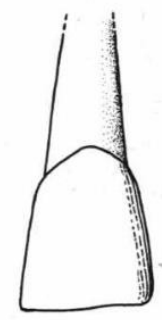

0

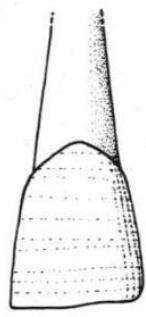

I

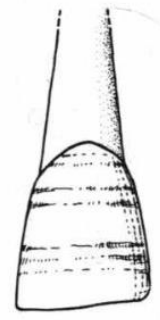

II

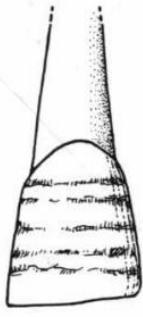

III

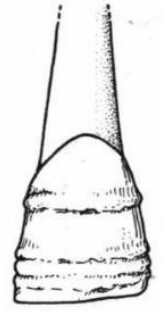

IV

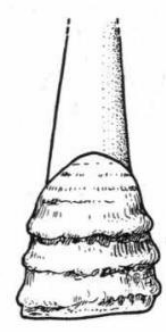

V

Abb. 20: Schweregrade der transversalen linearen Schmelzhypoplasien nach Schultz (1988b S. 494). Grad 0 ist der Normalzustand und Grad 1 eine Variation des Normalzustandes. Grad 2 - 5 stellen pathologische Veränderungen dar. 
Harris-Linien: Die Harris-Linien, auch Wachstumsstillstandslinien, sind vor allem im Langknochen sichtbar und ein wichtiger Hinweis für die Lebensbedingungen eines sich im Wachstum befindenden Individuums (Wells 1961, Wells 1967, Templin 1993). Wachstumsstörungen können Resultate von physischem Stress sein und hinterlassen oft dauerhafte Marken am Skelett (Goodman et al. 1980). Park (1954) berichtet, dass Harris-Linien durch schwere Krankheiten und Mangelernährung (qualitativ und quantitativ) entstehen. Auch Nothwang (2008) berichtet, dass Harris-Linien das direkte Ergebnis einer erhöhten Mineralisation infolge eines zurückgestellten Längenwachstums zugunsten der Genesung nach schweren Erkrankungen sein können. Allerdings kommen auch Unterernährung, Vitaminmangel oder emotionaler Stress als Verursacher infrage. Vom Vorhandensein der Harris-Linie kann also nicht auf die exakte Ursache geschlossen werden (Aufderheide und Rodríguez-Martin 1998), aber sie sind als Indikatoren für problematische Lebensumstände zu interpretieren. Die Proliferation von neuem Knochen stoppt durch die Rezession der Knorpelschicht und die spongiösen, trabekulären Strukturen werden resorbiert (Park 1954). Die neuen Osteoblasten können sich nicht selbst koordinieren und lassen sich an bereits geformten Strukturen, wie die Matrixsubstanz des Knorpels und bereits geformter trabekulärer Knochen, nieder. Dabei wird eine, nach wieder Einsetzen des Wachstums in der Knorpelschicht im Röntgenbild transversale erscheinende Linie gebildet (Ogden 1984). Die Entstehung einer Harris-Linie im Bereich der proximalen oder distalen Metaphyse ist nur bis zum Epiphysenschluss möglich. Diese Linien können allerdings durch ständig ablaufende Umbauprozesse im Erwachsenenalter wieder abgebaut werden (Schultz 1982).

\subsubsection{Mangelerkrankungen}

Skorbut: Die Möller-Barlow-Krankheit im Kindesalter und Skorbut im Erwachsenenalter sind das Resultat eines Vitamins C-Mangels. Diese Avitaminose führt zu fehlerhafter Kollagen- und Osteoidbildung sowie erhöhter Knochenresorption und Blutungsbereitschaft (Aufderheide und Rodriguez-Martin 1998). Kinder, die unter Skorbut leiden, sind sehr anfällig für weitere Infektionen (Steinbock 1976). Die porösen Knochenoberflächen und Auflagerungen in Form einer Periostose entstehen durch knöchern umgebaute subperiostale Hämatome. Vorzugsweise sind diese im Bereich des Orbitadachs, der Lamina interna und externa, des Kiefers und der Langknochendiaphysen (Ortner 2003, Melikan und Waldron 2003) zu finden. Im fortgeschrittenen Stadium kann der gesamte Langknochenschaft durch knöchern umgebaute Blutungsgeschehen verdickt sein (Steinbock 1976). Dies ist über ein Dünnschliffpräparat für Mikroskopuntersuchungen abzuklären. Ähnlich wie bei der Rachitis sind die Rippenenden 
verbreitert, allerdings sind sie beim Skorbut eher eckig, kantig und bei der Rachitis eher knaufartig (Steinbock 1976).

Osteomalazie: Die Rachitis im Kindesalter und Osteomalazie im Erwachsenenalter sind die Folge eines Mangels an Vitamin D. Grund dafür ist meist eine zu geringe UV-Exposition und/oder mangelnde Zufuhr von Vitamin D durch die Nahrung. Besonders Vitamin $\mathrm{D}_{3}$ besitzt eine ausgeprägte antirachitische Wirkung (Welzl 1985). Fehlendes Vitamin D führt zu einer Störung der Calcium- und Phosphorlevel im Blut. Daraufhin wird zu wenig Calcium im Knochen gespeichert, das bereits im Knochen eingelagerte Calcium wird wieder gelöst und es kommt $\mathrm{zu}$ einer unzureichenden beziehungsweise verminderten Knochenmineralisierung (Aufderheide und Rodriguez-Martin 1998). Die Osteomalazie äußert sich meist in einer Verformung der Langknochen unter Belastung. Im Kindesalter finden sowohl eine Stauchung des Humerus- und Femurkopfes sowie eine Verbiegung der Femur-, Tibia- und Fibuladiaphyse statt (Ortner und Putschar 1981). Die Metaphysenenden der Langknochen verbreitern sich keulenförmig (Vargová und Horáčková 2010), ebenso die Rippenenden an ihren costochondralen Übergängen (Jesserer 1971, Aufderheide und Rodriguez-Martin 1998). Im Röntgenbild erscheint die Knochenstruktur der Diaphysenenden unscharf und „besenreiserartig“ aufgefasert (Jesserer 1971).

Anämie: Eine Blutarmut kann unterschiedliche Ursachen haben, z. B. Eisenmangel, Blutverlust oder die angeborene Sichelzellanämie. Da die Notwenigkeit der Ausdehnung von hämatopoetischem Mark besteht, werden Knochenbereiche mit derartigem Vorkommen verändert (Ortner und Putschar 1981, nach Caffey 1937). Die Masse des blutbildenden Knochens wird vergrößert, woraufhin die Oberfläche porös erscheint. Die Anämie äußert sich häufig durch eine Cribra orbitalia, Cribra cranii externa, eine stark erweiterte Diploe, vermehrtes rotes Knochenmark in den Markhöhlen von Röhrenknochen, Knochenschwellungen, wabig aufgelockerte Spongiosastrukturen und einen sogenannten Bürstenschädel (Jesserer 1971, Reimann und Celik 1978, nach Wapler et al. 2004).

\subsubsection{Infektionserkrankungen}

Meningeale Reaktion: Die Spuren von meningealen Reaktionen lassen sich auf der Lamina interna erkennen. Die Auflagerungen hämorrhagischer Reaktionen sind porös und können lokal zungenartige Platten auf der Knochenoberfläche bilden (Schultz 2001). Die Ursachen sind meist Traumata mit anschließenden Blutungsgeschehen oder Skorbut im Kindesalter (Schultz 2001). Im Vergleich dazu verursachen entzündliche Reaktionen Veränderungen direkt auf der Oberfläche. Zu finden sind kleine eingesunkene Platten bis Stippchen und Gefäßimpressionen 
(Schultz 2001). Die bakterielle Meningitis hinterlässt entzündlich-hämorrhagische Spuren sowie Impressiones digitatae in Folge einer Störung der Resorption der Cerebrospinalflüssigkeit und daraus resultierend einer Steigerung des intrakranialen Hirndrucks (Schultz 2001). Die Spuren sind vor allem im Schädeldach in Form einer Haubenmeningitis erkennbar. Bei Unterscheidungen von hämorrhagischen und entzündlichen Reaktionen kann ein Dünnschliff für Mikroskopuntersuchungen behilflich sein. Dort ist deutlich zu erkennen, ob es sich um eine Auflagerung auf der Lamina interna oder eine Veränderung der endocranialen Oberfläche selbst handelt.

Die Ursache einer Meningitis kann zum Beispiel eine Mittelohrentzündung (Schultz und Teschler-Nicola 1987), aber auch eine Infektion mit Meningokokken (Hamperl 1960) sein.

Die tuberkulöse Meningitis, auch Leptomeningitis tuberculosa genannt, hingegen ist überwiegend basal im Bereich der Basis cranii interna lokalisiert. Es lassen sich granulare Impressionen der Tuberkel in Form von Grübchen in der Lamina interna finden (Schultz 2001). Im Dünnschliffpräparat für die lichtmikroskopische Untersuchung weist der Lamellenknochen der Lamina interna grübchenförmige Vertiefungen auf, welche durch Druckatrophie entstanden sind.

Epidurale Hämatome sind an den zungenartig gefelderten Auflagerungen oder großen porösen Platten erkennbar.

Sinusitis: Entzündliche Nasennebenhöhlenerkrankung umfassen den Sinus maxillaris, Cellulae ethmoidales, Sinus sphenoidalis und den Sinus frontalis. Die Oberflächen der Nasennebenhöhlen sind porös verändert. Handelt es sich um ein chronisches Entzündungsgeschehen, sind meist kleine Platten und Stippchen auf der Knochenoberfläche zu erkennen (Schultz 1993). Am häufigsten ist die Kieferhöhle betroffen, aufgrund ihrer unmittelbaren Nachbarschaft zu erkrankten Oberkieferzähnen und der Nasenhöhle (Teegen et al. 1997).

Stomatitis: Bei der Stomatitis handelt es sich um eine Entzündung der Mundschleimhaut, welche sich in ihrer chronischen Form auf den darunter liegenden Knochen auswirkt. Befundbar am Skelett ist allerdings nur die Oberfläche des Palatum durum. Zu erkennen ist eine unregelmäßige, über die Norm poröse Oberfläche des harten Gaumens, oft begleitet durch von der Norm abweichende Exostosen.

Osteomyelitis, Ostitis, Periostitis: Es handelt sich um entzündliche Erkrankungen des Knochenmarks, des Knochens und des Periosts. Oft treten diese drei in Kombination auf und 
werden deshalb auch unter „Osteomyelitis“ zusammengefasst. Typische Merkmale sind die Hyperostose, Bildung von Fisteln, Kloaken und Sequestern (nekrotischer Knochen) sowie Totenladen (neuer Knochen). Oft kommen zwei oder alle drei dieser oben genannten Teilaspekte der Osteomyelitis zur gleichen Zeit vor bzw. bedingen einander.

Otitis media: Die entzündliche Mittelohrerkrankung wird häufig durch Bakterien oder Pilzinfektionen verursacht und betrifft die Schleimhäute sowie den Knochen der Paukenhöhle (Flohr und Schultz 2009). Bei der chronischen Otitis media ist die Oberfläche des Mittelohrs porös und mit stippchenartigen Auflagerungen oder kleinen Platten versehen. Eine chronische Otitis media kann in eine Mastoiditis übergehen (Flohr und Schultz 2009).

Mastoiditis: Entzündliche Prozesse im Kindesalter können primär die vollständige Pneumatisation des Processus mastoideus einschränken oder sogar verhindern (Flohr et al. 2009). Eine fehlende Pneumatisation kann aber auch durch eine sekundäre Verfüllung der pneumatischen Hohlräume im Zuge einer Mastoiditis entstehen (Friedmann 1957, Flohr et al. 2009).

Tuberkulose: Durch die Entzündung der Pleura sind die Oberflächen der Rippeninnenseiten, vor allem im Bereich des Sulcus pulmonis und unter Umständen auch die Wirbelkörperseitenflächen, porös verändert. Die Knochentuberkulose ist als eine spezielle Manifestation einer tuberkulösen Erkrankung anzusehen (Jesserer 1971). Bestand der Verdacht auf Tuberkulose, wurden Knochen des entsprechenden Individuums auf Pathogen-DNA hin untersucht.

\subsubsection{Arthrose, Arthritis}

\section{$\underline{\text { Arthrose der großen Körpergelenke }}$}

Der Oberbegriff „,degenerative Erkrankungen“ umfasst Vorgänge, bei denen Knochen abgebaut werden. Dies kann alle Strukturen betreffen und führt zu funktionellen Einschränkungen. Meist handelt es sich bei degenerativen Erkrankungen um nutzungsbedingte Knorpel- und Knochenveränderungen, die mit zunehmendem Alter gehäuft vorkommen. Ebenso können starke körperliche Belastung und eine schwach ausgebildete Muskulatur die Bildung einer Arthrose begünstigen. Mehrheitlich werden „degenerative Erkrankungen“ wie Arthrose auch von proliferativen Prozessen begleitet.

Für die Analyse von Bewegungs- bzw. Arbeitsvorgängen eines Individuums werden die Extremitätengelenke jedes Individuums sorgfältig auf Abnutzungserscheinungen und 
proliferative Veränderungen hin untersucht. Die Befundung erfolgte mit einem standardisierten Bewertungsbogen nach Schultz (1988b). Bewertet wurden in erster Linie die arthrotischen Veränderungen der Gelenkflächen und Gelenkränder der großen Extremitätengelenke. Die Einteilung der Gelenkveränderung in unterschiedliche Schweregrade erfolgt nach Schultz (1988b) in Grad 0: Normzustand, Grad I: sehr geringfügige Verschleißspuren bzw. funktionell bedingte Varietäten, Grad II: leicht krankhafte Veränderungen, Grad III: mittlere krankhafte Veränderungen, Grad IV: starke krankhafte Veränderungen, Grad V: sehr starke krankhafte Veränderungen und Grad VI: komplett zerstörtes Gelenk (siehe auch Abbildung 21). Weitere Erläuterungen finden sich bei Schultz (1988b). Die zusätzliche Unterteilung in a, b und c gibt die morphologischen Erscheinungsbilder, wie a: eburnierte Oberfläche, b: poröse Oberfläche und c: mit Auflagerungen versehene Oberfläche, wieder. Im Verlauf der Bewertung wird eine Bewertungsziffer für eine gesamte Gelenkeinheit vergeben, welche jeweils aus Gelenkkopf und Gelenkpfanne besteht. Es werden jeweils der Gelenkrand und die Gelenkfläche beurteilt. Dabei entspricht die Bewertungsziffer dem Schweregrad der stärksten Gelenkveränderung in dieser Gelenkeinheit. Besteht eine Gelenkeinheit aus mehreren Teilgelenken, wie beispielsweise das proximale Sprunggelenk, werden die Bewertungsziffern addiert und es wird ein Mittelwert errechnet. Laut Schultz (1988b) ist das Überschreiten der Bewertungsziffer 1.0 als Zeichen für eine krankhafte Gelenkveränderung zu werten.
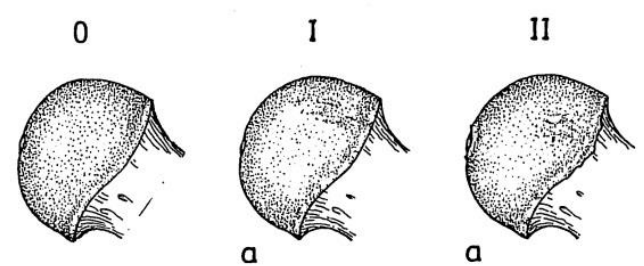

a
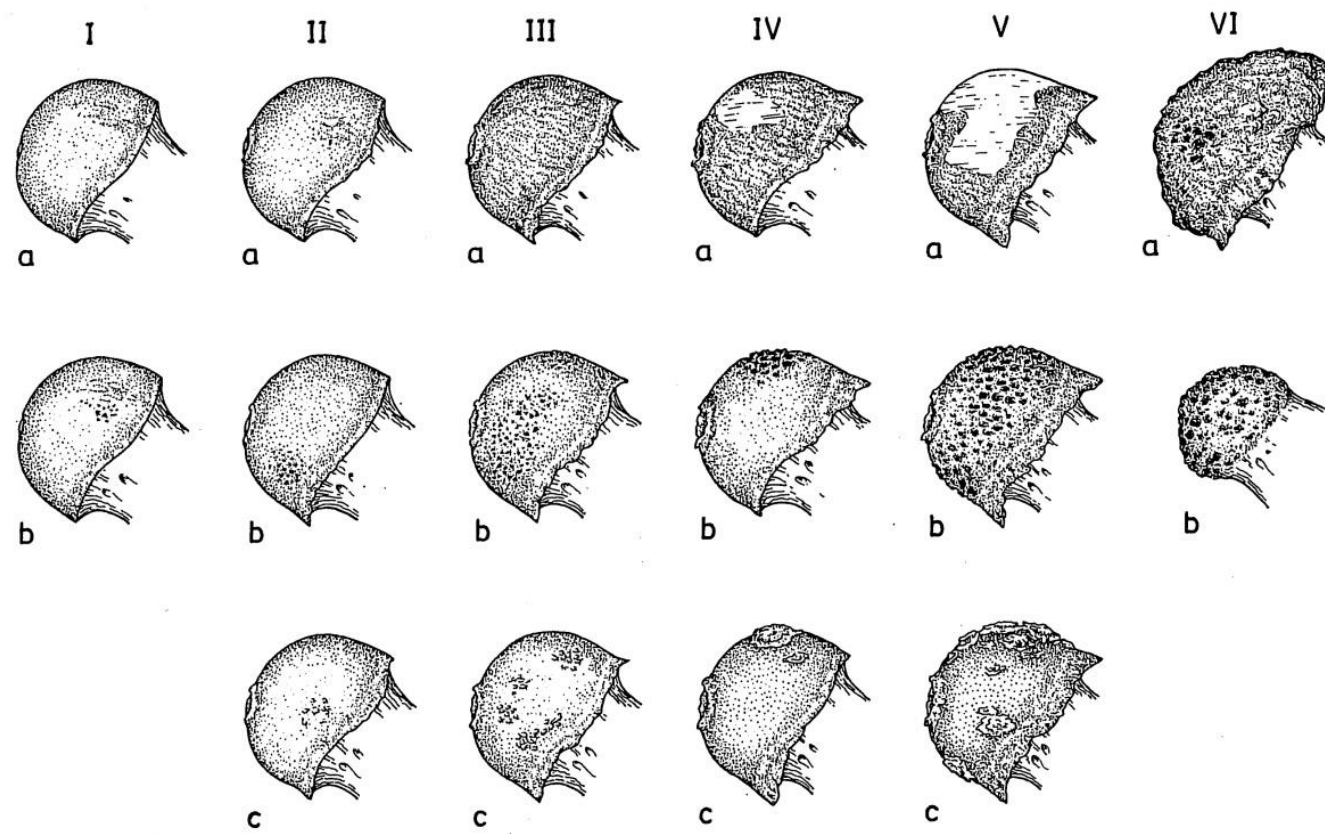

Abb. 21: Gelenkveränderungen in sieben Stufen am Beispiel des Caput femoris (Schultz 1988b S. 483) vom Normzustand Grad 0 bis zum zerstörten Gelenk Grad 6. 
$\underline{\text { Vergleich der Arthroseintensität in den Extremitätengelenken mit anderen Populationen }}$

Die Referenzserien, die mit der Skelettserie vom Göttinger Campus verglichen werden sollen, wurden unter dem Aspekt der zeitlichen und/oder räumlichen Nähe ausgewählt. Im Einzelnen sind das die Skelettserien aus Goslar, bei der es sich um eine Bergbaupopulation handelt, und die Serie aus Inden, bei der es sich um eine Population handelt, die auf dem Land lebte. Für diese zwei Serien sind umfassende biologische Basisdaten, basierend auf morphologischen, osteometrischen und lichtmikroskopischen Untersuchungen, zu Sterbealter, Geschlecht und Körperhöhe der Individuen, bekannt.

Die erste Skelettserie, die für Vergleichszwecke genutzt wird, stammt aus Goslar (Niedersachsen). 1993 wurden bei Baumaßnahmen auf dem Friedhofsgelände (1750 - 1810) des ehemaligen Klosters menschliche Überreste entdeckt. In dieser Skelettserie konnten 89 Individuen befundet werden; davon sind 43 männlich und 46 weiblich. Die Bestattungen werden den Bewohnern des Frankenbergviertels zugeschrieben. Hier lebten vor allem Hüttenleute, Bergbauarbeiter und Waldarbeiter. Die harte körperliche Arbeit der Bewohner dieses Viertels zeigt sich anhand von Belastungsmerkmalen am Knochen. So sind häufig degenerative Veränderungen der Gelenke durch typische, sich wiederholende Arbeitsabläufe bei der Verhüttung erkennbar. In Arbeitsberichten von Thomas Finke, Alexander Fabig und Dr. Barbara Bramanti aus dem Jahr 1999 lassen sich neben den Basisdaten auch Angaben über krankhafte Veränderungen, z. B. im Bereich der Gelenke, finden.

Die zweite Skelettserie stammt von einem Friedhof (1877 - 1924) in Inden (Kr. Düren, Nordrhein-Westfalen). Die Serie umfasst 225 Individuen, welche in Einzelgräbern beigesetzt wurden. Die Ausgrabung zog sich über mehrere Etappen von 1999 bis ins Jahr 2004 hin und wurde wegen der Ausweitung des Braunkohleabbaugebiets am Niederrhein erforderlich. Die Identität zahlreicher Individuen und die Belegung dieses Friedhofs sind durch Kirchenbücher sehr gut dokumentiert. Es liegen morphologische und osteometrische Basisdaten zu der Population von Landarbeitern vor (z. B. Kreye 2016).

Diese zwei Skelettserien sind zeitlich in etwa gleich gestellt mit der Serie aus Göttingen. So können anhand der Daten der degenerativen Gelenkveränderungen unter anderem Vergleiche zwischen der städtischen Population aus Göttingen, der Population vom Land aus Inden und der im Bergbau tätigen Population aus Goslar gezogen werden. 


\section{$\underline{\text { Untersuchungsmethoden - Erhebung biologischer Daten }}$}

$\underline{\text { Wirbelsäulenarthrose }}$

Zusätzlich zu den großen Gelenken wurden auch die Wirbelbogengelenke und Wirbelkörper hinsichtlich arthrotischer und arthritischer Veränderungen befundet. Die Befundung fand ebenfalls mit einem standardisierten Bewertungsbogen nach Schultz (1988b) statt. Für die Bewertung der Veränderungen wurden die gleichen Schweregrade und Standards wie für die Gelenkveränderungen der Extremitätengelenke angewendet. Die Bewertungsziffer setzt sich dabei aus den oberen und unteren Anteilen eines Bewegungssegmentes (BSG) zusammen. Dargestellt in Abbildung 22 ist ein solches BSG, umrandet in Rot. Es gibt 26 Bewegungssegmente, das 1. BSG befindet sich zwischen Schädel und Atlas, das 26. zwischen 5. Lumbalwirbel und 1. Sacralwirbel. Die Auswertung der Bewertungsziffern und die grafische Darstellung fand nach Schelzel (2005) statt.

Darüber hinaus werden auch Veränderungen der Wirbelkörperform, z. B. Keilwirbel, Ankylose (knöcherne Versteifung von Wirbelsäulenabschnitten) vermerkt, sowie Impressionen in die Grund- und Deckplatten aufgrund Schmorlscher Knorpelknötchen.

Am Skelett verknöcherte Bänder und veränderte Muskelansätze wurden ebenfalls dokumentiert.

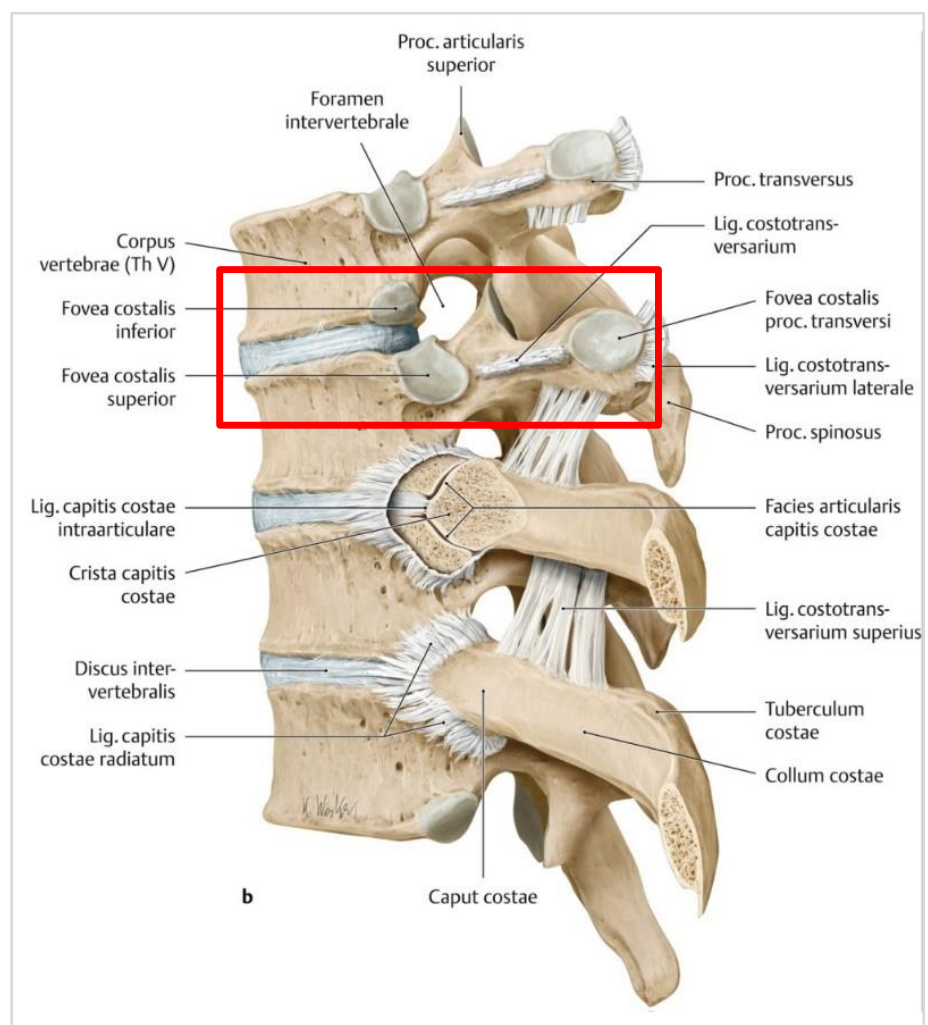

Abb. 22: Rot markiert ist ein Bewegungssegment (BSG) der Wirbelsäule. Ein BSG umfasst ein Wirbelkörpergelenk sowie ein rechtes und ein linkes Wirbelbogengelenk. Abbildung aus Schünke et al. (2011). 
Myotendopathien und Ligamentopathien

Bei Myotendopathien handelt es sich um exostotische Verstärkungen an Muskelursprungs- und Muskelansatzstellen sowie Grubenbildung durch Knochennekrosen. Die Ursache für solche periostalen Reaktionen im Übergangsbereich von Knochen zu Sehnen und Muskeln wird in der Literatur auf unterschiedlichste Art erklärt. Einige Studien erklären die Veränderung durch chronische Überbeanspruchung der Muskeln, Entzündungsprozesse, metabolische Prozesse oder diffuse idiopathische Skeletthyperostose (Villotte et al. 2010, Gresky et al. 2015). Ligamentopathien wie sie zum Beispiel an der Ansatzstelle des Ligamentum costoclaviculare entstehen wurden ebenfalls dokumentiert.

\subsubsection{Erkrankungen der Zähne und Kiefer}

Zu den häufigsten Zahnerkrankungen in nahezu allen Populationen gehören Karies, Zahnstein und Parodontitis. Diese Erkrankungen können nicht selten in apikalen Prozessen und intravitalem Zahnverlust resultieren. Die Häufigkeit von Zahnerkrankungen lässt Rückschlüsse auf die Ernährung und die orale Hygiene einer Population zu. Für die Interpretation und Kontextualisierung der Erkrankungen im Bereich des Kauapparates wurden die Rohdaten aus der Arbeit Frischalowski (2012) verwendet. Zahnstein ist eine sehr harte Ablagerung an den Zähnen, vor allem an Zahnkronen. Er besteht aus Kalziumsalzen (entsteht bei Ausfällung des Speichels), Mikroorganismen und einer Matrix, welche durch die Organismen selbst produziert wird und teilweise durch Proteine aus dem Speichel entsteht. Er entwickelt sich im alkalischen Milieu und mineralisiert dort. Zahnstein selbst ist keine krankhafte Veränderung, leistet aber Parodontopathien Vorschub und führt zur Entzündung und Abbau des Alveolarrandes. Da der Zahnstein bei der Bearbeitung der Skelette abplatzen kann, ist die absolute Häufigkeit von Zahnschmelz nicht zu bestimmen. Karies ist heutzutage die häufigste Erkrankung des Zahns (Roberts und Manchester 2010) und entsteht bei der Fermentation von Zucker aus der Nahrung durch Plaque-Bakterien wie Lactobacillus acidophilus (Jay 1938), die sich im Speichel befinden. Sie demineralisieren die Oberfläche des Zahns und hinterlassen Löcher, da der Zahnschmelz nicht in der Lage ist, sich zu regenerieren. Die Gründe für Karies können vielfältig sein. Sowohl die Ernährung, insbesondere pflanzliche Nahrung wie Getreideprodukte, Hygiene, Krankheitserreger, aber auch die Form der Zähne können infrage kommen. Zusätzlich wurde im Fundkatalog vermerkt, ob Individuen entzündliche Veränderungen (Parodontitis) oder nicht entzündliche Veränderungen (Parodontose) am Knochen aufweisen (Schultz 1988b). 


\section{$\underline{\text { Untersuchungsmethoden - Statistik }}$}

\subsubsection{Weitere Erkrankungen und Veränderungen}

Zusätzlich $\mathrm{zu}$ den beschriebenen und standardmäßig erhobenen Daten wurden weitere Krankheiten und/oder Symptome während der Skelettbearbeitung aufgenommen. Es handelt sich um häufig auftretende, aber teils auch sehr seltene Erkrankungen (siehe Kapitel 4.1.2.6).

\subsubsection{Traumata}

Es wurden Traumata, die Spuren am Knochen hinterlassen, wie unfallbedingte Frakturen, Stressfrakturen und knöchern umgebaute Blutungsgeschehen, vermerkt und fotografisch festgehalten. Auch sekundär entstandene, durch Traumata verursachte Knochenentzündungen oder Nekrosen, wurden dokumentiert.

\subsection{Statistik}

\subsubsection{Morphologische Daten}

Durch statistische Testverfahren sollte ermittelt werden, ob es signifikante Unterschiede in den und zwischen den zu vergleichenden Gruppen gibt. Bei den erhobenen Daten handelte es sich um Häufigkeiten ohne Normalverteilung. Die deskriptive Statistik kann die Häufigkeit und die Verteilungs- bzw. Verbreitungsmuster von Gelenkveränderungen beschreiben.

\section{Geschlechter-, Alters- und Krankheitsverteilung}

Unterschiede in der Geschlechter- und Altersverteilung in den und zwischen den Gruppen wurde mittels $\mathrm{Chi}^{2}$-Tests ermittelt. Ebenso wurde mit diesem Test ermittelt, ob es einen Zusammenhang zwischen Zugehörigkeit zu einer Gruppe und dem Auftreten von unspezifischen Stressmarkern bzw. Infektionskrankheiten gibt.

\section{$\underline{\text { Seitenspezifische Gelenkveränderungen }}$}

Es wurden die Gelenke beider Körperseiten nach der Methode von Schultz (1988b) bewertet und im entsprechenden Befundbogen (siehe Anhang Kapitel 8.2) eingetragen. Daran anschließend wurde mit dem U-Test nach Wilcoxon, Mann und Whitney überprüft, inwiefern die zu vergleichenden Datengruppen signifikante Unterschiede $(\alpha=0,05)$ aufweisen. Für die Kontrolle signifikanter Unterschiede in der Abnutzung durch Belastung in Form erhöhter Arthrosewerte beider Körperseiten wurden ausschließlich Individuen in die Berechnung einbezogen, deren linkes und rechtes Gelenk der jeweiligen Körperregion erhalten war. 


\section{$\underline{\text { Stärke der Gelenkveränderungen }}$}

Um erkennen zu können, welche Gelenke am stärksten abgenutzt sind, wurde für jedes Individuum der Mittelwert aus den Bewertungsziffern des rechten und linken Gelenkes gebildet. Es wurden für diese Untersuchung nur vollständig erhaltene Gelenke verwendet, obwohl alle Gelenkflächen - auch unvollständig erhaltene - im Katalog aufgenommen wurden. Dieser wurde anschließend in die Kategorien 0.0 - 0.9, 1.0 - 1.9, 2.0 - 2.9, 3.0 - 3.9, 4.0 - 4.9, 5.0 - 5.9 und 6 eingeordnet. Da nicht alle Skelette vollständige Gelenke bzw. Gelenke beider Körperseiten aufwiesen, musste hier mit einer Prozentzahl statt der tatsächlichen Häufigkeit gearbeitet werden, um vergleichbare Ergebnisse zu bekommen.

\section{Geschlechtsspezifische Gelenkveränderungen}

Um die Gelenkveränderungen auf Geschlechtsspezifität untersuchen zu können, musste validiert werden, ob sich die Altersstruktur der Frauen und Männer ähnelt. Andernfalls besteht das Risiko, durch einen Überhang von älteren oder jüngeren Individuen für eines der beiden Geschlechter gehäuft hohe oder niedrige Arthrosewerte zu erhalten. Für die Untersuchung wurden Individuen mit dem morphologischen und molekulargenetischen Geschlecht weiblich, eher weiblich und Tendenz weiblich zusammengefasst, ebenso männlich, eher männlich und Tendenz männlich. Mit dem U-Test nach Wilcoxon, Mann und Whitney wird kontrolliert, ob die Datengruppen signifikante Unterschiede $(\alpha=0,05)$ aufweisen.

\section{$\underline{\text { Altersspezifische Gelenk- und Wirbelsäulenveränderungen }}$}

In jeder der beiden Gruppen, Anatomieleichen und Regelbestattungen, wurden die Individuen ihrer jeweiligen Altersklasse zugeordnet. Die Daten der Altersklasse in und zwischen Gruppen sollten miteinander verglichen werden. Anschließend wurde mit dem U-Test nach Wilcoxon, Mann und Whitney überprüft, ob die Datengruppen signifikante Unterschiede $(\alpha=0,05)$ aufweisen. Im Vergleich von mehr als zwei Stichproben wurde auf den Kruskal-Wallis-Test ( $\alpha$ $=0,05)$ zurückgegriffen.

\subsubsection{Genetische Daten}

Um zu überprüfen, ob sich die Allelfrequenzen der beiden Gruppen voneinander unterscheiden, wurde der Exakte Test nach FISCHER angewendet. Das statistische Testverfahren ist dabei nicht von einer bestimmten Stichprobengröße abhängig. Das Signifikanzniveau lag bei $\alpha=0,05$. Der Test wurde mit R 3.4.0 in der Statistik-Software RStudio 1.0.143 durchgeführt. 


\subsection{Grabbeigaben und Beifunde}

Grabbeigaben und Beifunde können in der Regel Aufschluss oder wenigstens einen Hinweis auf die Zugehörigkeit zu einer sozialen Klasse eines Individuums geben. Eine Einteilung in unterschiedliche soziale Klassen aufgrund der Beigaben gestaltete sich hier schwierig, da die Beigabensitte im 19. Jahrhundert stark zurück gegangen ist. Allerdings konnten Überreste von Holzsärgen gefunden werden und einige Individuen wurden in repräsentativen Grüften bestattet, während in Armengräbern Individuen ohne Sarg bestattet wurden (Ströbl 2015).

\subsection{Bewertung der historischen Daten}

Die archivalischen Quellen sollen die medizinisch-naturwissenschaftliche Methodik ergänzen. Gegenstand dieser Untersuchungen sind geschichtswissenschaftliche Recherchen zu Fragen der Medizingeschichte und Herkunft von Leichen. In diesem Zusammenhang wurden sowohl universitätseigene Dokumente als auch die Chroniken der Stadt Göttingen eingesehen. Weiterhin wurden mehrere Archive (Bistum Hildesheim, Hauptstaatsarchiv Hannover, Staatsarchiv Wolfenbüttel) aufgesucht. Das Studium und die Auswertung geschichtlichen Quellenmaterials sollten dabei helfen, die Auswahlkriterien von Leichen für die medizinische Ausbildung zu rekonstruieren. Damit dient dieser Abschnitt des Forschungsvorhabens dazu, die medizinisch-anatomische Ausbildung der historischen Ärzteschaft sowie das Vorgehen der Universität Göttingen bei der Akquise von Anatomieleichen nachzuvollziehen. Zusätzlich sollten Anhaltspunkte zur Identifikation einzelner Individuen ermittelt werden. Dies würde ermöglichen, konkrete Lebenswege in sozial schwachen Schichten des 19. Jahrhunderts nachzuzeichnen. Der Fokus lag darauf, Einblicke in das Leben der Bewohner Göttingens Ende des 19. Jahrhunderts zu erhalten. Die Datengrundlage bildeten diverse Bücher über die Stadt Göttingen und die katholische Gemeinde der Stadt Göttingen sowie schriftlicher Verkehr und gesetzliche Anordnungen in Briefform aus den unterschiedlichen Archiven. Die erhobenen biologischen Basisdaten der Anatomieleichen wurden mit den Angaben auf den Meldescheinen Verstorbener abgeglichen.

\subsection{Struktur und Inhalt des Fundkatalogs}

Der Katalog mit den umfassenden Untersuchungsergebnissen der geborgenen Skelette ist in fortlaufender Nummerierung angelegt. Die Inventarnummer wurde während der Ausgrabung durch die Ausgrabungsfirma angelegt. Unternummern wurden angelegt, wenn sich herausstellte, dass unter einer Nummer mehrere Individuen gelistet waren. Einige 
Inventarnummern bezeichnen Steine oder Mauern. Diese Nummern werden im weiteren Verlauf nicht in den Listen und Katalogen aufgeführt.

Veränderungen pathologischer, traumatischer oder unbekannter Ursache wurden in Form und Art für jeden Knochen einzeln vermerkt. Symptomkomplexe, die auf eine spezifische Erkrankung hinweisen, werden ebenfalls im Befundkatalog vermerkt. Die Form des Katalogs wurde einem Entwurf entnommen, den Prof. Dr. Dr. Schultz (Zentrum für Anatomie UMG) für das Projekt „Liushui“ entwickelt hat (siehe Anhang Kapitel 8.2) und erlaubt eine umfassende und übersichtliche Datensammlung für jedes einzelne Skelett. Neben den anatomischen Veränderungen einzelner Knochen wurden auch die Daten der Gelenk- und Wirbelsäulenarthrosen eingearbeitet. Der Katalog beinhaltet Fotos, aufgenommen während der Grabung durch die Firma Arcontor Projekt GmbH sowie Übersichtsskizzen, welche kurz nach der Bergung im Rahmen einer Abschlussarbeit (Jugert 2012) erstellt wurden. Aus Gründen der Übersichtlichkeit befindet sich der ausführliche Fundkatalog als Anhang im Band 2 der Arbeit. 


\section{Befunde und Ergebnisse}

\subsection{Biologische Daten}

Knochenaufbau und -abbau sind Prozesse, welche sich über das gesamte Leben eines Menschen erstrecken. Ob dies kontinuierlich und geordnet oder aber ungeregelt abläuft, unterliegt den jeweiligen Umständen. Der Knochen kann auf unterschiedliche Weise auf innere und äußere Situationen, z. B. genetische Disposition, Erkrankungen und Umwelteinflüsse, reagieren.

Es gibt zwei Grundarten von Knochen, den primären Knochen, welcher Geflechtbeziehungsweise Faserknochen genannt wird, und den sekundären Knochen, welcher als Lamellenknochen bezeichnet wird. Der Geflechtknochen wird unter funktioneller Belastung zu Lamellenknochen umgebaut. Knochen entsteht durch zwei unterschiedliche Prozesse. Zum einen kann er direkt aus Knochenkernen im Bindegewebe entstehen und wächst dann in die Peripherie. Es handelt sich hierbei um eine desmale Ossifikation der Schädelknochen und dem größten Teil des Schlüsselbeins. Zum anderen kann sich Knochen an der Stelle vorgebildeter Knorpelanteile entwickeln. Hierbei handelt es sich um eine chondrale Ossifikation. Der Knochen wächst ,intermembranös“ unmittelbar unter der Knorpelhaut beziehungsweise der Knochenhaut durch die perichondrale Ossifikation der Diaphysen in die Breite, auch appositionelles Dickenwachstum genannt, und durch enchondrale Ossifikation in der Epiphysenfuge und der Epiphyse in die Länge (Hamperl 1960). Die Ossifikation kann im Laufe der Entwicklung durch verschiedene Faktoren und Krankheiten beeinflusst werden. Hormone, aber auch angeborene und erworbene Erkrankungen, können die Entwicklung beschleunigen, verzögern, und zeitweise oder endgültig zum Stillstand bringen (Brossmann et al. 1982). Der Knochenumbau von bereits gebildeten Knochen findet in folgenden Phasen statt (Waldron 2009): Ruhephase, Aktivierungsphase mit der Bereitstellung von Osteoklasten, Resorptionsphase mit der Resorption beschädigter Knochenoberflächen durch Osteoklasten, Umschaltphase mit der Bereitstellung der Osteoblasten, Anbauphase mit Osteoidproduktion sowie erneute Ruhephase. Die beschriebenen proliferativen und resorptiven Prozesse führen dazu, dass sich der Knochen über alle Lebensphasen hinweg unentwegt umbaut. Diese Umbauprozesse lassen nicht nur Aussagen zum Alter und Geschlecht einer Person zu, sondern auch zu ihrem Gesundheitszustand. Im Folgenden werden wichtige Faktoren erläutert, welche Aussagen über die Lebensumstände einer Person oder ganzen Populationen zulassen. 
Wie eingangs erwähnt, lag bei den Untersuchungen ein besonderes Augenmerk auf den menschlichen Überresten mit Sägespuren im Bereich des Craniums und/oder des postcranialen Skelettes. Anhand der Liste mit Kriterien zur Unterscheidung zwischen in der Rechtsmedizin obduzierten Leichen und in der Anatomie sezierten Leichen von Dittmar und Mitchell (2015) konnte eindeutig gezeigt werden, dass es sich nicht um Skelette von Individuen aus der Rechtsmedizin handelt. Allerdings kann nicht unterschieden werden, ob es sich um Skelette von Anatomie- oder Pathologieleichen der Universität Göttingen handelt. Im Vergleich der Kriterien mit den in der Campusserie gefundenen Spuren liegt der Verdacht nahe, dass es sich bei den Skeletten sowohl um ehemalige Anatomieleichen als auch um Pathologieleichen handelt. Typisch für die Öffnung einer Leiche im Rahmen von Forschungs- und Lehrzwecken sind die horizontale und median-sagittale Craniotomie sowie die Sternotomie oder Thorakotomie. In den meisten Fällen der Skelettserie konnten genau diese horizontalen und median-sagittalen Schnitte am Schädel entdeckt werden. Sägespuren im Bereich der mittleren Axillarlinie des Brustkorbs sind allerdings nicht erkennbar. Vorstellbar ist aber, dass die Organe des Brustkorbs über die Öffnung der Bauchhöhle entnommen worden. Ebenso sind keine Messerspuren wie sie beim Abschaben des Weichgewebes entstehen, Reste von Wachsausgüssen oder Rückstände von Färbemitteln zu erkennen. Die Hals- und Brustwirbel einiger Individuen sind vertikal auf- oder angesägt. Allerdings gibt es Merkmale, die für die Öffnung des Leichnams in der Pathologie sprechen. In der Pathologie werden, zusätzlich zu der Öffnung des Schädels, auch die Langknochen vertikal aufgesägt, um das Knochenmark zu untersuchen. Da beide Arten der Leichenöffnung innerhalb des Skelettkollektivs erkennbar sind, ist eine Zuordnung fraglich. Eine mögliche Erklärung für den Fund beider Arten der Leichenöffnung ist, dass im 19. Jahrhundert die Pathologie und die Anatomie der Universität Göttingen sehr eng zusammengearbeitet haben (Zimmermann 2009). Sezierte Leichen aus beiden Abteilungen sind anschließend auf demselben Friedhof bestattet wurden.

Wie in der Abbildung 23 zu erkennen ist, handelt es sich bei den insgesamt 159 Individuen in $\mathrm{n}=39$ Fällen um Individuen, deren Leiche nach dem Tod seziert wurde. 


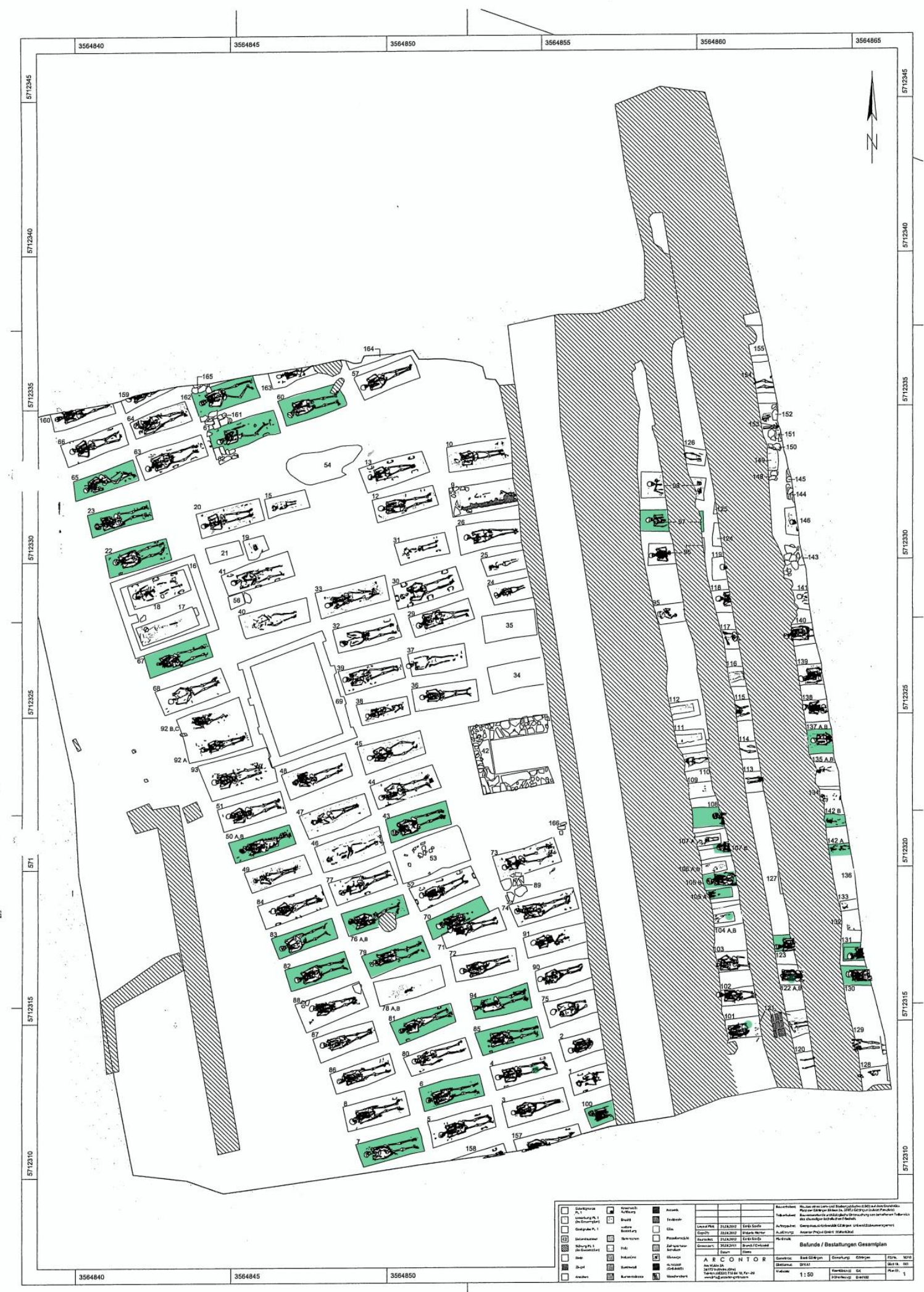

Abb. 23: Grabungsplan der Fa. Arcontor Projekt GmbH. Individuen, welche Spuren einer Sektion aufweisen, sind grün gekennzeichnet $(n=39)$. 


\subsubsection{Demografie}

\section{Geschlechterverteilung}

Die Skelette männlicher und weiblicher Individuen unterscheiden sich durch den voneinander abweichenden Hormonhaushalt ab dem Eintritt in die Pubertät. Vor allem die Anpassung der Frauen an den Geburtsvorgang ermöglicht somit eine morphologische Geschlechtsbestimmung am Becken. In dieser Arbeit wurde die Methode mit der Anwendung der Kriterien für „kaukasische“ Populationen nach Acsádi und Nemekéri (1970), Ferembach et al. (1980) und Herrmann et al. (1990) genutzt. In Fällen, in denen entscheidende Knochen zu stark fragmentiert waren oder fehlten, konnte mithilfe der Molekulargenetik eine Geschlechtsbestimmung erfolgen. Die molekulargenetischen Analysen sind in der Regel zuverlässiger als morphologische Untersuchungen, da die Geschlechtschromosomen direkt nachgewiesen werden. Morphologische Geschlechtsuntersuchungen hingegen beziehen sich auf Merkmale, auf denen der Geschlechtsdimorphismus beruht. Die Ausprägung dieser Merkmale kann in ihrer Intensität aufgrund individueller Lebensbedingungen variieren. In den beiden hier untersuchten Gruppen ist der Geschlechtsdimorphismus am Becken, Schädel und in Form einer unterschiedlichen Robustizität der Langknochen deutlich ausgeprägt. Beispielhaft sind in Abbildung 24 die jeweils linke Os coxae eines weiblichen und eines männlichen Individuums zu sehen.

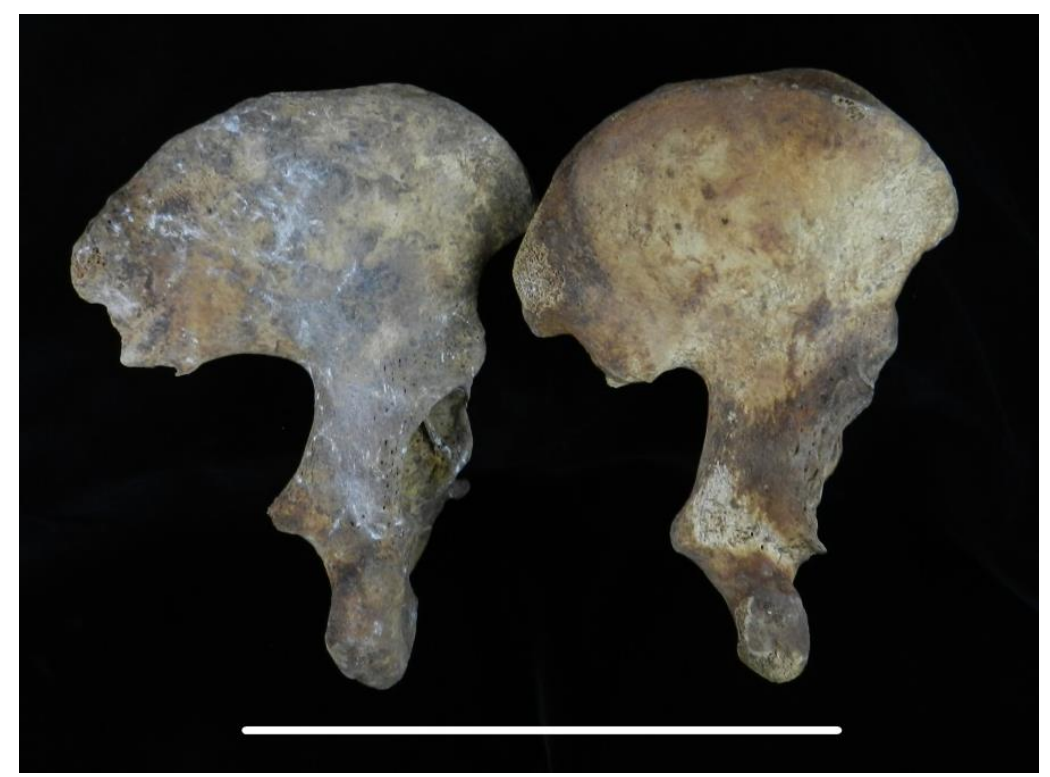

Abb. 24: Größenunterschied einer rechten weiblichen und einer rechten männlichen Os coxa, laterale Ansicht, Strich entspricht $30 \mathrm{~cm}$. Links Fundnummer 36 weiblich und rechts Fundnummer 5 männlich. 
In Fällen, in denen eine morphologische Geschlechtsdiagnose unsicher war (Tendenz männlich/weiblich bzw. eher männlich/weiblich) oder den vorhergehenden Untersuchungen widersprochen hat, konnte die genetische Geschlechtsdiagnose die Richtigkeit des morphologischen Ergebnisses bestätigen. Damit wurde die morphologische Diagnose des Geschlechts mit den hier verwendeten Kriterien zuverlässig angewendet.

Die Gruppe der Anatomieleichen $(\mathrm{n}=39)$ hat mit 34 männlichen und vier weiblichen Individuen ein Geschlechterverhältnis von 8,5 zu 1. Lediglich ein Individuum (2,5\%) konnte weder morphologisch noch molekulargenetisch einem Geschlecht zugeordnet werden. In der Gruppe der Regelbestattungen $(n=120)$ liegt das Geschlechterverhältnis, mit 62 männlichen und 30 weiblichen Individuen, bei etwa 2 zu 1. Allerdings konnten 28 Individuen (23,3\%) keinem Geschlecht zugeordnet werden. In diesen Fällen waren sowohl die Knochen zu schlecht erhalten als auch die DNA für eine Auswertung zu stark degradiert. Der Unterschied zwischen den Gruppen bezüglich des Geschlechterverhältnisses ist allerdings statistisch nicht signifikant $\left(\mathrm{x}^{2}(1 ; 130)=0,31 ; \mathrm{p}=0,07\right)$.

Das zahlenmäßige Verhältnis beider Geschlechter zueinander widerspricht in beiden Gruppen der Annahme von Herrmann et al. (1990), wonach in einer städtischen Population tendenziell ein Frauenüberschuss herrscht. Allerdings handelt es sich bei den untersuchten Skeletten um ein durch die Fundumstände selektiertes Fundgut. Für die Individuen, die einen guten DNAErhalt aufweisen, konnte ausnahmslos das männliche Geschlecht diagnostiziert werden. Daher ist $\mathrm{zu}$ erwarten, dass auch die restlichen, nicht untersuchbaren Individuen beider Gruppen überwiegend männlichen Geschlechts sind. Das bedeutet, dass es sich bei dem morphologisch und molekulargenetisch ermittelten Geschlechterverhältnis von achteinhalb zu eins und zwei zu eins ausschließlich um Minimalwerte handelt. Das Ergebnis der Untersuchung zum Geschlechterverhältnis ist visuell im Bergungsplan in Abbildung 25 dargestellt. 


\section{$\underline{\text { Befunde und Ergebnisse - Biologische Daten }}$}

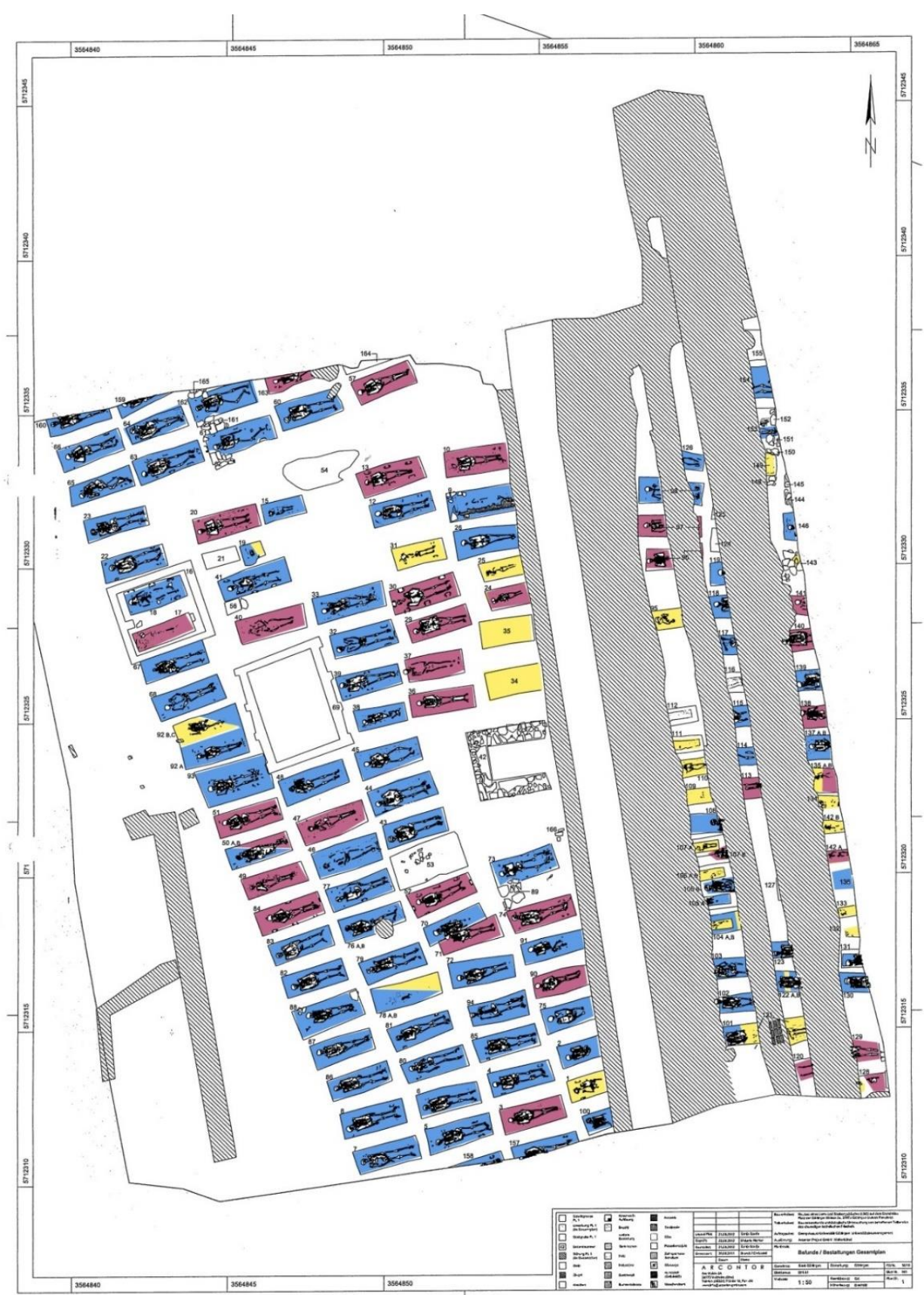

Abb. 25: Grabungsplan der Fa. Arcontor Projekt GmbH. Blau sind männliche Individuen gekennzeichnet, rot Weibliche und gelb nicht bestimmbare Individuen. Die grauen Areale entsprechen alten Kabelschächten. Es gibt unter den 159 Skeletten und Skelettfragmenten 96 männliche Individuen (34 Anatomieleichen, 62 Regelbestattungen), 34 weibliche Individuen (4 Anatomieleichen, 30 Regelbestattungen) und 29 nicht bestimmbare Individuen (1 Anatomieleiche, 28 Regelbestattungen). 
$\underline{\text { Altersverteilung }}$

Im folgenden Abschnitt werden die Ergebnisse der morphologischen und lupenmikroskopischen Altersbestimmung beider Gruppen sowie die grafische Darstellung der Verteilung auf die Altersklassen vorgestellt. In Tabelle 3 befinden sich alle Untersuchungsergebnisse zum Erhaltungszustand, Alter, Geschlecht und den sonstigen Auffälligkeiten.

Tab. 3: Erhaltungszustand der Knochen, Altersdiagnose (morphologisch), Geschlechtsdiagnose (morphologisch und molekulargenetisch) und Vermerk zu Sektionsspuren und sonstigem. ND = nicht determinierbar, $\mathrm{w}=$ weiblich, m = männlich. Die Ergebnisse der molekulargenetischen Untersuchungen stammen aus Dicks (2012), Schröder (2012), Trede (2016) und Frischalowski (Zwischenbericht unveröffentlicht).

\begin{tabular}{|c|c|c|c|c|c|}
\hline Individuum & $\begin{array}{l}\text { Erhaltungs- } \\
\text { zustand }\end{array}$ & Alter & $\begin{array}{l}\text { Geschlecht } \\
\text { Morphologie }\end{array}$ & $\begin{array}{l}\text { Geschlecht } \\
\text { Molekular- } \\
\text { genetik }\end{array}$ & Sonstiges \\
\hline 1 & schlecht & mat $<(40<)$ & ND & & $\begin{array}{lll}\text { Rosenkranz, Statuette mit } \\
\text { Kruzifix }\end{array}$ \\
\hline 2 & sehr gut & $\operatorname{sen}(60<)$ & $\mathrm{m}$ & & Buntmetallmünze \\
\hline 3 & mäßig & $\operatorname{sen}(60<)$ & $\mathrm{W}$ & & Rosenkranz \\
\hline $4(\mathrm{~A})$ & gut & fad-mad $(20-30)$ & $\mathrm{Tm}$ & $\mathrm{m}$ & \\
\hline $4(\mathrm{~B})$ & gut & erwachsen & ND & $\mathrm{m}$ & $\begin{array}{l}\text { Sektion: Unterschenkel; } \\
\text { in Grab } 4 \text { (A) }\end{array}$ \\
\hline 5 & sehr gut & $\operatorname{ad}(25-40)$ & $\mathrm{m}$ & & \\
\hline 6 & sehr gut & mat $(40-60)$ & $\mathrm{m}$ & & Sektion: Cranium \\
\hline 7 & gut & fad-mad $(23-30)$ & $\mathrm{m}$ & & Sektion: Cranium; Fingerhut \\
\hline 8 & sehr gut & fmat-mmat $(40-50)$ & $\mathrm{m}$ & & \\
\hline 9 & gut & $\mathrm{ad}<(20<)$ & $\mathrm{m}$ & & Goldfüllung in 38 \\
\hline 10 & mäßig & mmat-msen $(50-70)$ & w & & \\
\hline 12 & gut & mat $<(40<)$ & $\mathrm{m}$ & & \\
\hline 13 & $\begin{array}{l}\text { mäßig- } \\
\text { schlecht }\end{array}$ & fsen-msen $(60-70)$ & $\mathrm{W}$ & & \\
\hline 15 & $\begin{array}{l}\text { mäßig- } \\
\text { schlecht }\end{array}$ & $\operatorname{Inf} \mathrm{I}(4 \mathrm{~J} \pm 12 \mathrm{M})$ & ND & $\mathrm{m}$ & \\
\hline 17 & sehr schlecht & erwachsen & ND & $\mathrm{w}$ & Ohrringe \\
\hline 18 & schlecht & smat-fsen $(60 \pm 7)$ & $\mathrm{m}$ & & \\
\hline $19(1)$ & mäßig & $\operatorname{Inf} \mathrm{I}(4 \mathrm{~J} \pm 12 \mathrm{M})$ & ND & $\mathrm{m}$ & \\
\hline $19(2)$ & mäßig & erwachsen & ND & ND & In Grab 19 (1) \\
\hline 20 & mäßig & $\operatorname{ssen}(70-80)$ & W & & Rosenkranz, Zahnprothese \\
\hline 22 & gut-mäßig & mat $(40-60)$ & $\mathrm{m}$ & & $\begin{array}{l}\text { Sektion: Cranium; } \\
\text { Rosenkranz }\end{array}$ \\
\hline 23 & gut & mmat-smat $(50-60)$ & $\mathrm{m}$ & $\mathrm{m}$ & Sektion: Cranium, Atlas \\
\hline 24 & gut-mäßig & $\operatorname{Inf} \mathrm{I}(6 \mathrm{~J} \pm 24 \mathrm{M})$ & ND & $\mathrm{w}$ & \\
\hline 25 & schlecht & $\operatorname{Inf} \mathrm{I}(4 \mathrm{~J} \pm 12 \mathrm{M})$ & ND & & Rosenkranz \\
\hline 26 & mäßig & $\operatorname{sen}(60<)$ & $\mathrm{m}$ & & \\
\hline 29 & mäßig & mat $(40-60)$ & $\mathrm{w}$ & & Rosenkranz \\
\hline 30 & mäßig & mat $<(40<)$ & $\mathrm{w}$ & & Rosenkranz \\
\hline 31 & mäßig & $\operatorname{Inf} \mathrm{I}(5 \mathrm{~J} \pm 16 \mathrm{M})$ & ND & ND & Rosenkranz \\
\hline 32 & mäßig & $\operatorname{ad}(23-49)$ & $\mathrm{m}$ & & Zahnprothese \\
\hline
\end{tabular}


$\underline{\text { Befunde und Ergebnisse - Biologische Daten }}$

\begin{tabular}{|c|c|c|c|c|c|}
\hline Individuum & $\begin{array}{l}\text { Erhaltungs- } \\
\text { zustand }\end{array}$ & Alter & $\begin{array}{l}\text { Geschlecht } \\
\text { Morphologie }\end{array}$ & $\begin{array}{l}\text { Geschlecht } \\
\text { Molekular- } \\
\text { genetik }\end{array}$ & Sonstiges \\
\hline 33 & mäßig & fad-mad $(20-30)$ & $\mathrm{m}$ & & Rosenkranz \\
\hline 34 & $\begin{array}{l}\text { mäßig- } \\
\text { schlecht }\end{array}$ & erwachsen & ND & & Rosenkranz \\
\hline 35 & $\begin{array}{l}\text { mäßig- } \\
\text { schlecht }\end{array}$ & erwachsen $(30-60)$ & ND & ND & \\
\hline 36 & gut & $\operatorname{sad}(35-40)$ & w & w & Rosenkranz \\
\hline 37 & schlecht & mad-sad $(30-40)$ & $\mathrm{W}$ & $\mathrm{W}$ & $\begin{array}{l}\text { Rosenkranz, Schreibgriffel } \\
\text { und Schiefertafel }\end{array}$ \\
\hline 38 & gut-mäßig & $\operatorname{Inf}$ II $(8 \mathrm{~J} \pm 24 \mathrm{M})$ & ND & $\mathrm{Tm}$ & $\begin{array}{l}\text { Buntmetallmünze, } \\
\text { Klappmesser }\end{array}$ \\
\hline 39 & $\begin{array}{l}\text { mäßig- } \\
\text { schlecht }\end{array}$ & mat-smat $(50-60)$ & $\mathrm{m}$ & & Rosenkranz \\
\hline 40 & sehr schlecht & erwachsen & Tw & & Rosenkranz \\
\hline 41 & mäßig & smat-fsen $(60 \pm 7)$ & $\mathrm{m}$ & & Holzkreuz \\
\hline 43 & gut & mat $(40-60)$ & $\mathrm{m}$ & & Sektion: Cranium, 2 Wirbel \\
\hline 44 & gut-mäßig & mad-sad $(30-40)$ & $\mathrm{m}$ & $\mathrm{m}$ & Rosenkranz \\
\hline 45 & gut-mäßig & $\operatorname{mad}(25-35)$ & $\mathrm{w}$ & $\mathrm{m}$ & Rosenkranz \\
\hline 46 & sehr schlecht & $\operatorname{ad}(20-40)$ & $\operatorname{Tm}$ & $\mathrm{m}$ & \\
\hline 47 & schlecht & mat $(40-60)$ & $\mathrm{w}$ & $\mathrm{W}$ & Rosenkranz, Ohrringe \\
\hline 48 & mäßig & $\operatorname{sen}(60-80)$ & $\mathrm{m}$ & & Rosenkranz, Bruchband \\
\hline 49 & sehr schlecht & erwachsen & W & $\mathrm{W}$ & $\begin{array}{l}\text { Schreibgriffel und } \\
\text { Schiefertafel }\end{array}$ \\
\hline $50(1)$ & sehr gut & fmat-mmat (40 - 50) & $\mathrm{Tm}$ & $\mathrm{w}$ & $\begin{array}{l}\text { Sektion: Cranium, rechtes } \\
\text { Femur }\end{array}$ \\
\hline $50(2)$ & schlecht & mmat-ssen $(50-80)$ & ND & $\mathrm{m}$ & $\begin{array}{l}\text { Sektion: Cranium, rechtes } \\
\text { Femur; } \\
\text { in Grab } 50 \text { (1) }\end{array}$ \\
\hline 51 & sehr gut & fmat-mmat $(40-50)$ & W & & $\begin{array}{l}\text { Rosenkranz, Schüssel zur } \\
\text { Leichenwaschung }\end{array}$ \\
\hline 52 & sehr gut & sjuv-fad $(19-21)$ & w & & Rosenkranz \\
\hline 57 & sehr gut & mad-sad $(25-40)$ & $\mathrm{W}$ & & Rosenkranz, Ehering \\
\hline 60 & gut & mmat-msen $(50-70)$ & $\mathrm{m}$ & & $\begin{array}{l}\text { Sektion: Cranium; } \\
\text { Holzkreuz }\end{array}$ \\
\hline 61 & gut & mat $(40-60)$ & $\mathrm{m}$ & $\mathrm{m}$ & $\begin{array}{l}\text { Sektion: Cranium, linke } \\
\text { Tibia und Fibula }\end{array}$ \\
\hline 62 & sehr gut & sjuv-fad $(19-21)$ & $\mathrm{m}$ & $\mathrm{Tm}$ & Sektion: Cranium \\
\hline 63 & gut-mäßig & fsen-msen $(60-70)$ & $\mathrm{m}$ & & \\
\hline 64 & gut & mmat-smat (50 - 60) & $\mathrm{m}$ & & \\
\hline 65 & gut & mmat-msen $(50-70)$ & $\mathrm{m}$ & & $\begin{array}{l}\text { Sektion: Cranium, } \\
\text { Wirbelbögen }\end{array}$ \\
\hline 66 & sehr gut & $\operatorname{fad}(20-24)$ & $\mathrm{em}$ & $\mathrm{m}$ & \\
\hline 67 & gut-mäßig & mat $(40-60)$ & $\mathrm{m}$ & & $\begin{array}{l}\text { Sektion: Cranium, } \\
\text { Wirbelkörper der HWS }\end{array}$ \\
\hline 68 & mäßig & mmat-smat $(50-60)$ & $\mathrm{m}$ & & \\
\hline 70 & gut & sjuv-fad $(18-20)$ & $\mathrm{m}$ & & $\begin{array}{l}\text { Sektion: Cranium, rechte } \\
\text { und linke Langknochen, } \\
\text { Wirbel }\end{array}$ \\
\hline 71 & $\begin{array}{l}\text { mäßig- } \\
\text { schlecht }\end{array}$ & mmat-ssen $(50-80)$ & $\mathrm{W}$ & & \\
\hline 72 & sehr gut & mmat-msen $(50-70)$ & $\mathrm{m}$ & & \\
\hline
\end{tabular}




\begin{tabular}{|c|c|c|c|c|c|}
\hline Individuum & $\begin{array}{l}\text { Erhaltungszu } \\
\text { stand }\end{array}$ & Alter & $\begin{array}{l}\text { Geschlecht } \\
\text { Mophologie }\end{array}$ & $\begin{array}{c}\text { Geschlecht } \\
\text { Molekular- } \\
\text { genetik }\end{array}$ & Sonstiges \\
\hline 73 & $\begin{array}{l}\text { mäßig- } \\
\text { schlecht }\end{array}$ & mmat-msen $(50-70)$ & $\mathrm{Tm}$ & $\mathrm{m}$ & Rosenkranz, Holzkreuz \\
\hline 74 & gut & mmat-msen $(50-70)$ & w & & \\
\hline 75 & mäßig & mmat-smat $(50-60)$ & $\mathrm{m}$ & & Buntmetallmünze \\
\hline $76 \mathrm{~A}$ & gut & fad-mad (23-27) & $\mathrm{m}$ & & $\begin{array}{l}\text { Sektion: Cranium, rechtes } \\
\text { Femur }\end{array}$ \\
\hline $76 \mathrm{~B}$ & gut & sjuv-fad $(18-20)$ & $\mathrm{m}$ & & $\begin{array}{l}\text { Sektion: Cranium; } \\
\text { Doppelbestattung mit } 76 \text { A }\end{array}$ \\
\hline 77 & mäßig & mmat-smat $(50-60)$ & $\mathrm{m}$ & & $\begin{array}{l}\text { Buntmetallmünze, } \\
\text { Naturschwamm }\end{array}$ \\
\hline $78 \mathrm{~A}$ & gut & neonat (Geburt-2 M) & ND & & \\
\hline $78 \mathrm{~B}$ & mäßig & $\operatorname{sen}(60-70)$ & em & $\mathrm{m}$ & Buntmetallmünze \\
\hline 79 & gut & sjuv $(17-20)$ & $\mathrm{Tm}$ & $\mathrm{m}$ & Sektion: Cranium \\
\hline 80 & gut-mäßig & $\operatorname{mad}(25-30)$ & $\mathrm{m}$ & & \\
\hline 81 & mäßig & mmat-smat $(50-60)$ & $\mathrm{m}$ & & Sektion: Cranium \\
\hline 82 & sehr gut & sad-mmat $(35-55)$ & $\mathrm{m}$ & $\mathrm{m}$ & Sektion: Cranium \\
\hline 83 & $\begin{array}{l}\text { mäßig- } \\
\text { schlecht }\end{array}$ & fmat-mmat $(40-50)$ & $\mathrm{m}$ & & Sektion: Cranium \\
\hline 84 & gut & mmat-smat $(50-60)$ & $\mathrm{w}$ & & $\begin{array}{l}\text { Rosenkranz, Holzkreuz, } \\
\text { Kamm }\end{array}$ \\
\hline 85 & gut & mmat-msen $(50-70)$ & $\mathrm{m}$ & & Sektion: 3. Cervicalwirbel \\
\hline 86 & sehr gut & mad-sad $(30-40)$ & $\mathrm{m}$ & & \\
\hline 87 & gut-mäßig & mmat-smat $(50-60)$ & $\mathrm{m}$ & & \\
\hline 88 & sehr gut & fad $(22-24)$ & $\mathrm{m}$ & & \\
\hline 90 & gut-mäßig & mmat-msen $(50-70)$ & $\mathrm{w}$ & & Buntmetallmünze \\
\hline 91 & gut & juv $(15 \pm 36 \mathrm{M})$ & $\mathrm{Tm}$ & $\mathrm{Tm}$ & Buntmetallmünze \\
\hline $92 \mathrm{~A}$ & gut & juv $(15 \pm 36 \mathrm{M})$ & $\mathrm{Tm}$ & $\mathrm{Tm}$ & \\
\hline $92 \mathrm{~B}$ & $\begin{array}{l}\text { mäßig- } \\
\text { schlecht }\end{array}$ & $\mathrm{fad}(20-24)$ & $\mathrm{m}$ & & \\
\hline $92 \mathrm{C}$ & $\begin{array}{l}\text { mäßig- } \\
\text { schlecht }\end{array}$ & juv $(15 \pm 36 \mathrm{M})$ & ND & ND & Doppelbestattung mit $92 \mathrm{~B}$ \\
\hline 93 & gut & fsen-msen $(60-70)$ & $\mathrm{m}$ & & $\begin{array}{l}\text { Holzkreuz, } \\
\text { Buntmetallmünze }\end{array}$ \\
\hline 94 & mäßig & $\operatorname{sen}(60-80)$ & $\mathrm{m}$ & & $\begin{array}{l}\text { Sektion: Cranium, linker } \\
\text { Humerus, rechte Clavicula }\end{array}$ \\
\hline 95 & schlecht & Inf II $(9 \mathrm{~J} \pm 24 \mathrm{M})$ & indifferent & ND & Porzellanpüppchen \\
\hline 96 & mäßig & fad-mad $(23-30)$ & $\mathrm{W}$ & & Buntmetallmünze \\
\hline 97 & mäßig & fsen-msen $(60-70)$ & $\mathrm{W}$ & & Sektion: Cranium \\
\hline 98 & schlecht & fsen-msen $(60-70)$ & $\mathrm{m}$ & & \\
\hline 100 & mäßig & mad-mmat (30 - 50) & $\mathrm{m}$ & & Sektion: Cranium \\
\hline 101 & gut & mat $(40-60)$ & $\mathrm{m}$ & & \\
\hline $101(2 ?)$ & gut & erwachsen & ND & & $\begin{array}{l}\text { Sektion: rechtes Femur und } \\
\text { Tibia }\end{array}$ \\
\hline 102 & gut & mad-mmat $(30-50)$ & $\mathrm{m}$ & & Sektion: Cranium; Fingerhut \\
\hline 103 & gut & mmat-msen $(50-70)$ & $\mathrm{m}$ & $\mathrm{m}$ & \\
\hline $104 \mathrm{~A}$ & schlecht & Inf I-II & ND & & \\
\hline $104 \mathrm{~B}(1)$ & gut & mat $(40-60)$ & $\mathrm{m}$ & $\mathrm{m}$ & Sektion: Cranium \\
\hline 104 B (2) & mäßig & juv & ND & & In Grab 104 B (1) \\
\hline
\end{tabular}


$\underline{\text { Befunde und Ergebnisse - Biologische Daten }}$

\begin{tabular}{|c|c|c|c|c|c|}
\hline Individuum & $\begin{array}{l}\text { Erhaltungszu } \\
\text { stand }\end{array}$ & Alter & $\begin{array}{l}\text { Geschlecht } \\
\text { Morphologie }\end{array}$ & $\begin{array}{l}\text { Geschlecht } \\
\text { Molekular- } \\
\text { genetik }\end{array}$ & Sonstiges \\
\hline $104 \mathrm{~B}(3)$ & mäßig & erwachsen & ND & $\mathrm{m}$ & In Grab 104 B (1) \\
\hline $104 \mathrm{~B}(4)$ & mäßig & erwachsen & ND & $\mathrm{m}$ & In Grab 104 B (1) \\
\hline $105 \mathrm{~A}$ & gut & $\operatorname{Inf} \mathrm{I}(5 \mathrm{~J} \pm 16 \mathrm{M})$ & ND & $\mathrm{m}$ & Sektion: Cranium \\
\hline $105 \mathrm{~B}$ & gut-mäßig & mat $(40-60)$ & $\mathrm{m}$ & $\mathrm{m}$ & Sektion: Cranium \\
\hline $106 \mathrm{~A}$ & mäßig & Neonat-Inf I & ND & & Porzellanpuppe \\
\hline $106 \mathrm{~B}$ & sehr schlecht & $\operatorname{Inf} \mathrm{I}(4 \mathrm{~J} \pm 12 \mathrm{M})$ & ND & & Buntmetallmünze \\
\hline $107 \mathrm{~A}$ & $\begin{array}{l}\text { mäßig- } \\
\text { schlecht }\end{array}$ & $\operatorname{Inf} \mathrm{I}(3 \mathrm{~J} \pm 12 \mathrm{M})$ & ND & ND & \\
\hline $107 \mathrm{~B}$ & $\begin{array}{l}\text { mäßig- } \\
\text { schlecht }\end{array}$ & smat-fsen $(60)$ & $\mathrm{w}$ & $\mathrm{W}$ & $\begin{array}{l}\text { Sektion: Cranium; Wirbel } \\
\text { der HWS und BWS }\end{array}$ \\
\hline 108 & mäßig & $\operatorname{sen}(60<)$ & $\mathrm{m}$ & & Sektion: Cranium \\
\hline 109 & sehr schlecht & $\operatorname{Inf} \mathrm{I}(1 \mathrm{~J} \pm 4 \mathrm{M})$ & ND & & \\
\hline 110 & gut-mäßig & $\operatorname{Inf} \mathrm{I}(3-4 \mathrm{~J} \pm 12 \mathrm{M})$ & ND & ND & \\
\hline 111 & sehr schlecht & Neonat-Inf I $(0-6 \mathrm{~J})$ & ND & & \\
\hline 113 & mäßig & erwachsen & ND & $\mathrm{w}$ & \\
\hline 114 & mäßig & erwachsen & ND & $\mathrm{m}$ & \\
\hline 115 & gut & smat-sen $(50-80)$ & $\mathrm{m}$ & & \\
\hline 117 & $\begin{array}{l}\text { mäßig- } \\
\text { schlecht }\end{array}$ & erwachsen & $\mathrm{m}$ & & \\
\hline 118 & gut & $\operatorname{mad}(30-35)$ & $\mathrm{m}$ & $\mathrm{m}$ & \\
\hline 119 & gut & mat $(40-60)$ & $\mathrm{m}$ & & \\
\hline 120 & schlecht & erwachsen & ND & Tw & \\
\hline 121 & $\begin{array}{l}\text { mäßig- } \\
\text { schlecht }\end{array}$ & erwachsen & ND & & \\
\hline $122 \mathrm{~A}(1)$ & sehr gut & mat $(40-60)$ & $\mathrm{m}$ & $\mathrm{m}$ & \\
\hline $122 \mathrm{~A}(2)$ & mäßig & erwachsen & ND & $\mathrm{m}$ & In Grab 122 A (1) \\
\hline $122 \mathrm{~B}$ & gut-mäßig & mat $(40-60)$ & $\mathrm{m}$ & & \\
\hline 123 & gut-mäßig & mad-mmat $(30-50)$ & $\mathrm{m}$ & & $\begin{array}{l}\text { Sektion: Cranium; } \\
\text { Goldfüllung in } 38,47 \text { und } 48\end{array}$ \\
\hline 126 & $\begin{array}{l}\text { mäßig- } \\
\text { schlecht }\end{array}$ & Inf II-fjuv $(<15)$ & ND & $\mathrm{m}$ & \\
\hline 128 & gut-mäßig & juv $(15-17)$ & $\mathrm{w}$ & & \\
\hline Ostprofil & mäßig & senil & ND & & \\
\hline 129 & gut & mat $(40-60)$ & $\mathrm{w}$ & & \\
\hline 130 & gut & mad-sad $(30-40)$ & $\mathrm{m}$ & & Sektion: Cranium \\
\hline 131 & gut-mäßig & fmat-mmat $(40-50)$ & $\mathrm{m}$ & $\mathrm{m}$ & Sektion: Cranium \\
\hline 132 & sehr schlecht & $\mathrm{ND}$ & ND & & Buntmetallmünze \\
\hline 133 & sehr schlecht & $\operatorname{Inf} \mathrm{I}(1 \mathrm{~J} \pm 4 \mathrm{M})$ & ND & & \\
\hline 134 & mäßig & neonat $(9 \mathrm{M} \pm 3 \mathrm{M})$ & ND & & Heiligenbild: HI. Laurentius \\
\hline $135 \mathrm{~A}$ & sehr schlecht & $\begin{array}{l}\text { Neonat-Inf I }(18 \mathrm{M} \pm \\
6 \mathrm{M})\end{array}$ & ND & & Rosenkranz \\
\hline $135 \mathrm{~B}$ & gut & mmat-msen $(50-70)$ & w & & \\
\hline 136 & sehr schlecht & neonat (Geburt - 6M) & ND & $\mathrm{m}$ & \\
\hline $137 \mathrm{~A}$ & mäßig & Inf II $(9 \mathrm{~J} \pm 24 \mathrm{M})$ & ND & $\mathrm{m}$ & $\begin{array}{l}\text { Sektion: Cranium; } \\
\text { Rosenkranz }\end{array}$ \\
\hline $137 \mathrm{~B}$ & gut & mmat-msen $(50-70)$ & $\mathrm{m}$ & $\mathrm{m}$ & \\
\hline 138 & gut & fad $(18-23)$ & $\mathrm{w}$ & $\mathrm{W}$ & Rosenkranz \\
\hline
\end{tabular}




\begin{tabular}{|c|c|c|c|c|c|}
\hline Individuum & $\begin{array}{l}\text { Erhaltungszu } \\
\text { stand }\end{array}$ & Alter & $\begin{array}{l}\text { Geschlecht } \\
\text { Morphologie }\end{array}$ & $\begin{array}{c}\text { Geschlecht } \\
\text { Molekular- } \\
\text { genetik }\end{array}$ & Sonstiges \\
\hline 139 & gut & mmat-smat $(50-60)$ & $\mathrm{m}$ & & \\
\hline 140 & gut & mmat-smat $(50-60)$ & $\mathrm{w}$ & & \\
\hline 141 & schlecht & juv $(15-18)$ & $\mathrm{w}$ & ND & Rosenkranz \\
\hline $142 \mathrm{~A}$ & schlecht & $\operatorname{Inf} \mathrm{I}(4 \mathrm{~J} \pm 12 \mathrm{M})$ & ND & $\mathrm{w}$ & Sektion: Cranium \\
\hline $142 \mathrm{~B}$ & sehr schlecht & $\operatorname{Inf} \mathrm{I}(3 \mathrm{~J} \pm 12 \mathrm{M})$ & ND & & Sektion: Cranium \\
\hline 143 & gut-mäßig & erwachsen & ND & ND & \\
\hline 146 & gut-mäßig & $\operatorname{sen}(60<)$ & $\mathrm{Tm}$ & $\mathrm{m}$ & \\
\hline 149 & mäßig & erwachsen & ND & & \\
\hline 153 & schlecht & erwachsen & ND & $\mathrm{m}$ & \\
\hline 154 & gut & erwachsen & ND & $\mathrm{m}$ & \\
\hline 157 & gut & mat $(40-60)$ & $\mathrm{m}$ & & \\
\hline 158 & gut & erwachsen $(20-60)$ & $\mathrm{m}$ & $\mathrm{m}$ & \\
\hline 159 & mäßig & mat $(40-60[70])$ & $\mathrm{m}$ & & Rosenkranz, Holzkreuz \\
\hline 160 & gut & mmat-msen $(50-70)$ & $\mathrm{m}$ & & \\
\hline 163 & gut-mäßig & mat $(50-70)$ & $\mathrm{w}$ & & \\
\hline $\begin{array}{l}\text { nördl. von } \\
156\end{array}$ & gut & erwachsen & $\mathrm{Tm}$ & & \\
\hline Streufund 1 & gut & Inf I & ND & $\mathrm{m}$ & \\
\hline Streufund 2 & mäßig & erwachsen & ND & & \\
\hline Streufund 3 & gut & erwachsen & ND & $\begin{array}{l}1 \mathrm{Tm} ; 2 \\
\mathrm{ND} ; 3 \mathrm{ND}\end{array}$ & \\
\hline Streufund 4 & $\begin{array}{l}\text { mäßig- } \\
\text { schlecht }\end{array}$ & erwachsen & ND & & \\
\hline Streufund 5 & mäßig & Inf I & $\mathrm{ND}$ & & \\
\hline Streufund 6 & gut & erwachsen & $\mathrm{Tm}$ & & \\
\hline Streufund 7 & gut-mäßig & juv $(15-17 \mathrm{~J})$ & $\mathrm{Tm}$ & $\mathrm{m}$ & \\
\hline
\end{tabular}

Aus der morphologischen Untersuchung der Gruppe der Anatomieleichen ergab sich die in Abbildung 26 dargestellte Altersverteilung. Die Gruppe der subadulten Individuen umfasst lediglich sechseinhalb Individuen. Die ungerade Zahl ergibt sich aus der anteiligen Verteilung auf die Altersklassen. Ist ein Individuum zum Beispiel der Altersklasse adult bis matur zugeordnet worden, geht es zur Hälfte in die Berechnung der adulten und zur Hälfte in die Berechnung der maturen Individuen mit ein. Deutlich höher, mit 32,5 Individuen, ist der Anteil in den Altersklassen Adultas (20 - 40 Jahre), Maturitas (40 - 60 Jahre) und Senium (60 Jahre und älter). Wie schon bei der Geschlechtsbestimmung erkennbar, ist der Männeranteil sehr hoch. Der Sterbegipfel der Männer liegt im maturen Altersbereich. Für die Frauen ist ein Sterbegipfel aufgrund der wenigen Individuen nicht festzustellen. 


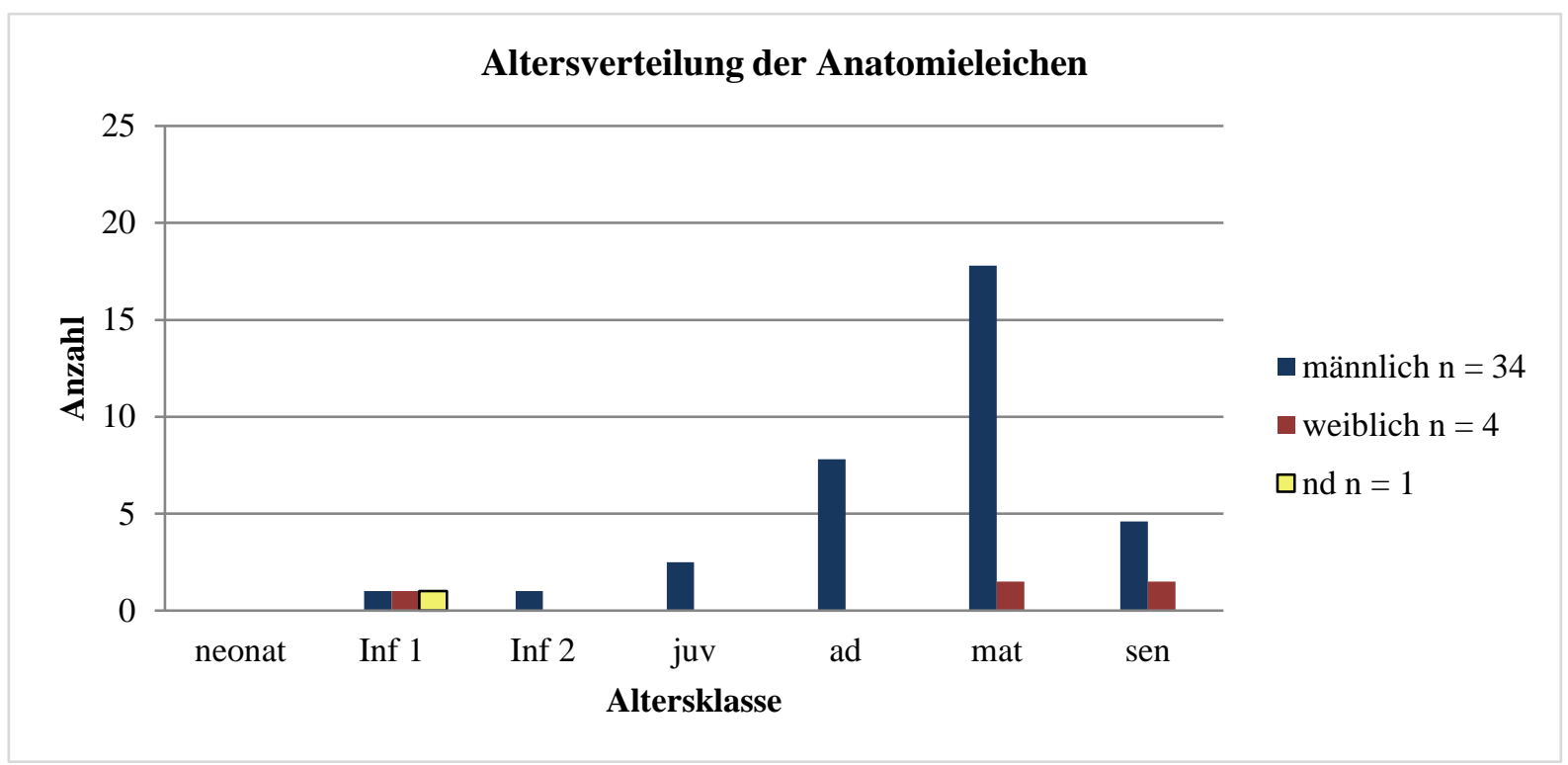

Abb. 26: Absolute Häufigkeit der Altersverteilung (nach morphologischen Kriterien) der Anatomieleichen in Abhängigkeit vom Geschlecht $(\mathrm{n}=39)$. nd = nicht determinierbar, neonat = Neonatus, Inf1 = Infans 1 , Inf2 = Infans 2, juv = Juvenis, ad = Adultas, mat $=$ Maturitas, sen $=$ Senium .

Auf die Berechnung der Sterberate und der Abbildung einer Sterbetafel wird verzichtet, da es sich bei der Bergung der beiden Gruppen lediglich um eine Teilgrabung und damit nicht um ein reales Abbild eines Anteils der katholischen Gemeinde handelt. Ebenso lässt sich die Säuglings- bzw. Kindersterblichkeit aufgrund des Säuglings- und Kleinkinderdefizits nicht berechnen.

In der Gruppe der Regelbestattungen ist der Unterschied in der Geschlechterverteilung deutlich geringer. Die Altersverteilung der Regelbestatteten in Abbildung 27 weicht aber kaum von der Altersverteilung der Anatomieleichen ab. Auch statistisch gibt es keinen Unterschied zwischen den Gruppen $\left(\mathrm{x}^{2}(6 ; 159)=1,72 ; \mathrm{p}=0,46\right)$. In der Altersklasse der subadulten sind - mit einer Anzahl von 29,5 - deutlich mehr Individuen vertreten als in der Gruppe der Anatomieleichen. Der Sterbegipfel der subadulten Individuen liegt im Altersbereich Infans 1 (0 - 6 Jahre). Ein hoher Anteil der subadulten Individuen konnte nicht geschlechtsbestimmt werden.

Der Sterbegipfel der erwachsenen Individuen liegt sowohl für Männer als auch für Frauen im maturen Altersbereich. 


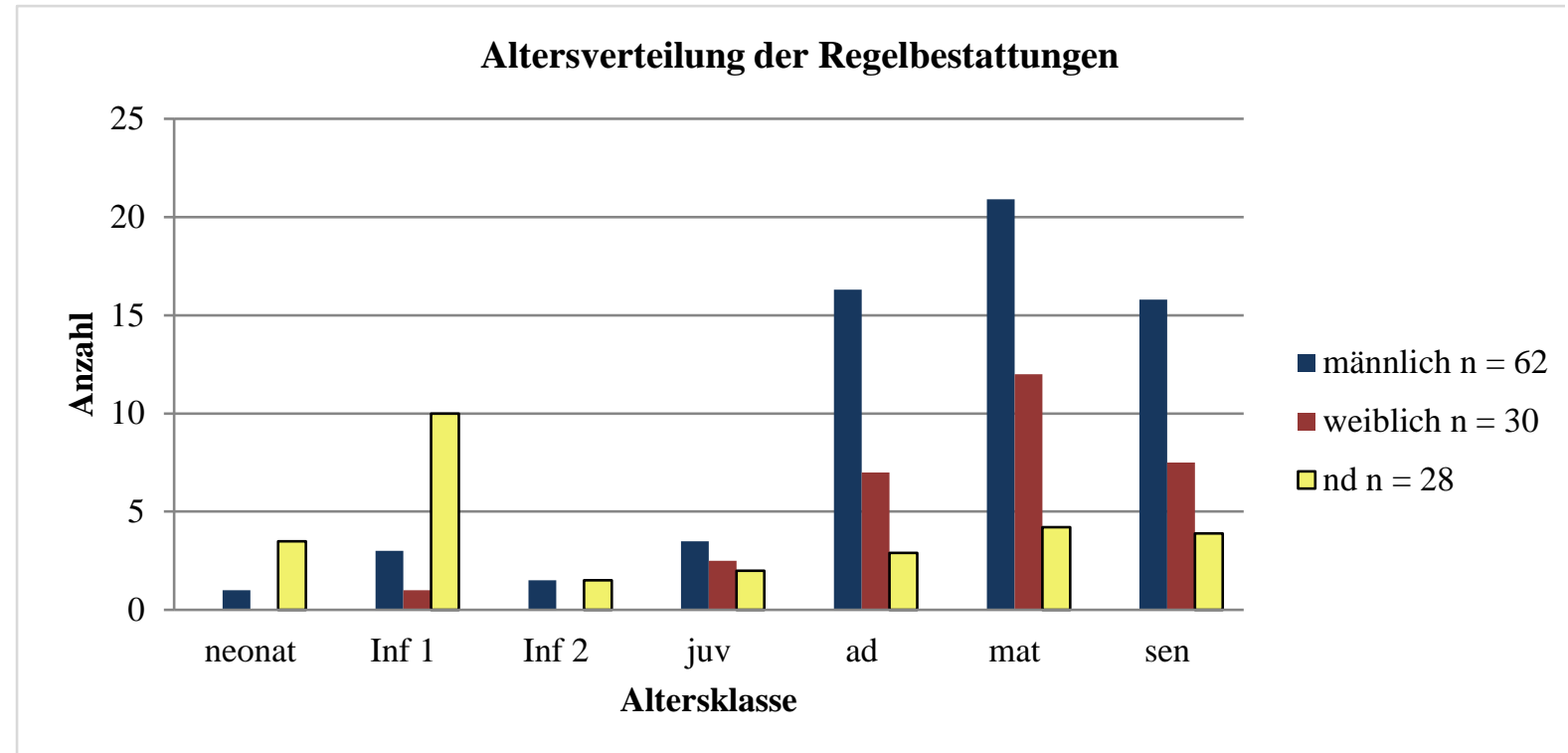

Abb. 27: Absolute Häufigkeit der Altersverteilung (nach morphologischen Kriterien) der Regelbestatteten in Abhängigkeit vom Geschlecht $(\mathrm{n}=120)$. $\mathrm{nd}=$ nicht determinierbar, neonat $=$ Neonatus, Inf $1=\operatorname{Infans} 1$, Inf $2=$ Infans 2, juv = Juvenis, ad = Adultas, mat $=$ Maturitas, sen $=$ Senium.

Um zu überprüfen, wie weit das makro- und das mikromorphologische bestimmte Alter voneinander abweichen, wurden zusätzlich für einige Individuen beider Gruppen lichtmikroskopische Zahndünnschliffe untersucht. Gezählt wurden die Zuwachsringe (siehe Abbildung 28A und 28B) im Zahnzement (Großkopf 1990), welche im circannualen Rhythmus entstehen. Die Diskrepanz zwischen dem morphologisch bestimmten Alter und dem durch die Dentochronologie bestimmten Alter ist in der Gruppe der Anatomieleichen etwas größer als in der Gruppe der Regelbestattungen. Die meisten Individuen beider Gruppen sind scheinbar kalendarisch jünger als ihr biologisches Alter. Die Anatomieleichen $(n=14)$ weisen eine durchschnittliche Abweichung von 6,95 Jahren (Maximalabweichung 17,2 Jahre) auf, während die Regelbestattungen $(n=13)$ eine durchschnittliche Abweichung von lediglich 3,9 Jahren (Maximalabweichung 14,61 Jahre) zeigen. Die Auszählung der Zuwachsringe im Zahnzement wurde bei einigen Individuen durch den teilweise starken Mikroorganismenbefall (siehe Abbildung 28C) erschwert. Zudem ist erkennbar, dass die Zähne der Anatomieleichen sehr häufig in allen Schnittebenen Lakunen von Zementozyten (siehe Abbildung 28D) im Zahnzement aufweisen. Zementozyten befinden sich im zellulären, gemischten lamellären Zement der Wurzelspitze, gehen aus Zementoblasten hervor und besitzen verzweigte Fortsätze, mit denen sie mit ihren Nachbarzellen in Kontakt stehen (Schumacher et al. 1990). Sie haben synthetisierende und resorbierende Funktionen (Schumacher et al. 1990). 


\section{Befunde und Ergebnisse - Biologische Daten}

A
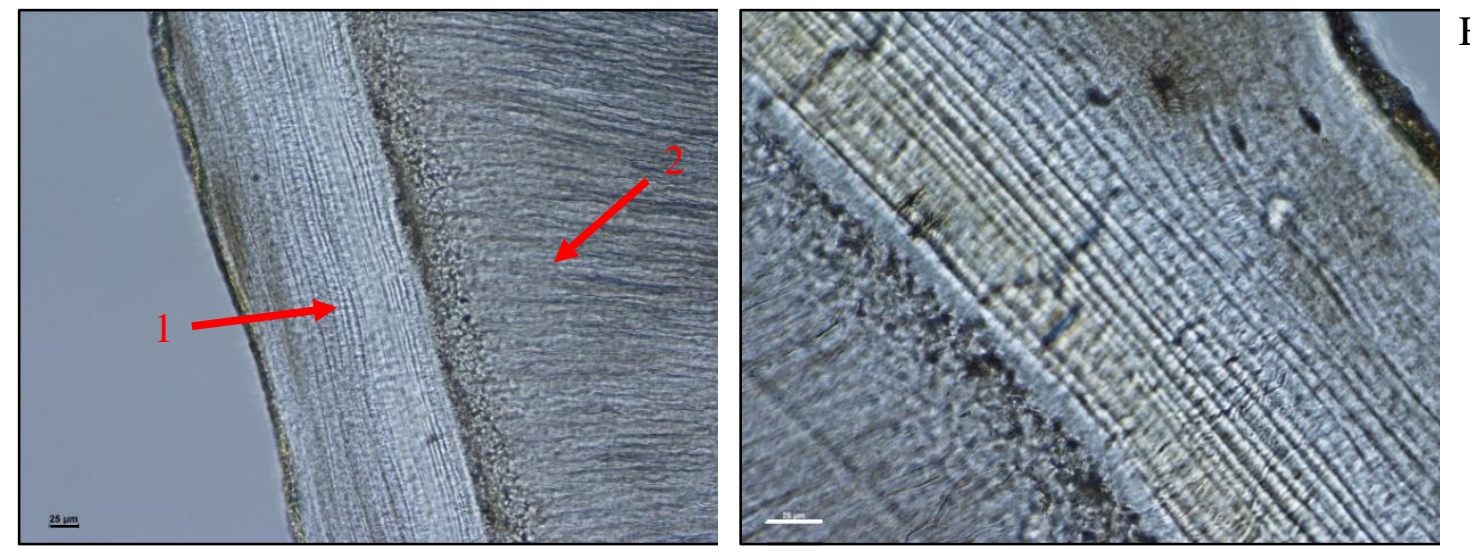

$\mathrm{C}$
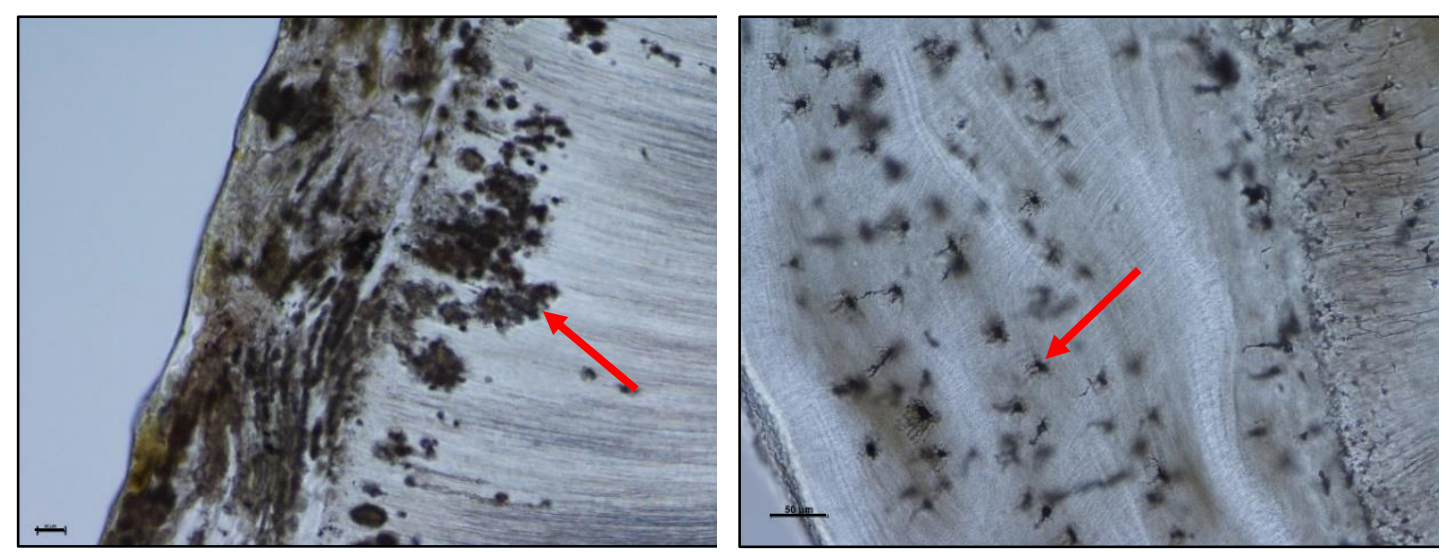

$\mathrm{D}$

Abb. 28: Mikroskopische Betrachtung von Zahnwurzeldünnschliffen. A Zuwachsringe im Zahnzement, 100 $\mu \mathrm{m}, 200$-fache Vergrößerung, Strich entspricht $25 \mu \mathrm{m}$. Zahnzement mit Zuwachsringen (Pfeil 1), Dentin (Pfeil 2). Fundnummer 159, Zahn 23, männlich, 40 - 60 Jahre. B Zuwachsringe im Zahnzement, $100 \mu$ m, 400-fache Vergrößerung, Strich entspricht $25 \mu \mathrm{m}$. Fundnummer 39, Zahn 13, männlich, 50 - 60 Jahre. C Mikroorganismen (Pfeil) und Bohrkanäle im Zahnzement und Dentin, $100 \mu \mathrm{m}, 100$-fache Vergrößerung, Strich entspricht $50 \mu \mathrm{m}$. Fundnummer 61, Zahn 23, männlich, 40 - 60 Jahre. D Lakune eines Zementozyten (Pfeil) im Zahnzement, 100 $\mu \mathrm{m}, 200$-fache Vergrößerung, Strich entspricht $50 \mu \mathrm{m}$. Fundnummer 83, Zahn 23, männlich, 40 - 50 Jahre. 


\subsubsection{Körperhöhenverteilung}

Die Maße der vorhandenen Langknochen sind bereits nach den Messstrecken von Martin (1928) durch Jugert aufgenommen worden (Grosskopf unveröffentlichter Katalog).

Aufgrund der Datenlage wurden für den Vergleich zwischen den Gruppen lediglich die als männlich identifizierten Skelette aus den Altersklassen adult, matur und senil herangezogen. In der Gruppe der Anatomieleichen wurden ausschließlich die als männlich identifizierten Skelette vermessen. Keines der beiden weiblichen und nur ein Individuum mit unsicherer Geschlechtszuordnung ließen eine Messung aufgrund des Erhaltungszustandes zu. Ähnliche Probleme sind auch bei der Gruppe der subadulten Skelette unter den Regelbestattungen zu erkennen. Um vergleichbare Mittelwerte zu erhalten, wurden lediglich männliche Individuen beider Gruppen im Altersbereich adult bis senil berücksichtigt. Dabei betrugen die Mittelwerte der Körperhöhen, errechnet mit der Formel nach Pearson (1899) für historische Skelette, in der Gruppe der Regelbestattungen $(\mathrm{n}=33)$ 165,4 cm und in der Gruppe der Anatomieleichen $(\mathrm{n}=$ 17) $165,1 \mathrm{~cm}$. Für die Berechnung der zentralen Tendenz, unter Vernachlässigung einiger Ausreißer, wurden zusätzlich die Mediane ermittelt. Der Median in der Gruppe der Regelbestattungen $(n=33)$ lag bei $164,8 \mathrm{~cm}$ und in der Gruppe der Anatomieleichen $(n=17)$ bei $166,0 \mathrm{~cm}$.

\subsubsection{Diskrete Merkmale}

Die Naht zwischen den zwei Ossa frontalia verwächst typischerweise bereits im Kindesalter und ist beim erwachsenen Individuum nicht mehr sichtbar. Wenn sie nicht obliteriert sind, bleibt die persistierende Frontalnaht als sogenannte Sutura metopica (siehe Abbildung 29A) sichtbar. Sowohl bei zwei Männern, als auch bei drei Frauen war die Sutura metopica vollständig oder teilweise sichtbar. Eines der männlichen Individuen gehört zu der Gruppe der Anatomieleichen. Ein weibliches Individuum wies zusätzlich zur Sutura metopica einige Nahtknochen in der Sutura lambdoidea auf. Es wurden zwei männliche Individuen mit einem Inkabein (Os incae) gefunden (siehe Abbildung 29C). Die obere und untere Hinterhauptschuppe, jeweils bestehend aus mehreren Knochenkernen, verschmelzen im Säuglingsalter. Dabei kann es zu Asymmetrien und Verknöcherungszentren kommen, welche in Nahtknochen oder einem Os incae resultieren (Starck 1975). Da in einigen geografischen Regionen und ethnischen Populationen ein gehäuftes Vorkommen zu beobachten ist, muss eine gewisse genetische Komponente bei der Bildung eines Inkabeins vermutet werden (Hanihara und Ishida 2001a). Im Vergleich dazu weisen etliche Untersuchungen darauf hin, dass 
Nahtknochen in der Schädelnaht, wie sie in Abbildung 29D abgebildet sind, ihren Ursprung sowohl in genetischen Faktoren, Krankheiten bzw. Syndromen als auch mechanischen Belastungen haben können (Hanihara und Ishida 2001b, Manzi et al. 2000, O'Loughlin 2004, Bellary et al. 2013). Unter den 15 überwiegend männlichen Individuen mit cranialen Nahtknochen befanden sich drei männliche Individuen mit relativ großen Bregmaknochen (Os bregmaticum), in einem Fall fast vollständig verwachsen (siehe Abbildung 29B). Eins dieser drei Individuen war ein seziertes Kind in der Altersklasse Infans 2 mit deutlich ausgeprägtem Hydrocephalus.

A
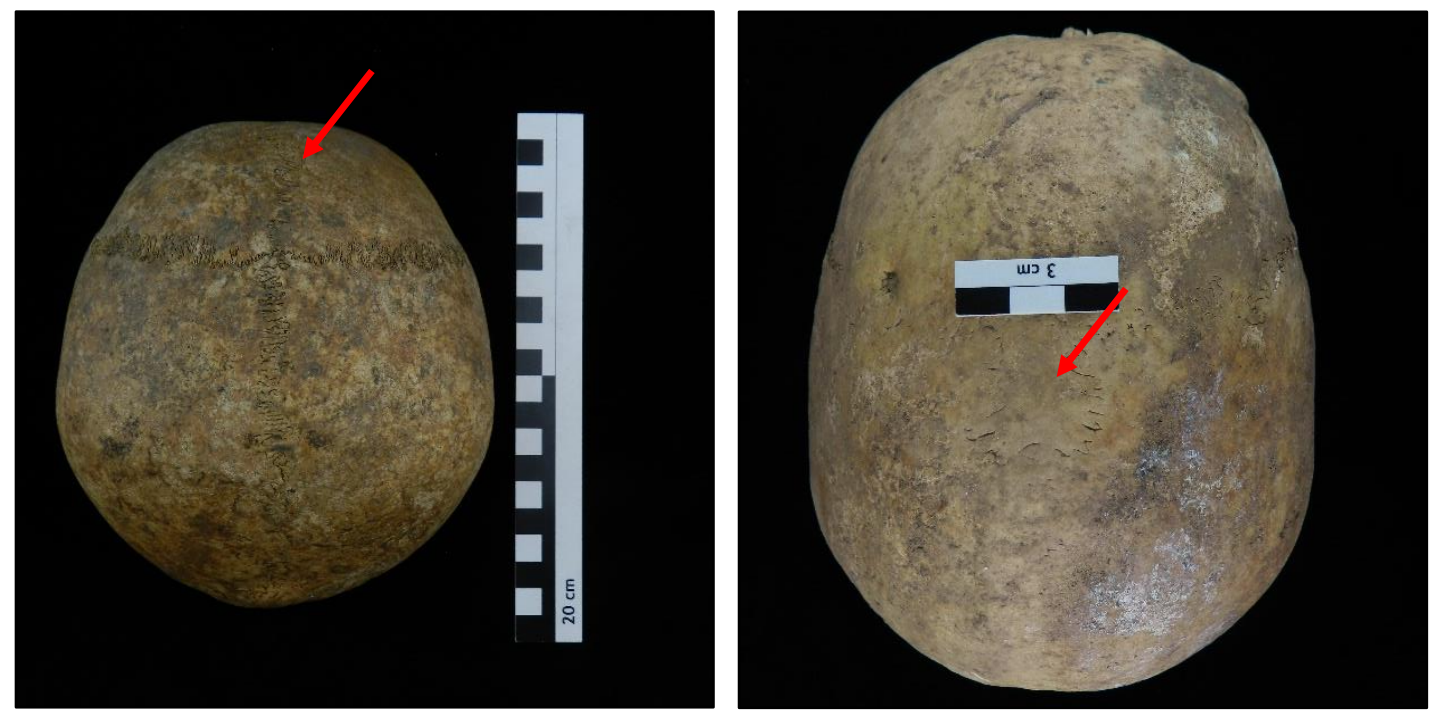

$\mathrm{C}$

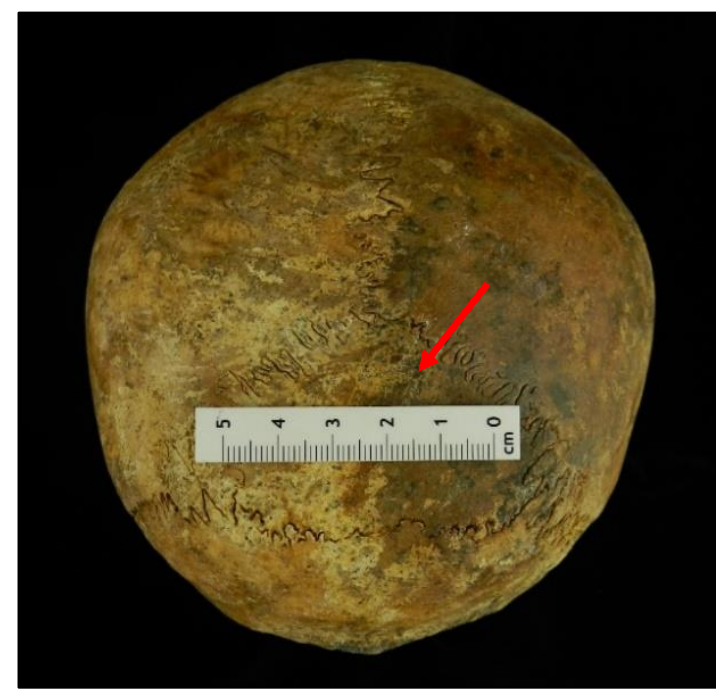

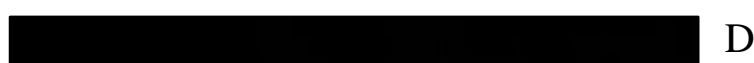

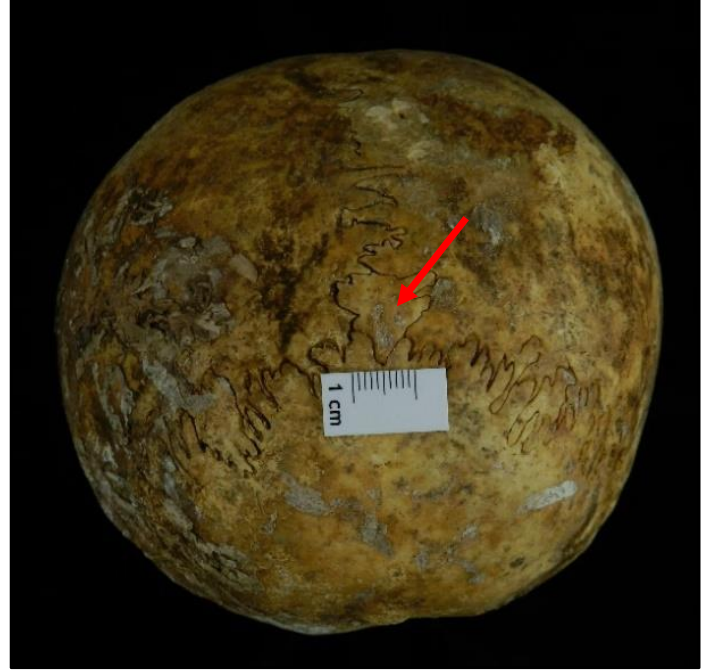

Abb. 29: Diskrete Merkmale am Schädel. A Schädeldach mit unverschlossener Sutura metopica (Pfeil), Norma verticalis. Fundnummer 6, männlich, 40 - 60 Jahre. B Schädeldach mit Bregmaknochen (Os bregmaticum, Pfeil), Norma verticalis. Fundnummer 63, männlich, 60 - 70 Jahre. C Hinterhaupt mit Inkabein (Os incae, Pfeil), Norma occipitalis. Fundnummer 5, männlich, 25 - 40 Jahre. D Hinterhaupt mit Spitzenknochen (Os lambda, Pfeil), Norma occipitalis. Fundnummer 52, weiblich, 19 - 21 Jahre.

Im Kieferbereich wurden ebenfalls etliche diskrete Merkmale oder anatomische Varianten gefunden. So konnte in dieser Skelettserie sowohl Hyperdontie (zusätzliche Zahnanlagen) als 
auch Hypodontie (Fehlen von Zahnanlagen) beobachtet werden. Es wurde ein Fall (Individuum 61) mit jeweils zwei zusätzlichen Zahnanlagen posterior des 18 und des 28 unter den Anatomieleichen beobachtet (siehe Abbildung 30A). Dabei handelt es sich um sogenannte Distomolaren (Bolk 1914). Oft liegt die Begründung für zusätzliche Zahnanlagen in der Vererbung oder in Umweltfaktoren. Mehrere zusätzliche Zahnanlagen sind allerdings fast immer die Folge einer Krankheit beziehungsweise eines Syndroms (Pereira et al. 2011). Weitaus häufiger allerdings, in zwölf Fällen, tritt die Hypodontie auf. Dies betrifft vor allem die Weisheitszähne.

Ein habituelles Merkmal konnte bei einem älteren Mann (Individuum 8) gefunden werden. Es handelt sich um eine sogenannte Pfeifenlücke (siehe Abbildung 30C). Dabei werden die Zähne, mit denen das vorwiegend aus Ton bestehende Mundstück der Pfeife festgehalten wird, nach und nach durch das Material abgeschliffen. Gleichzeitig weist dieses Individuum auch einen Torus mandibularis (siehe Abbildung 30B) auf. Bei einem Torus mandibularis handelt es sich um eine „Exostose“ im lingualen Bereich des Unterkiefers.
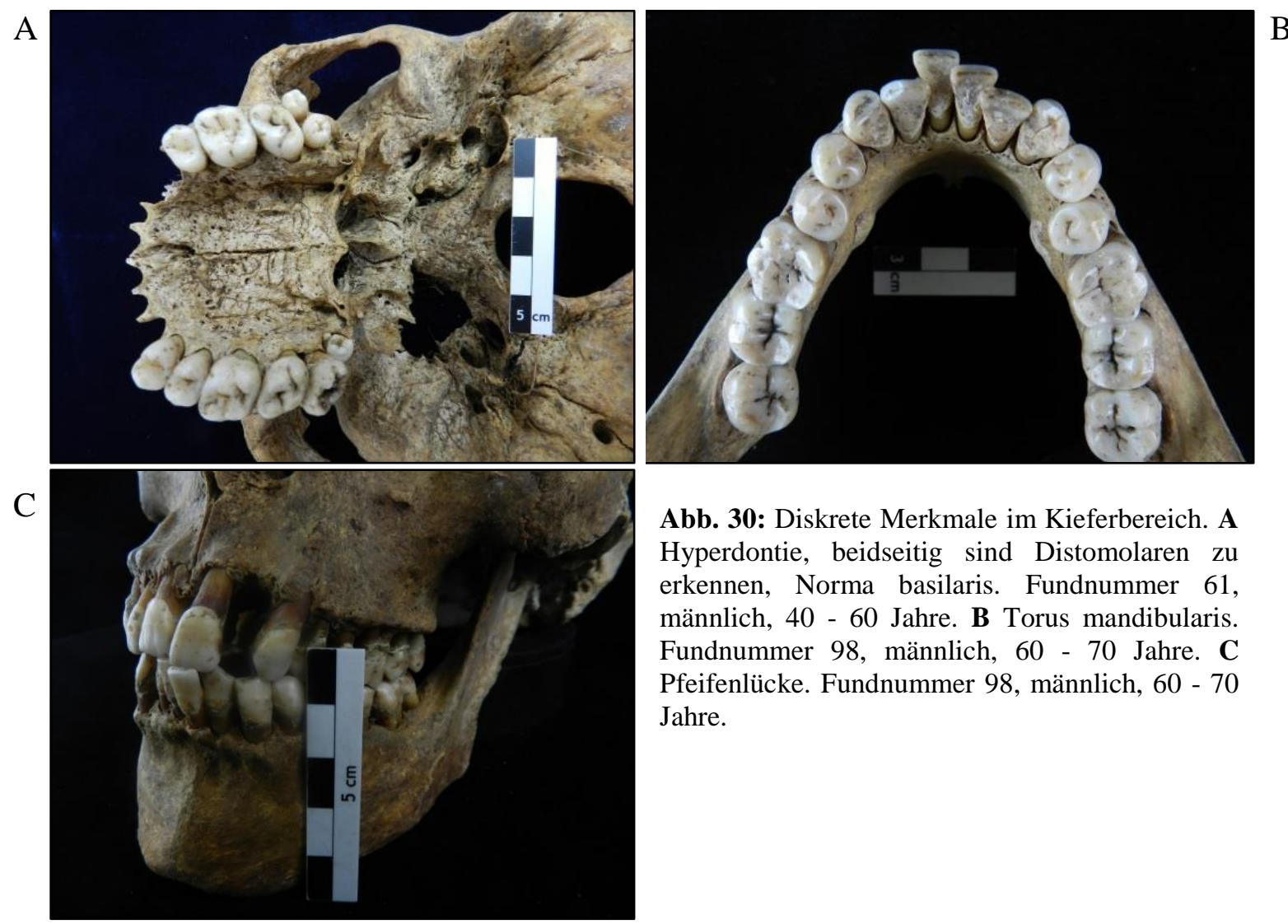

Abb. 30: Diskrete Merkmale im Kieferbereich. A Hyperdontie, beidseitig sind Distomolaren $\mathrm{zu}$ erkennen, Norma basilaris. Fundnummer 61, männlich, 40 - 60 Jahre. B Torus mandibularis. Fundnummer 98, männlich, 60 - 70 Jahre. C Pfeifenlücke. Fundnummer 98, männlich, 60 - 70 Jahre.

Ein Foramen im Corpus sterni weisen die vier Individuen 18, 76A, 100 und 102 auf. Die anatomischen Varianten tritt in dieser Skelettserie nur bei männlichen Individuen im adulten, maturen und senilen Altersbereich aufzutreten. 
Eine anatomische Variante im Bereich der Wirbelsäule ist eine Spondylolyse (siehe Abbildung 31A und 31B), wie sie bei dem Individuum 86 am fünften Lendenwirbel zu finden ist. Bei der Spondylolysis interarticularis ist der Wirbelbogen nicht an den Wirbelkörper angewachsen. Laut Diehlmann (1987) lässt sich die Spondylolyse in $90 \%$ der Fälle am vierten oder fünften Lendenwirbel feststellen und tritt in der „kaukasischen“ Bevölkerung bei vier bis fünf Prozent der Menschen auf. Neben der erblichen Form können Spondylolysen gelegentlich auch durch Traumata entstehen.

A
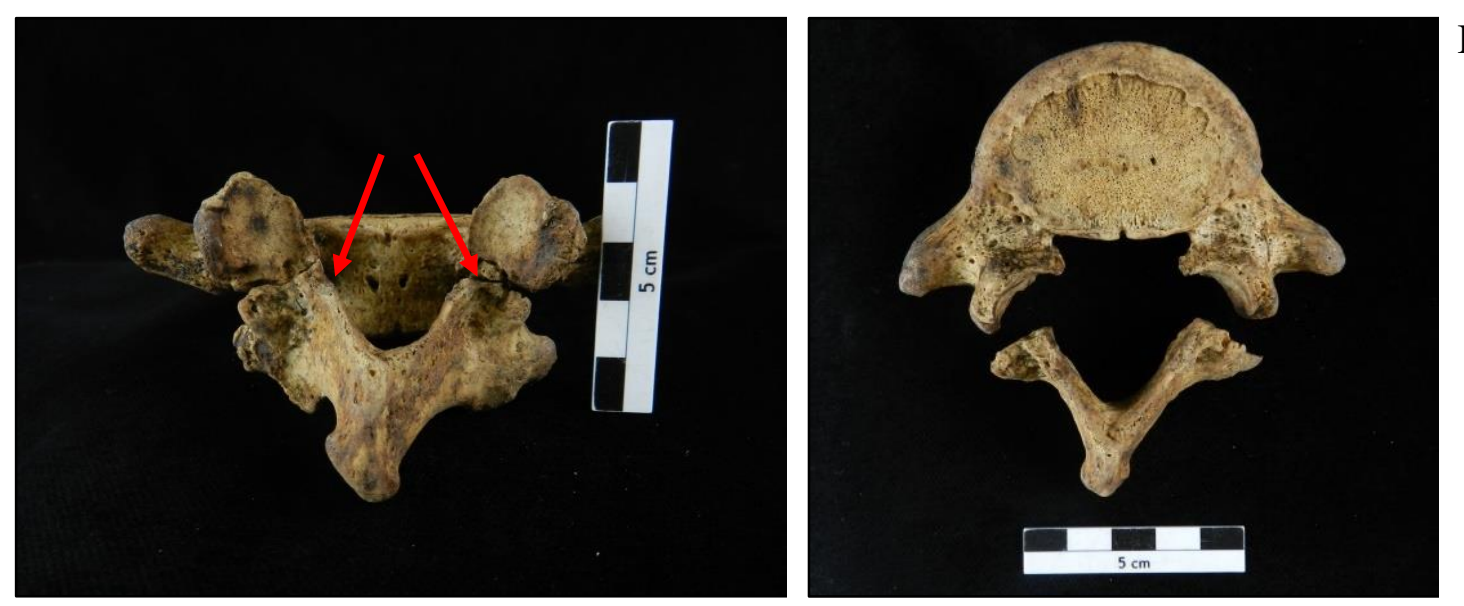

$\mathrm{C}$

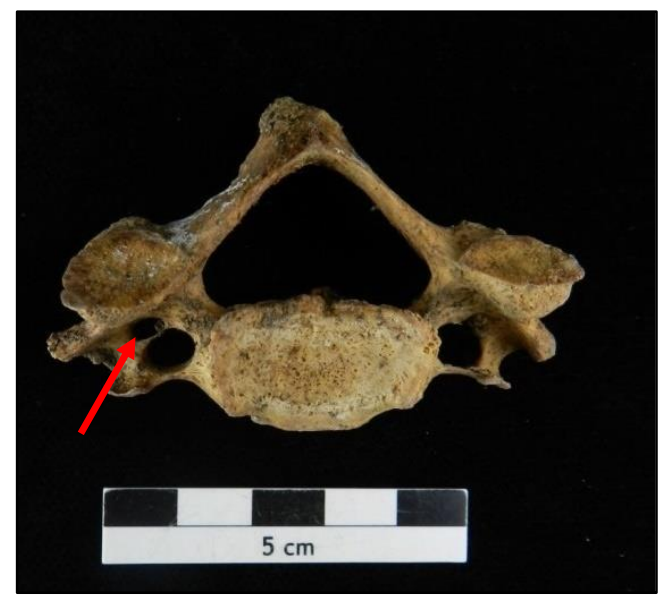

Abb. 31: Diskrete Merkmale im Bereich der Wirbelsäule. A Spondylolyse am 5. Lumbalwirbel, dorsale Ansicht, Pfeile weisen auf die fehlende Verknöcherung von Wirbelkörper und Wirbelbogen. Fundnummer 86, männlich, 30 - 40 Jahre. B Spondylolyse am 5. Lumbalwirbel, craniale Ansicht. Fundnummer 86, männlich, 30 40 Jahre. C Rechts doppeltes Foramen transversum (Pfeil) am 5. Halswirbel, craniale Ansicht. Fundnummer 85, männlich, 50 - 70 Jahre.

Im Bereich der Halswirbelsäule haben die Wirbel links und rechts kleine runde Öffnungen im Processus transversus, sogenannte Foramina transversaria. In einigen Fällen waren diese Formina ein- oder beidseitig doppelt angelegt (siehe Abbildung 31C). Dies betrifft beide Gruppen und Körperseiten, allerdings fast ausschließlich Männer. Die acht Individuen sind 85, 96, 102, 104B (1), 122A (1), 122B, 157 und 159. Bis auf ein adultes Individuum sind die restlichen Individuen im maturen Altersbereich angesiedelt. Am häufigsten sind der fünfte und sechste Cervicalwirbel betroffen.

Eine Spina bifida occulta befindet sich häufig im dorsalen Bereich des Os sacrum, wenn die Wirbelbögen nicht miteinander verwachsen. Es bildet sich dann keine Crista mediana aus. Je 


\section{$\underline{\text { Befunde und Ergebnisse - Biologische Daten }}$}

nach Ausbildungsgrad kann dies schon im neonatalen Alter tödlich sein. Sind die Wirbelbogenteile allerdings trotzdem nah genug beieinander, um das Rückenmark zu schützen, kann ein hohes Alter ohne oder mit nur leichten Einschränkungen erreicht werden. Neun regelbestattete Individuen und drei Anatomieleichen zeigen eine unvollständige Verknöcherung der Processus spinosus. Allerdings haben nur die Individuen 36, 72 (siehe Abbildung 32A), 91 (Regelbestattungen) und 104B (1) (Anatomieleiche, siehe Abbildung 32B) eine vollständige Wirbelspalte. Bei allen anderen Individuen (64, 77, 87, 90, 101, 102, 138, 159) ist lediglich der Wirbelbogen des ersten Sacralwirbels nicht geschlossen. Damit ist die anteilige Häufigkeit in beiden Gruppen gleich groß.

A
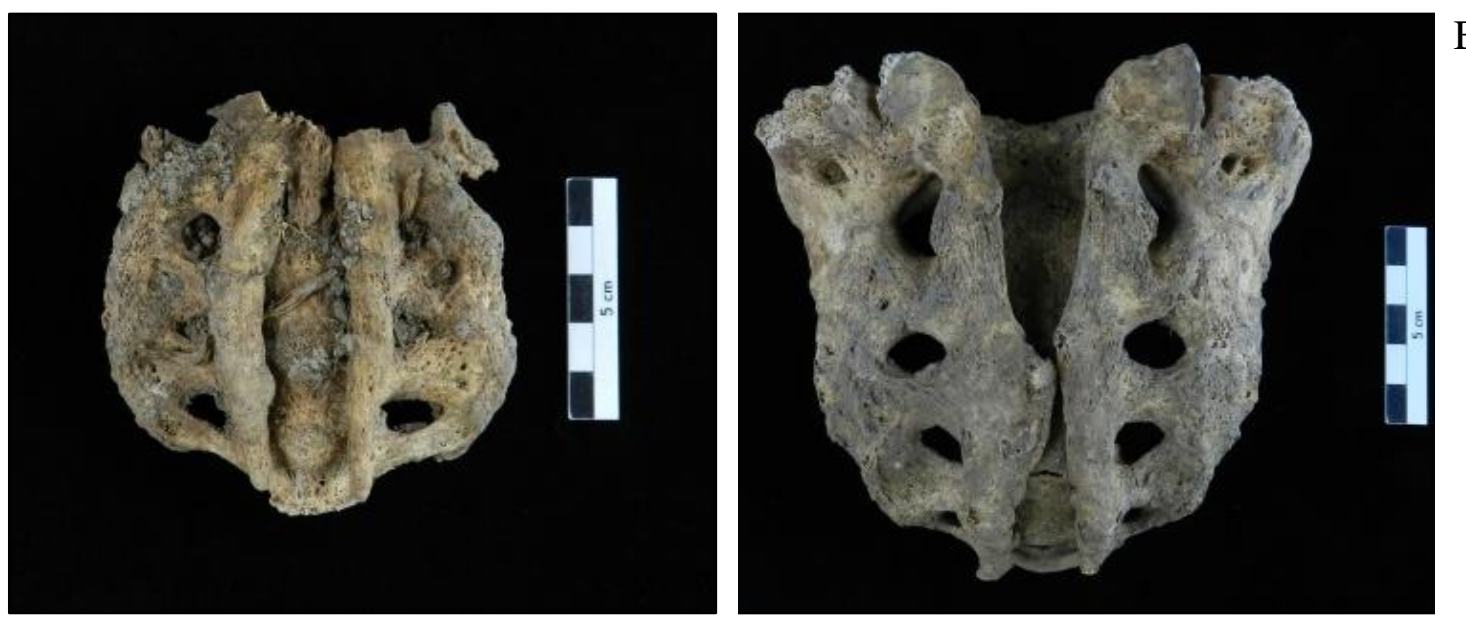

Abb. 32: Diskretes Merkmal im Bereich des Os sacrum. A Os sacrum mit Spina bifida in dorsaler Ansicht. Fundnummer 72, männlich, 50 - 70 Jahre. B Os sacrum mit Spina bifida in dorsaler Ansicht. Fundnummer 104B (1), männlich, 40 - 60 Jahre. 


\subsubsection{Krankheiten}

\subsubsection{Unspezifische Stressmarker}

\section{Cribra orbitalia}

Für die Auswertung der Untersuchung wurden lediglich Cribra orbitalia wie sie bei einer Blutarmut entstehen berücksichtigt. War makroskopisch nicht abzuklären, ob es sich um eine Cribra orbitalia aufgrund einer Anämie handelt oder, ob das Orbitadach zum Beispiel entzündungsbedingt porös war, wurde ein Dünnschliffpräparat für die lichtmikroskopische Untersuchung angefertigt. Poröse Orbitadächer infolge eines Blutungsgeschehens oder einer Entzündung wurden nicht in die folgenden Berechnungen aufgenommen. Der Anteil von Individuen mit Cribra orbitalia (siehe Abbildung 33A) in dieser Skelettserie ist hoch. Mit $\mathrm{n}=$ 15/31 (48,4 \%) zeigen die Anatomieleichen im Vergleich zu der Gruppe der Regelbestattungen mit $\mathrm{n}=22 / 61(36,1 \%)$ ein prozentual höheres Vorkommen (siehe Abbildung 33B). Allerdings sind diese Abweichungen nicht signifikant $\left(x^{2}(1 ; 92)=0,07 ; p=0,25\right)$. Beim Vergleich der Individuen, deren Geschlecht morphologisch und molekulargenetisch bekannt ist, gibt es keinen signifikanten Unterschied zwischen dem Auftreten von Cribra orbitalia bei den Männern der Regelbestattungen und denen der Anatomieleichen $\left(\mathrm{x}^{2}(1 ; 66)=0,05 ; \mathrm{p}=0,43\right)$, beziehungsweise zwischen den Frauen und Männern der Regelbestattungen $\left(x^{2}(1 ; 60)=0,08\right.$; $\mathrm{p}=0,44)$. Die Anzahl der weiblichen Anatomieleichen ist zu gering, um sie statistisch mit den anderen Gruppen vergleichen zu können.

A

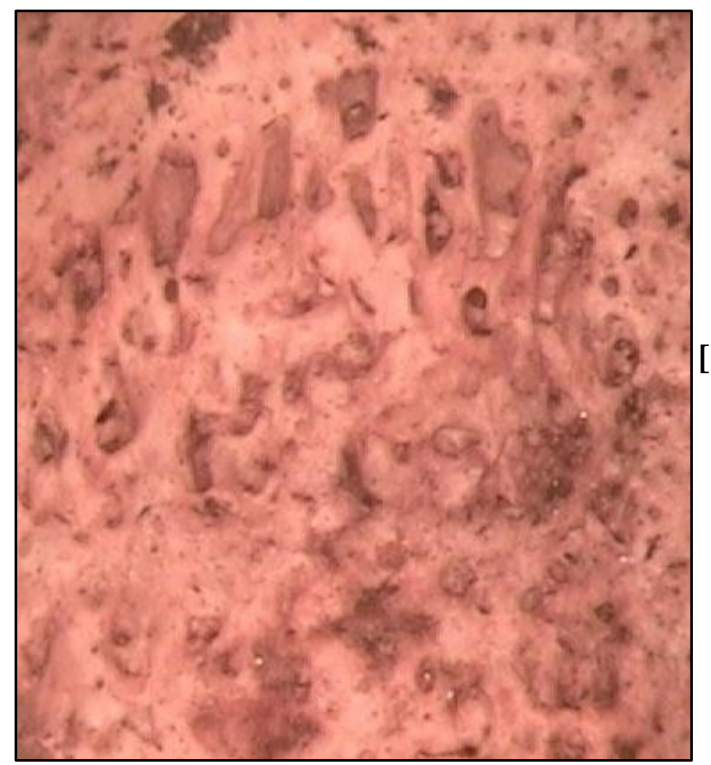

Cribra orbitalia

B

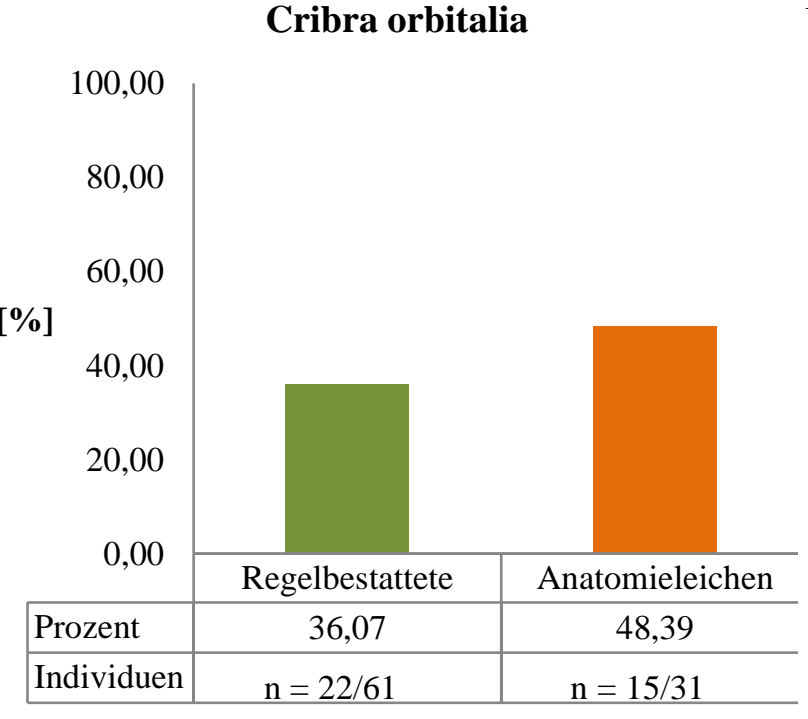

Abb. 33: Unspezifische Stressmarker. A Betrachtung mit dem Endoskop, Ausschnitt aus der linken Orbita mit Cribra orbitalia, ca. 10-fache Vergrößerung. Fundnummer 32, männlich, 23 - 40 Jahre. B Absolute und relative Häufigkeit von Cribra orbitalia ein- oder beidseitig in der jeweiligen Gruppe, $n=$ Anzahl pathologisch veränderter Individuen/Anzahl der untersuchten Individuen. 


\section{$\underline{\text { Harris-Linien }}$}

Es konnten die Tibiae (links und/oder rechts) von 85 Individuen verschiedenen Alters mithilfe eines Röntgengerätes untersucht werden. Dabei zeigten sich bei $n=17 / 22$ Anatomieleichen und bei $\mathrm{n}=30 / 63$ Regelbestatteten Harris-Linien (siehe Abbildung 34A) im proximalen und/oder distalen Diaphysenbereich. In allen Altersgruppen konnten diese Wachstumsstillstandslinien, welche sich im Röntgenbild als weiße, parallel zueinander verlaufende Linien darstellen, sichtbar gemacht werden. Die Anzahl der gefundenen HarrisLinien variierte zwischen einer und zehn Linien. Der prozentuale Anteil von Anatomieleichen, die Harris-Linien aufweisen, ist mit 77,3 \% weitaus höher als der Anteil der Regelbestattungen mit 47,6 \% (siehe Abbildung 34B). Der Unterschied ist statistisch signifikant $\left(\mathrm{x}^{2}(1 ; 80)=0,11\right.$; $\mathrm{p}=0,014)$. Beim Vergleich morphologisch und molekulargenetisch geschlechtsbekannter Individuen gibt es keinen signifikanten Unterschied zwischen den weiblichen Regelbestatteten und den männlichen Regelbestatteten $\left(x^{2}(1 ; 57)=0,11 ; p=0,05\right)$. Es konnten keine Tibiae von weiblichen Anatomieleichen untersucht werden.
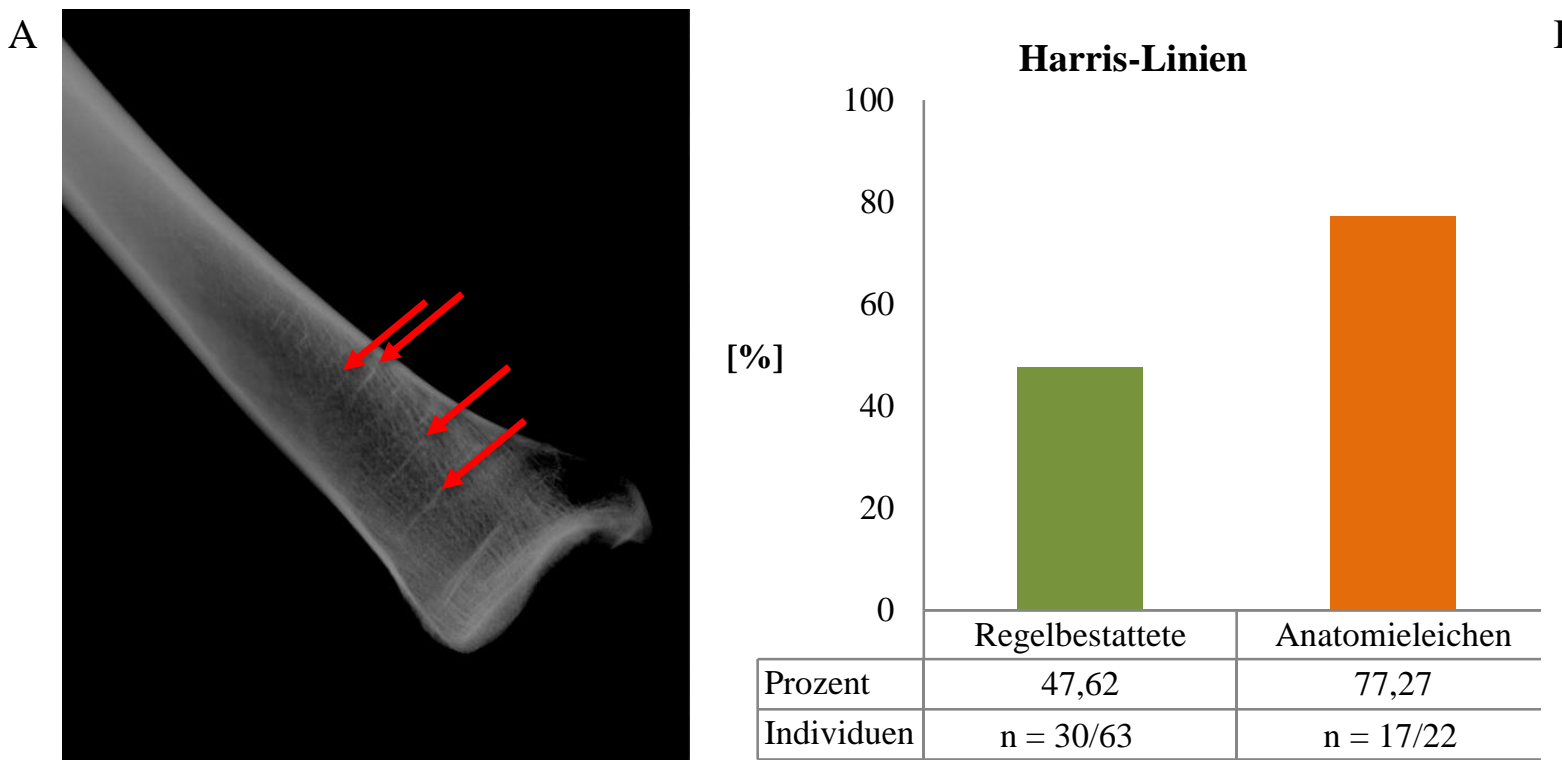

Abb. 34: Unspezifische Stressmarker. A Betrachtung im Röntgengerät, rechte Tibia in der anterior-posterioren Ansicht mit mehreren Harris-Linien (Pfeile). Diagenesespuren im Bereich des Malleolus medialis. Fundnummer 80, männlich, 25 - 30 Jahre. B Absolute und relative Häufigkeit von Harris-Linien in der jeweiligen Gruppe, n = Anzahl pathologisch veränderter Individuen/Anzahl der untersuchten Individuen.

Transversale lineare Schmelzhypoplasie

Die meisten Individuen der Skelettserie zeigen keine transversalen linearen Schmelzhypoplasien (siehe Abbildungen 36A und 36B). Die Individuen, die Schmelzhypoplasien aufweisen, zeigen in einer Vielzahl von Fällen eine eher geringe bis mittlere Ausprägung (Grad 2 bis 3). Gebisse mit höheren Ausprägungsgraden (Grad 4 bis 5) sind noch seltener. Die prozentuale Häufigkeit von transversalen linearen Schmelzhypoplasien 
fällt in beiden Gruppen mit $n=14 / 73(19,2 \%)$ bei den Regelbestattungen und $n=11 / 35(31,4$ $\%)$ bei den Anatomieleichen unterschiedlich aus. Allerdings konnten keine signifikanten Unterschiede zwischen den beiden Gruppen gefunden werden $\left(x^{2}(1 ; 109)=0,17 ; p=0,16\right)$. Auch der Vergleich zwischen den Männern beider Gruppen $\left(\mathrm{x}^{2}(1 ; 74)=0,14 ; \mathrm{p}=0,32\right)$ bzw. der Vergleich zwischen den Geschlechtern in der Gruppe der Regelbestattungen $\left(x^{2}(1 ; 64)=\right.$ 0,37; $\mathrm{p}=0,22)$ zeigte keinen signifikanten Unterschied. Die Gruppe der weiblichen Anatomieleichen war zu klein für eine statistische Untersuchung.

A

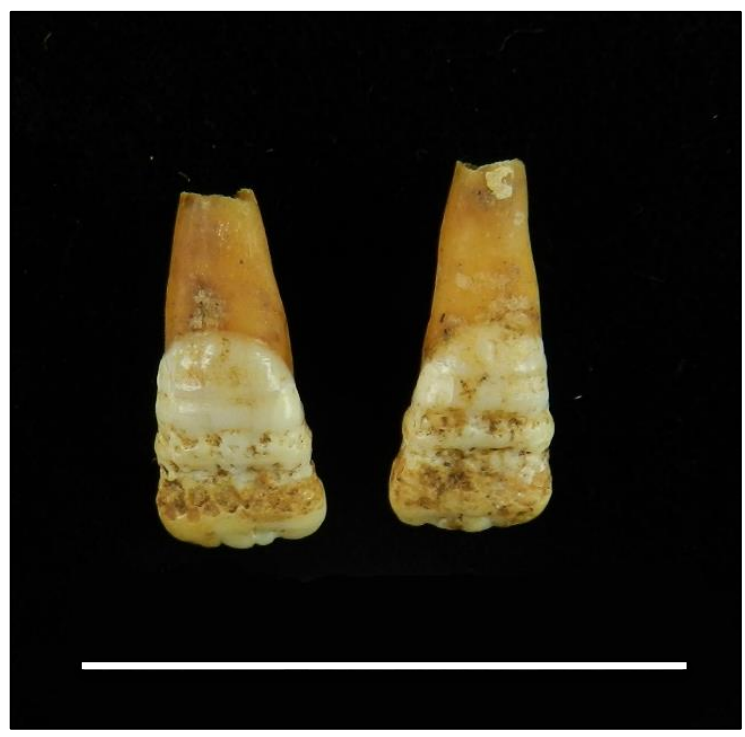

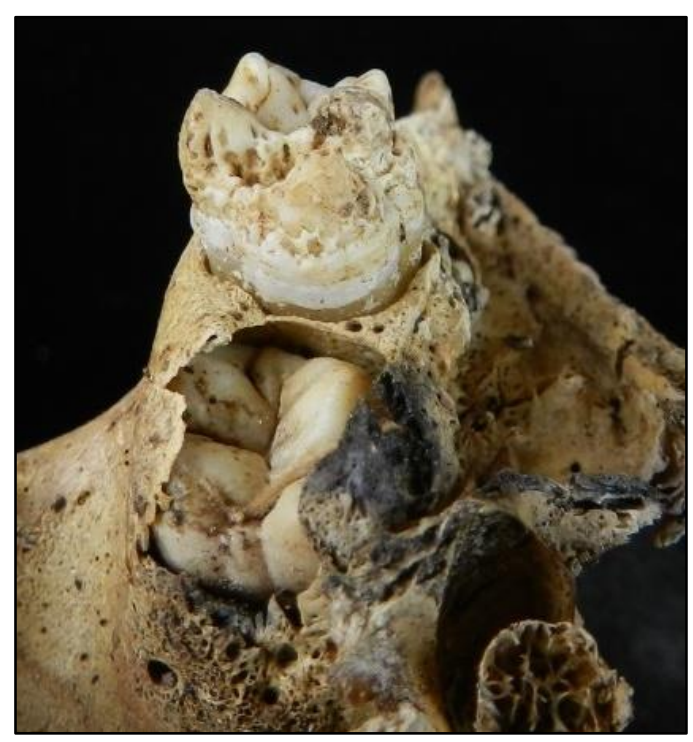

Abb. 35: Unspezifische Stressmarker. A Transversale Schmelzhypoplasien, Incisivi 11 und 21, Strich entspricht $3 \mathrm{~cm}$. Fundnummer 38, Tendenz männlich, 8 Jahre \pm 24 Monate. B Maulbeermolar 16, 1. Quadrant. Fundnummer 38, Tendenz männlich, 8 Jahre \pm 24 Monate.

Das Individuum 38 weist starke Schmelzdefekte im Rahmen einer Amelogenesis imperfecta auf. Aufgrund der Mineralisationsstörung des Zahnschmelzes haben sich starke transversale Schmelzhypoplasien an den Schneidezähnen (siehe Abbildung 35A) und sogenannte Maulbeermolaren (siehe Abbildung 35B) entwickelt. Es besteht der Verdacht einer kongenitalen Syphilis. Allerdings gibt es keine weiteren Symptome, welche auf die Erkrankung Hinweise geben könnten. Das Individuum ist im Kindesalter verstorben. 
A

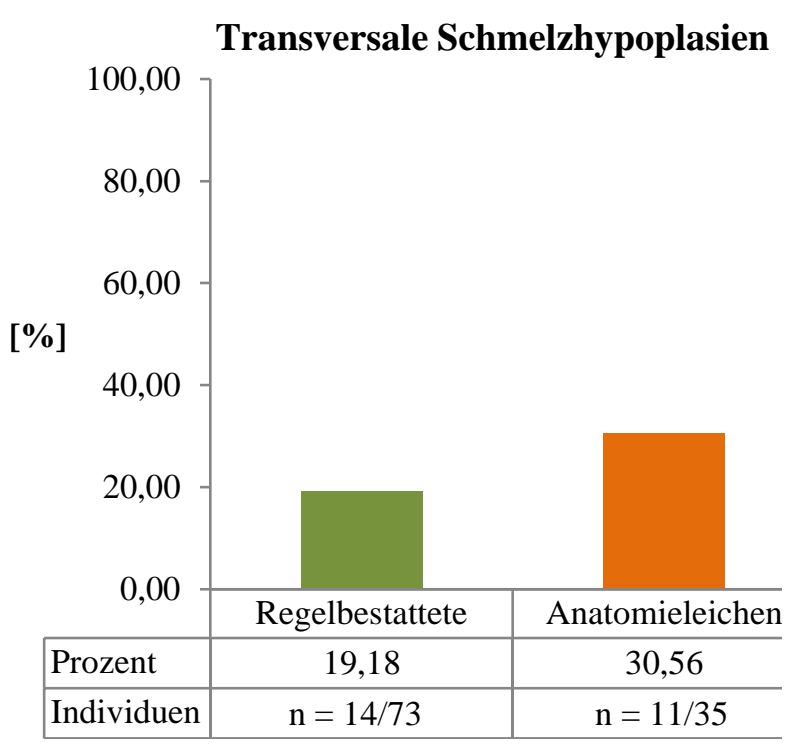

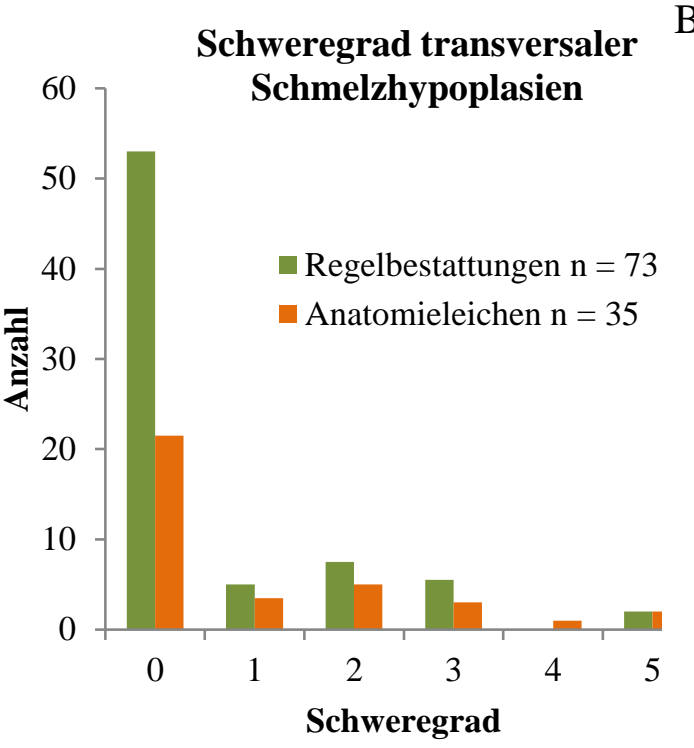

Abb. 36: Unspezifische Stressmarker. A Relative und absolute Häufigkeit von transversalen linearen Schmelzhypoplasien in der jeweiligen Gruppe, $\mathrm{n}=$ Anzahl pathologisch veränderter Individuen/Anzahl der untersuchten Individuen. In dieses Diagramm gehen nur Werte von Grad 2 bis 5 ein. B Absolute Häufigkeit der transversalen linearen Schmelzhypoplasien aufgetrennt nach Schweregrad (Schultz 1988b) und Gruppen.

Zusammenfassend kann festgestellt werden, dass es nur bei den Harris-Linien einen signifikanten Unterschied zwischen den Gruppen bezüglich der Häufigkeit der unspezifischen Stressmarker gab. Allerdings ist erkennbar, dass die Anatomieleichen tendenziell häufiger von allen unspezifischen Stressmarkern betroffen sind als die Skelette der Regelbestattungen.

\subsubsection{Mangelerkrankungen}

\section{$\underline{\text { Skorbut }}$}

Bei der morphologischen Untersuchung zeigen drei Individuen Anzeichen von Skorbut (Vitamin C-Mangel). Zum einen handelt es sich um das Skelett eines regelbestatteten Individuums (38) im Altersbereich Infans 2, unbekannten Geschlechts. Das Individuum weist neben Anzeichen für weitere pathologische Veränderungen, z. B. Maulbeermolaren, knöchern umgebaute, verheilte multiple Blutungsgeschehen im Bereich der Maxilla auf. Bei den zwei erwachsenen Individuen handelt es sich um Männer, welche nach ihrem Tod seziert wurden. Das mature Individuum 6 zeigt Periostose (siehe Abbildung 37A) auf beiden Tibiae und poröse Oberflächen in beiden Orbitadächern (siehe Abbildung 37B). Das spätjuvenil-frühadulte Individuum 76B zeigt stark poröse Oberflächen der Orbitadächer und der Lamina interna durch ein knöchern umgebaute Blutungsgeschehen. 
A
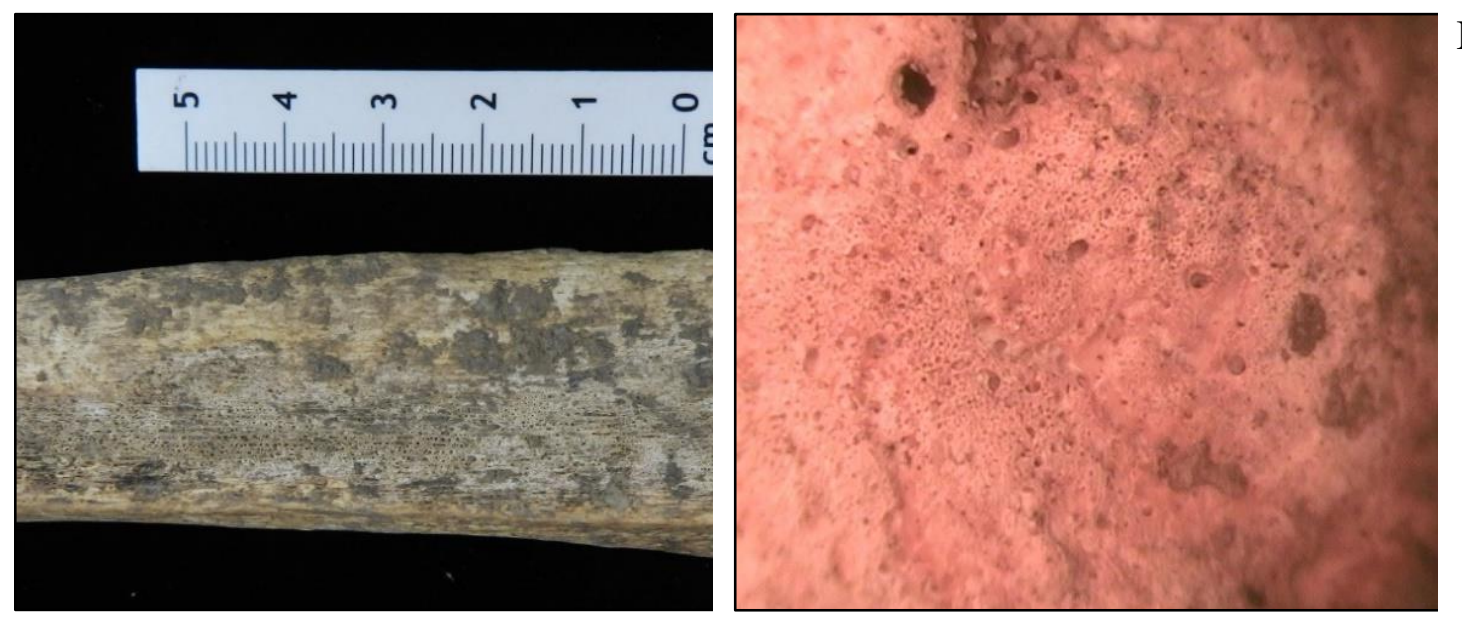

Abb. 37: Anzeichen für Skorbut. A Periostose auf der Diaphysenoberfläche der linken Tibia, laterale Ansicht. Fundnummer 6, männlich, 40 - 60 Jahre. B Betrachtung des Orbitadach mit dem Endoskop. Poröse Oberfläche infolge eines knöchern umgebauten Blutungsgeschehens, ca. 10-fache Vergrößerung. Fundnummer 62, männlich, 19 - 21 Jahre.

\section{$\underline{\text { Anämie }}$}

Ein Fall von Anämie mit allen bekannten Anzeichen der Blutarmut konnte nicht gefunden werden. Es gibt etliche Individuen mit porösem Orbitadach, vor allem in der Gruppe der Anatomieleichen. Allerdings konnten andere charakteristische Merkmale, wie eine poröse Hyperostose, Knochenschwellungen oder ein sogenannter Bürstenschädel, nicht gefunden werden.

\section{Osteomalazie}

Deutliche Anzeichen für Osteomalazie/Rachitis hervorgerufen durch einen Vitamin D-Mangel zeigen die regelbestatteten Individuen 24 und 88. Individuum 24 weist Verformungen an der linken Ulna, dem linken Radius, den Femora (siehe Abbildung 38A), Tibiae (siehe Abbildung 38B) und Fibulae auf. Individuum 88 hat, erkennbar aufgrund des Collum-Diaphysen-Winkels, eine Coxa vera und weist eine deutliche Krümmung der Femora und Tibiae (siehe Abbildung 38C und 38D) in der Frontal- und Sagittalebene sowie eine leichte Drehung um die Längsachse auf. Offenbar sind die Individuen, die nach ihrem Tod obduziert wurden, nicht schlechter mit Vitamin D versorgt gewesen als die regelbestatteten Individuen. Allerdings sind die Erweichung und Krümmung der Knochen chronische und damit lang anhaltende Prozesse. Kurzfristiger Mangel kann nicht durch die bloße Betrachtung mit dem Auge am Skelett nachgewiesen werden. 
A

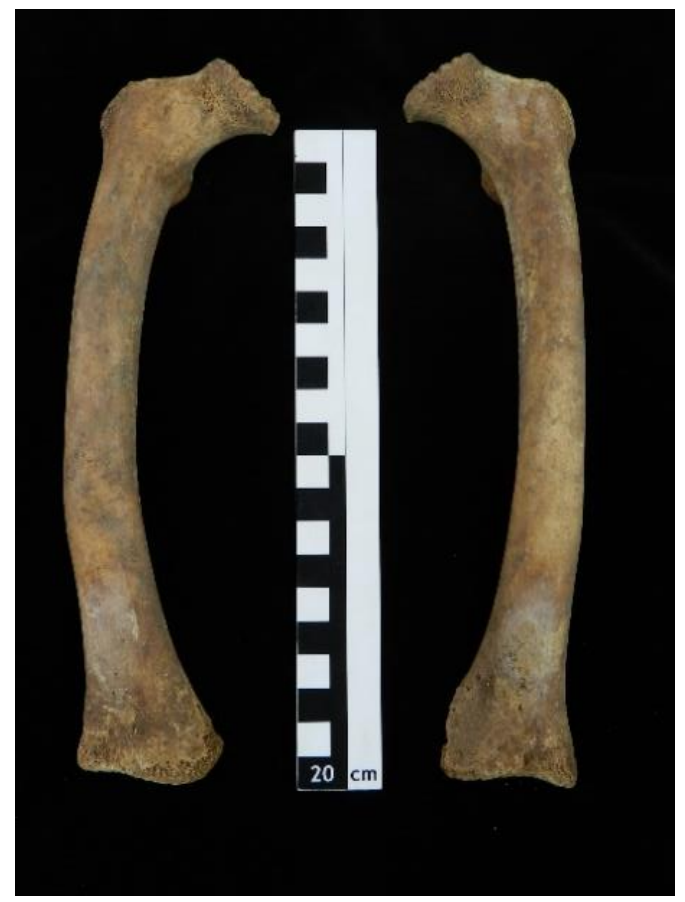

$\mathrm{B}$

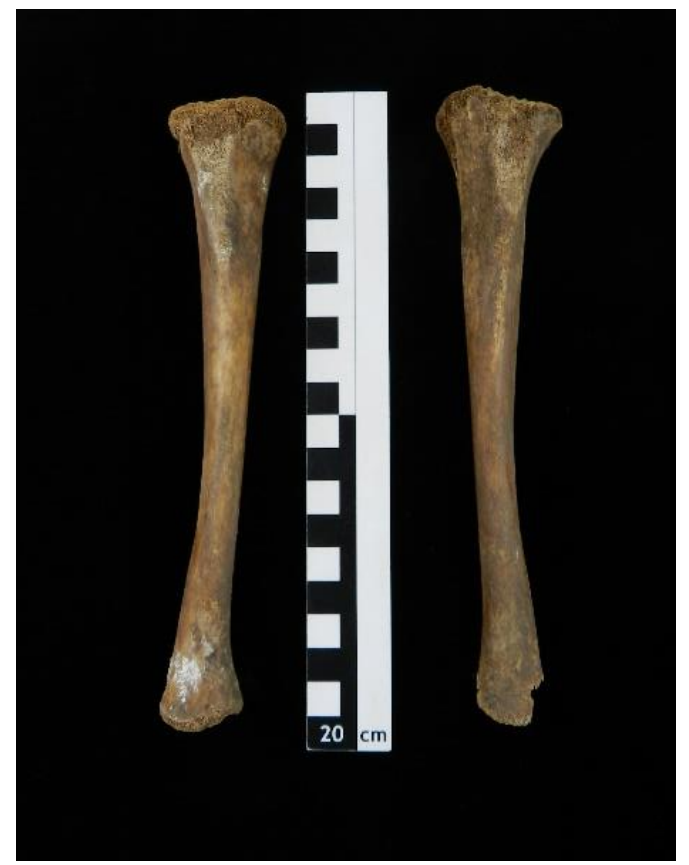

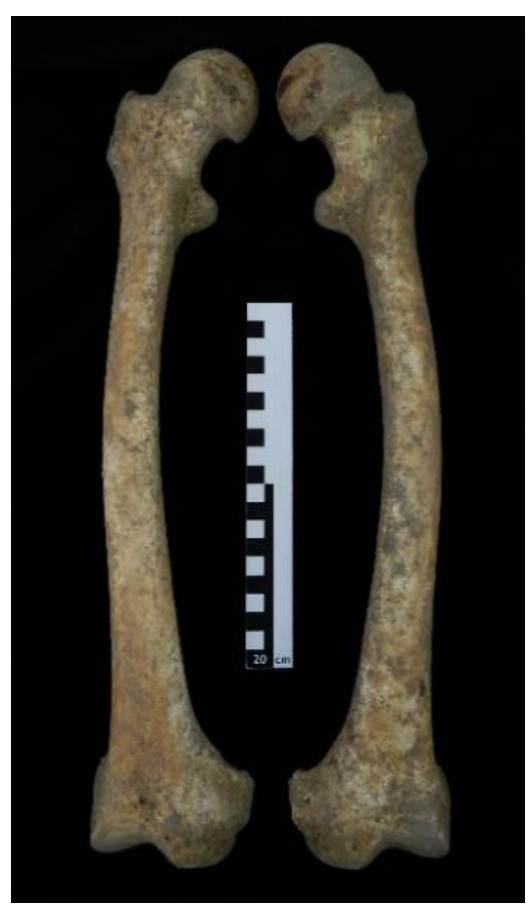

C

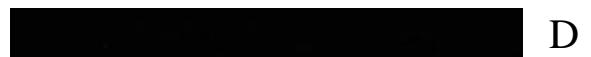

$\mathrm{D}$

Abb. 38: Anzeichen einer Osteomalazie. A und B Krümmung beider Femora und Tibiae, anteriore Ansicht. Fundnummer 24, weiblich, 6 Jahre \pm 24 Monate. C und D Krümmung beider Femora und Tibiae, anteriore Ansicht. Fundnummer 88, männlich, 22 - 24 Jahre.

Zusammenfassend kann festgestellt werden, dass es keine Hinweise auf einen signifikanten Unterschied im Vorkommen von chronischen Mangelerkrankungen zwischen der Gruppe der Regelbestattungen und der Gruppe der Anatomieleichen gibt. 


\section{$\underline{\text { Befunde und Ergebnisse - Biologische Daten }}$}

\subsubsection{Infektionskrankheiten}

\section{$\underline{\text { Meningeale Reaktion }}$}

Meningeale Reaktionen, wie sie in Abbildung 39A und 39B $\mathrm{zu}$ sehen sind, betreffen die Meningen und werden in hämorrhagische und entzündliche Reaktionen unterschieden. 15 Individuen der Serie weisen Zeichen von meningealen Reizungen, z. B. in Form von knöchern umgebauten Blutungsgeschehen, auf. In vier Fällen sind Zeichen eines erhöhten Hirndrucks (Impressiones digitatae) erkennbar. Bei drei von vier Fällen handelt es sich um Skelette ehemaliger Anatomieleichen. Darunter sind zwei Individuen mit einem Hydrocephalus. Bei dem Individuum 137A handelt es sich um ein Kind, bei dem Individuum 61 dagegen um ein Individuum im maturen Altersbereich. Aufgrund weiterer pathologischer Auffälligkeiten bei Individuum $61 \mathrm{im}$ Bereich des Craniums (siehe Kapitel 4.1.5 Traumata) ist zu vermuten, dass die Hirndrucksymptomatik mit einem Trauma in Verbindung steht. Die Spuren dieses Geschehens sind deutlich erkennbar, aber gut verheilt. Darüber hinaus sind in vielen Fällen Impressionen von der Norm abweichender Blutgefäße auf der Lamina interna sichtbar.

A

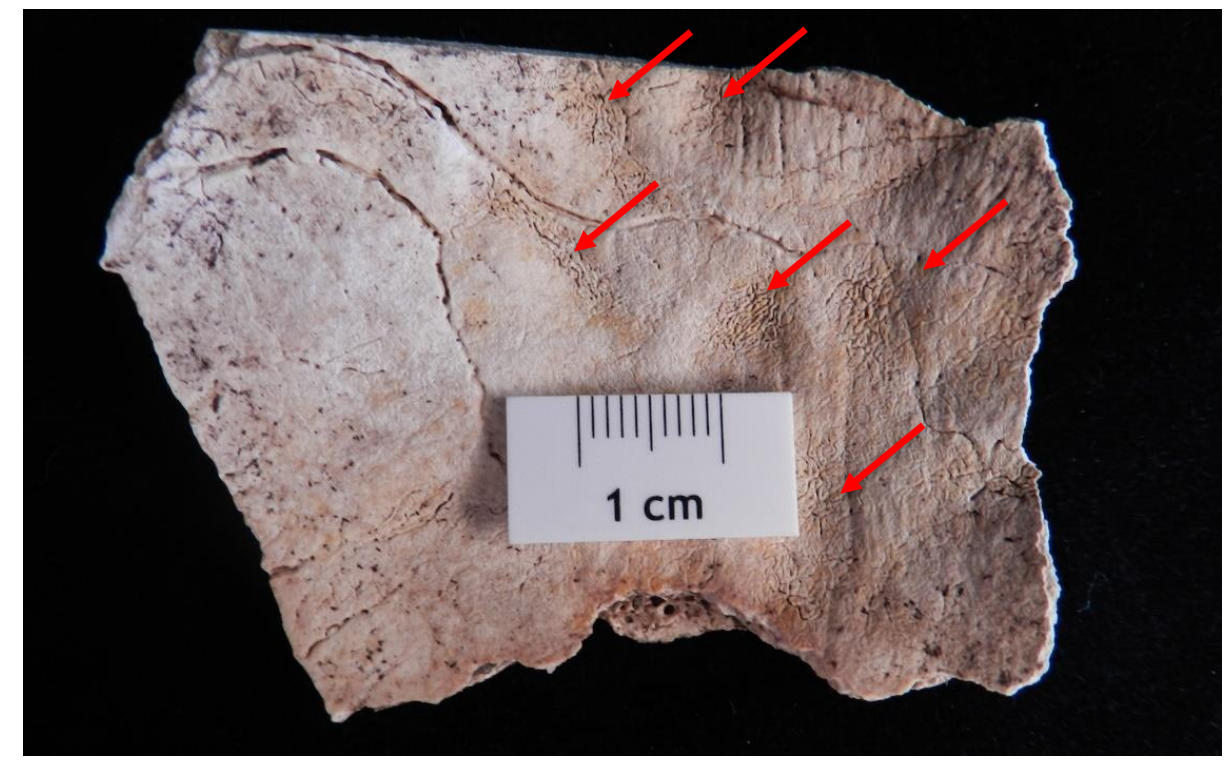

B

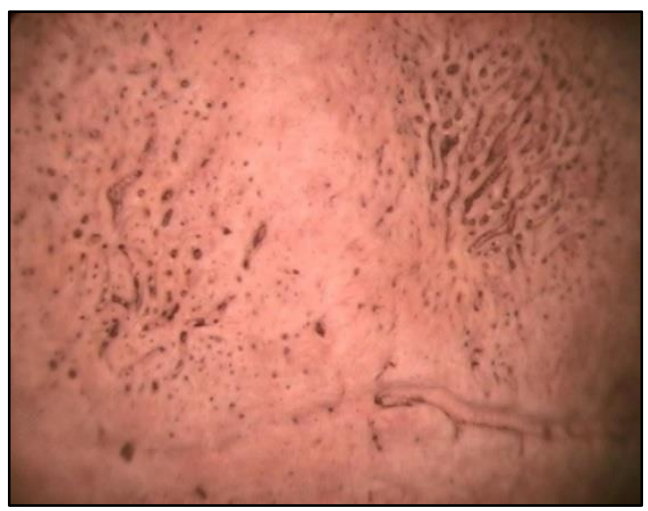

Abb. 39: Meningeale Reaktionen. A Lamina interna mit vielen kleinen Gefäßimpressionen (Pfeile). Fundnummer 76A, männlich, 23 - 27 Jahre B Betrachtung mit dem Endoskop, Lamina interna mit vielen kleinen Gefäßimpressionen, ca. 10-fache Vergrößerung. Fundnummer 32, männlich, 23 - 40 Jahre. 
Für das Individuum 159 ist beispielhaft ein Dünnschliffpräparat aus dem betroffenen Areal hergestellt worden. Es handelt sich um ein männliches regelbestattetes Individuum im maturen Altersbereich. Wie in Abbildung 40A zu erkennen ist, befinden sich Spuren einer meningealen Reaktion auf der Lamina interna im Sulcus sinus sagittalis superioris und parasinuös linksseitig. Offenbar ist ein entzündlicher Prozess von der Hirnhaut in den Knochen infiltriert und hat zeitgleich einen Blutungsprozess hervorgerufen. Unter dem Mikroskop werden die Auflagerungen auf der Lamina interna anhand des Dünnschliffpräparates deutlich (siehe Abbildung 40B). Die Auflagerungen sind scharf von der ursprünglichen Schicht der Lamina interna abgegrenzt (siehe Abbildung 40C bis 40E). Des Weiteren zeigen sich Anzeichen von Resorptionsprozessen inklusive Howshipscher Lakunen in der Diploe und mehrere Durchbrüche auf der Seite der Lamina interna (siehe Abbildung 40F bis 40H).

A

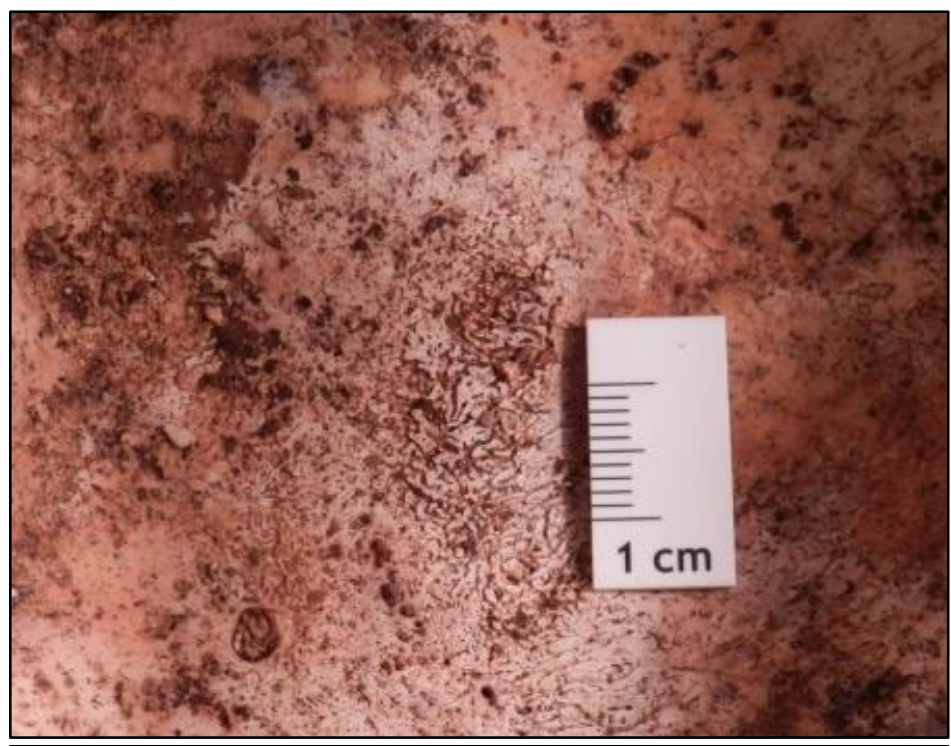

$\mathrm{B}$

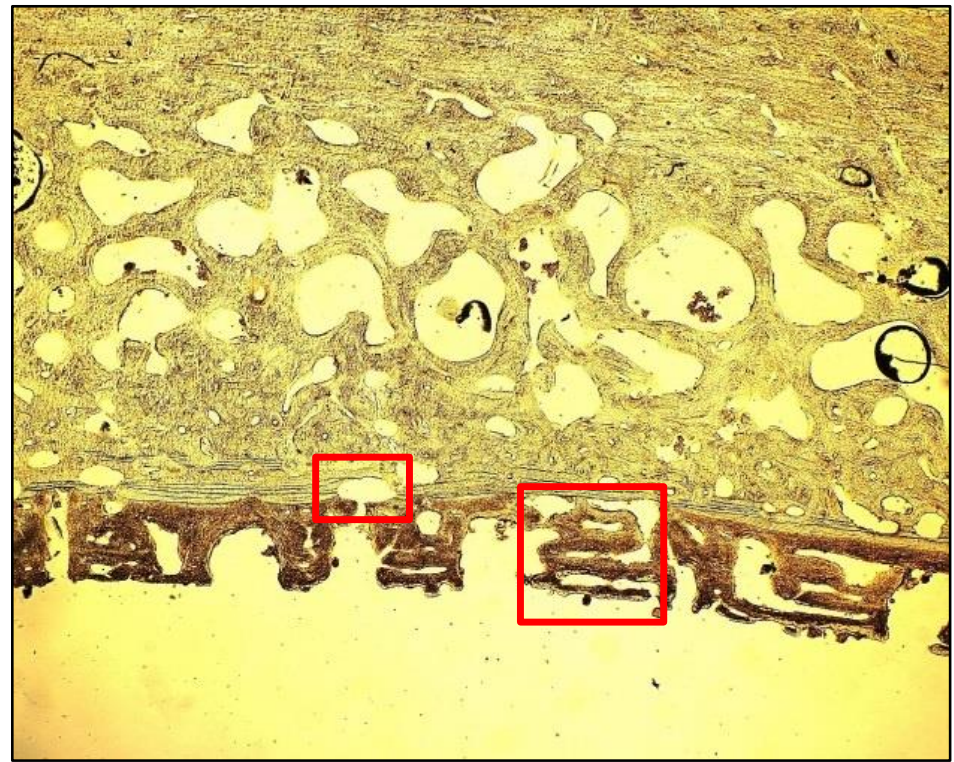

Abb. 40: Meningeale Reaktionen. A Ossa parietalia mittig. Fundnummer 159, männlich, 40 - 60 Jahre. B Betrachtung mit dem Mikroskop, Ossa parietalia mittig, $50 \mu \mathrm{m}$ Stärke, 16fache Vergrößerung. Auflagerungen auf der Lamina interna (umrandet, Vergrößerung Abb. 42C bis 42E). Die Auflagerungen sind scharf von der ursprünglichen Schicht der Lamina interna abgegrenzt. Diploe mit Resorptionsprozessen in Form von Howshipschen Lakunen. Durchbruch auf der Seite der Lamina interna (umrandet, Vergrößerung Abb. 42F bis $42 \mathrm{H})$. 
$\mathrm{C}$

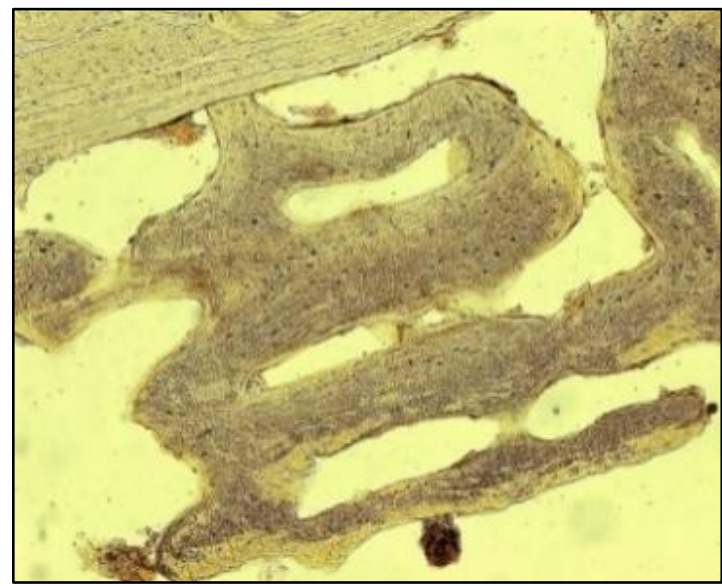

$\mathrm{D}$

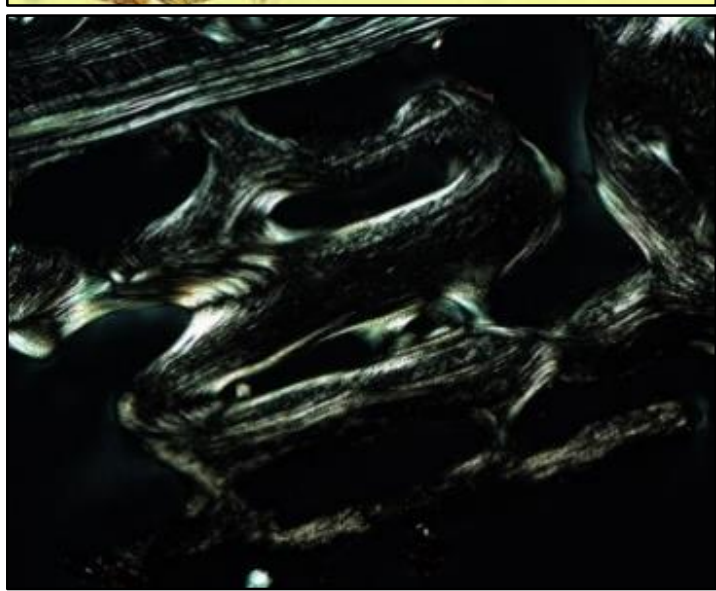

$\mathrm{E}$

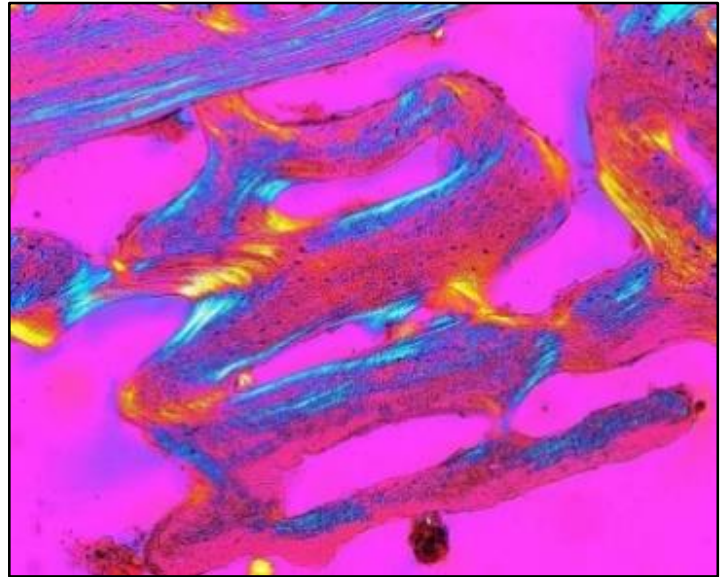

F

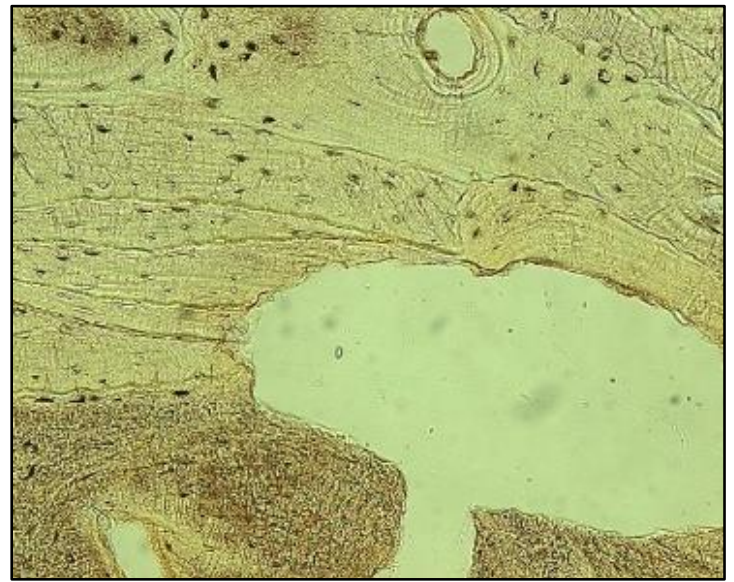

$\mathrm{G}$

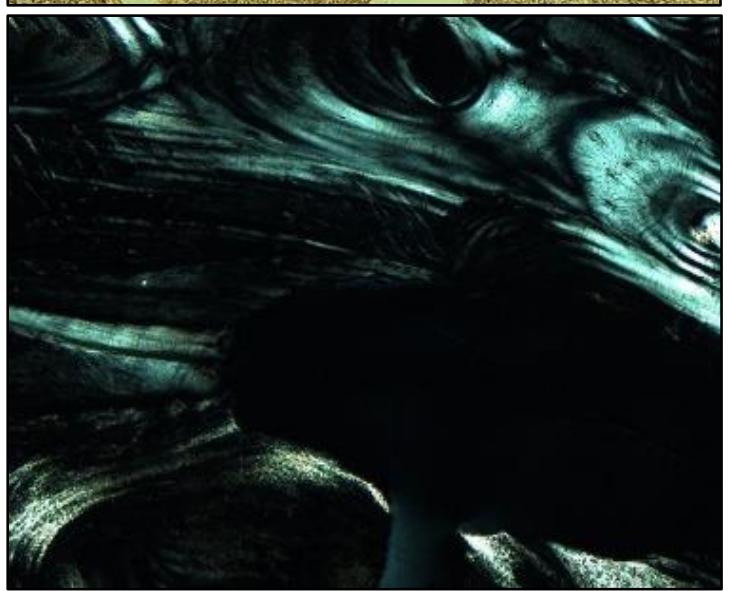

$\mathrm{H}$

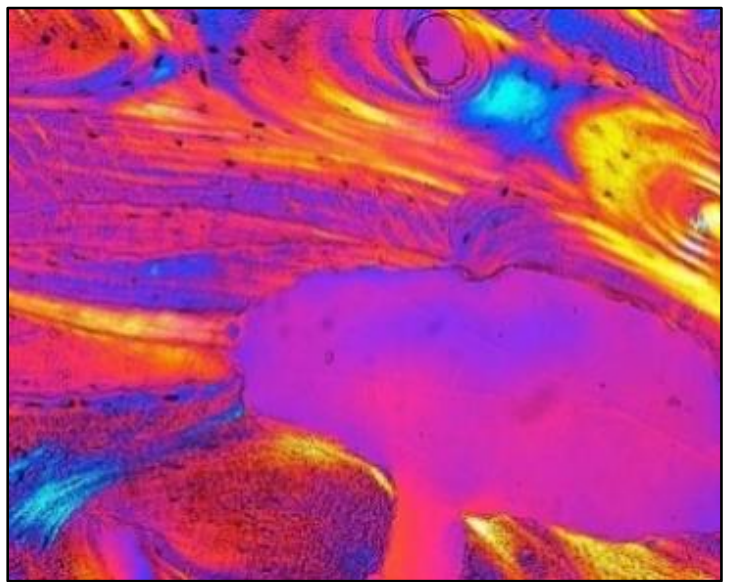

Abb. 40: Meningeale Reaktionen. C bis E Betrachtung mit dem Mikroskop, Ossa parietalia mittig, $50 \mu \mathrm{m}$ Dicke, 100-fache Vergrößerung. D Im polarisierten Licht. E Im polarisierten Licht unter Verwendung eines Hilfsobjekts Rot 1. Ordnung (Quarz) als Kompensator. Der Knochen ist wenig von Diagenese betroffen. F bis H Betrachtung mit dem Mikroskop, Ossa parietalia mittig, $50 \mu \mathrm{m}$ Dicke, 200-fache Vergrößerung. G Im polarisierten Licht. H Im polarisierten Licht unter Verwendung eines Hilfsobjekts Rot 1. Ordnung (Quarz) als Kompensator. Der Knochen ist wenig von Diagenese betroffen.

\section{$\underline{\text { Otitis media }}$}

Die Mittelohren der Anatomieleichen waren stärker von entzündlichen Prozessen (siehe Abbildung 42A) betroffen als die der regelbestatteten Individuen. Bei den Anatomieleichen litten $83 \%$ der Individuen ein- oder beidseitig an Otitis media, während es unter den Regelbestattungen 56,5 \% der Individuen betrifft (siehe Abbildung 41). Die Häufigkeit der Otitis media erweist sich unter statistischen Test als nicht geschlechtsabhängig. Allerdings gibt 
es einen signifikanten Unterschied in der Häufigkeit zwischen den zwei untersuchten Gruppen $\left(\mathrm{x}^{2}(1 ; 75)=0,18 ; \mathrm{p}=0,019\right)$. Der Unterschied tritt vor allem zwischen den männlichen Anatomieleichen und den männlichen Regelbestatteten auf $\left(x^{2}(1 ; 59)=0,12 ; p=0,025\right)$.

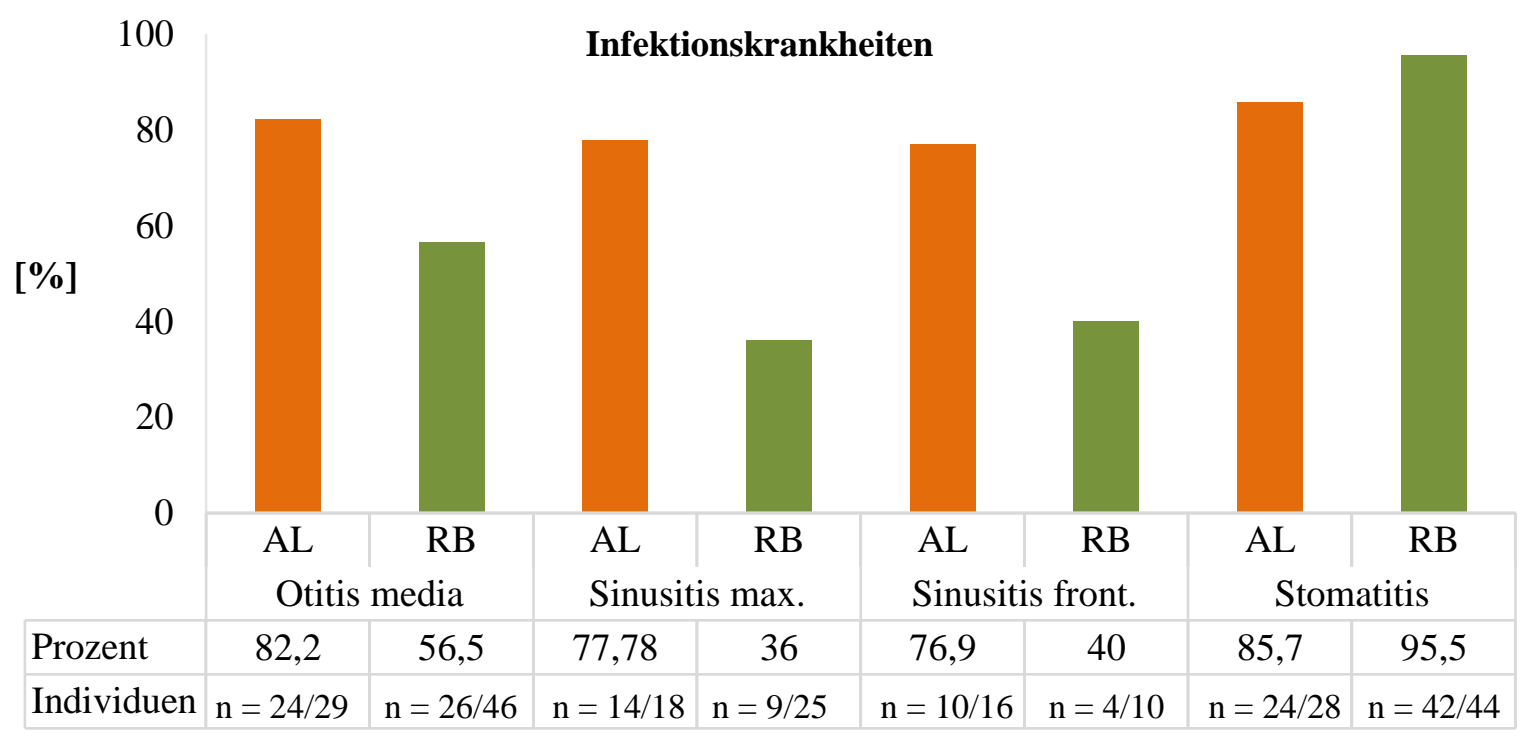

Abb. 41: Infektionskrankheiten. Relative und absolute Häufigkeit betroffener Individuen in der jeweiligen Gruppe. $\mathrm{AL}=$ Anatomieleichen und $\mathrm{RB}=$ Regelbestattete, $\mathrm{n}=$ Anzahl pathologisch veränderter Individuen/Anzahl der untersuchten Individuen.

\section{$\underline{\text { Sinusitis }}$}

Bei der Datenaufnahme zu entzündlich veränderten Nasennebenhöhlenerkrankungen wurden der Sinus maxillaris, frontalis und ethmoidalis untersucht. Allerdings konnten für die beiden letztgenannten Sinus aufgrund des Erhaltungszustandes des Schädels oft keine Angaben gemacht werden. War der Schädel intakt, konnten die Sinuswände aufgrund ihrer unzugänglichen Lage nicht beurteilt werden. Die folgenden Angaben gelten für Individuen, bei denen mindestens ein Sinus (rechts oder links) betroffen war. Die Zahl der Krankheitsfälle in der Gruppe der Anatomieleichen überstieg bei allen untersuchten Nasennebenhöhlen stets die der Regelbestatteten. Für die Häufigkeit (siehe Abbildung 41) der Sinusitis (siehe Abbildung 42B) im Sinus maxillaris gibt es einen signifikanten Unterschied zwischen den Gruppen ( $\mathrm{x}^{2}(1$; 43) $=0,04 ; \mathrm{p}=0,007)$, da 77,8 \% der Anatomieleichen und $36 \%$ der Regelbestattungen Anzeichen einer Sinusitis zeigten. Dieser ist vor allem zwischen den männlichen Individuen beider Gruppen zu finden $\left(\mathrm{x}^{2}(1 ; 32)=0 ; \mathrm{p}=0,032\right)$. Der Unterschied im Bereich das Sinus frontalis ist nicht signifikant zwischen den Gruppen $\left(\mathrm{x}^{2}(1 ; 23)=0,09 ; \mathrm{p}=0,72\right) .76,9 \%$ der Anatomieleichen und $40 \%$ der Regelbestatteten zeigten Anzeichen einer Sinusitis im Sinus frontalis. 
A

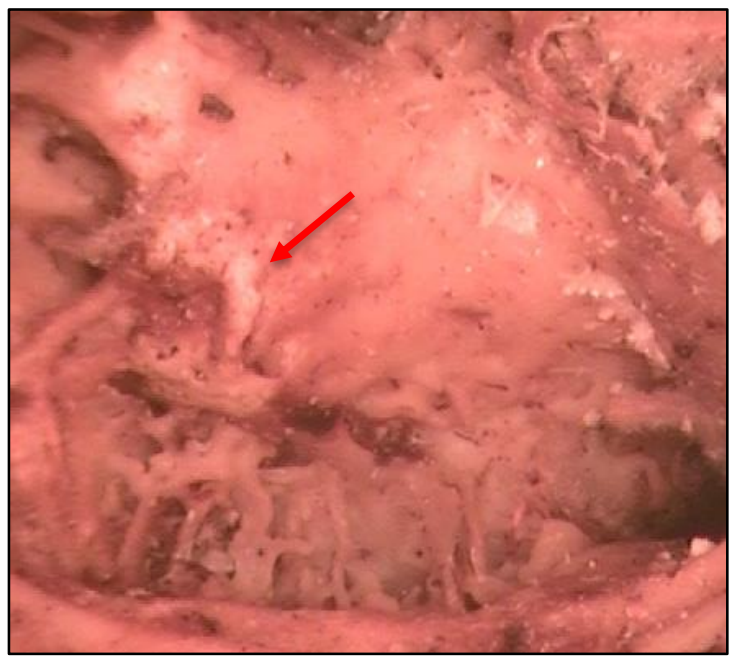

C

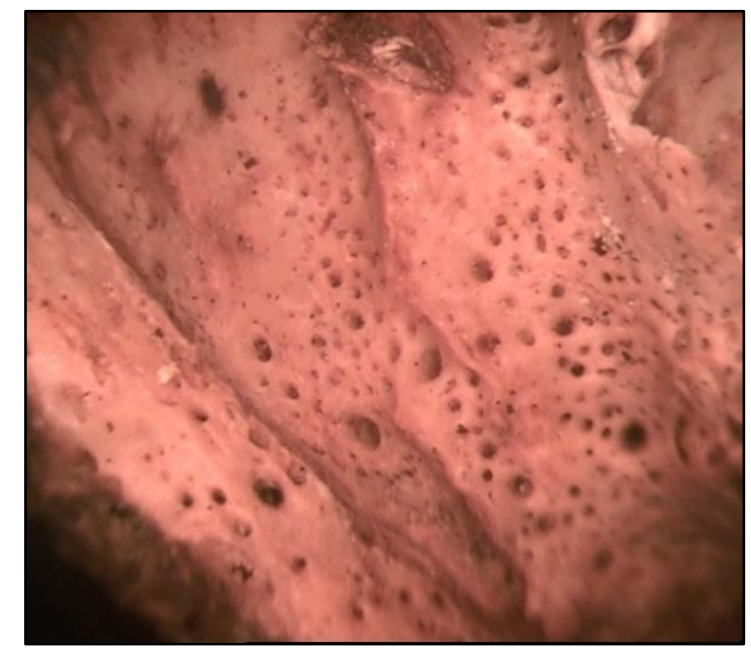

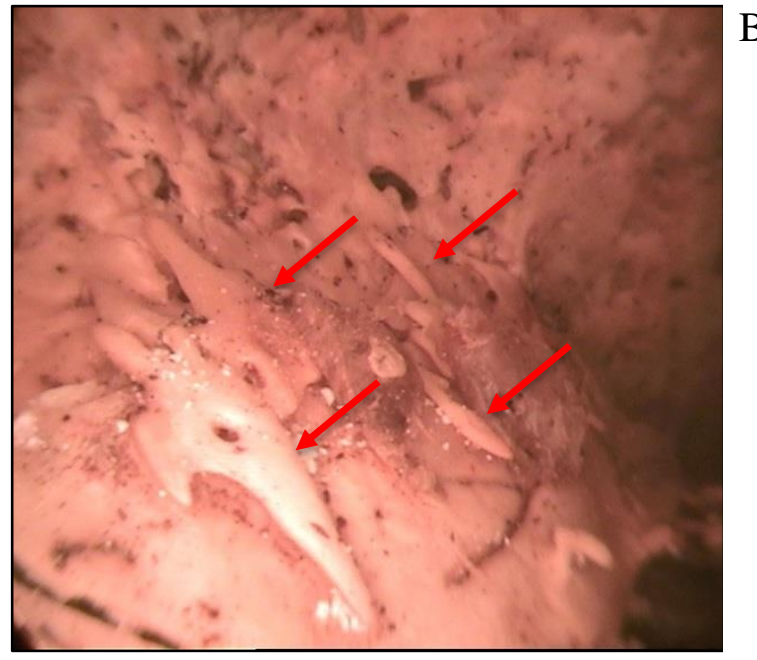

Abb. 42: Infektionskrankheiten. A Mittelohr rechts, Promontorium mit Auflagerung (Pfeil), ca. 10-fache Vergrößerung. Fundnummer 38, Tendenz männlich, 8 Jahre \pm 24 Monate. B Laterale Wand des rechten Sinus maxillaris mit Auflagerungen (Pfeile), ca. 10-fache Vergrößerung. Fundnummer 138, weiblich, 18 23 Jahre. C Ausschnitt des harten Gaumens, ca. 10-fache Vergrößerung. Fundnummer 38, Tendenz männlich, 8 Jahre \pm 24 Monate.

\section{$\underline{\text { Stomatitis }}$}

Sowohl in der Gruppe der Regelbestattungen mit 95,5\% als auch in der Gruppe der Anatomieleichen mit 85,7 \% (siehe Abbildung 41) gibt es viele Individuen die Anzeichen einer leichten bis starken Entzündung des harten Gaumens (siehe Abbildung 42C) zeigen. Der Unterschied macht sich vor allem zwischen den Männern beider Gruppen bemerkbar $\left(\mathrm{x}^{2}(1 ; 56)\right.$ $=0,45 ; p=0,047)$.

\section{$\underline{\text { Osteomyelitis, Periostitis }}$}

Das Individuum 22 (Anatomieleiche) und das regelbestattete Individuum 129 zeigen beide Anzeichen einer Osteomyelitis in Verbindung mit einer Periostitis (siehe Abbildung 43A und 43B). Im Dünnschliffpräparat lässt sich für das Individuum 129 deutlich eine neu gebildete Knochenschicht auf dem ursprünglichen Knochen erkennen (siehe Pfeil in Abbildung 43C und 43D). Es handelt sich um eine pathologische Neubildung, die morphologisch einem appositionellen Dickenwachstum entspricht. Für die Individuen 104B (4) und 122A (2) wurde überprüft, ob sich molekulargenetisch Pathogen-DNA in den osteomyelitisch veränderten Tibiae nachweisen lässt. Es konnte allerdings in keiner der beiden Proben Staphylococcus 
aureus nachgewiesen werden. Ein Spiking-Experiment zeigte, dass das Ausbleiben von Staphylococcus nicht an einer Inhibition durch zum Beispiel Huminstoffe (Hummel 2003) lag. Bei der Überprüfung der Insertion-Sequenz IS1081 konnten in der PCR Signale erhalten werden. Für die Pathogen-DNA aus den Knochen des Individuums 122 konnte im Anschluss mithilfe der BLAST-Suche ein 90\%ige Übereinstimmung mit Sequenzen von Mycobacterium abscessus subsp. bolletii gefunden werden. Bei dem gefunden Mycobacterium abscessus subsp. bolletii handelt es sich um ein nicht-tuberkulöses Mykobakterium (Bryant et al. 2013, Griffith 2015). Für die Sequenzen aus dem Knochenmaterial des Individuums 104B (4) gab es keine Übereinstimmungen.

A

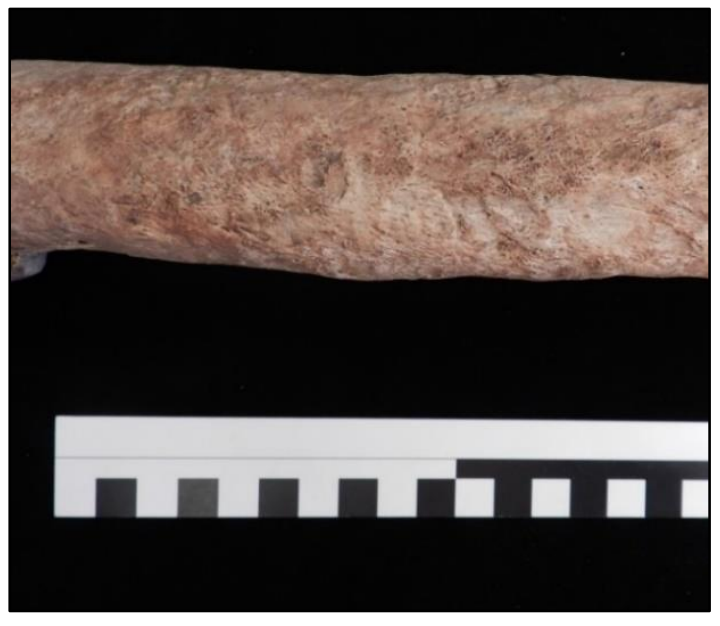

$\mathrm{C}$

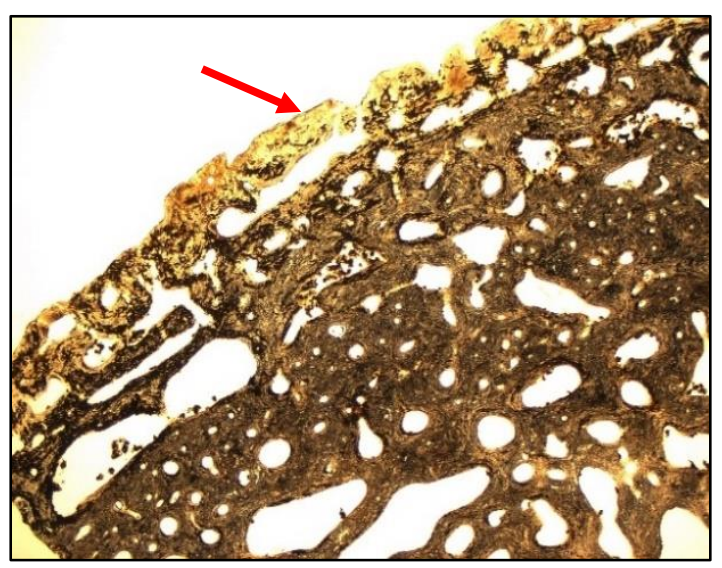

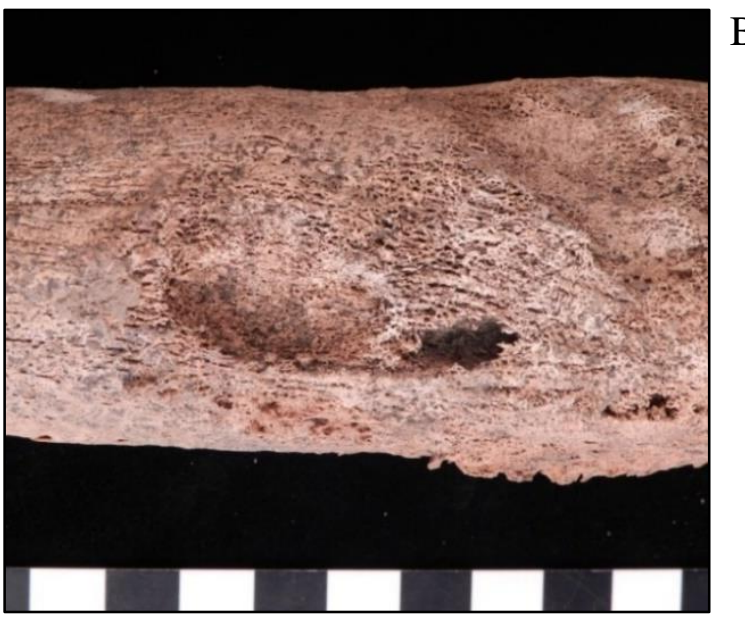

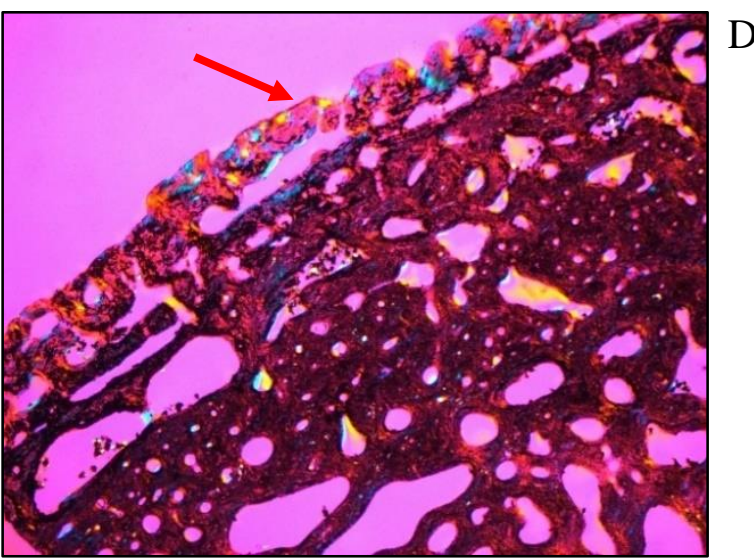

Abb. 43: Osteomyelitis. A Femur links, anteriore Ansicht, ausgeheilte Osteomyelitis. Fundnummer 22, männlich, 40 - 60 Jahre. B Tibia rechts, mediale Ansicht, Osteomyelitis. Fundnummer 129, weiblich, 40 - 60 Jahre. C und D Betrachtung mit dem Mikroskop, Femur rechts, neugebildeter Knochen (Pfeil) im Rahmen einer Osteomyelitis, $70 \mu \mathrm{m}$ Dicke, 16-fache Vergrößerung. Fundnummer 129, weiblich, 40 - 60 Jahre. D Im polarisierten Licht unter Verwendung eines Hilfsobjekts Rot 1. Ordnung (Quarz) als Kompensator. Sowohl der ursprüngliche als auch der neu gebildete Knochen sind stark von Diagenese betroffen. 


\section{$\underline{\text { Befunde und Ergebnisse - Biologische Daten }}$}

\section{Coxitis}

Das regelbestattete Individuum 138 zeigt im Bereich der rechten Hüfte Veränderungen, welche anfangs den Verdacht einer Knochentuberkulose erweckten (Schultz und Schmidt-Schultz 2015, Schmidt-Schultz und Schultz 2015). Sowohl das Acetabulum (siehe Abbildung 44A und 44B) als auch der Caput femoris sind vollständig durch degenerative und proliferative Prozesse verändert. Das rechte Femur ist im Bereich der Diaphyse deutlich graziler als das linke Femur. Zudem sind die Knochenbälkchen im Trochanter major und minor rarefiziert mit osteomyelitischen Veränderungen des rechten Os femoris (Abbildung 44C). Eine Kloakenbildung ist auf der dorsalen Fläche mittig oberhalb der Condylen erkennbar.

A
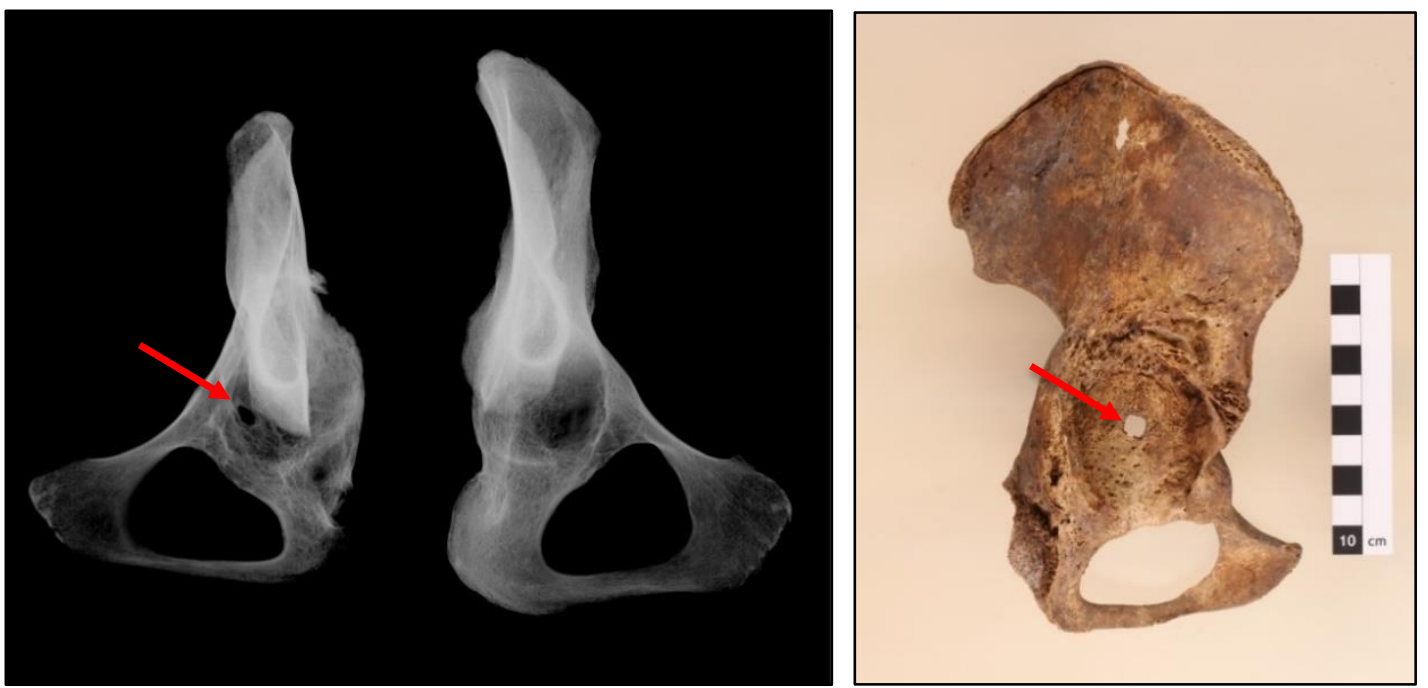

$\mathrm{C}$
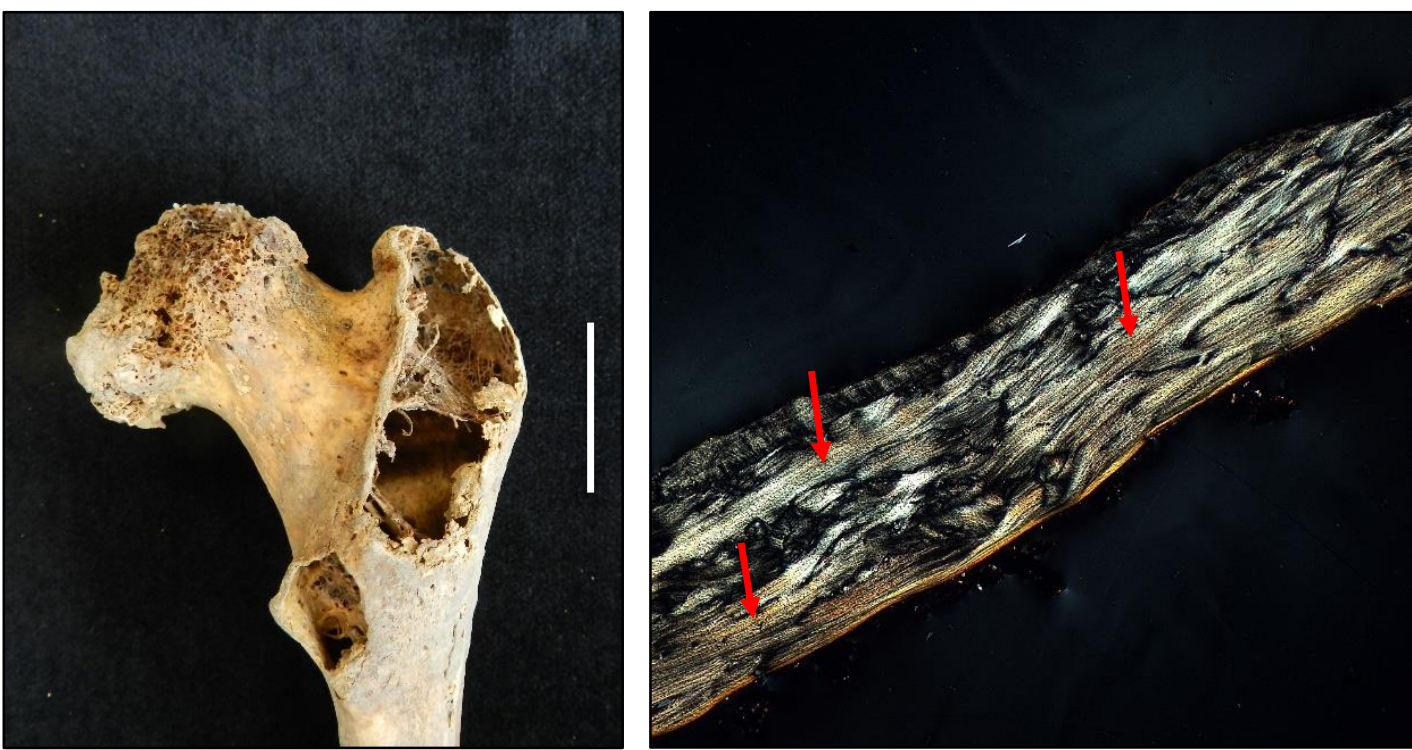

Abb. 44: Anzeichen einer eitrigen Coxitis. A Röntgenbild der Ossa coxae, mediale Ansicht. Links: rechtes Os coxae, Fistelöffnung im Acetabulum (Pfeil). Rechts: linkes Os coxae. Fundnummer 138, weiblich, 18 - 23 Jahre. B Rechtes Os coxae, laterale Ansicht, Fistelöffnung im Acetabulum (Pfeil). C Rechtes Femur, posteriore Ansicht (Strich entspricht $3 \mathrm{~cm}$ ). D Betrachtung mit dem Mikroskop im polarisierten Licht, Femur rechts, atrophierter Knochen ohne Osteone (Pfeile), 70 m Dicke, 16-fache Vergrößerung. 
Der mikroskopische Befund aus drei Ebenen des Femurschafts belegt eine ausgeprägte Inaktivitätsatrophie (Abbildung 44D). Die kompakte Knochenstruktur selbst erinnert stark an den mikroskopischen Aufbau eines Involucrums.

Auch im Rahmen einer DNA-Analyse konnten keine Tuberkuloseerreger gefunden werden. Staphylococcus aureus, der als Opportunist von Zeit zu Zeit in Tuberkulosefällen anzutreffen ist, wurde hier nicht gefunden. Die typischen Tuberkuloseerreger wie Mycobacterium tuberculosis oder Mycobacterium bovis wurden auf das Gen katG hin untersucht, konnten aber nicht nachgewiesen werden. Mithilfe der Überprüfung der Insertion-Sequenz IS1081 konnten in der PCR Signale erhalten werden. Die BLAST-Suche erbrachte allerdings keine Übereinstimmung mit einer bekannten Pathogen-DNA.

Die Fistel- und Kloakenöffnungen, die mikroskopische Auswertung und die DNA-Analyse sprechen gegen den anfänglichen Verdacht einer Knochentuberkulose, aber für eine eitrige Coxitis. Gleiche Veränderungen wurden auch an einem Skelett (Ind.-D 11) aus dem Karner der St. Martins-Kirche in Klosterneuburg, Niederösterreich, beschrieben (Schultz und TeschlerNicola 1987 S. 240 - 241).

Zusammenfassend kann gesagt werden, dass sich die Männer beider Gruppen hinsichtlich der Verteilung der Otitis media, Sinusitis im Sinus maxillaris und der Stomatitis signifikant unterscheiden. Die Gruppe der Anatomieleichen leidet häufiger an den Infektionskrankheiten Otitis media und Sinusitis. Die Regelbestatteten hingegen zeigen etwas häufiger Anzeichen einer leichten bis starken Stomatitis. Andere Infektionskrankheiten, Osteomyelitis und meningeale Reaktionen finden sich selten in beiden Gruppen.

\subsubsection{Arthrose, Arthritis}

\section{$\underline{\text { Arthrose }}$}

Bei der Arthrose handelt es sich um einen überwiegend degenerativen aber auch proliferativen Prozess. Sie entsteht im Rahmen körperlicher Belastung in den Gelenken durch Verschleiß der Gelenkoberflächen und -ränder (siehe Abbildung 45) bis zur Eburnierung. Ebenso kann eine Arthrose bei geringer körperlicher Tätigkeit entstehen, wenn die Muskeln atrophieren und die Gelenke nicht mehr ausreichend gestützt werden. Der Grad der Arthrose wurde nach Schultz (1988b) für folgende Gelenke ermittelt: Schultergelenk, Ellenbogengelenk, proximales Handgelenk, Hüftgelenk, Kniegelenk, proximales und distales Fußgelenk. 

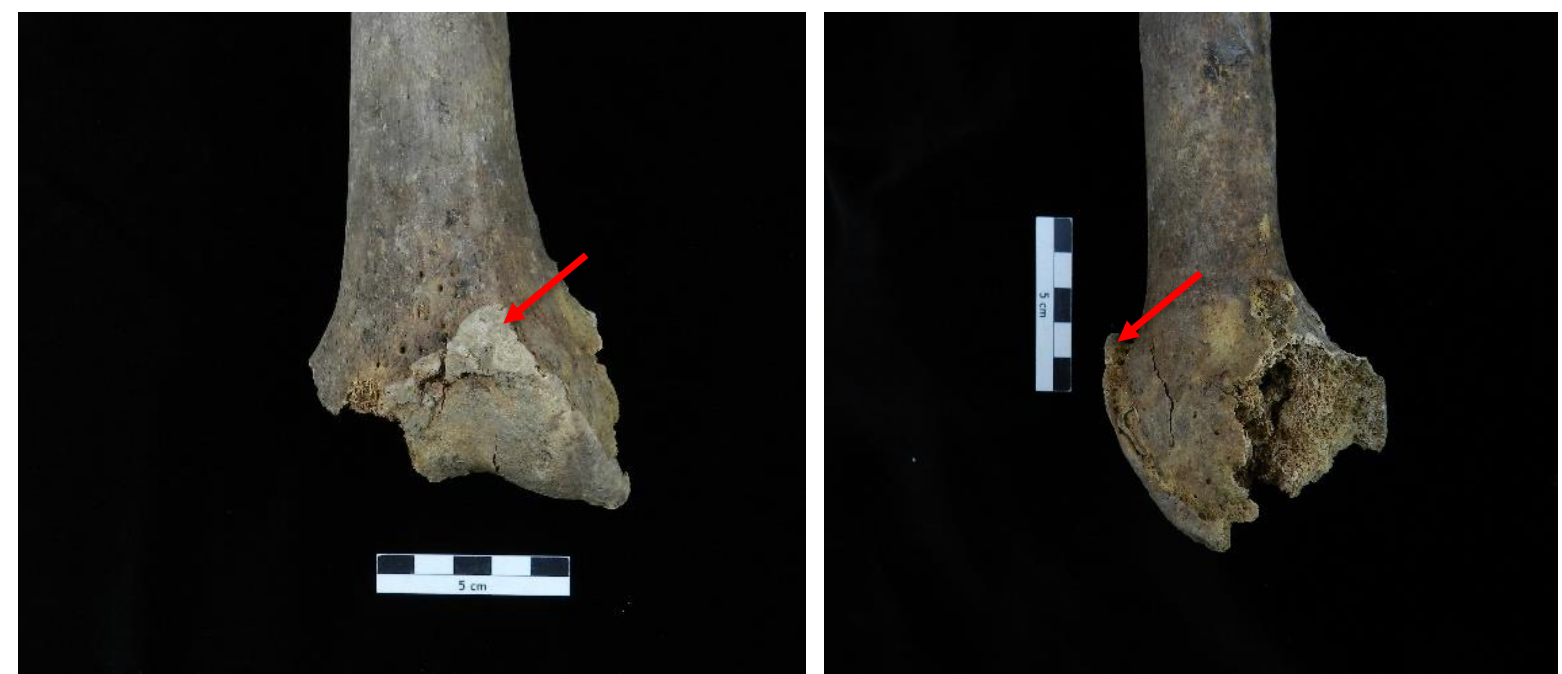

Abb. 45: Arthrose. Linkes Femur distal. Rechts: anteriore Ansicht, Knochenneubildung (Pfeil). Links: laterale Ansicht, Knochenneubildung (Pfeil). Fundnummer 60, männlich, 50 - 70 Jahre.

Bei einem Teil der 159 untersuchten Individuen waren die Gelenke nicht oder nur einseitig gut erhalten. In manchen Fällen waren die Gelenke zwar erhalten, aber so stark degradiert, dass keine aussagekräftigen Beurteilungen mehr vorgenommen werden konnten. Die untersuchten Gruppen sind nicht normal verteilt, denn die Anzahl subadulter Individuen ist sehr gering und der Männeranteil liegt mit Abstand deutlich über dem Frauenanteil (Verhältnis 8,5 : 1 beziehungsweise $2: 1$ ). Die zu vergleichenden Datensätze sind partiell sehr klein, weswegen eine geringe Teststärke vorliegt. Bei der Interpretation dieser Ergebnisse kann es sich trotz der Signifikanz um ein statistisches Zufallsereignis handeln.

Die Gelenkveränderungen der befundbaren Anatomieleichen ( $\mathrm{n}=32$ ) sowie der Regelbestatteten $(\mathrm{n}=70)$ sind vermutlich in den meisten Fällen durch die körperliche Belastung im Laufe des Lebens zu erklären. Weitere Informationen dazu sind dem Kapitel 5.1 „Methodenkritik“ zu entnehmen. In Ausnahmefällen, wie bei Individuum 48, können erhebliche Gelenkveränderung aber auch durch Traumata entstehen (siehe Kapitel 4.1.5 Traumata).

\section{Seitenspezifische Gelenkveränderungen}

Der U-Test zeigt weder für die Anatomieleichen noch für die Regelbestatteten Unterschiede zwischen der rechten sowie linken Körperseite der jeweiligen Körperregion (siehe Anhang, Tabelle 16). Daher wird in den folgenden statistischen Berechnungen für jede Körperregion ein Mittelwert aus den Bewertungsziffern der Arthroseintensität des jeweiligen rechten und linken Gelenks gebildet. 


\section{Ausprägungsgrad der Gelenkveränderungen}

Wie in Abbildung $46 \mathrm{zu}$ sehen ist, sind die Körperregionen der Anatomieleichen unterschiedlich stark durch degenerative Prozesse betroffen. Die Abnutzung von Hüft-, Schulter- und proximalen Handgelenken unterscheidet sich signifikant von der Abnutzung der restlichen Gelenke $(H=21,96 ; p<0,001)$. Der geringste Gelenkverschleiß ist im Bereich der Ellenbogengelenke und proximalen Sprunggelenke $\mathrm{zu}$ finden. Es gibt jedoch keinen signifikanten Unterschied zwischen den Gelenken der oberen und den unteren Extremitäten (U $=7 ; \mathrm{p}=0,77)$.

Auch die Gelenke der Regelbestatteten sind unterschiedlich stark von Arthrose betroffen. Zwar sind vor allem die Hüft- und Schultergelenke höchst signifikant stärker abgenutzt als die restlichen Gelenke $(\mathrm{H}=48,01 ; \mathrm{p}<0,001)$. Der geringste Verschleiß ist im Bereich der proximalen Sprunggelenke zu finden. Es zeigte sich kein signifikanter Unterschied zwischen den Gelenken der oberen und den unteren Extremitäten $(U=7 ; p=0,77)$.

Insgesamt sind die Mittelwerte der regelbestatteten Individuen in fast allen Körperregionen gleich hoch oder höher als die der Anatomieleichen (siehe Anhang, Tabelle 17 und 19). Die größte Differenz liegt im Bereich des Hüftgelenks mit einem Wert von 0,4. Der Unterschied zwischen den Gruppen hinsichtlich der Arthroseintensität ist statistisch nicht signifikant $(\mathrm{U}=$ $87 ; \mathrm{p}=0,12)$.

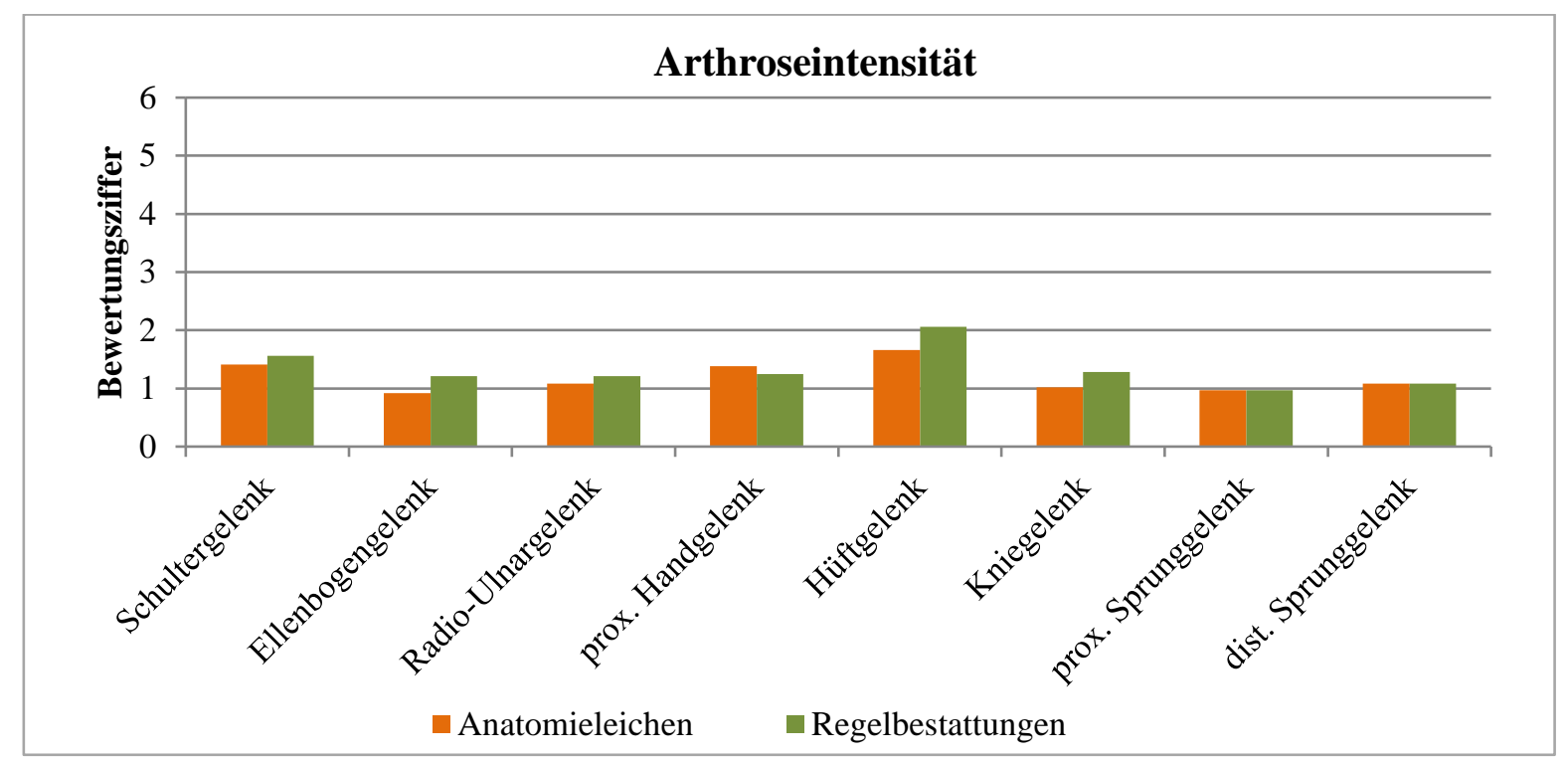

Abb. 46: Mittelwert aller Bewertungsziffern für jede Körperregion (Arthroseintensität) in der Gruppe der Anatomieleichen $(n=32)$ und Regelbestattungen $(n=70)$.

In den Abbildungen 47 und 48 ist die Verteilung der Bewertungsziffern der Arthroseintensität für jede Körperregion einzeln abgebildet. Die Bewertungsziffer wurde jeweils in eine der in der Legende rechts abgebildeten Kategorien (0.0 - 0.9 usw.) eingeordnet. Zum Beispiel haben 
$20 \%$ der Anatomieleichen in der Schulterregion einen Arthrosewert zwischen 0 und 0,9. Weitere $56 \%$ der Individuen weisen einen Arthrosewert von 1,0 - 1,9 auf und $24 \%$ einen Wert von $2,0-2,9$.

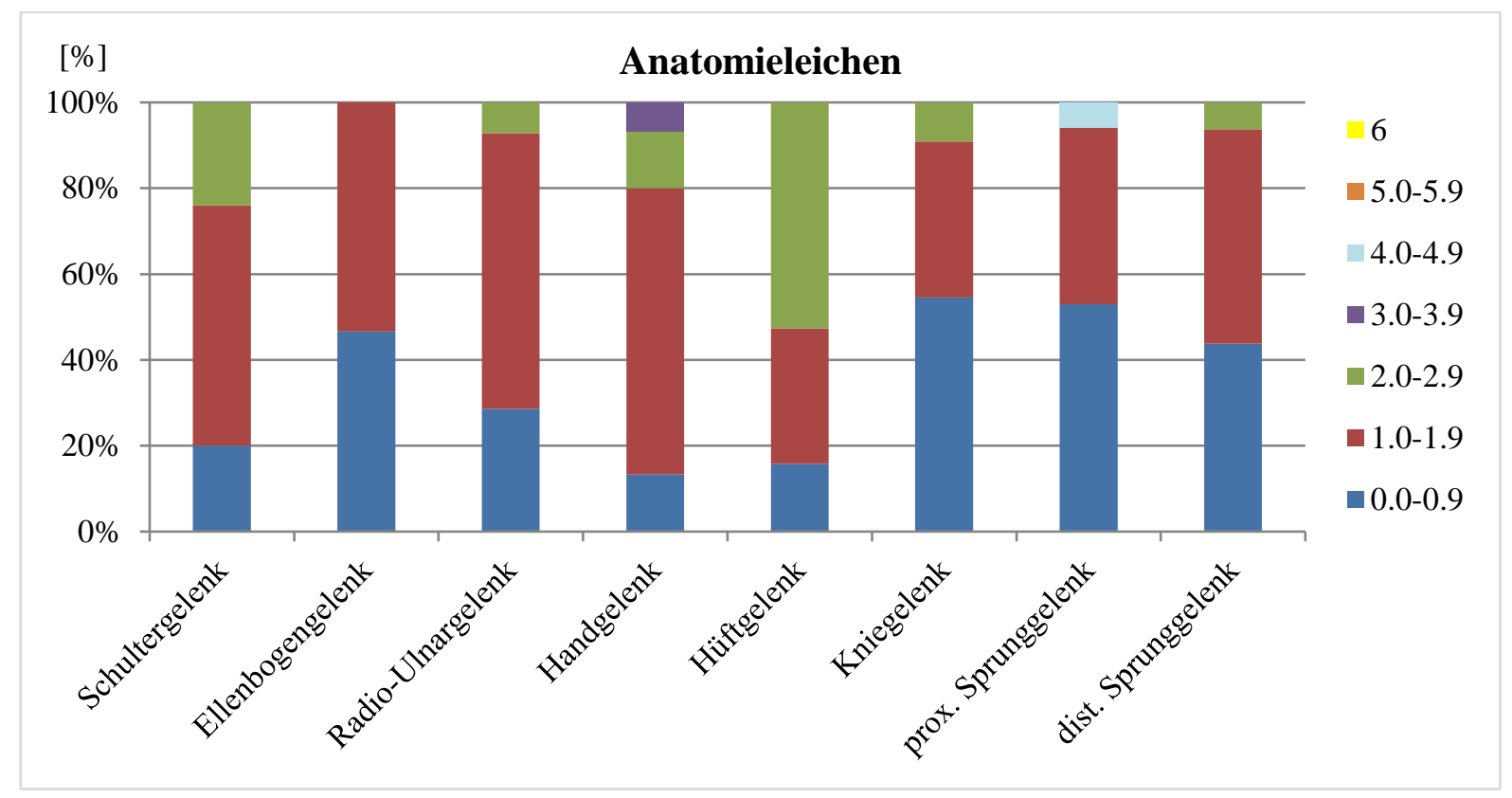

Abb. 47: Prozentuale Verteilung der Bewertungsziffern der Arthroseintensität der einzelnen Körperregionen für die Anatomieleichen.

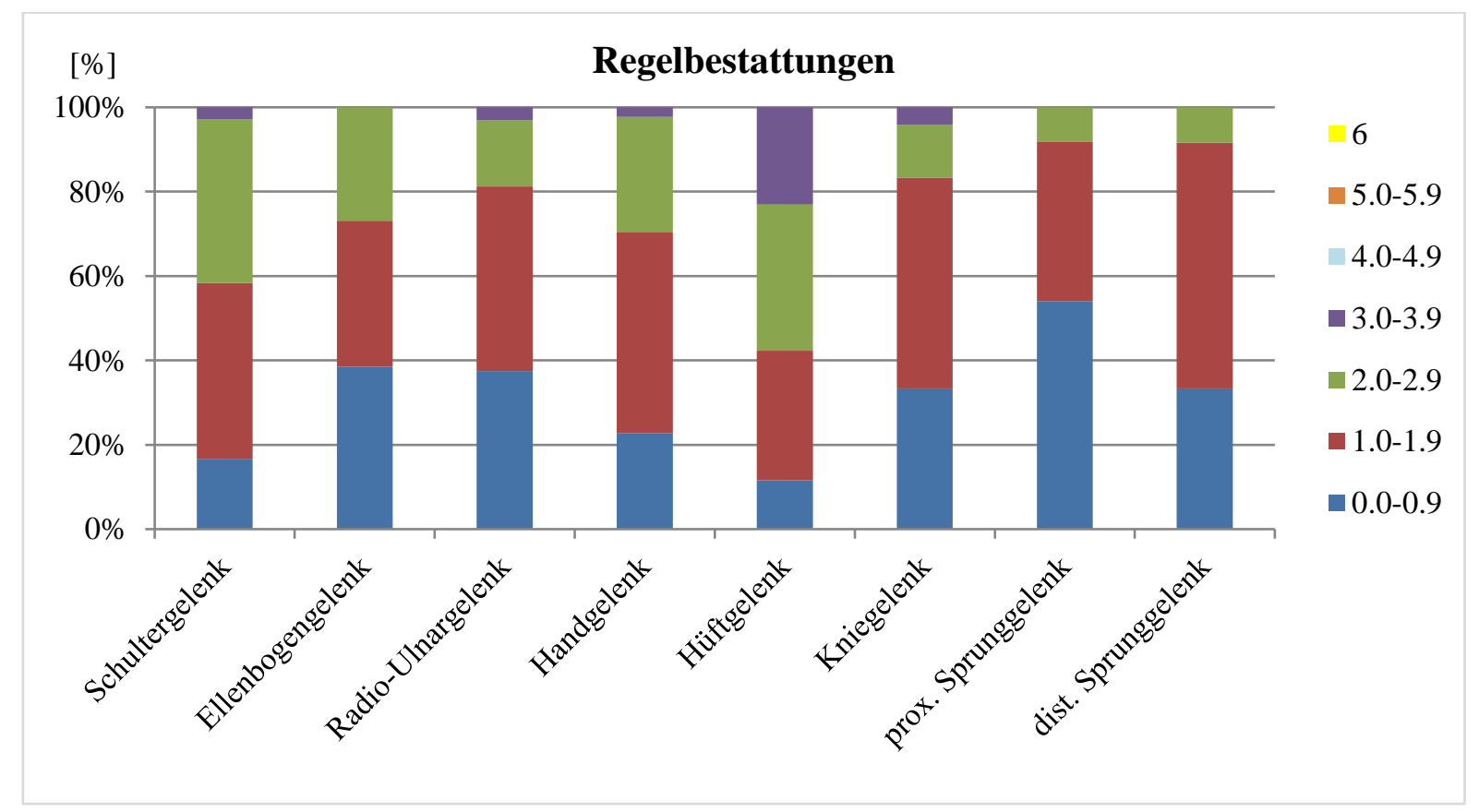

Abb. 48: Prozentuale Verteilung der Bewertungsziffern der Arthroseintensität der einzelnen Körperregionen für die regelbestatteten Individuen.

Bei dem Vergleich der beiden Abbildungen fällt auf, dass die regelbestatteten Individuen einen höheren Anteil an Werten zwischen 2,0 - 2,9 aufweisen als die Anatomieleichen (siehe Anhang Tabelle 22). 


\section{Geschlechtsspezifische Gelenkveränderungen}

In der Gruppe der Regelbestattungen ist der prozentuale Anteil weiblicher und männlicher Individuen in jeder Altersklasse in etwa gleich groß. Daher ist ein Vergleich hinsichtlich der Arthroseintensität möglich. In der Gruppe der Anatomieleichen ist der Frauenanteil sehr gering $(n=2)$, sodass kein Vergleich mit den männlichen Anatomieleichen stattfinden kann. Bei einem Vergleich der männlichen Regelbestatteten mit den männlichen Anatomieleichen ist zu beachten, dass der Anteil an Anatomieleichen im maturen Alter höher und der im senilen Alter geringer ist.

Beim Vergleich der Arthroseintensität von Frauen und Männern in der Gruppe der Regelbestattungen ist in Abbildung 49 zu erkennen, dass die Gelenke der Männer im Bereich der oberen Extremitäten einen höheren Abnutzungsgrad aufweisen als die der Frauen. Die größte Differenz liegt dabei im Schultergelenk $(U=106,5 ; p=0,06)$. Im Bereich der unteren Extremitäten hingegen haben die Frauen einen höheren Abnutzungsgrad im Kniegelenk (U = $45,5 ; \mathrm{p}=0,21)$.

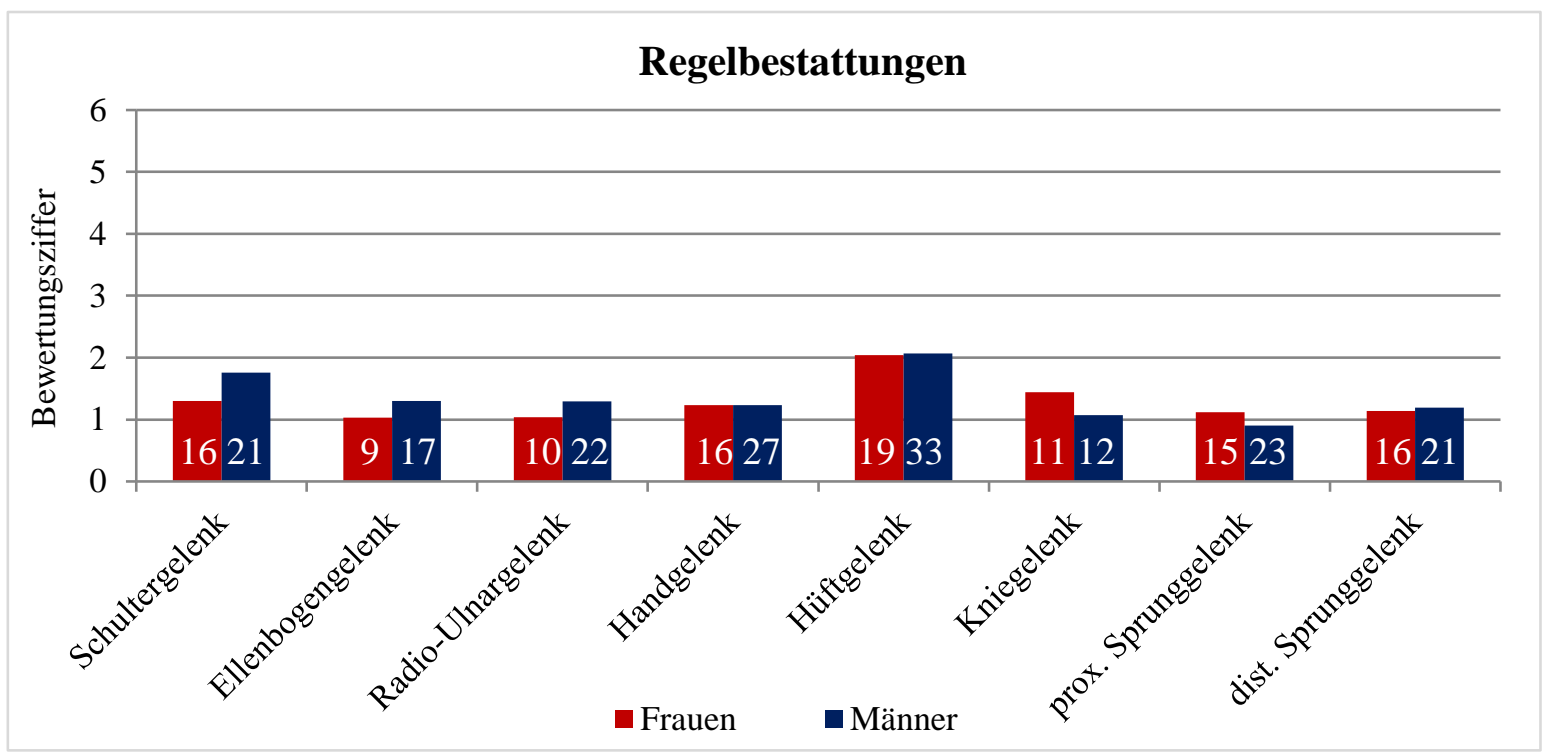

Abb. 49: Mittelwert aller Bewertungsziffern für jede Körperregion (Arthroseintensität) der Frauen und Männer in der Gruppe der Regelbestattungen. Die Zahlen in den Balken geben die Anzahl der befundbaren Gelenke jeder Körperregion an.

Vergleicht man die männlichen Individuen beider Gruppen wie in Abbildung 50 miteinander, ist $\mathrm{zu}$ erkennen, dass die Regelbestatteten bei den meisten Gelenken eine höhere Arthroseintensität aufweisen als die Anatomieleichen. Die größten Unterschiede liegen im Bereich der Schulter $(U=163 ; p=0,07)$, des Ellenbogens $(U=84,5 ; p=0,10)$ und des Hüftgelenks $(\mathrm{U}=244 ; \mathrm{p}=0,19)$. 


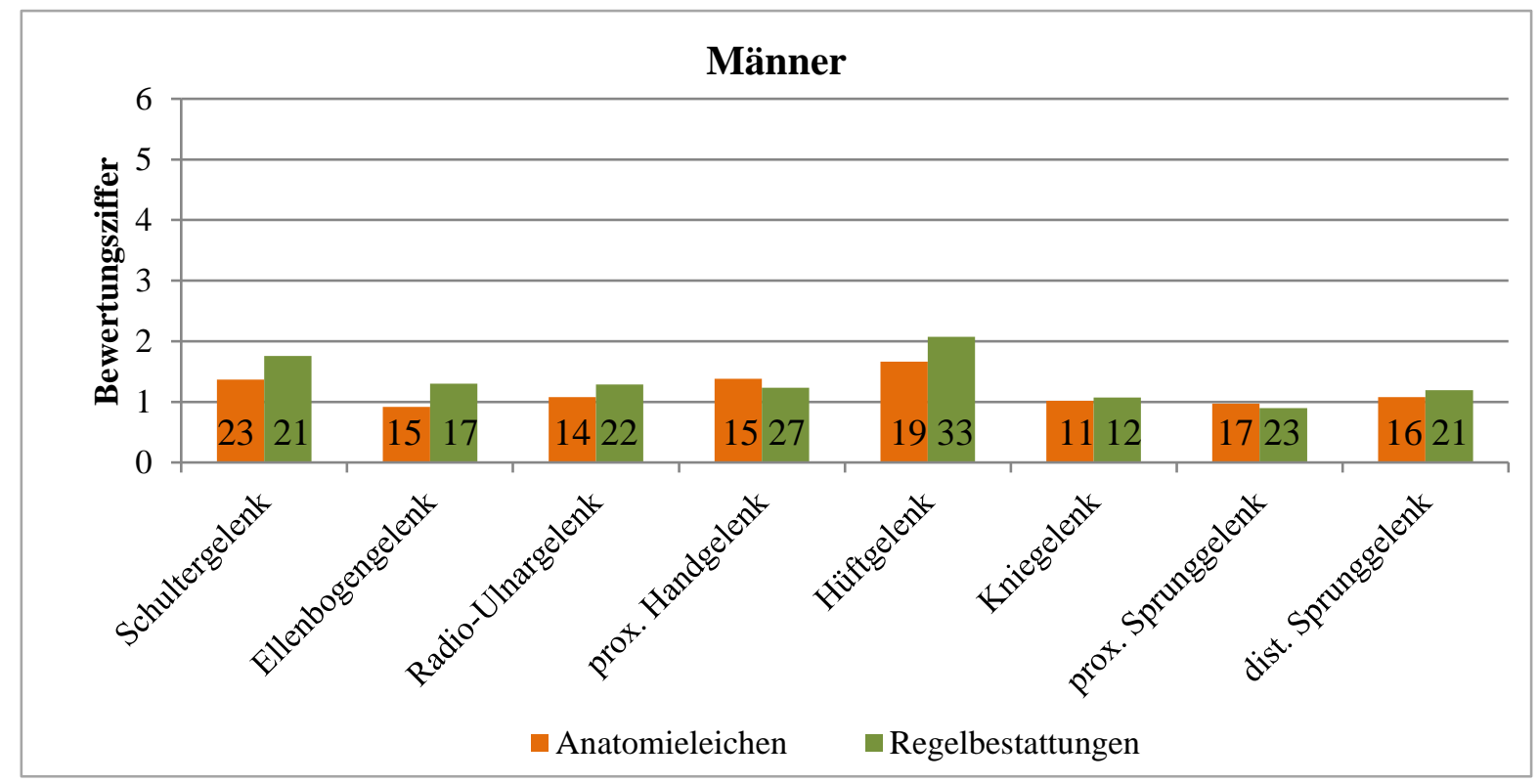

Abb. 50: Mittelwerte aller Bewertungsziffern für jede Körperregion (Arthroseintensität) der Männer beider Gruppen. Die Zahlen in den Balken geben die Anzahl der befundbaren Gelenke jeder Körperregion an.

Der Unterschied in der Gruppe der Regelbestattungen ist kleiner (vgl. Frauen mit Männern Regelbestattungen) als der Unterschied zwischen den Gruppen (vgl. Männer Anatomieleichen mit Männern Regelbestattungen). Die Lebensweise beeinflusst in geringem Maße indirekt die Arthroseintensität der Gelenke.

\section{Altersspezifische Gelenkveränderungen}

Wie in Abbildung 51 und $52 \mathrm{zu}$ erkennen ist, steigt der Mittelwert der Bewertungsziffer aufgrund des Belastungszeitraums mit zunehmendem Alter. Für jede Altersklasse wurde getestet, ob es einen signifikanten Unterschied der Mittelwerte zwischen den Gruppen gibt. Aufgrund der geringen Datenmenge konnte für die subadulten Individuen lediglich das proximale Sprunggelenk verglichen werden. Für die Altersklasse senil sind nicht genug Daten für das Ellenbogengelenk vorhanden. Für keine der Altersklassen gab es signifikante Unterschiede zwischen den beiden Gruppen (siehe Anhang, Tabelle 25). 


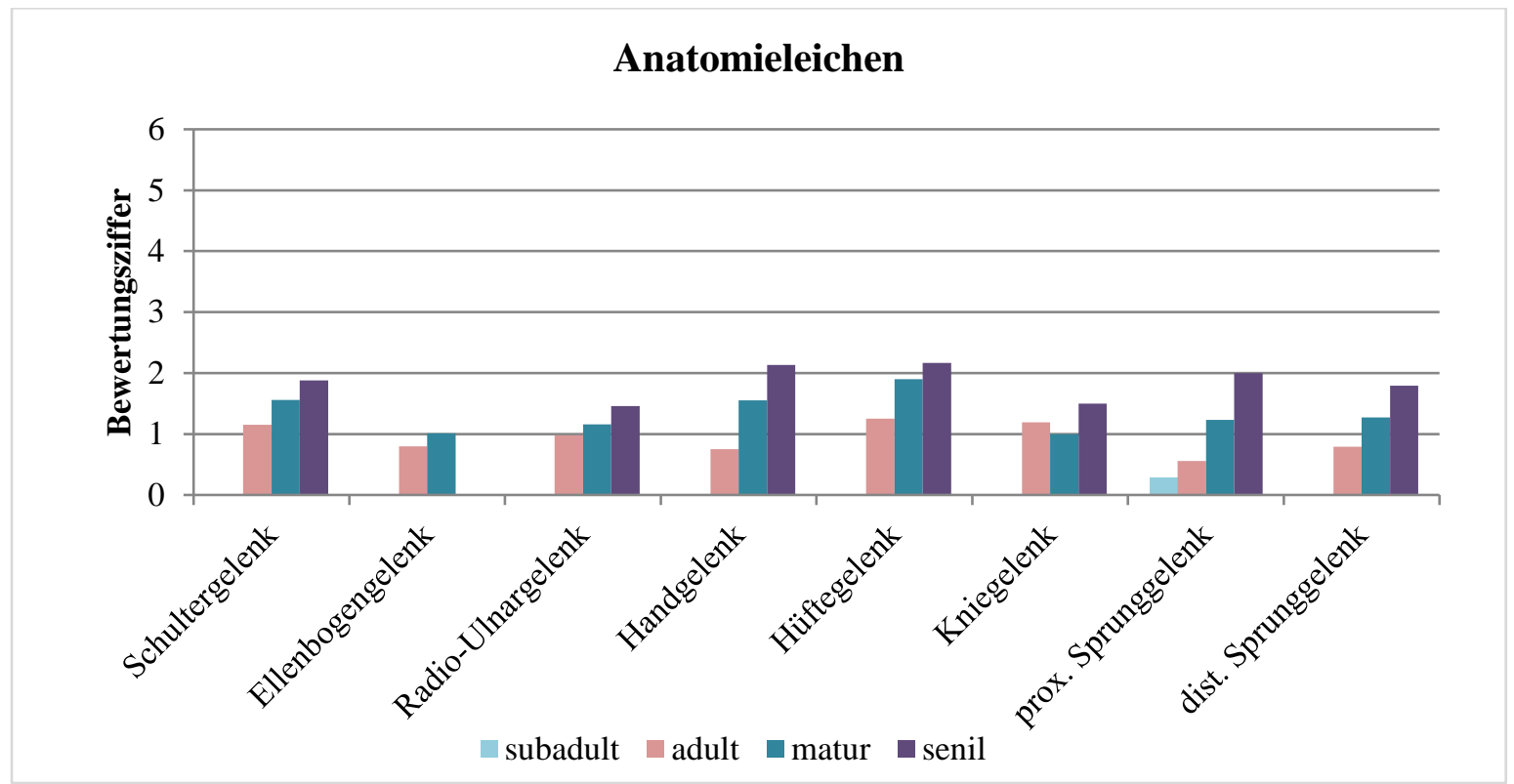

Abb. 51: Mittelwerte aller Bewertungsziffern für jede Körperregion (Arthroseintensität) nach Altersklassen in der Gruppe der Anatomieleichen.

In der Gruppe der Anatomieleichen zeigt sich für das proximale Sprunggelenk ein signifikanter Unterschied zwischen den Altersklassen hinsichtlich der Arthroseintensität (H $=9,61 ; \mathrm{p}=0,022)$.

\section{Regelbestattungen}

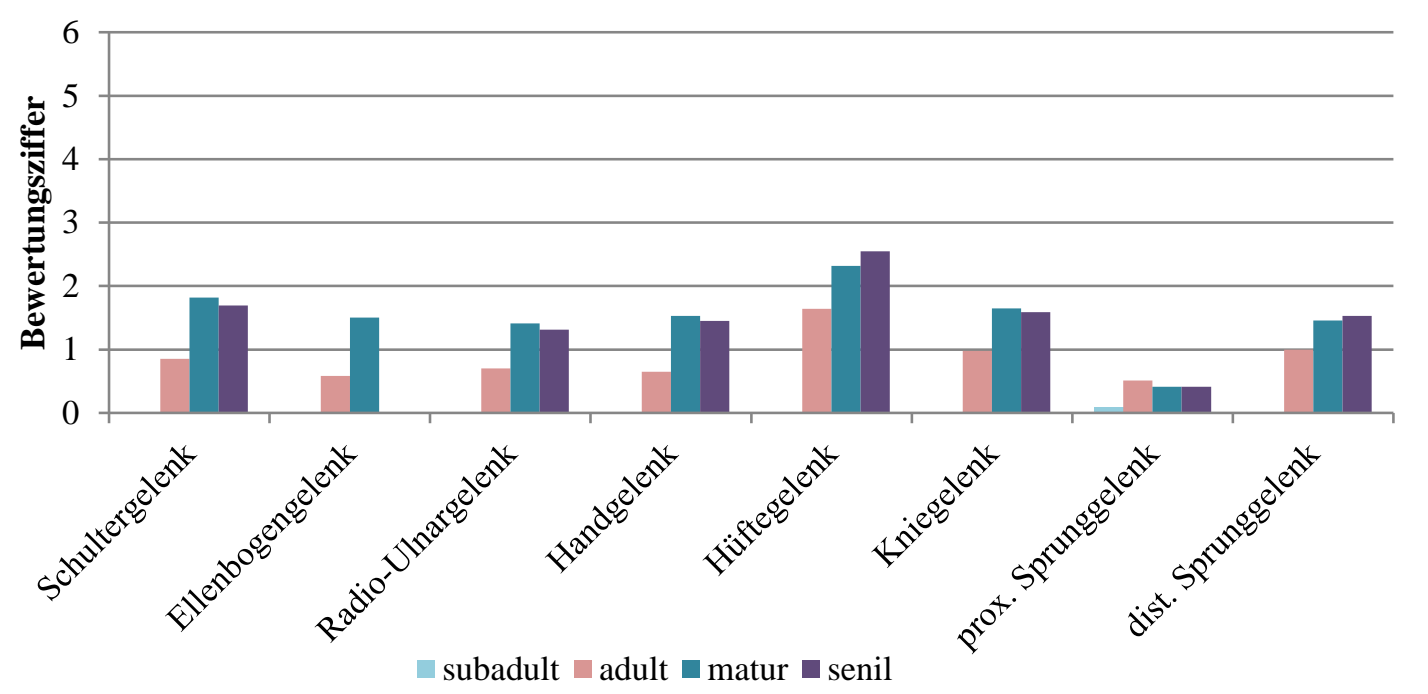

Abb. 52: Mittelwerte aller Bewertungsziffern für jede Körperregion (Arthroseintensität) nach Altersklassen in der Gruppe der Regelbestattungen.

Bei den regelbestatteten Individuen liegt ein signifikanter Unterschied zwischen den Altersklassen im Schultergelenk $(H=11,93 ; p=0,003)$, Handgelenk $(H=10,39 ; p=0,006)$, Hüftgelenk $(H=8,47 ; p=0,014)$ und proximalen Sprunggelenk $(H=14,27 ; p=0,003)$ vor. Der Mittelwert der Bewertungsziffern für die Arthroseintensität steigt mit zunehmendem Alter an. In allen Gelenken ist eine sprunghafte Zunahme der Arthroseintensität zwischen der adulten 
und maturen Altersklasse zu beobachten. Die höchsten Arthrosewerte sind im Bereich des Hüftgelenkes und Schultergelenkes in der maturen und senilen Altersklasse zu beobachten.

$\underline{\text { Vergleich der Arthroseintensität mit anderen Populationen }}$

Sowohl die Anatomieleichen als auch die regelbestatteten Individuen gehören der Stadtbeziehungsweise Kleinstadtbevölkerung an. Verglichen wurde deren Arthroseintensität mit den Skeletten einer Population aus Inden, Kreis Düren, Nordrhein-Westfalen (Kreye 2016). Hierbei handelte es sich um eine Population, die in einem ländlichen Gebiet gelebt haben. Es ist zu vermuten gewesen, dass sie unterschiedliche Werte hinsichtlich der Arthroseintensität aufweisen. In Abbildung 53 sind die mittleren Arthrosewerte aller Gelenke für die drei Gruppen dargestellt.

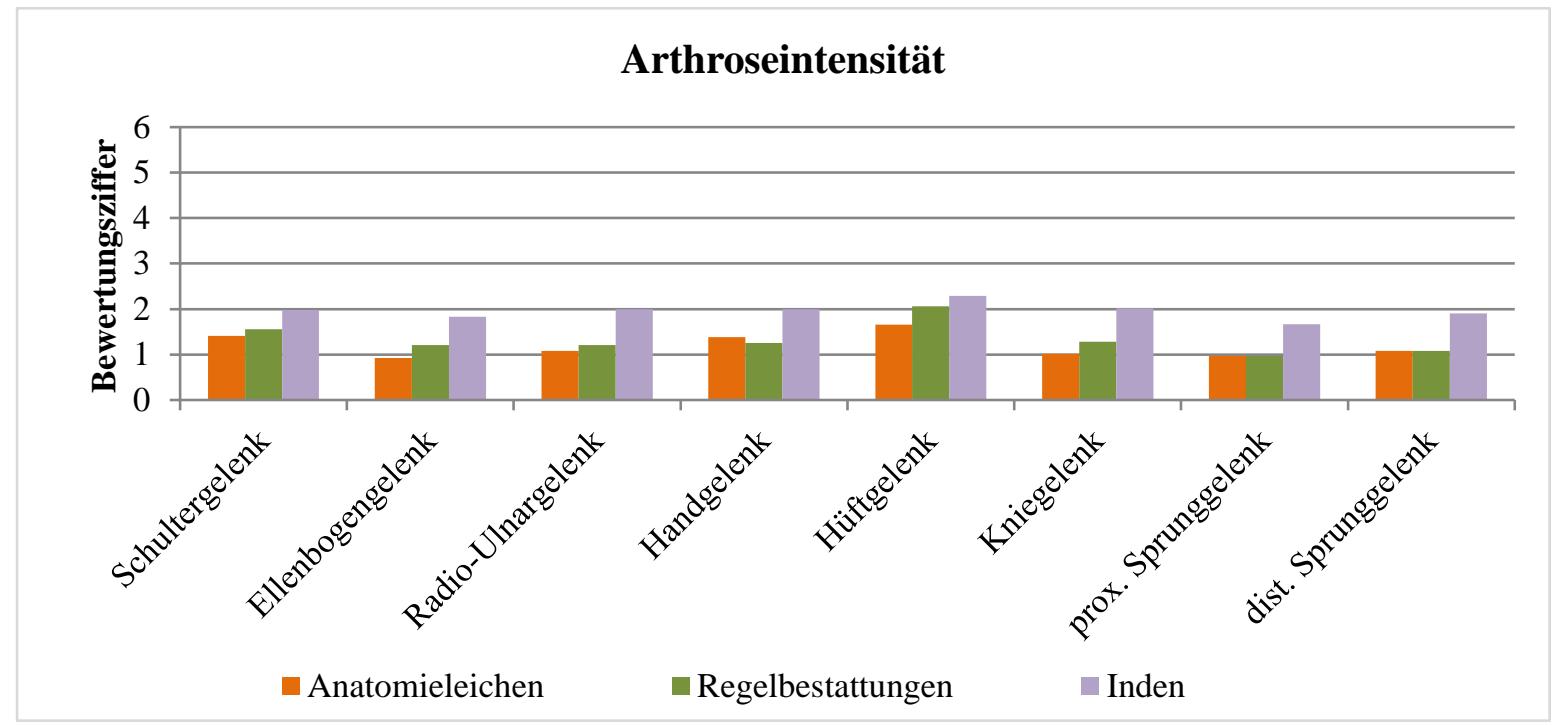

Abb. 53: Mittelwert aller Bewertungsziffern für jede Körperregion (Arthroseintensität) in der Gruppe der Anatomieleichen, Regelbestattungen und der Population aus Inden.

Sowohl die Gruppe der Anatomieleichen als auch die Gruppe der regelbestatteten Individuen weist eine geringere Arthroseintensität auf als die Skelette der Referenzserie.

Auch die Skelette der im Bergbau tätigen Population aus Goslar weisen sehr hohe Arthrosewerte aufgrund ihrer beruflichen Beschäftigung auf. Allerdings konnte kein direkter Vergleich mit den Göttinger Individuen durchgeführt werden, da es für diese Population keine Bewertung der Arthroseintensität nach Schultz (1988) gab.

$\underline{\text { Arthritis }}$

Bei der Arthritis handelt es sich um eine entzündliche Gelenkerkrankung. Diese kann durch eine Infektionskrankheit, rheumatische Erkrankung, genetische Disposition, Stoffwechselstörung oder aber Krankheitserreger (z. B. Staphylokokken) ausgelöst werden. In Folge der 
arthritischen Prozesse kommt es meist auch zu einem geringen Anteil von arthrotischen Prozessen und umgekehrt.

In beiden Gruppen konnten nur wenige Fälle von Arthritis beobachtet werden. Sieben Anatomieleichen und 18 Regelbestattete hatten vorrangig Arthritis im Bereich der Wirbelsäule und des Schultergürtels. Das regelbestattete Individuum 60 zeigt im Bereich des oberen Abschnitts des oberen Sprunggelenks beidseitig starke arthritische Veränderungen. Diese Veränderungen sind in der Abbildung 54 erkennbar. Die Fußknochen sind ebenfalls arthritisch verändert und miteinander ankylosiert (siehe Abbildung 55C).
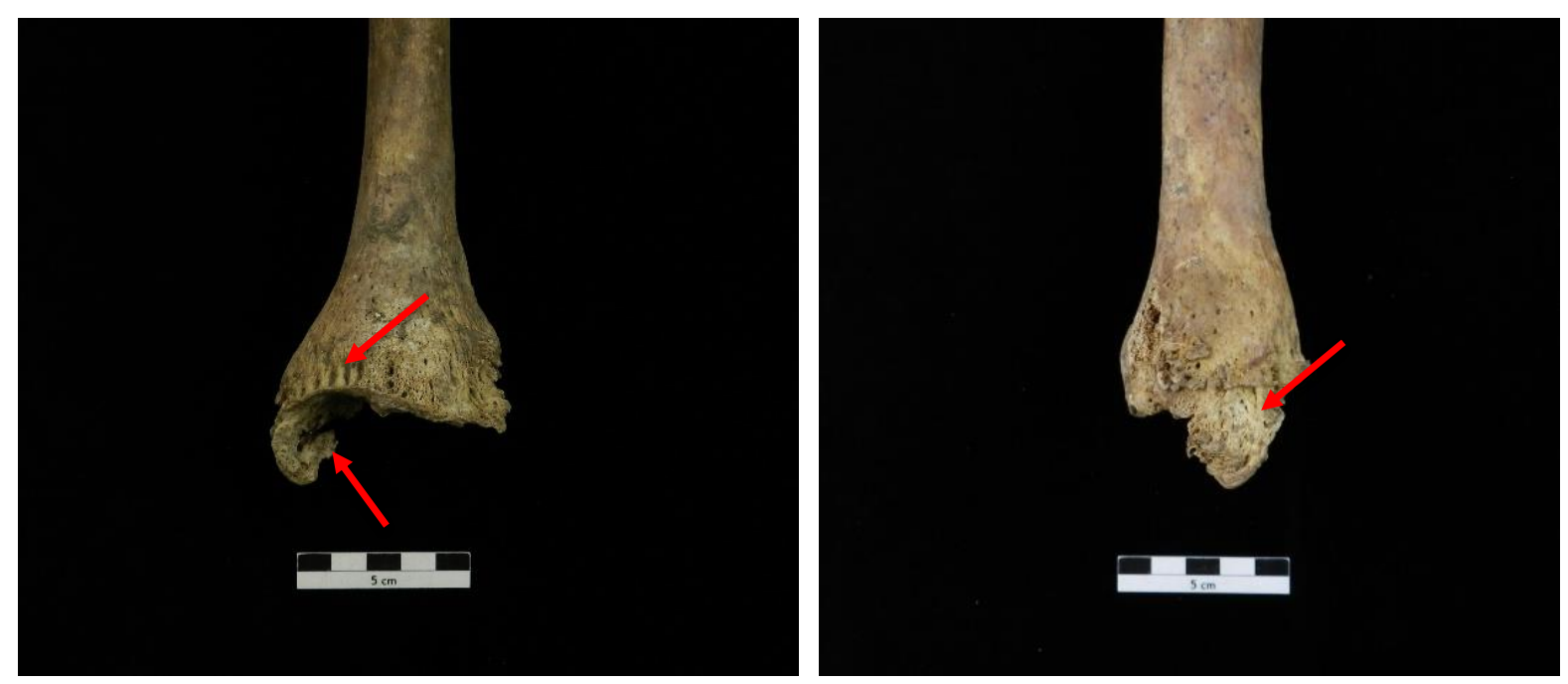

Abb. 54: Arthritis. Linke Tibia distal. Links: Anteriore Ansicht, Knochenneubildung (Pfeile). Rechts: Mediale Ansicht, Knochenneubildung (Pfeil). Fundnummer 60, männlich, 50 - 70 Jahre.

\section{$\underline{\text { Ankylose }}$}

Bei der Ankylose handelt es sich um eine Versteifung der Gelenke durch den knöchernen oder bindegewebigen Umbau der Gelenkkapsel. Einer der häufigsten Gründe der ankylosierenden Spondylitis (AS) ist die entzündliche rheumatoide Arthritis in Verbindung mit einer starken genetischen Komponente. Die typischen betroffenen Stellen sind in der Regel die Wirbelsäulengelenke und das Iliosacralgelenk (Khan 2009). Dies trifft auf die beiden regelbestatteten Individuen 73 und 63 zu. Bei dem Individuum 73 (siehe Abbildung 55A) sind beide Ossa coxae mit dem Os sacrum knöchern im Bereich der Facies auricularis verwachsen. Das Individuum ist männlich und 50 - 70 Jahre alt. Bei dem Individuum 63 (siehe Abbildung 55B) sind zehn Brustwirbel im Bereich der Wirbelkörper knöchern miteinander verwachsen. Das Individuum ist männlich und 60 - 70 Jahre alt. Die AS tritt zwei- bis dreimal häufiger bei Männern auf und beginnt typischerweise in der Altersklasse mitteladult (Khan 2009).

Bei dem regelbestatteten Individuum 60 (siehe Abbildung 55C) sind beiderseits etliche Ossa tarsalia und Ossa metatarsalia miteinander verwachsen. Das proximale Sprunggelenk zeigt 
ebenfalls Anzeichen arthritischer Veränderungen in Form von proliferativen Prozessen. Das Individuum ist männlich und 50 - 70 Jahre alt.

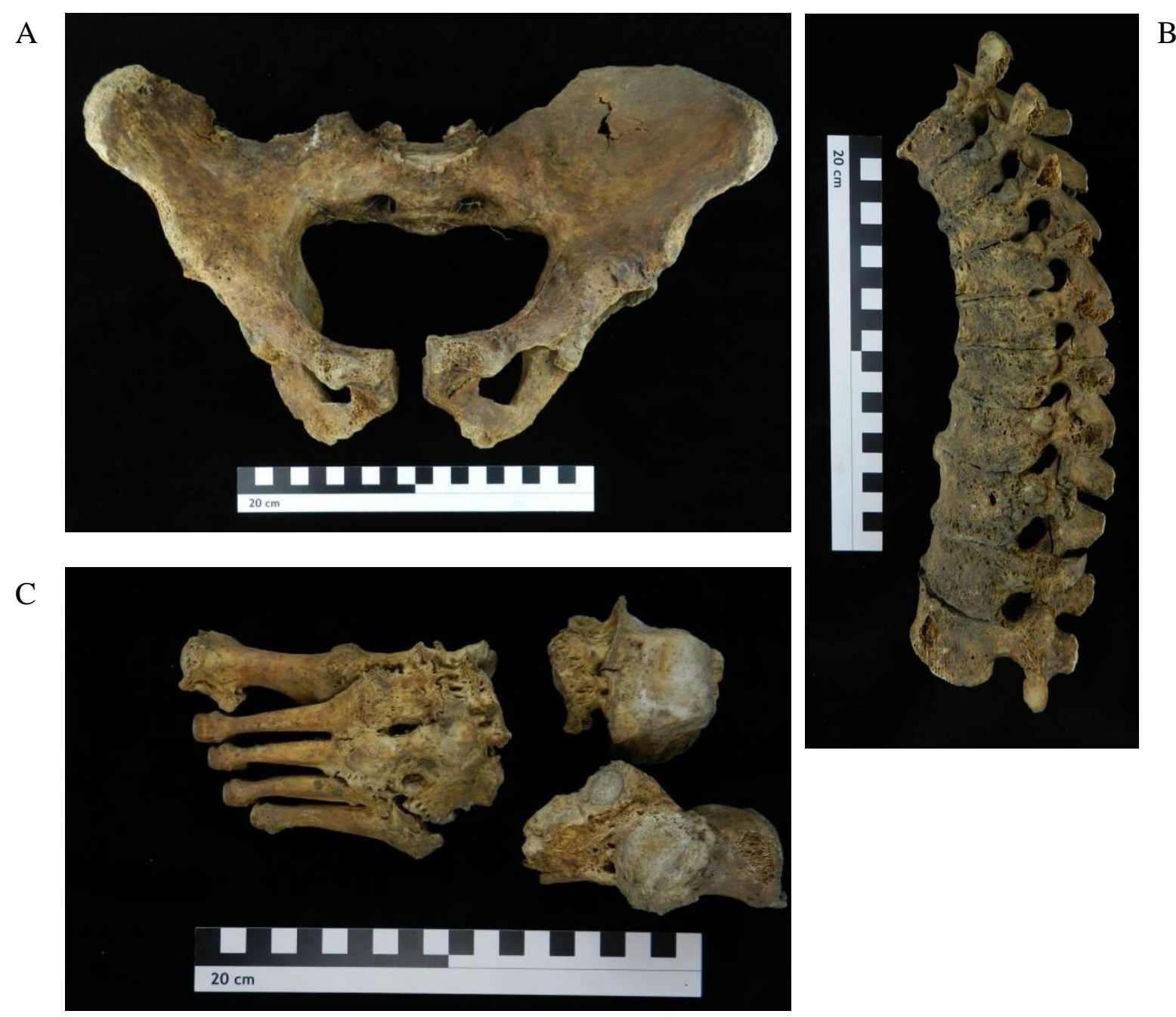

Abb. 55: Ankylose: Versteifung von Gelenken. A Ankylose der Ossa coxae mit dem Os sacrum. Fundnummer 73, Tendenz männlich, 50 - 70 Jahre. B Ankylose der Brustwirbelsäule, Ansicht von rechts. Fundnummer 63, männlich, 60 - 70 Jahre. C Teilweise Ankylose der Ossa tarsi und Ossa metatarsi. Fundnummer 60, männlich, 50 - 70 Jahre.

\section{Verknöcherte Bänder und Muskelansätze}

Es wurden oft Myotendopathien und Ligamentopathien im Bereich der Tuberositas deltoidea und der Ansatzstelle des Ligamentum costoclaviculare gefunden. Beides sind Bereiche, welche Ansatzstellen der Muskulatur und der Bänder des Oberkörpers darstellen.

Die Skelette der Anatomieleichen zeigen häufiger $(n=23 / 39)$ Vertiefungen cranial am sternalen Ende der Claviculae als die Skelette der Regelbestatteten ( $n=35 / 120)$. Dabei sind es bei den Anatomieleichen vor allem Individuen im maturen Altersbereich, während es bei den Regelbestattungen mature und senile Individuen sind. In beiden Gruppen gibt es jeweils ein Kind im Infans 2 mit auffälligen Vertiefungen an der Tuberositas lig. costoclavicularis. 
In dem Fall des Individuums 12 konnten am ganzen Körper starke Myotendopathien in Folge der diffusen idiopathischen Skeletthyperostose (DISH) gefunden werden.

\section{$\underline{\text { Wirbelsäulenveränderungen }}$}

\section{Wirbelbogengelenke}

Die arthrotische Veränderung (Arthrosis deformans) im Bereich der Wirbelbogengelenke (Articulationes zygapophyseales) wird als Spondylarthrosis deformans bezeichnet. Zuerst wurde getestet, ob es einen Unterschied zwischen der linken und rechten Seite der Wirbelbogengelenke hinsichtlich der Arthroseintensität gab. Da dieser Test sowohl für die Anatomieleichen $(\mathrm{U}=289 ; \mathrm{p}=0,65)$ als auch die Regelbestatteten $(\mathrm{U}=279 ; \mathrm{p}=0,52)$ negativ ausfiel, konnte der Mittelwert aus den linken und rechten Gelenken eines jeden Wirbels für die weiterführenden Tests verwendet werden.

Wie in der Abbildung 56 erkennbar ist, zeigen beide Gruppen im Mittel eine geringe bis mittlere Arthroseintensität im Bereich der Wirbelbogengelenke. Als Nächstes wurde getestet, ob sich die Mittelwerte der Bewegungssegmente, bestehend aus einem Wirbelkörpergelenk und den korrespondierenden Wirbelbogengelenken, zwischen den Gruppen unterscheiden. Der Test zeigte, dass es einen statistisch höchst signifikanten Unterschied $(U=105 ; p<0,001)$ gibt. Obwohl die Regelbestatteten im Bereich der Körpergelenke tendenziell leicht höhere Bewertungsziffern für die Messung der Arthroseintensität erhielten, verhielt es sich im Bereich der Wirbelsäule genau anders herum.

Für die Untersuchung der Altersklassen hinsichtlich der Arthroseintensität konnten aufgrund der geringen Individuenzahl $(\mathrm{n}=2)$ die weiblichen Anatomieleichen nicht berücksichtigt werden. Wie in den Abbildungen 57 bis 59 zu sehen ist, steigt die Arthroseintensität mit dem Alter deutlich an. Die Unterschiede zwischen den Altersklassen sind in der Gruppe der weiblichen Regelbestattungen $(\mathrm{H}=51,5 ; \mathrm{p}<0,001)$, in der Gruppe der männlichen Regelbestattungen $(\mathrm{H}=34,05 ; \mathrm{p}<0,001)$ und in der Gruppe der männlichen Anatomieleichen $(\mathrm{H}=19,9 ; \mathrm{p}<0,001)$ statistisch höchst signifikant. 


\section{Wirbelbogengelenke}
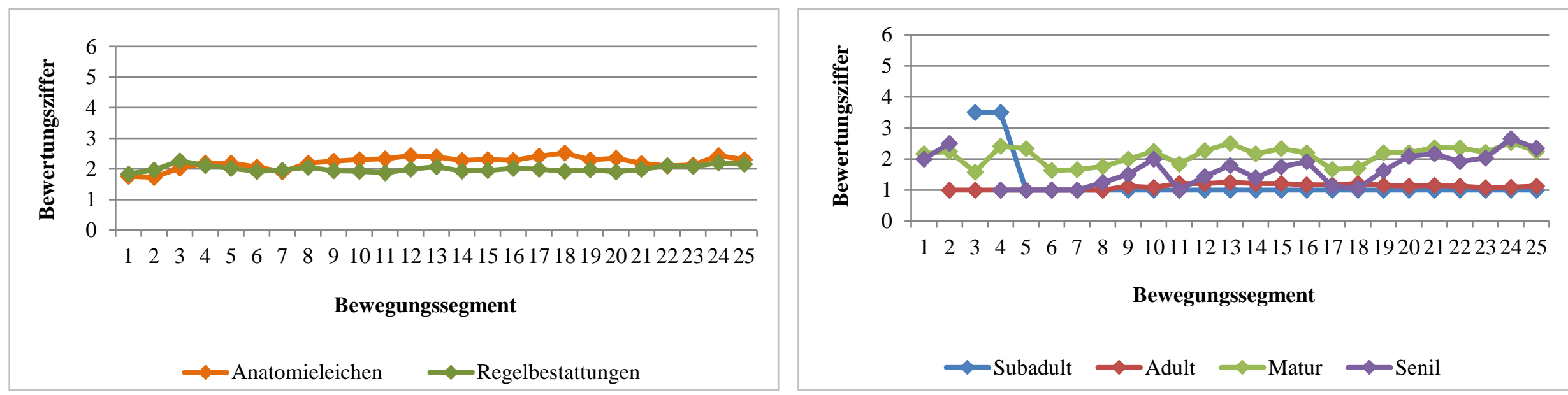

Abb. 56: Mittelwerte aller Bewertungsziffern für jedes Bewegungssegment (Arthroseintensität) in der Gruppe der Anatomieleichen und Regelbestattungen.

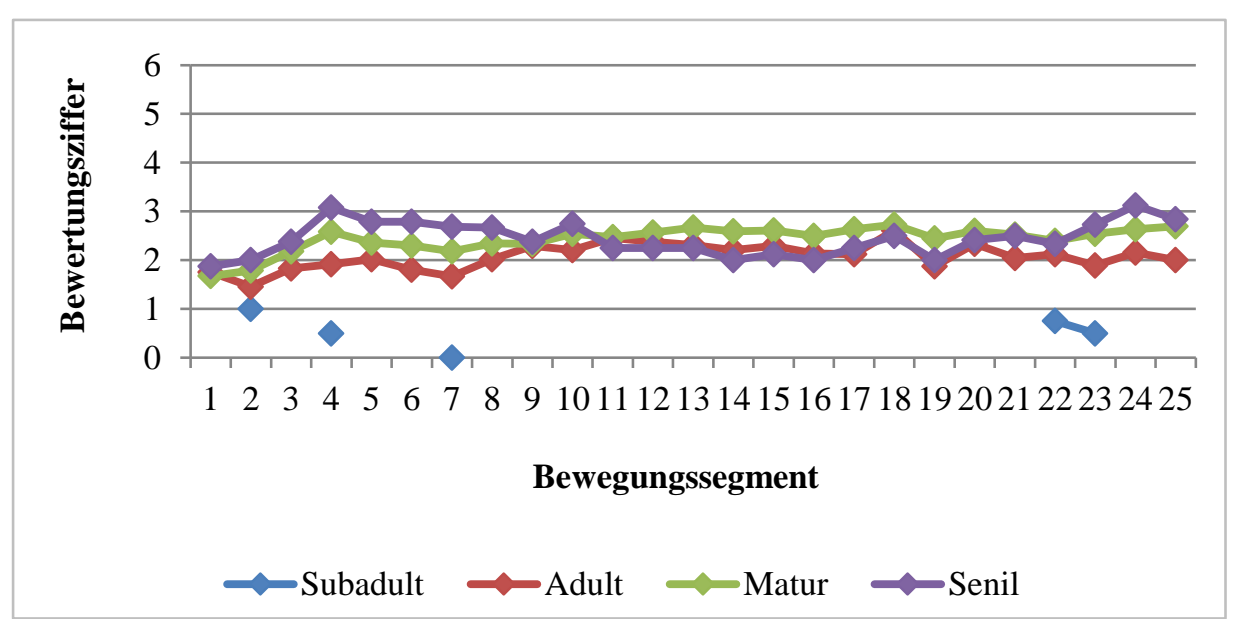

Abb. 58: Mittelwerte aller Bewertungsziffern für jedes Bewegungssegment

(Arthroseintensität) der männlichen Anatomieleichen $(n=27)$.

Abb. 57: Mittelwerte aller Bewertungsziffern für jedes Bewegungssegment (Arthroseintensität) der weiblichen Regelbestattungen $(\mathrm{n}=19)$.

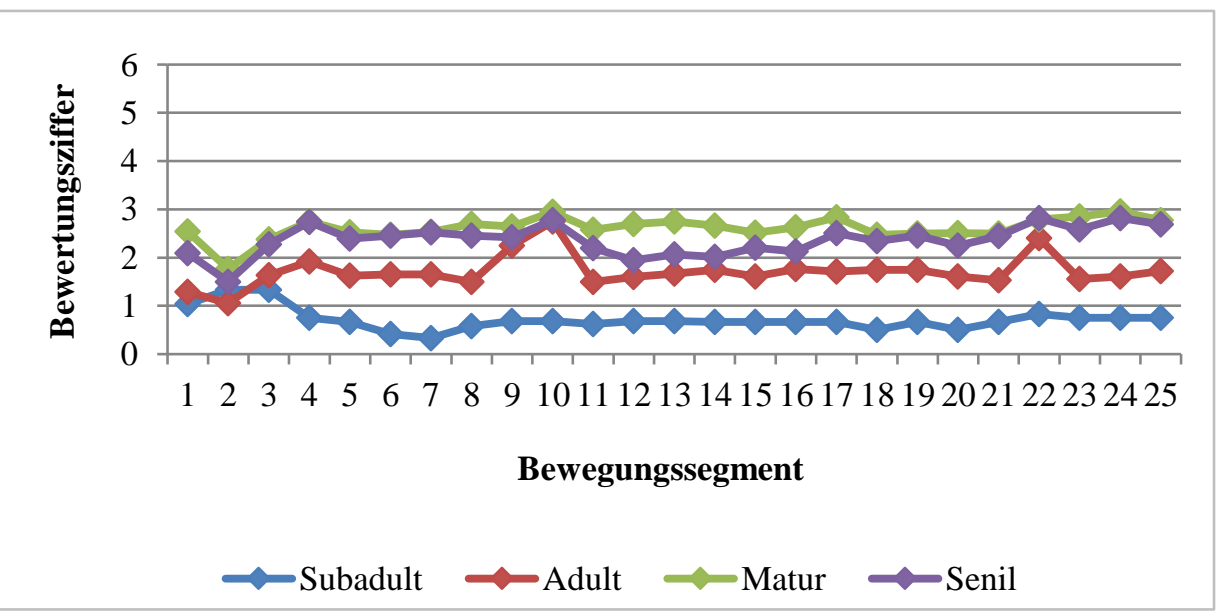

Abb. 58: Mittelwerte aller Bewertungsziffern für jedes Bewegungssegment (Arthroseintensität) der männlichen Regelbestattungen $(n=39)$. 


\section{$\underline{\text { Befunde und Ergebnisse - Biologische Daten }}$}

\section{Wirbelkörper}

Die arthrotische Veränderung (Arthrosis deformans) im Bereich der Wirbelkörper (Intervertebralräume) wird als Spondylosis deformans bezeichnet. Meist entsteht die Spondylosis, wie sie in Abbildung $60 \mathrm{zu}$ sehen ist, im Rahmen einer Osteochondrosis intervertebralis. Durch die alltägliche Belastung der Wirbelsäule, aber auch durch Traumata und Übergewicht, kommt es zu einem Verschleiß und anschließender Höhenminderung der Bandscheiben. Sukzessive verschleißen daraufhin die Wirbelkörperdeckplatten und grundplatten (Spondylosis), es bilden sich Spondylophyten, welche im Extremfall zu knöchernen Überbrückungen zwischen den Wirbelkörpern führen können.

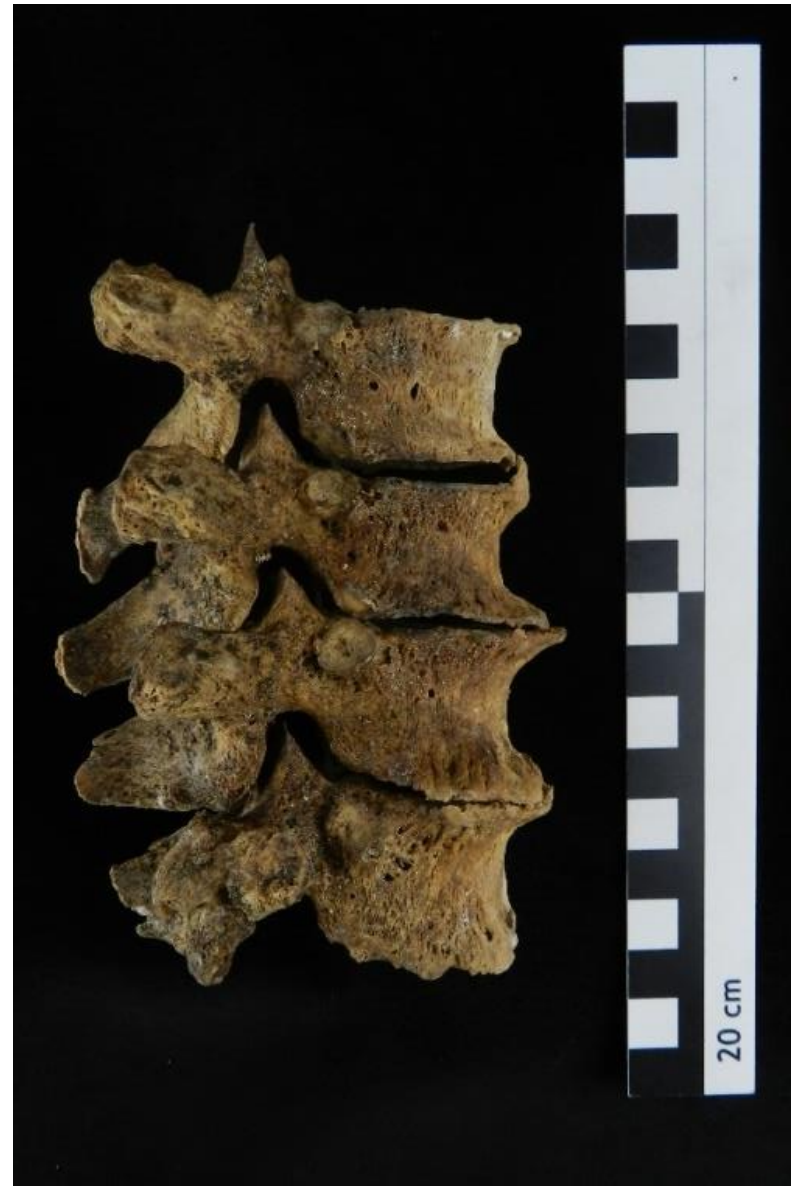

Abb. 60: Spondylosis der Brustwirbel, Ansicht von links. Fundnummer 85, männlich, 50 - 70 Jahre.
Es wurde getestet, ob sich die Mittelwerte der Bewertungsziffern der Bewegungssegmente im Bereich der Wirbelkörper zwischen den Gruppen (siehe Abbildung 61) unterscheiden. Der Test zeigte, dass es keinen Unterschied $(U=255 ; p=0,5)$ in der Arthroseintensität zwischen den Gruppen gibt. Beide Gruppen zeigen eine geringe bis mittlere Arthroseintensität über alle Bewegungssegmente hinweg.

Anhand der Diagramme lässt sich erkennen, dass in allen untersuchten Szenarien, sichtbar in Abbildung 62 bis 64, die Arthroseintensität mit dem Alter für alle Bewegungssegmente steigt. Lediglich die weiblichen Anatomieleichen konnten aufgrund der geringen Anzahl $(n=2)$ statistisch nicht untersucht werden.

Die Unterschiede zwischen den Altersklassen sind in der Gruppe der weiblichen Regelbestattungen ( $\mathrm{H}=45,52 ; \mathrm{p}<0,001)$, in der Gruppe der männlichen Regelbestattungen ( $\mathrm{H}$ $=79,47 ; \mathrm{p}<0,001)$ und in der Gruppe der männlichen Anatomieleichen $(\mathrm{H}=63,20 ; \mathrm{p}<0,001)$ statistisch höchst signifikant. 


\section{Wirbelkörper}

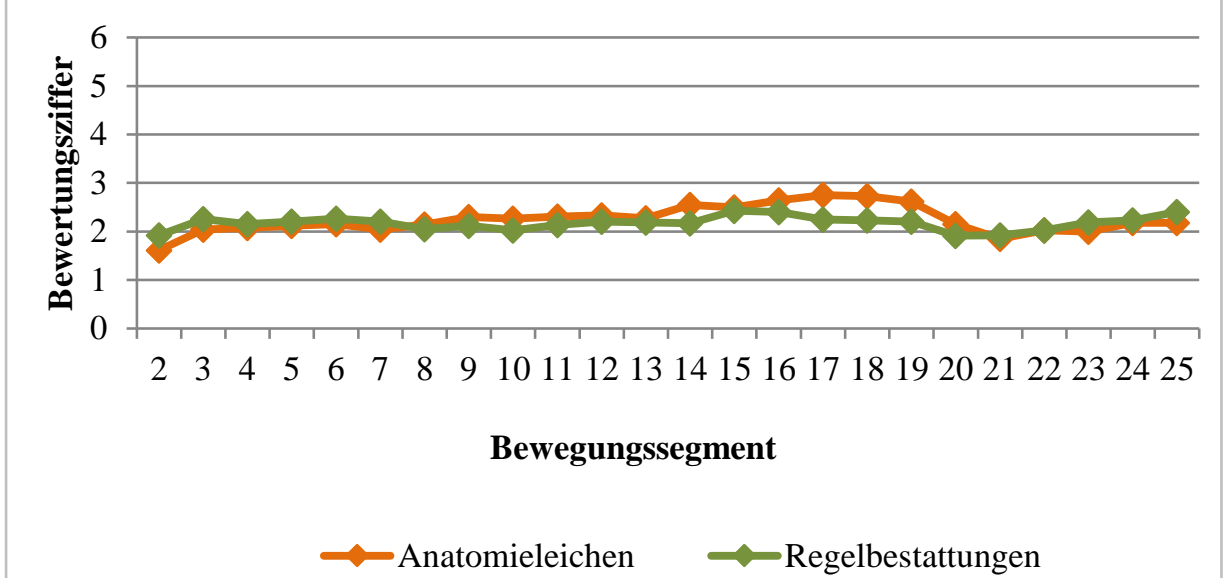

Abb. 61: Bewertungsziffern für jedes Bewegungssegment (Arthroseintensität) in der Gruppe der Anatomieleichen und Regelbestattungen.

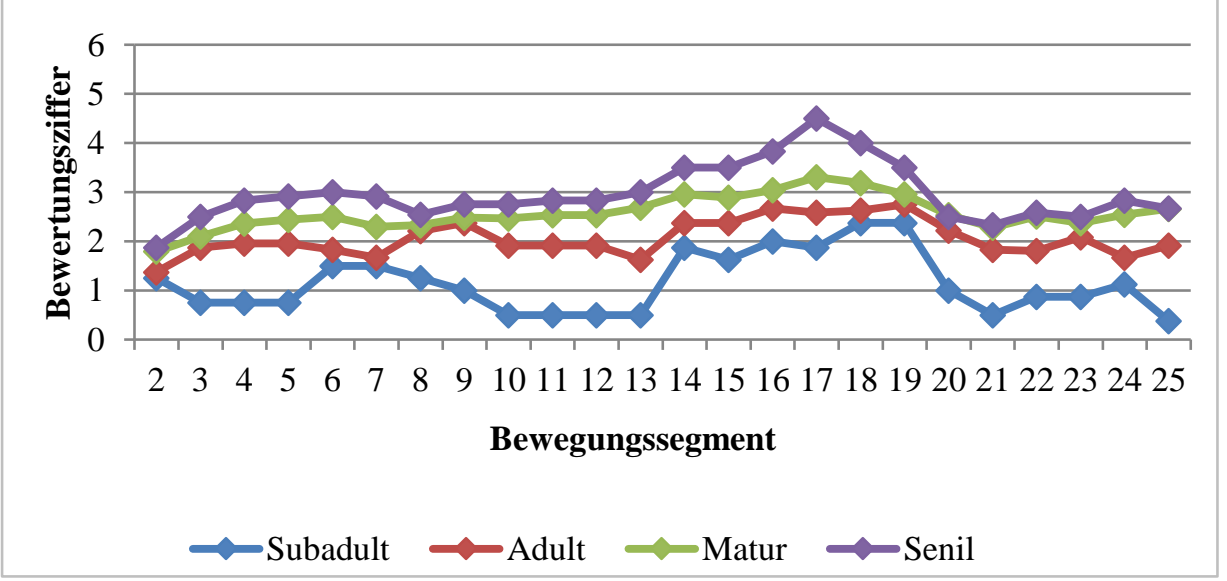

Abb. 63: Mittelwerte aller Bewertungsziffern für jedes Bewegungssegment

(Arthroseintensität) der männlichen Anatomieleichen $(n=27)$.

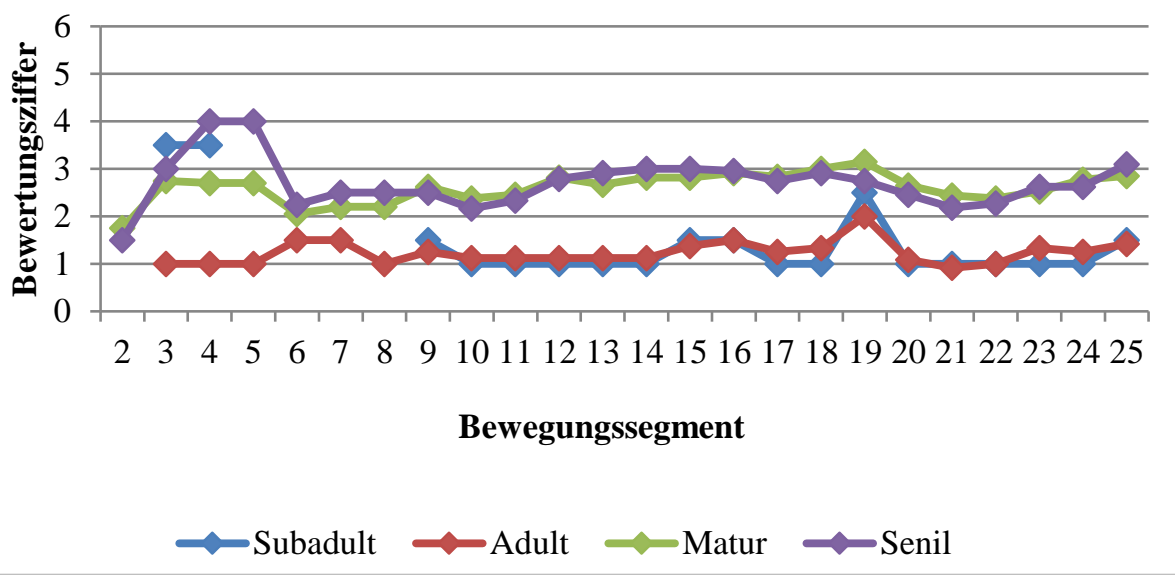

Abb. 62: Mittelwerte aller Bewertungsziffern für jedes Bewegungssegment (Arthroseintensität) der weiblichen Regelbestattungen $(n=18)$.

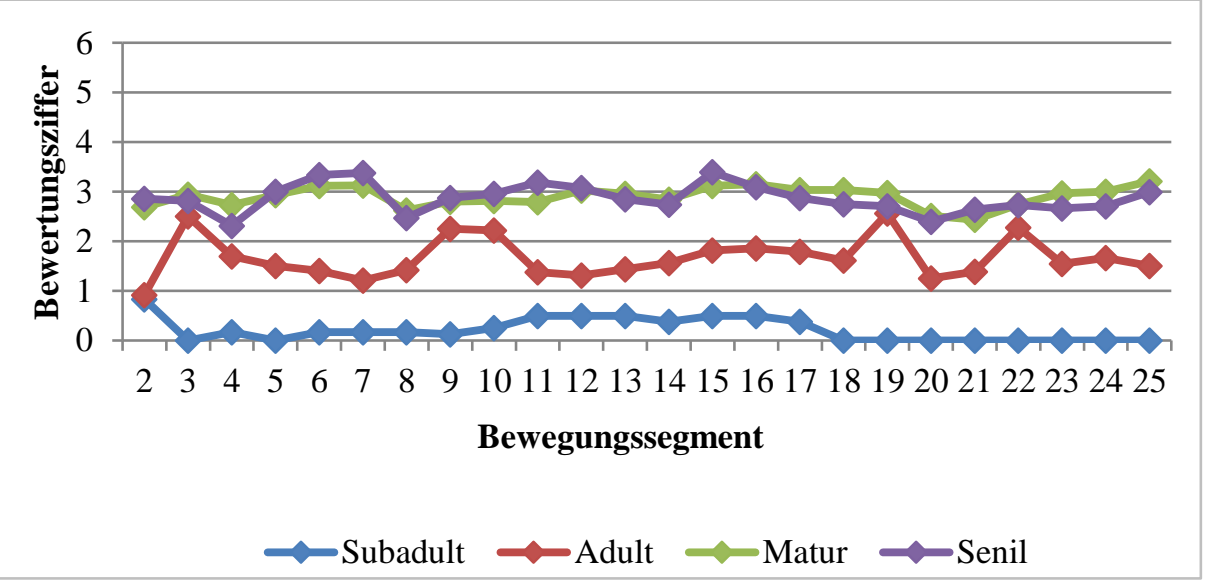

Abb. 64: Mittelwerte aller Bewertungsziffern für jedes Bewegungssegment (Arthroseintensität) der männlichen Regelbestattungen $(n=42)$. 
Vergleich der Arthroseintensität der großen Extremitätengelenke mit der Wirbelsäule

Für den Vergleich der Arthroseintensität wurden ausschließlich Individuen berücksichtigt, welche sowohl beurteilbare Extremitätengelenke als auch Wirbelsäulen aufwiesen.

In der Gruppe der Regelbestattungen $(n=43)$ zeigen drei Individuen in beiden Körperregionen gleich hohe Arthrosewerte und 40 Individuen zeigen 1,2 bis 16-fach höhere Werte in den Bewegungssegmenten (siehe Abbildung 65). Die Regelbestatteten haben im Mittel 2,25-fach stärker abgenutzte und beanspruchte Wirbelsäulen als Extremitätengelenke. Ohne den einmaligen Außreiser (Individuum 80) handelt es sich um einen Mittelwert von 1,93.

In der Gruppe der Anatomieleichen $(n=22)$ gibt es fünf Individuen, deren Extremitätengelenke im Vergleich zu den Bewegungssegmenten der Wirbelsäule minimal stärker oder gleich stark abgenutzt sind (siehe Abbildung 66). 17 Individuen zeigen allerdings eine 1,4 bis 11,25-fach höhere Arthroseintensität in den Bewegungssegmenten. Die Anatomieleichen haben im Mittel 2,3-fach stärker abgenutzte und beanspruchte Wirbelsäulen als Extremitätengelenke. Ohne den einmaligen Außreiser (Individuum 76B) handelt es sich um einen Mittelwert von 1,86.

Bei den Individuen, deren Arthosewerte der Extremitätengelenke und der Wirbelsäule gleich sind, handelt es sich meist um junge Individuen. Die Arthrosewerte liegen ausschließlich zwischen null und eins.

Beide Außreiser sind männlich und der früh- bis spätadulten Altersklasse zuzuordnen.

Zusammenfassend kann festgestellt werden, dass in beiden Gruppen eine deutlich höhere Arthroseintensität in den Wirbelsäulen zu sehen ist als in den Extremitätengelenken. 
Befunde und Ergebnisse - Biologische Daten

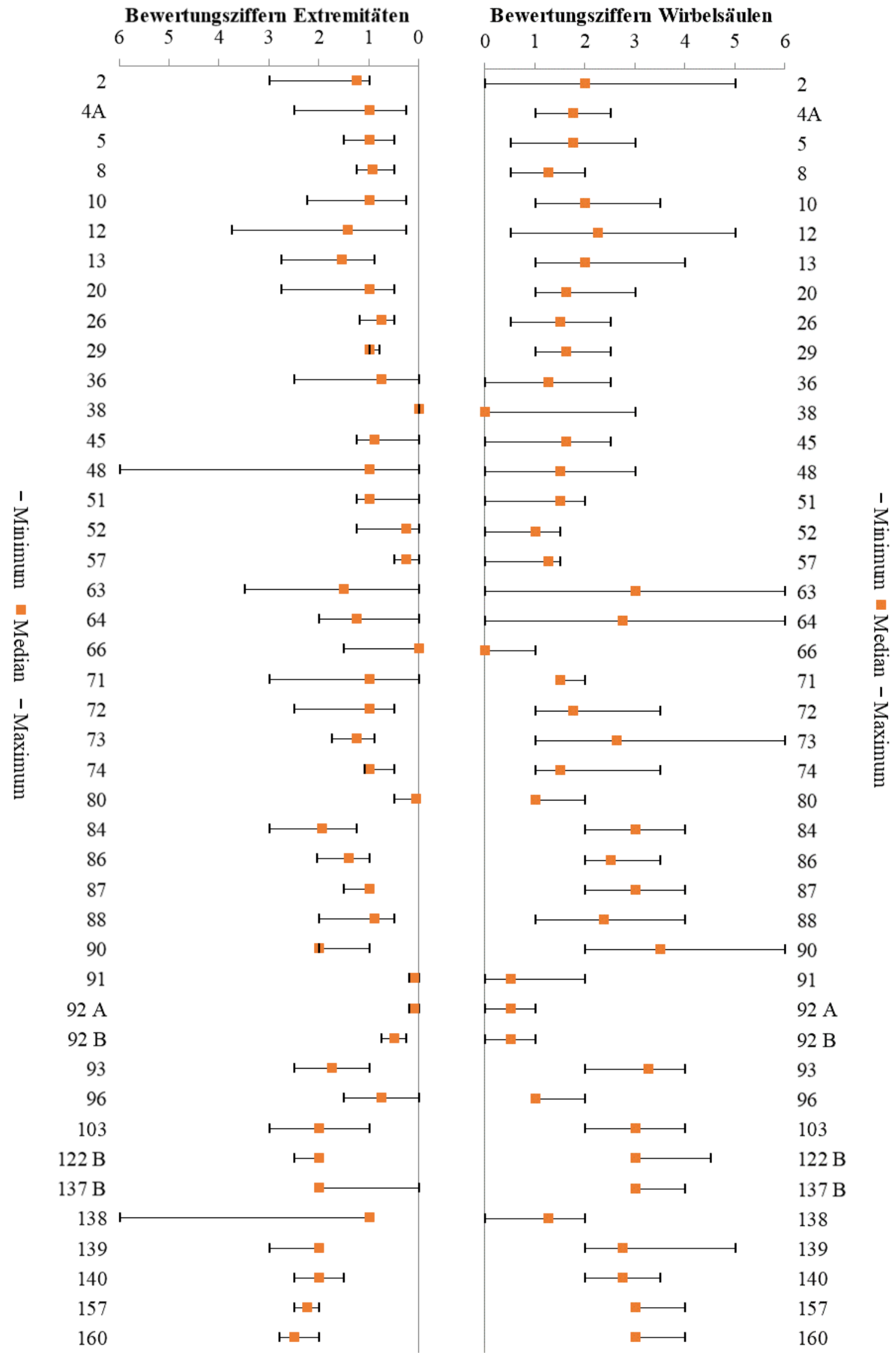

Abb. 65: Regelbestattungen $(n=43)$. Vergleiche der Arthroseintensität von Extremitäten und Wirbelsäulen. 


\section{$\underline{\text { Befunde und Ergebnisse - Biologische Daten }}$}

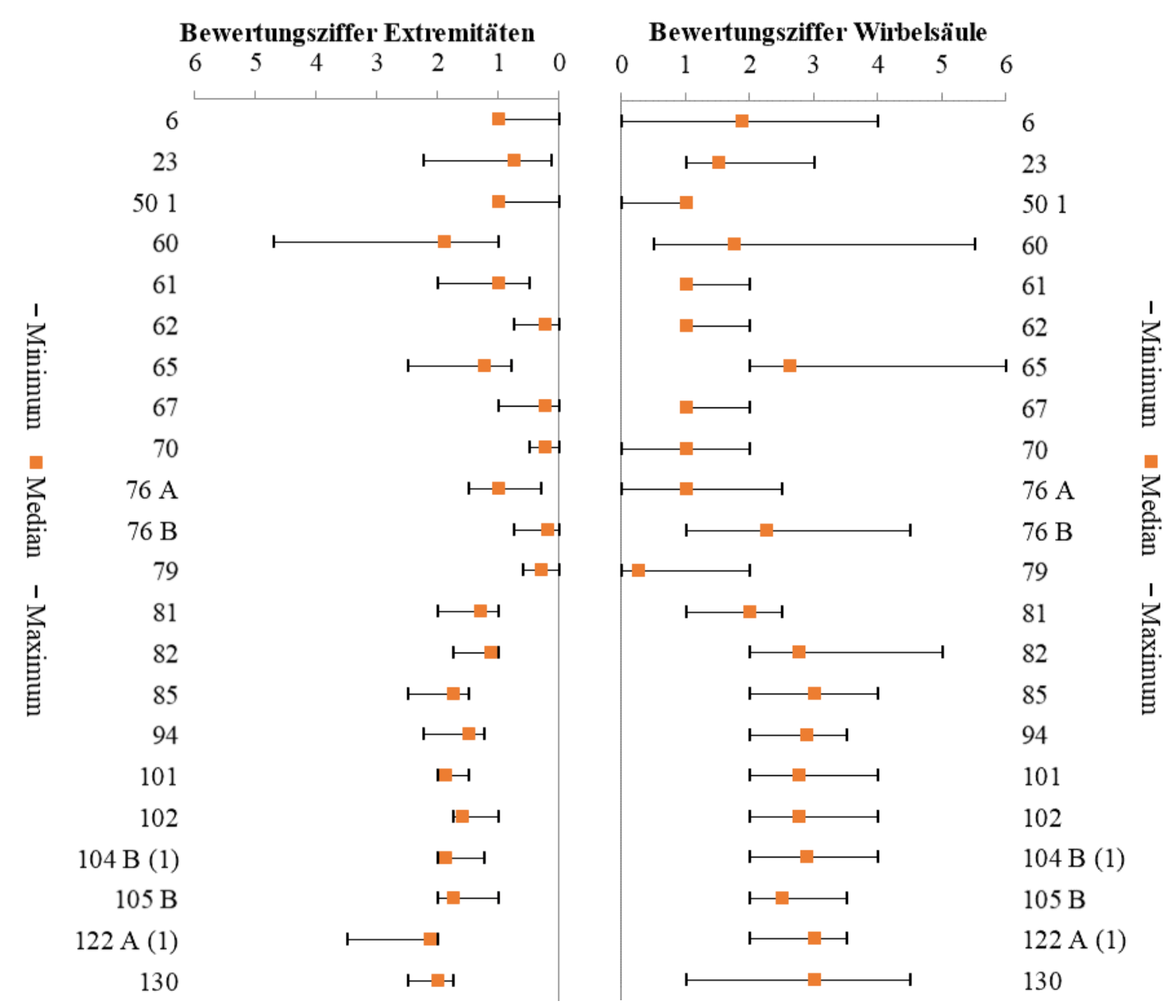

Abb. 66: Anatomieleichen $(n=22)$. Vergleiche der Arthroseintensität von Extremitäten und Wirbelsäulen.

\subsubsection{Erkrankungen der Zähne und Kiefer}

\section{Gruppenspezifische Unterschiede}

In der Gruppe der Anatomieleichen konnten 30 Individuen (728 Zähne) untersucht werden. Es zeigte sich, dass bei den Individuen $\mathrm{n}=381 / 728(52,3 \%)$ der untersuchten Zähne Auflagerungen von Zahnstein aufwiesen. Bei den 65 untersuchten regelbestatteten Individuen (1634 Zähne) wiesen lediglich n = 560/1634 (34,4 \%) der untersuchten Zähne Zahnstein auf. In beiden Gruppen gibt es mit zunehmendem Alter auch eine geringe Zunahme an Zahnstein, wie in den Abbildungen 67 und 68 zu erkennen ist.

$\mathrm{N}=333 / 1634$ (20 \%) der untersuchten Zähne von regelbestatteten Individuen und lediglich n $=111 / 728(15,3 \%)$ der Anatomieleichen weisen Karies auf. Es konnte kein klarer Trend bezüglich der Zunahme mit steigendem Alter nachgewiesen werden. Intravitaler Zahnverlust konnte bei 524/1634 (33,1\%) der regelbestatteten Individuen, aber lediglich bei $\mathrm{n}=108 / 728$ 
$(14,8 \%)$ der Anatomieleichen, beobachtet werden. Der Verlust von Zähnen steigt mit zunehmendem Alter in beiden Gruppen.

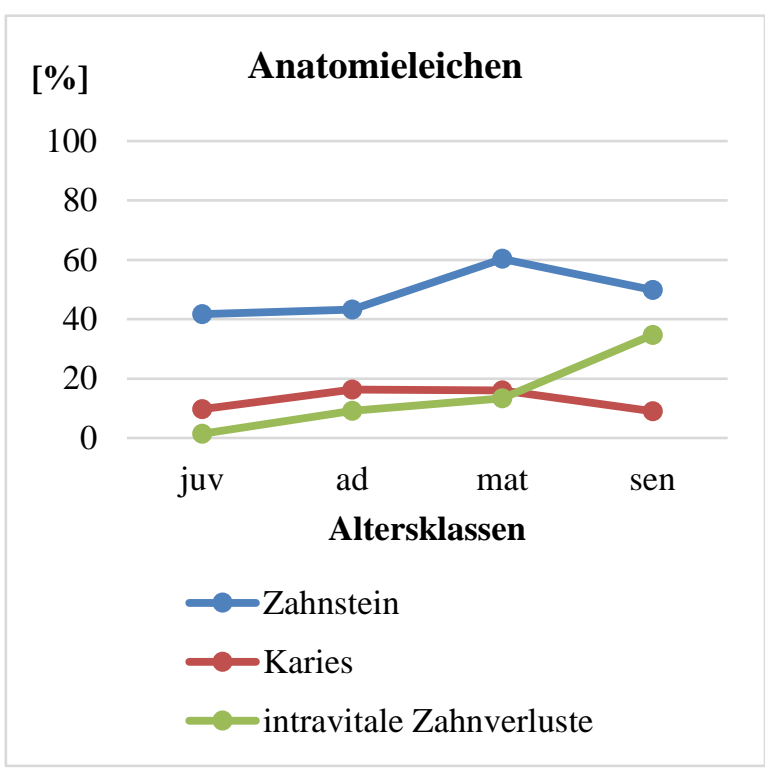

Abb. 67: Erkrankte Zähne in der Gruppe der Anatomieleichen $(n=30)$ in Prozent. Juv = Juvenis, ad $=$ Adultas, mat $=$ Maturitas, sen $=$ Senium.

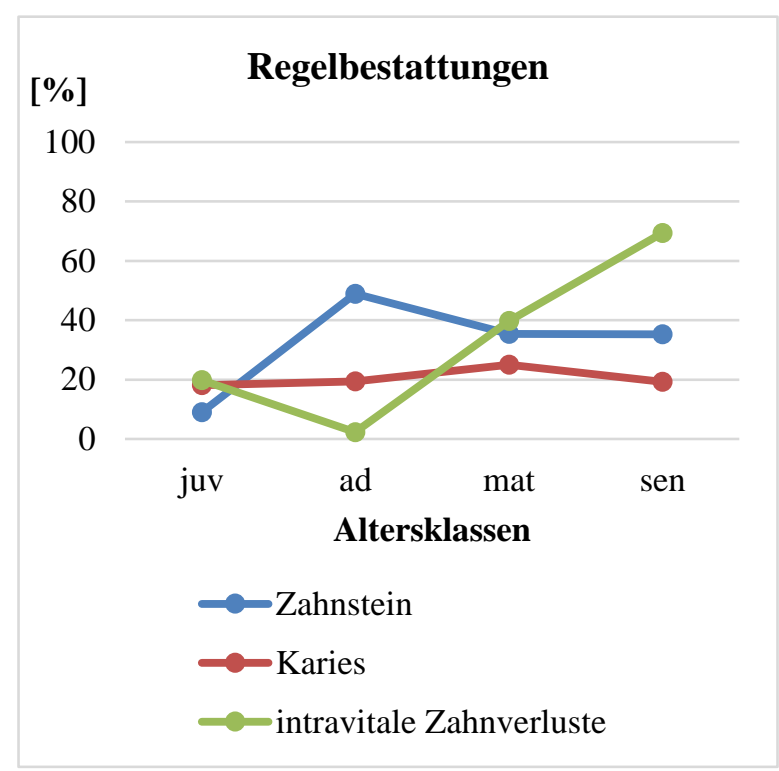

Abb. 68: Erkrankte Zähne in der Gruppe der Regelbestattungen $(n=65)$ in Prozent. Juv = Juvenis, ad $=$ Adultas, mat $=$ Maturitas, sen $=$ Senium .

\section{Geschlechtsspezifische Unterschiede}

Die weiblichen regelbestatteten Individuen hatten anderthalbmal häufiger durch Karies befallene Zähne als die männlichen Individuen. N = 138/504 (27,4 \%) der weiblichen Zähne, aber lediglich $n=182 / 1081(16,8 \%)$ der männlichen Zähne zeigten durch Karies entstandene Löcher unterschiedlicher Größe. Darüber hinaus zeigten sich bei den Frauen mit n =172/504 $(34,1 \%)$ auch geringfügig häufiger intravitale Zahnverluste als bei den Männern mit $\mathrm{n}=$ 352/1081 (32,6 \%). Die männlichen Individuen weisen mit $n=430 / 1081$ (39,8 \%) zweimal häufiger Zahnstein auf als die Weiblichen mit $\mathrm{n}=114 / 504(22,6 \%)$.

Der Vergleich in der Gruppe der Anatomieleichen ist kritisch zu sehen, da lediglich die Zähne von drei weiblichen Individuen mit den Zähnen von 27 männlichen Individuen verglichen werden konnten. Bei weiblichen Anatomieleichen zeigte sich, dass $n=14 / 62(22,6 \%)$ der untersuchten Zähne Karies aufwiesen, aber nur n = 97/666 (14,6 \%) der Zähne von männlichen Individuen waren kariös. Ebenso waren n = 37/62 (59,7 \%) der Zähne weiblicher Individuen von intravitalem Zahnverlust betroffen und lediglich $\mathrm{n}=71 / 666(10,7 \%)$ der Männlichen. $\mathrm{N}=$ 363/666 (54,4 \%) der Zähne der männlichen Individuen wiesen Zahnstein auf, dagegen nur n = 18/62 (29\%) der Weiblichen.

Neben den pathologischen Zahnveränderungen wie Zahnstein, Karies, Abszess und intravitaler Zahnverlust (siehe Abbildung 69A bis 69C) konnten auch Parodontopathien (siehe Abbildung 
69B) und anatomische Varietäten gefunden werden. $\mathrm{Zu}$ nennen sind hier in erster Linie Zahnfehlstellungen, wie sie in Abbildung 69D zu sehen sind. In einem Fall wurde ein ungewöhnlich hoher Gaumen, auch „Gotischer Gaumen“ oder „Wolfsrachen“ genannt, gefunden. Er ist in Abbildung 69E abgebildet.

A

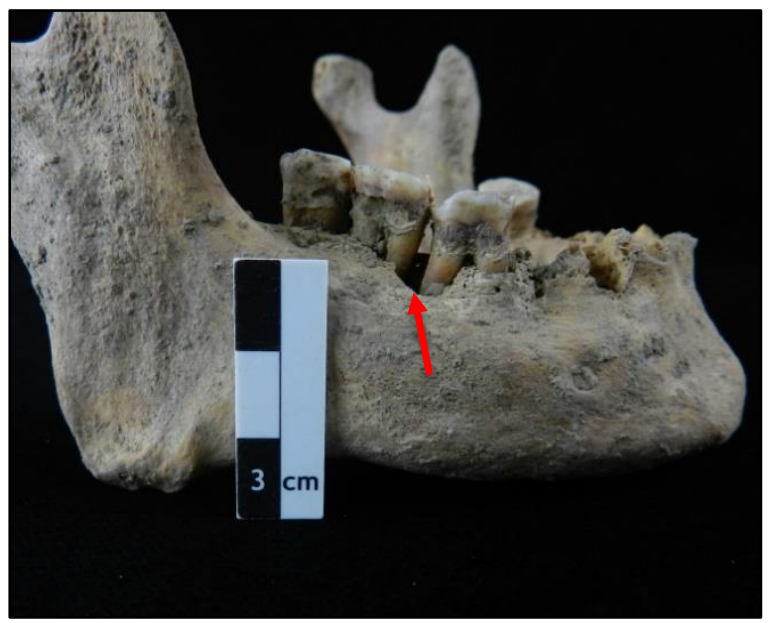

$\mathrm{C}$

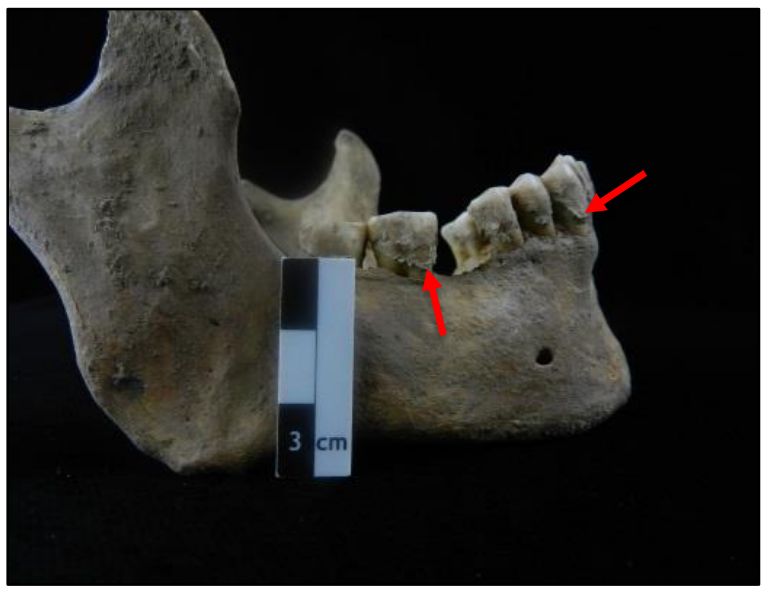

$\mathrm{E}$

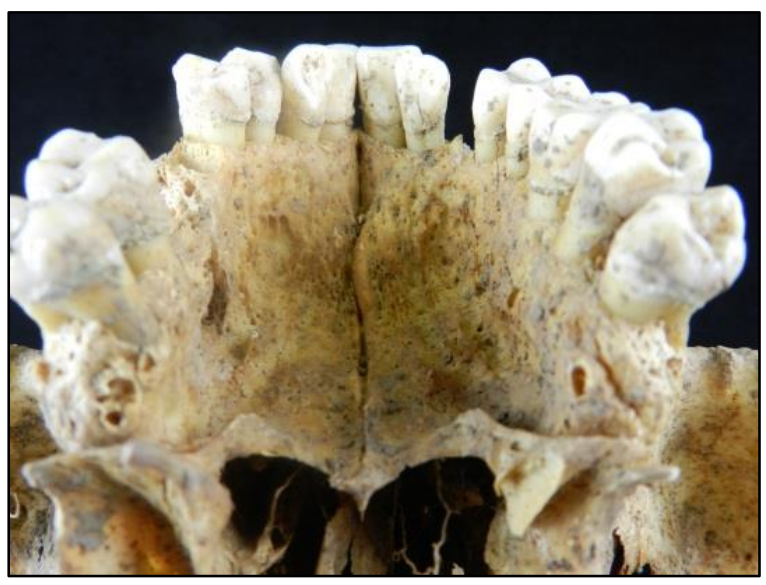

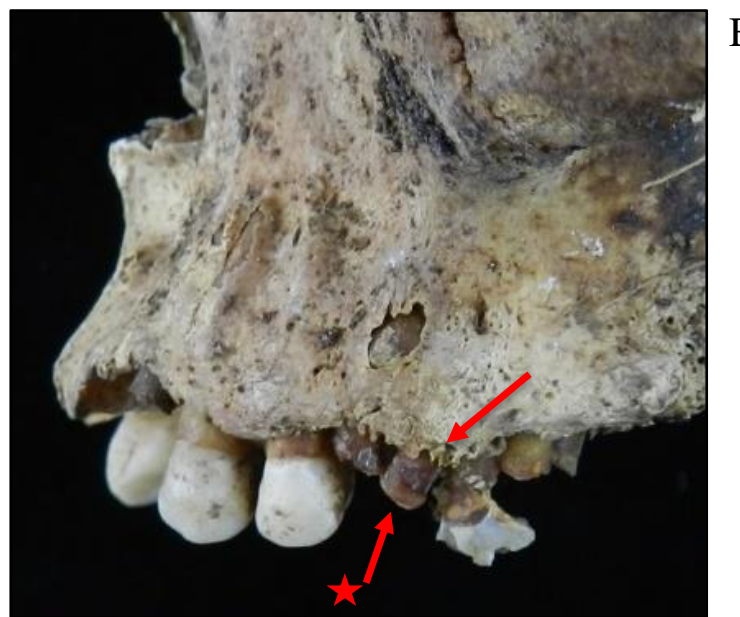

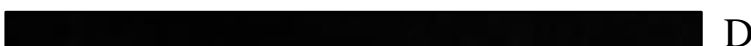

Abb. 69: Zahnerkrankungen und Fehlstellungen. A Abszess (Pfeil). Fundnummer 160, männlich, 50 - 70 Jahre. B Parodontitis (gezackter Alveolarrand, Pfeil) und Karies (fehlende Zahnkrone, Pfeil mit Stern). Fundnummer 36, weiblich, 35 - 40 Jahre. C Intravitaler Zahnverlust, Parodontitis und Zahnstein (Pfeile). Fundnummer 159, männlich, 40 - 60 Jahre. D Verdrehter Prämolar. 35. Fundnummer 43, männlich, 40 - 60 Jahre. E „Gotischer Gaumen“. Fundnummer 159, männlich, 40 - 60 Jahre.

Zusammenfassend kann gesagt werden, dass sich in beiden Gruppen in erster Linie die Fälle von intravitalem Zahnverlust mit steigendem Alter häufen. In beiden Gruppen weisen die männlichen Individuen zweimal häufiger Zahnstein, die weiblichen Individuen anderthalbmal häufiger Karies aber auch intravitale Zahnverluste auf. 


\subsubsection{Weitere Erkrankungen und Veränderungen}

\section{Hydrocephalus internus (Hirndrucksymptomatik)}

Es sind zwei Individuen mit Zeichen einer Hirndrucksymptomatik in Form eines Hydrocephalus internus gefunden worden. Bei dem Individuum 137A (siehe Abbildung 70A und 70B) handelte es sich um ein Kind in der Altersklasse Infans 2, welches molekulargenetisch als männlich bestimmt wurde. Bei dem Individuum 61 (siehe Abbildung 70C und 70D) handelte es sich um einen Mann im maturen Altersbereich.

A

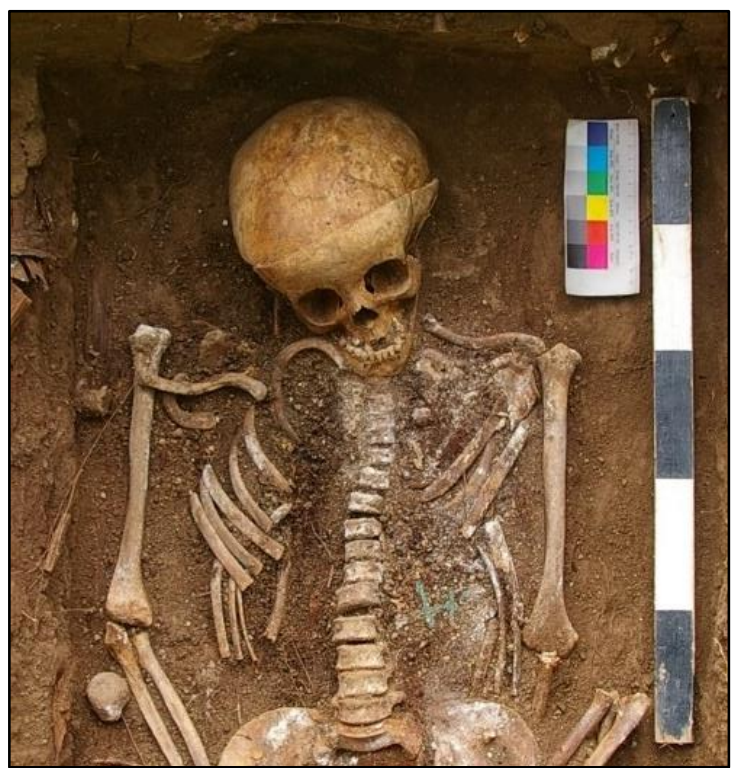

$\mathrm{C}$

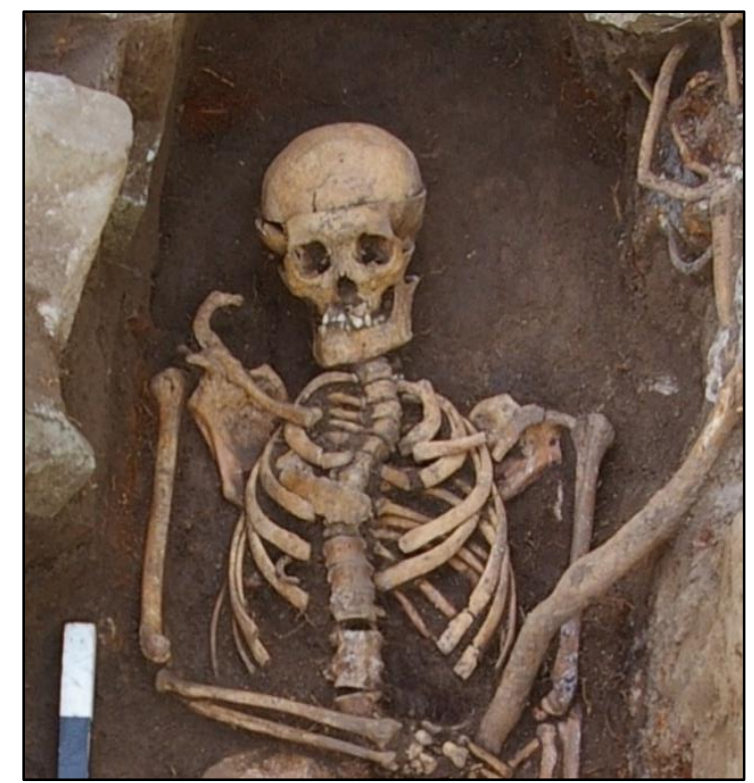

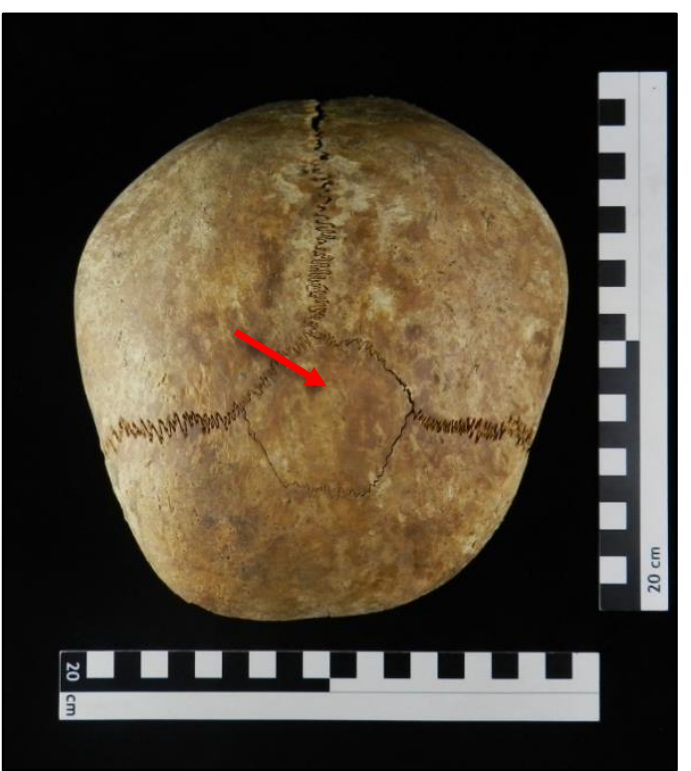

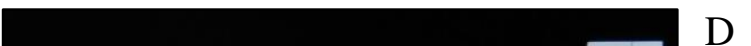

Abb. 70: Hirndrucksymptomatik. A Hydrocephalus. Bild Fa. Arcontor Projekt GmbH. Fundnummer 137A, männlich, 9 Jahre \pm 24 Monate. B Os bregmaticum (Pfeil) in Norma verticalis. Fundnummer 137A. C Hydrocephalus. Bild Fa. Arcontor Projekt GmbH. Fundnummer 61, männlich, 40 - 60 Jahre. D Norma verticalis. Fundnummer 61. 
Beide Individuen sind nach ihrem Tod seziert worden. Es ist zu vermuten, dass diese beiden Individuen aufgrund ihrer äußeren Morphologie bewusst für die Lehrsektionen ausgewählt wurden. Das Individuum 61 zeigt zudem Spuren eines oder mehrerer Traumata (siehe Kapitel 4.1.5 Traumata). Möglich ist, dass im Kindesalter (vor Obliteration der Schädelnähte) ein Trauma überlebt wurde, dessen Folge unter anderem ein gesteigerter intracranialer Hirndruck mit einhergehender Vergrößerung des Schädelvolumens war. Zusätzlich zum Hydrocephalus weist das Individuum 137A ein sehr großes Os bregmaticum auf.

\section{Diffuse idiopathische Skeletthyperostose (DISH)}

Das regelbestattete Individuum 12 weist rechtsseitig auf der anterolateralen Wirbelkörperseite eine kerzenwachsartige Überbrückung (siehe Abbildung 71A) von vier Thorakalwirbeln auf. Des Weiteren hatte das Individuum beidseitig einen oberen Fersensporn (siehe Abbildung 71B). Nahezu alle Sehnenursprünge der Muskeln zeigen knöcherne Umbauten, sogenannte ossifizierte Enthesien. Das beschriebene Krankheitsbild ist in der Literatur als Diffuse Idiopathische Skeletthyperostose (DISH) und Morbus Forestier sowie Morbus Ott (Ottsche Hyperostose) bekannt, erstmalig beschrieben durch Forestier und Rotes-Querol (1950) als "senile ankylosing vertebral hyperostosis". Es handelt sich hierbei um eine systemische, nicht primär entzündliche Skeletterkrankung, die vornehmlich bei älteren Menschen vorkommt. Es kommt zu einer Versteifung der Wirbelsäulenabschnitte, welche einem kerzenwachsartigen Überzug ähnelt. Die genaue Ursache ist bisher unbekannt. Allerdings scheint es genetische Faktoren, aber auch eine Verbindung mit Diabetes mellitus, zu geben (Nascimento et al. 2014). Im Bereich der Linea m. solei (Übersichtsaufnahme siehe Abbildung 71C) wurden Knochendünnschliffe (siehe Abbildung 71D bis 71F) hergestellt, die eine deutliche Verdickung inklusive knöchernem Umbau im Bereich des Muskelansatzes in Zugrichtung aufweisen. Die Aufnahme im polarisierten Licht zeigt, dass der neugebildete Knochen dicht mit Osteonen gepackt ist (siehe Abbildung 71E). Bei dem Individuum handelt es sich um einen Mann im maturen bis senilen Altersbereich, damit passt das Individuum in die beschriebene Risikogruppe. 
A

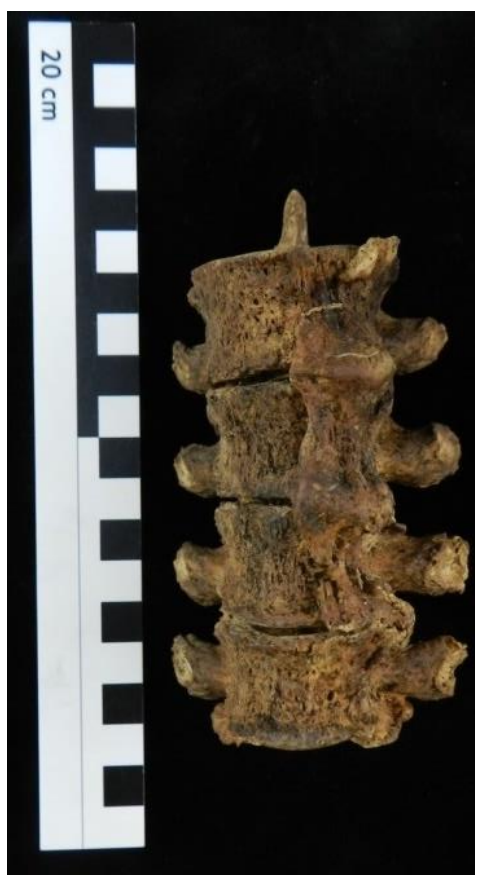

D

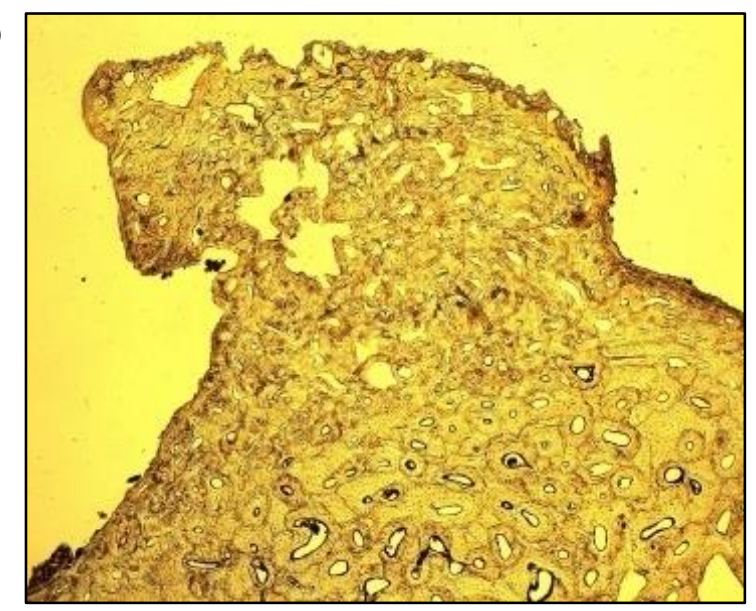

F

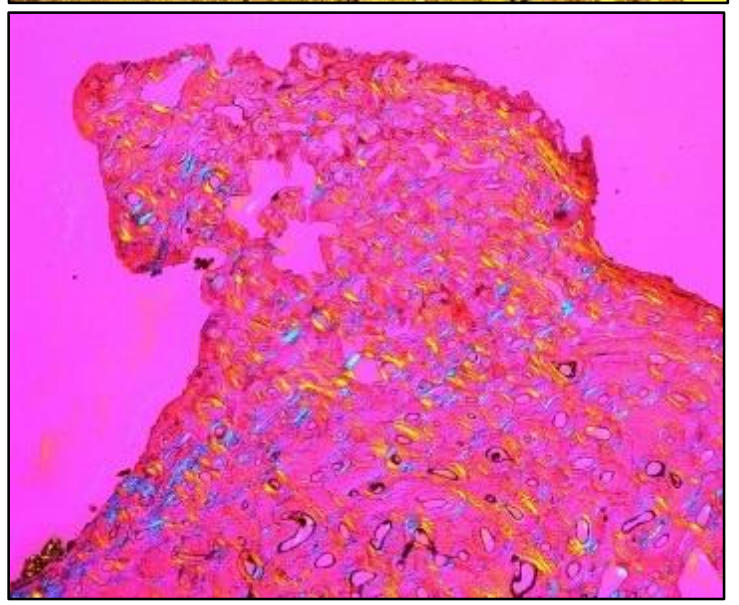

B
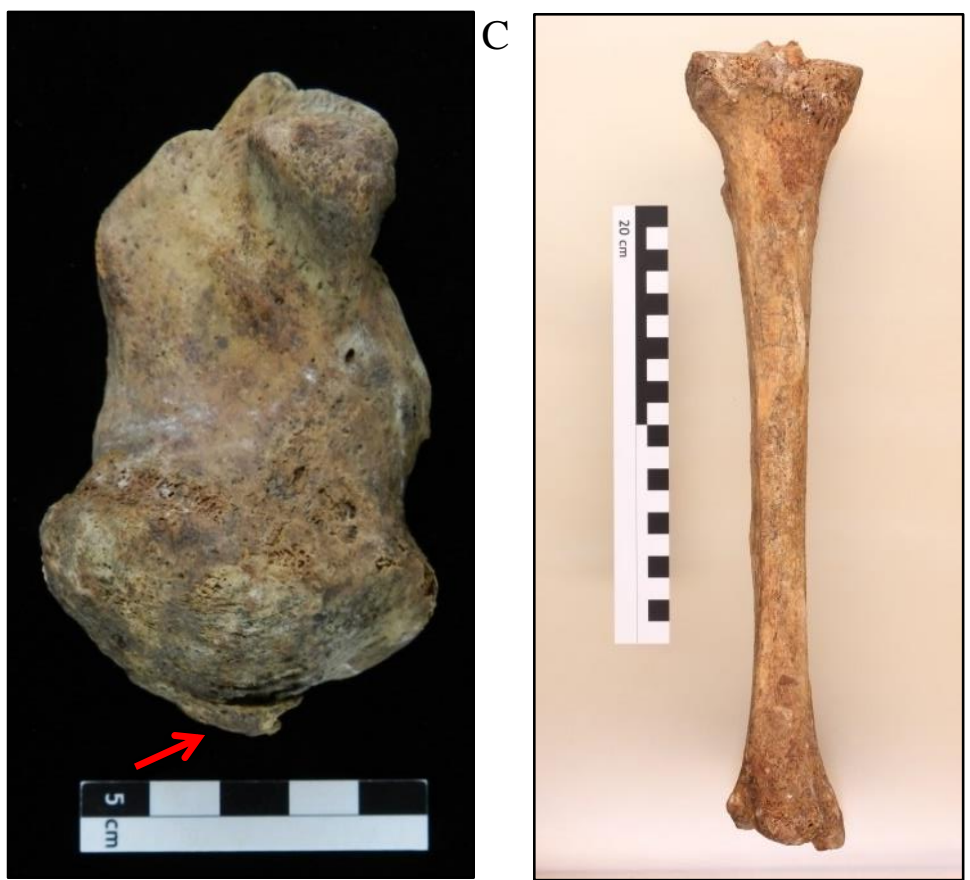

E

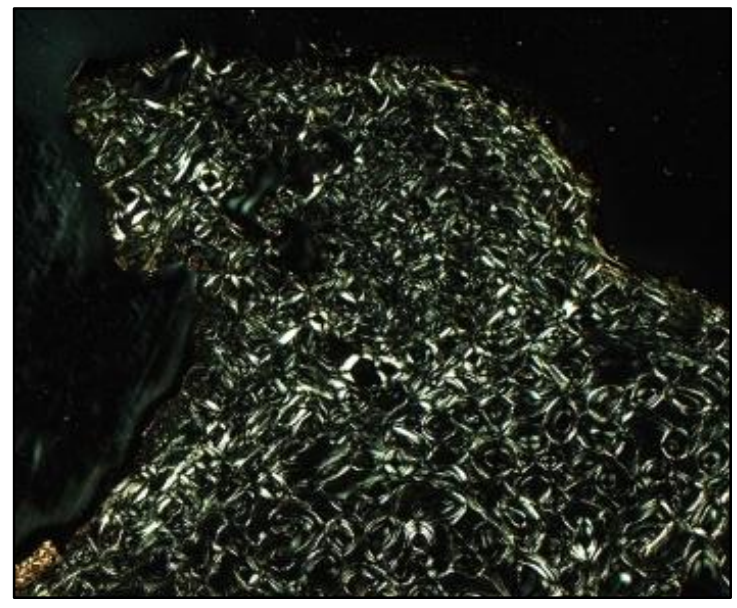

Abb. 71: Diffuse idiopathische Skeletthyperostose (DISH). A Knöcherner Übergang zwischen den unteren Brustwirbeln, ventrale Ansicht. Fundnummer 12, männlich, > 40 Jahre. B Oberer Fersensporn am rechten Calcaneus, mediale Ansicht. C Tibia links, posteriore Ansicht mit prominenter Linea musculi solei. D bis $\mathbf{F}$ Betrachtung mit dem Mikroskop, Tibia links Linea m. solei $50 \mu \mathrm{m}$ Dicke, 16 -fache Vergrößerung. E Im polarisierten Licht. F Im polarisierten Licht unter Verwendung eines Hilfsobjekts Rot 1. Ordnung (Quarz) als Kompensator. Sowohl der ursprüngliche als auch der neu gebildete Knochen sind stark von Diagenese betroffen.

\section{$\underline{\text { Nicht-metrische Variationen }}$}

Das Foramen suprascapularis entsteht durch die Verknöcherung des Ligamentum transversum scapulae superius (Hrdlička 1942, Finnegan 1978). Eine mögliche Ursache für die Verknöcherung des Bandapparates ist die zuvor genannte diffuse idiopathische Skeletthyperostose. Die Ausbildung eines Foramen suprascapularis (siehe Abbildung 72A) im 
Bereich der Incisura scapulae lässt sich sowohl bei beiden Gruppen als auch bei beiden Geschlechtern finden. Hrdlička (1942) fand heraus, dass es nur vereinzelt einen geringen Geschlechter- und Körperseitenunterschied in den Populationen gibt. Betroffen ist in dieser Serie allerdings nur die linke Scapula bei den drei Individuen 26, 97 und 101. Alle Individuen befinden sich im maturen oder senilen Altersbereich.

Ein weiteres Foramen lässt sich am distalen Schaft des Humerus finden. Als mögliche Ursache für die Entstehung des Foramen olecrani wird die zeitweilige mechanische Belastung in Kombination mit einem weniger robusten Humerus diskutiert (Paraskevas et al. 2010). Das Foramen olecrani (siehe Abbildung 72B) ist in dieser Serie in vier Fällen links und in drei Fällen bilateral ausgeprägt. Es gibt keinen Unterschied zwischen den Geschlechtern oder den Gruppen. Betroffen sind die sieben Individuen 6, 29, 32, 43, 81, 92B und 96. Davon befinden sich drei Individuen im adulten, drei im maturen und ein Individuum im senilen Altersbereich. Untersuchungen (Lamb 1890, Singhal und Rao 2007, Paraskevas et al. 2010) haben ergeben, dass der linke Humerus häufiger ein Foramen olecrani aufweist als der rechte.

A

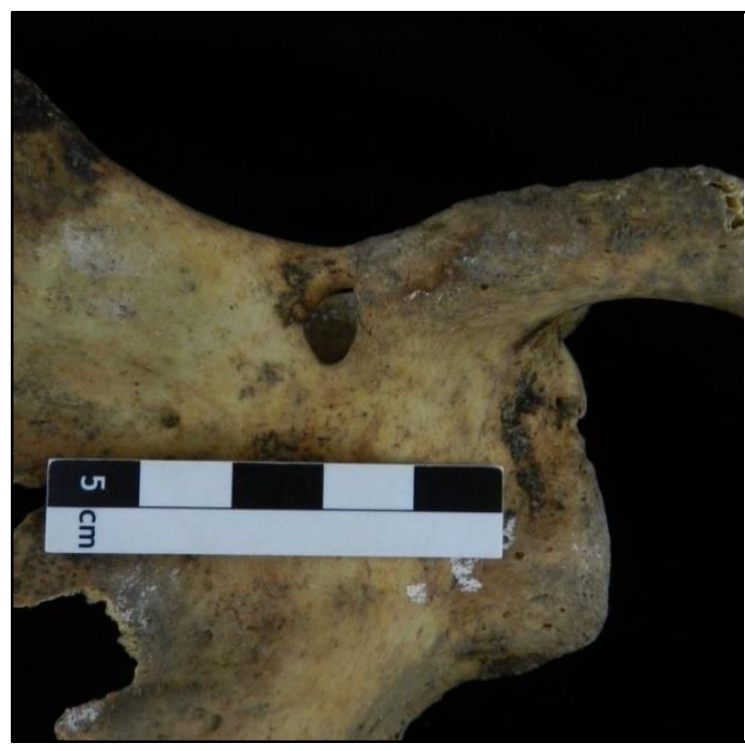

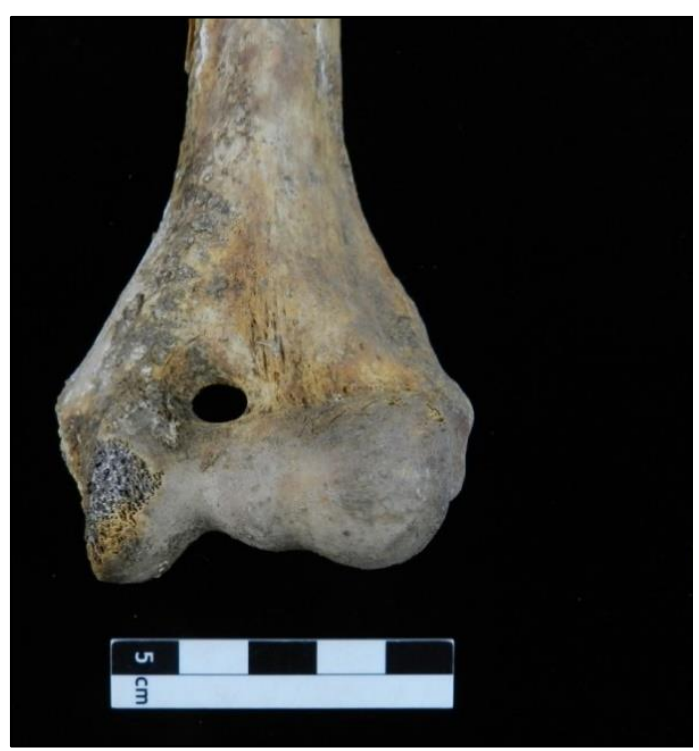

B

Abb. 72: Foramina. A Scapula links, anteriore Ansicht. Foramen subscapulae. Fundnummer 26, männlich, > 60 Jahre. B Humerus links, anteriore Ansicht. Foramen olecrani. Fundnummer 43, männlich, 40 - 60 Jahre. 
Hypertrophische pulmonale Osteoarthropathie

Das regelbestattete Individuum 90 zeigt ausgeprägte Anzeichen einer hypertrophischen pulmonalen Osteoarthropathie. In Abbildung 73 sind die betroffenen Stellen grün markiert. Ein Syndrom, das erste Mal beschrieben durch Bamberger $(1889,1891)$ und Marie (1890), welches Knochenneubildungen auf der Oberfläche und in der Compacta der Diaphysen, trommelschlegelartig verbreiterte Finger und Zehen sowie Uhrglasnägel umfasst. Dem Syndrom liegt heute meist ein Bronchialkarzinom zugrunde und kann nach erfolgreicher Behandlung der Primärerkrankung vollständig abklingen (Fietz et al. 1998).

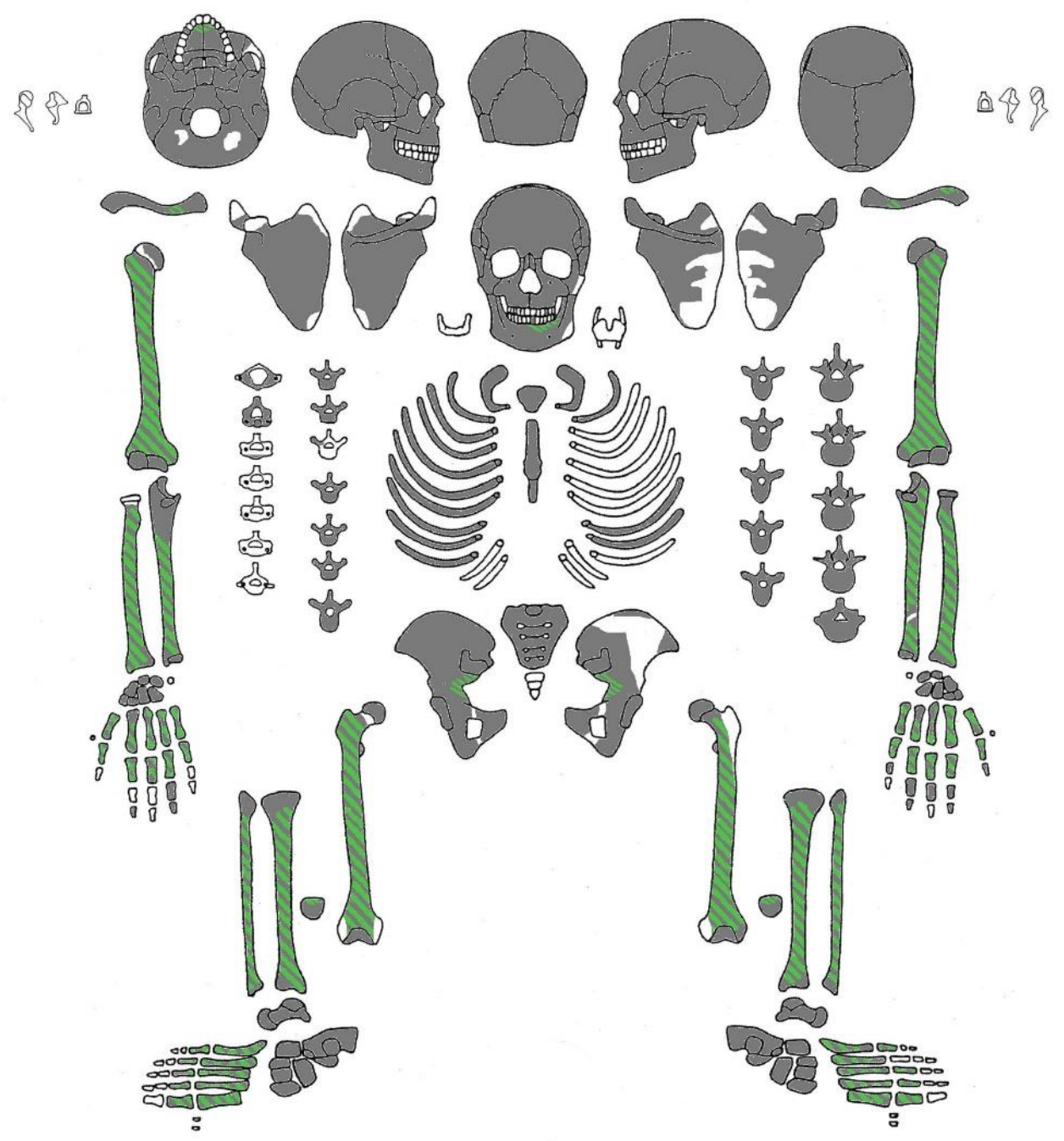

Abb. 73: Hypertrophische pulmonale Osteoarthropathie. Skelettschema, grauschatiert sind die erhaltenen Knochen, grüngestreift sind die mit Knochenneubildungen überzogenen Bereiche. Fundnummer 90, weiblich, 50 - 70 Jahre. 
A

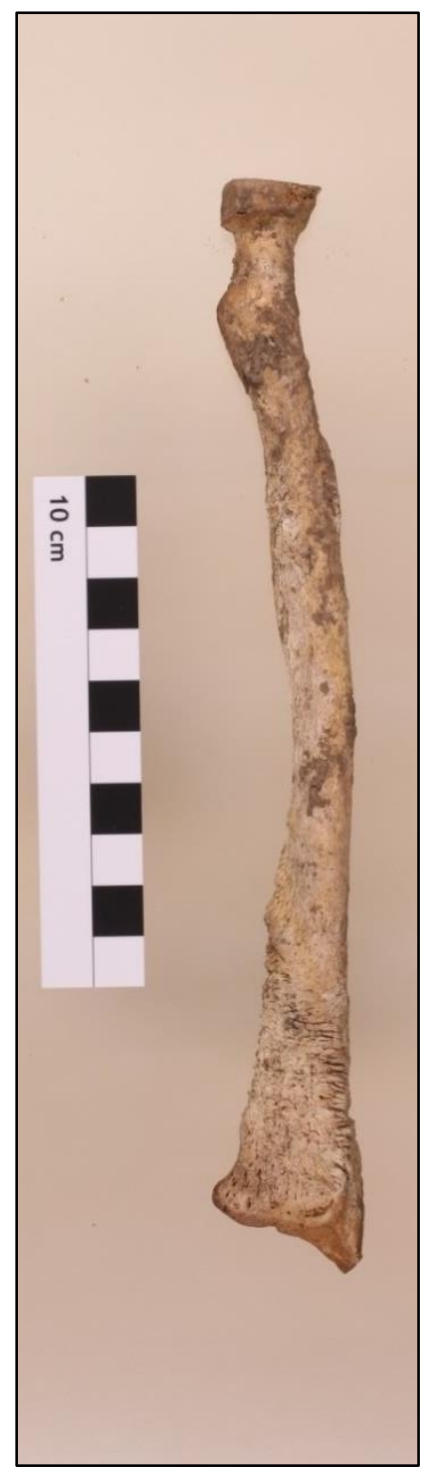

B

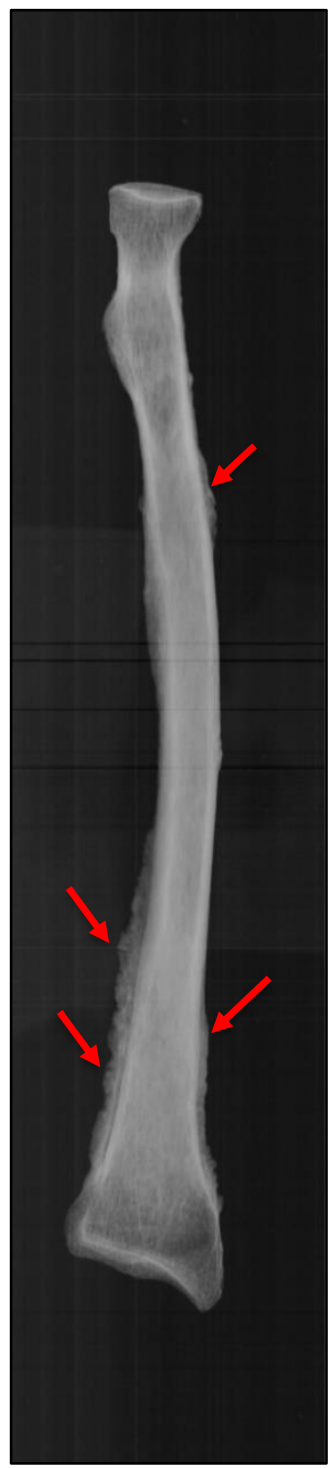

$\mathrm{C}$

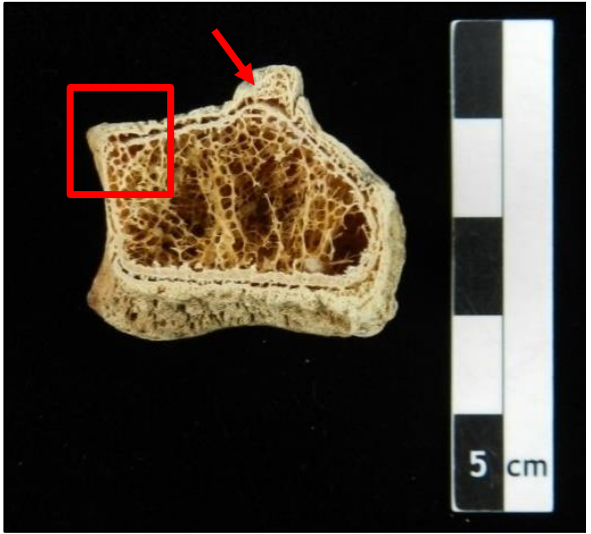

$\mathrm{D}$

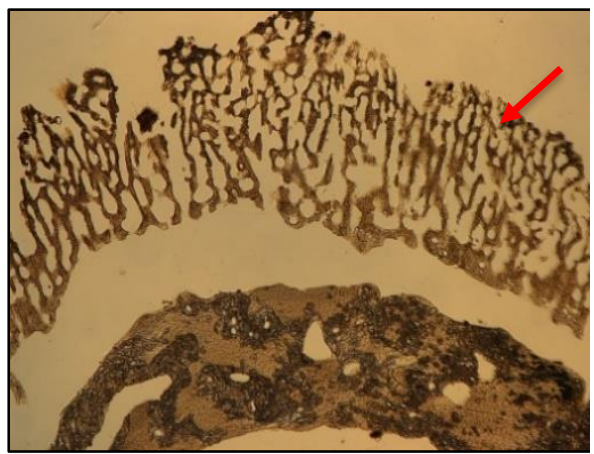

$\mathrm{E}$

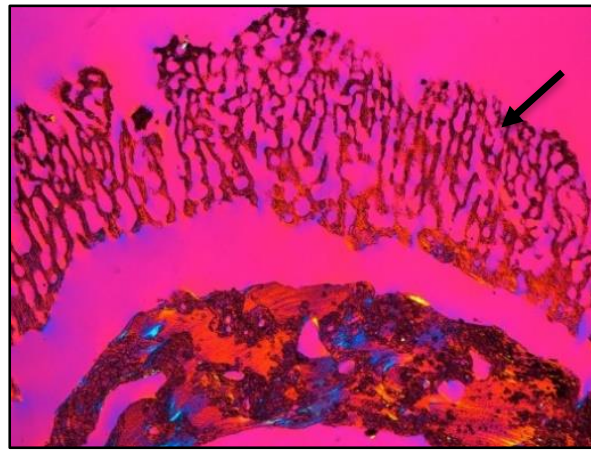

Abb. 74: Hypertrophische pulmonale Osteoarthropathie. A und B Radius links, anteriore Ansicht. Fundnummer 90, weiblich, 50 - 70 Jahre. B Röntgenbild, neu gebildete Knochenschicht (Pfeile). C Radius links, Querschnitt durch das distale Diaphysenende. Auflagerung einer neuen Knochenschicht (Pfeil und umrandet, Vergrößerung Abb. 74D und 74E). D und E Betrachtung mit dem Mikroskop, Radius links $70 \mu \mathrm{m}$ Dicke, 25-fache Vergrößerung. E Im polarisierten Licht unter Verwendung eines Hilfsobjekts Rot 1. Ordnung (Quarz) als Kompensator. Sowohl der ursprüngliche als auch der neu gebildete Knochen sind stark von Diagenese betroffen.

Die Abbildung 74A zeigt die unregelmäßige Oberfläche des Knochens, hier als Beispiel der linke Radius. Im Röntgenbild (siehe Abbildung 74B) ist zu erkennen, dass es sich bei der Knochenneubildung um eine Auflagerung handelt. Zwischen dem neuen Knochen und der ursprünglichen Langknochendiaphyse befindet sich ein Spalt. Sowohl in der Übersichtsaufnahme der aufgesägten Radiusdiaphyse (siehe Abbildung 74C) als auch im Dünnschliffpräparat (siehe Abbildung 74D und 74E) lässt sich deutlich die neugebildete Schicht erkennen. Es können sich eine oder mehrere Schichten auflagern, je nach Dauer der Erkrankung. Bei dem betroffenen Individuum handelt es sich um eine Frau im maturen bis senilen Altersbereich. Sie zeigt die oben genannten Auflagerungen an allen 
Langknochendiaphysen, den Ossa coxae sowie den Hand- und Fußknochen. Zusätzlich lassen sich an der Wirbelsäule zudem deutliche Anzeichen von Spondylosis und Spondylarthrosis erkennen. Die Brustwirbelsäule ist skoliotisch (Wirbelrotation mit Wirbelkörpertorsion nach rechts) gekrümmt und die Brustwirbel Th3 - Th4 und Th9 - Th11 sind miteinander verwachsen.

Da das Syndrom bei chronischen Herz-Kreislauf- und Lungenerkrankungen vorkommt, muss hier auch an eine Lungentuberkulose gedacht werden. Allerdings gab es im Bereich des Sulcus pulmonalis keine Knochenneubildungen, die auf einen entzündlichen Prozess der Pleura hindeuten.

In seltenen Fällen kann es sich bei den beschriebenen Symptomen auch um eine primär hypertrophische Osteoarthropathie (Touraine-Solente-Golé Syndrom) handeln. In dem Fall liegt der Krankheit eine Genmutation auf dem vierten Chromosom zugrunde. Diese Möglichkeit kann bei dem Individuum 90 nicht vollständig ausgeschlossen werden, da es keine morphologischen Anzeichen einer Lungenerkrankung auf den Innenseiten der Ossa costalia gibt.

\section{$\underline{\text { Morbus Scheuermann }}$}

Bei der Scheuermann-Krankheit (auch Adoleszentenkyphose, Morbus Scheuermann oder Osteochondritis deformans juvenilis dorsi) handelt es sich um eine Wachstumsstörung mit anschließender Fehlbildung der Wirbelsäule („Rundrücken“). Die Scheuermann-Krankheit bildet sich in der Pubertät und kommt bei Jungen vier- bis fünfmal häufiger vor (Dihlmann 1987). Die knorpeligen Wirbelkörperabschlussplatten sind dabei „,biologisch minderwertig“ (Dihlmann 1987). Anzeichen sind Brustkyphose, keilförmige Wirbelkörper, Schmorlsche Knorpelknötchen und Irregularitäten der Abschlussplatten (Dihlmann 1987). Durch die Biegebelastung der unteren Wirbelsäule bei gleichzeitig schwacher Rückenmuskulatur kommt es zu einer ungleichmäßigen Belastung der Brustwirbelkörper (Th4 - Th12) und Lendenwirbelkörper. Daraus resultieren Schäden an den Knorpel-Knochen-Verbindungen der Deck- und Grundplatten der Wirbelkörper. Das Bandscheibenmaterial bildet Schmorlsche Knorpelknötchen, welche wiederum Impressionen auf den Wirbelplatten hinterlassen. Sowohl die Schmorlschen Knorpelknötchen selbst als auch deren Impressionen im Knochen sind beschwerdefrei. Allerdings werden im Rahmen der Scheuermann-Krankheit oft Rückenschmerzen beklagt, bedingt durch Verspannungen aufgrund einer schwachen, untrainierten Rückenmuskulatur. Die Wachstumszone an den Wirbelkörperkanten wird beschädigt, wodurch die Wirbelkörper vorne langsamer wachsen und sich keilförmig entwickeln können. In Abbildung 75 sind die Thorakalwirbel des Individuums 79 
(Anatomieleiche) zu erkennen. Auf den Deck- und Grundplatten sind die Impressionen der Schmorlschen Knorpelknötchen, teilweise dorsal mit Abdrücken eines Bandscheibenprolaps, zu erkennen. Das Individuum ist männlich und 17 - 20 Jahre.

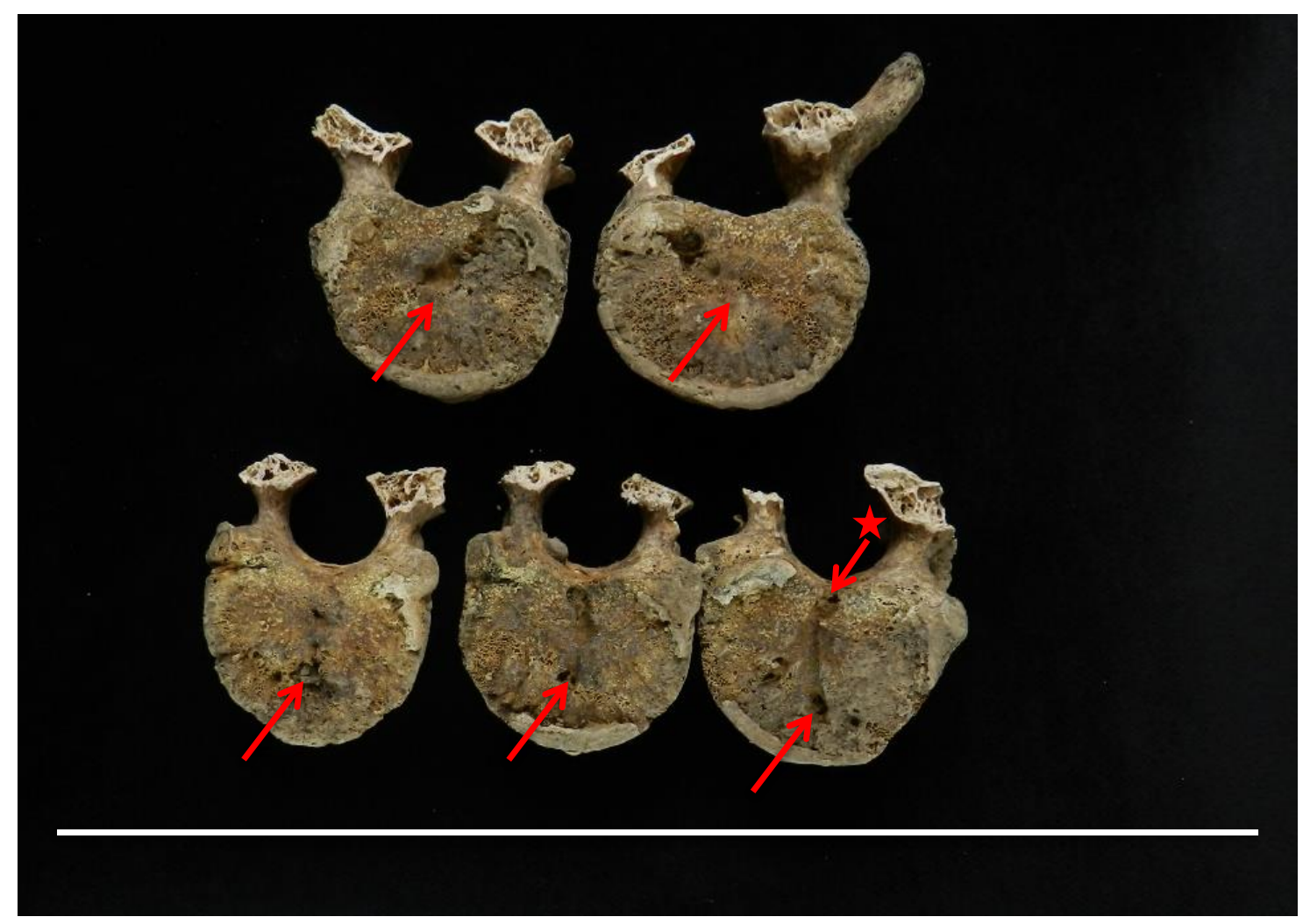

Abb. 75: Morbus Scheuermann. Grundplatten von Thorakalwirbeln, caudale Ansicht, Strich entspricht $30 \mathrm{~cm}$. Abdrücke Schmorlscher Knorpelknötchen (Pfeil), Spuren eines dorsalen Bandscheibenprolaps (Pfeil mit Stern). Fundnummer 79, männlich, 17 - 20 Jahre. 


\subsubsection{Traumata}

\section{$\underline{\text { Frakturen }}$}

Drei Anatomieleichen (6, 85 und 100) und sechs Regelbestattete (2, 40, 48, 64, 75 und 78 B) weisen Anzeichen traumatischer Geschehen auf. In Tabelle 4 sind die betroffenen Individuen mit den jeweiligen Verletzungen aufgelistet. Frakturen der Rippen treten gehäuft auf, da diese, z. B. im Vergleich zu den Langknochen, weniger robust sind. Das Individuum 2 zeigt Anzeichen einer verheilten Fraktur der rechten Ulna (siehe Abbildung 76B) und einer massiven Schulterverletzung im Bereich des Tuberculum majus (siehe Abbildung 76A). Bei einer Fraktur in dieser Region wird es vermutlich begleitend $\mathrm{zu}$ einer Rotatorenmanschettenläsion gekommen sein.

A

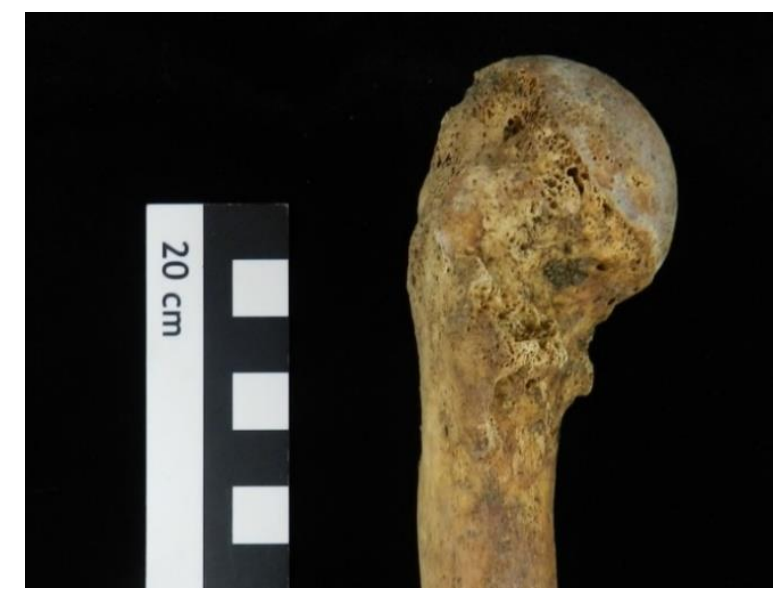

$\mathrm{C}$

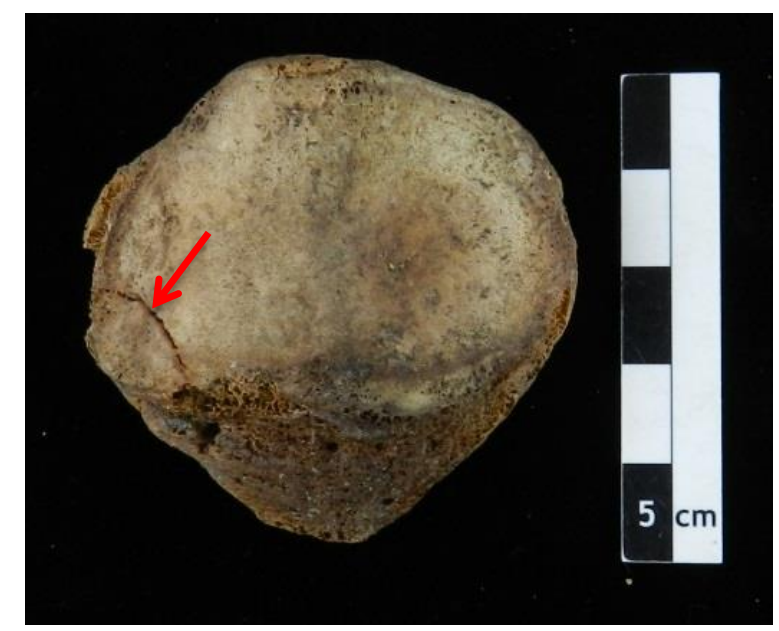

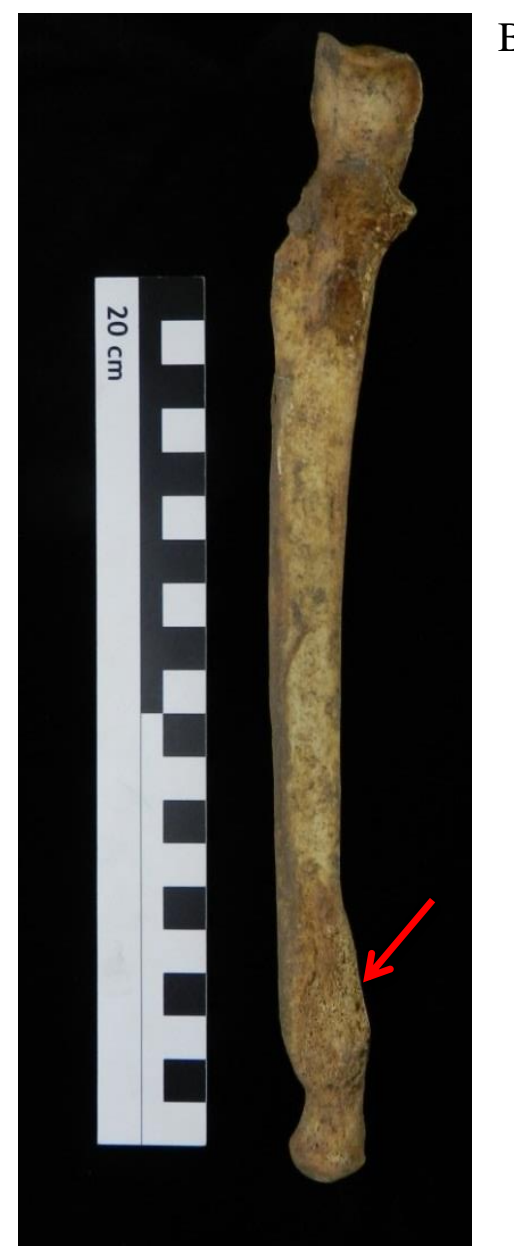

B

Abb. 76: Verheilte Spuren traumatischer Geschehen. A Humerus links, posteriore Ansicht. Fundnummer 2, männlich, > 60 Jahre. B Ulna rechts, anteriore Ansicht, Kallusbildung (Pfeil). Fundnummer 2, männlich, > 60 Jahre. C Patella rechts, posteriore Ansicht, Fraktur (Pfeil). Fundnummer 75, männlich, 50 - 60 Jahre. 
Tab. 4: Individuen, welche verheilte Knochenfrakturen bzw. Traumata aufweisen. AL = Anatomieleiche.

\begin{tabular}{|l|l|}
\hline Individuum & Frakturbereich \\
\hline \hline 2 & Os costale, rechte Ulna und linker Humerus \\
\hline $6 \mathrm{AL}$ & Corpus sterni \\
\hline 40 & rechtes Os femoris \\
\hline 48 & Acetabulum, rechtes Caput femoris, rechter Talus \\
\hline 64 & Os costale \\
\hline 75 & rechte Patella (siehe Abbildung 76C) \\
\hline $78 \mathrm{~B}$ & Beide Ossa nasalia und linke Os costale \\
\hline $85 \mathrm{AL}$ & Corpus sterni, mehrere rechte und linke Ossa costalia \\
\hline $100 \mathrm{AL}$ & drei Ossa costalia \\
\hline
\end{tabular}

Das Individuum 48, welches, wie im Kapitel 4.2 „Grabbeigaben, Beifunde und Sozialstatus“ beschrieben, mit Samthaube gefunden wurde, zeigt Anzeichen eines Traumas im Hüftbereich. Das Individuum (siehe Abbildung 77A) ist männlich, zwischen 60 - 80 Jahre alt und gehört zu der Gruppe der Regelbestattungen. Wie in Abbildung 77B deutlich wird, hat bei der Ausgrabung ein Bruchgurt/-band im Bereich der Leisten gelegen. Laut dem archäologischen Befundbogen bestand es aus Holz mit Eisen und Lederfragmenten sowie Buntmetallnägeln. Oft wurde in Folge einer Leistenhernie das Tragen eines Bruchbands verordnet. Die operative Behebung eines Vorfalls wurde erst Ende des 19. Jahrhunderts vereinzelt eingeführt (Schumpelick et al. 2015). Leistenbrüche und Bauchwandbrüche waren im 19. Jahrhundert eine sehr häufige Erkrankung. Die Ursache sind laut Kuna (2014) in den Lebensbedingungen, wie schwere körperliche Arbeit, mangelnde Bewegung, einseitige Ernährung, einer Vielzahl an Schwangerschaften, erbliche Vorbelastung oder altersbedingte Gewebeschwäche zu suchen. Aufgrund der regionalen Nähe ist zu vermuten, dass der Leistenbruch zur selben Zeit wie das Trauma des rechten Acetabulum geschehen ist. Das rechte Caput femoris (siehe Abbildung 77C) ist vollständig durch Arthrose (Grad VI) verformt. Die Ränder sind pilzförmig ausgezogen, das eigentliche Caput ist stark in die Länge gezogen und auf seiner Oberfläche eburniert. Der Centrum-Collum-Diaphysen-Winkel liegt unter $120^{\circ}$ und entspricht demnach einer Coxa vara. Die Linea intertrochanterica ist entzündlich verändert. Die rechte Fossa acetabuli, die Facies lunata und der Acetabulumrand sind massiv durch Arthrose (Grad VI) verändert (siehe Abbildung 77D und 77E). Des Weiteren sind Osteophyten rund um das Acetabulum entstanden. Auf der Innenseite des rechten Os coxae im Bereich der Rückseite des Acetabulum ist umgebauter Knochen zuerkennen. Vermutlich litt das Individuum an einer Protrusio acetabuli, bei der sich die der Acetabulumboden in das Becken vorwölbt. 
A

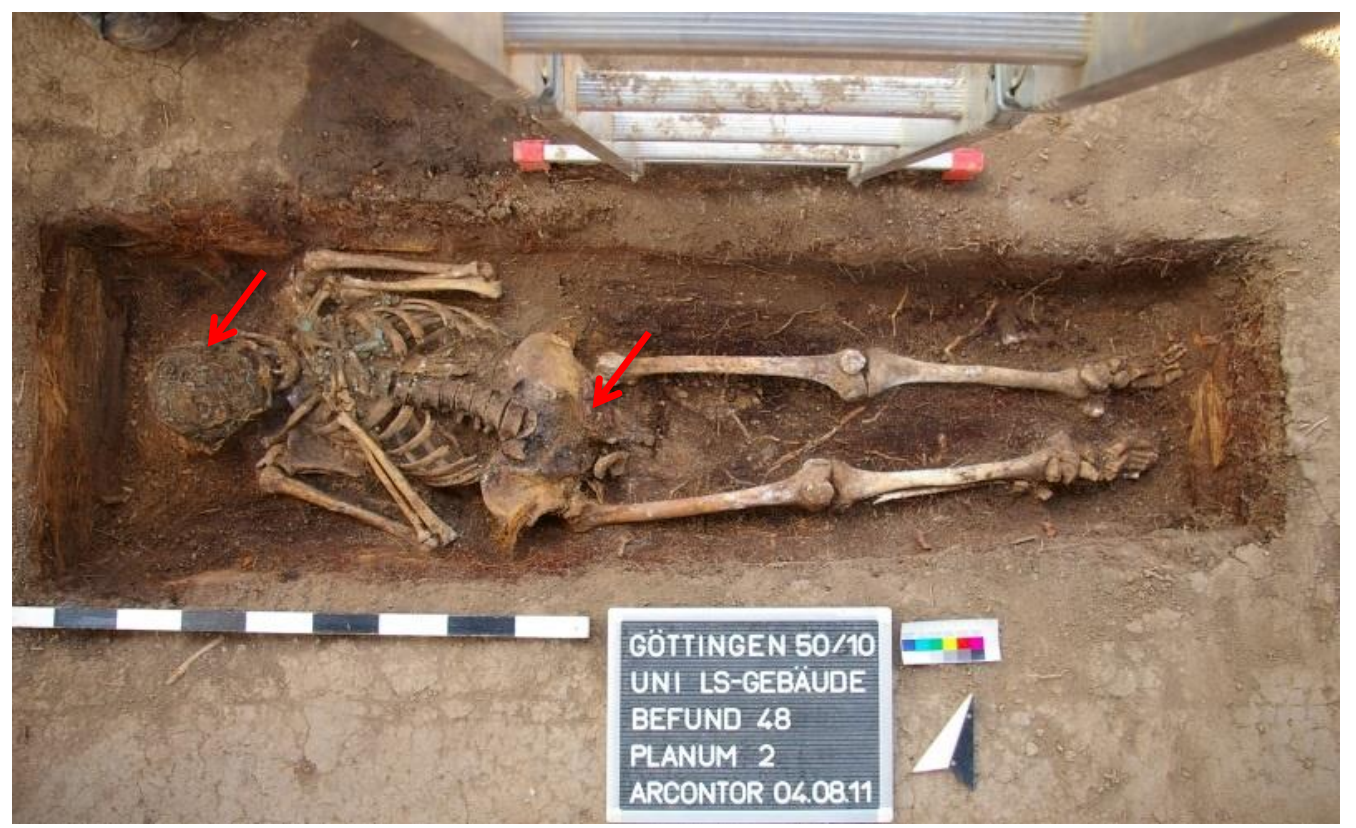

B
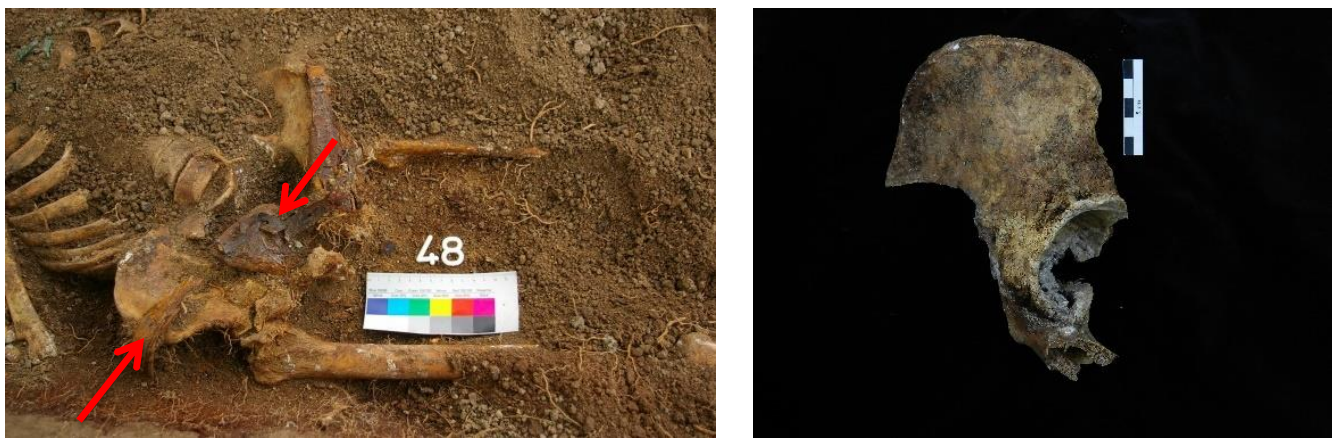

$\mathrm{C}$
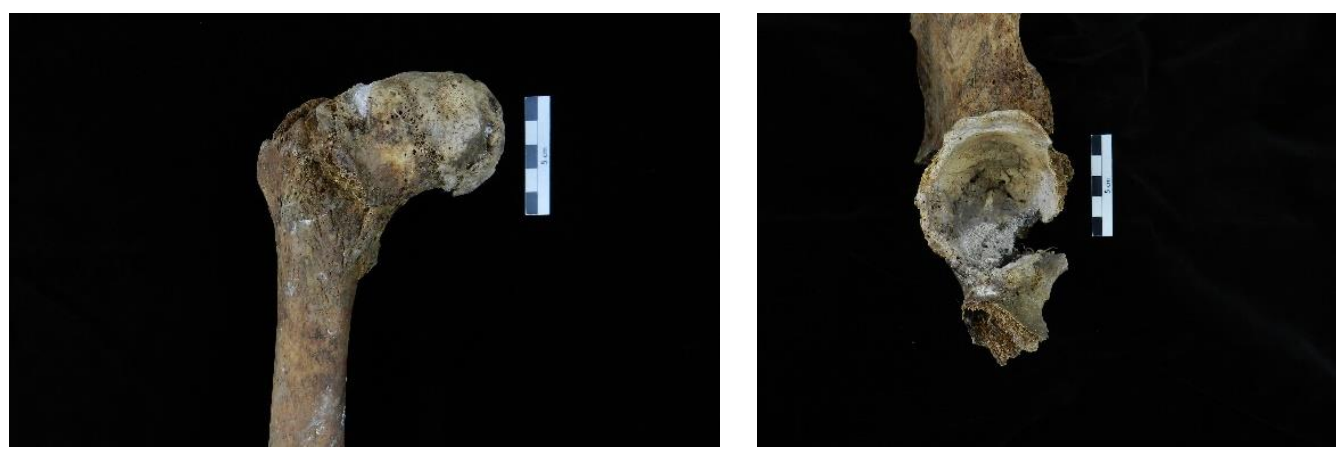

$\mathrm{D}$

$\mathrm{E}$

Abb. 77: Individuum mit Hüftfraktur. A Übersichtsaufnahme mit Samthaube und Buchband (Pfeile). Bild Fa. Arcontor Projekt GmbH. Fundnummer 48, Mann, 60 - 80 Jahre. B Überreste des Bruchbandes im Hüftbereich (Pfeile). Bild Fa. Arcontor Projekt GmbH. C Coxa vara rechts, anteriore Ansicht, Centrum-Collum-DiaphysenWinkel liegt unter $120^{\circ}$. Arthrotische Veränderungen aufrund der Protrusionshüfte. D und E Os coxae rechts. Arthrotisch veränderter Acetabulumrand. D Lateral Ansicht. E Antero-laterale Ansicht.

\section{$\underline{\text { Verheilte Kieferverletzung }}$}

Das Individuum 61 (Anatomieleiche) zeigt etliche Auffälligkeiten. Zum einen hat es, wie in Kapitel 4.1.3 erwähnt, einen Hydrocephalus als Folge einer Hirndrucksymptomatik. Zum anderen fehlt ihm die rechte Gonionregion (siehe Abbildung 78A und 78B). Allerdings ist das traumatische Erlebnis viele Jahre überlebt wurden, da der Knochen am Bruchrand gut verheilt ist. Handelt es sich bei dem Hydrocephalus tatsächlich um die Folgen eines Traumas, muss dieses Geschehen im Kindes- oder Jugendalter stattgefunden haben, da die Schädelnähte mit 
20 - 26 Jahren beginnen zu obliterieren (Todd und Lyon 1925). Die Asymmetrie des Unterkiefers, welche für einen unterschiedlichen Muskelzug auf beiden Kieferseiten während der Knochenwachstumsphase spricht, deutet darauf hin, dass die Verletzung in jungen Jahren stattgefunden hat. Der rechte Gehörgang fehlt, wie man in der Abbildung 78C und 78D erkennen kann. Auch hier ist der Knochen in Höhe des Mittelohrs vollständig verheilt. Vermutlich sind die rechte Seite des Unterkiefers und der rechte Gehörgang gleichzeitig verletzt wurden, da beide in gleichem Maße verheilt sind. Möglich ist, dass dieses Individuum wegen der Auffälligkeiten am Schädel seziert wurde.

A
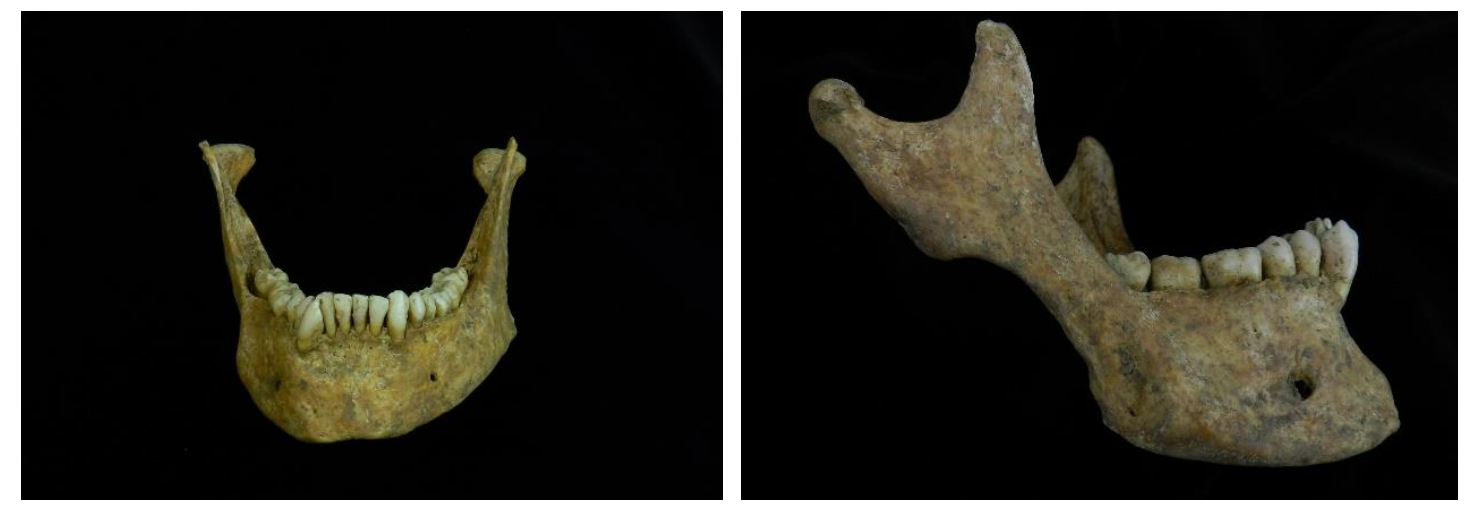

$\mathrm{C}$
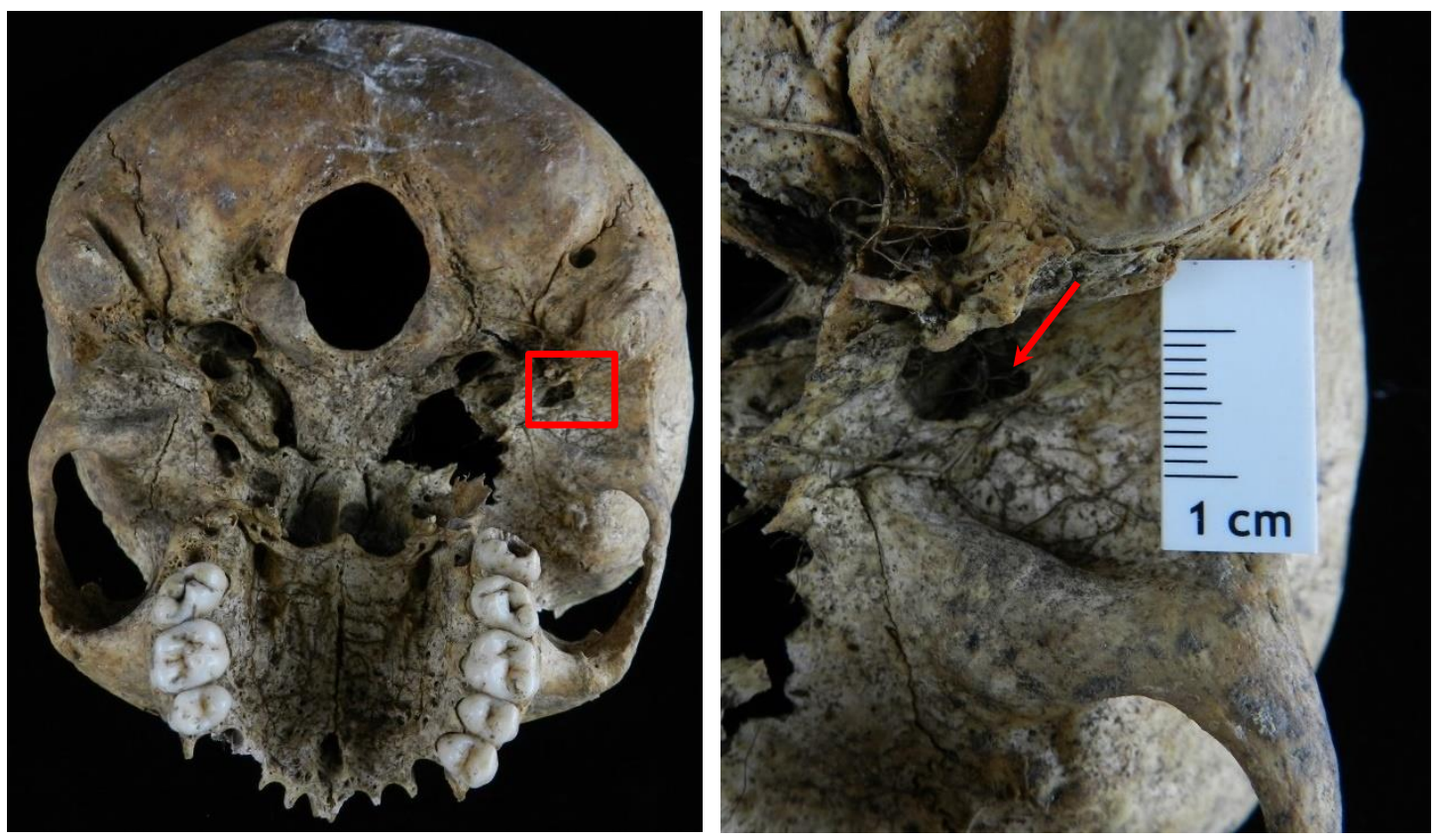

Abb. 78: Verheilte Kieferverletzung. A Asymmetrie des Unterkiefers mit fehlender Gonionregion rechts, anteriore Ansicht. Fundnummer 61, männlich, 40 - 60. B Unterkiefer mit fehlender Gonionregion rechts, laterale Ansicht von rechts. C Übersicht der Schädelbasis, Norma basilaris. Gehörgang rechts fehlt (umrandet, Vergrößerung Abb. 80D). D Detailansicht. Gehörgang rechts fehlt (Pfeil).

$\underline{\text { Sulcus praeauricularis }}$

Lediglich das regelbestattete Individuum 52 hat beidseitig an den Ossa coxae direkt neben der Facies auricularis eine tiefe Einkerbung (siehe Abbildung 79). Es handelt sich um einen Sulcus praeauricularis, dem Ort, an welchem sich die Ligamenta sacroiliaca anteriora anheften. Der 
Sulcus praeauricularis wurde das erste Mal von Zaaijer (1866) an einer Skelettserie javanischer Frauen beschrieben. Bei dem hier gefundenen Individuum 52 handelt es sich um eine Frau im gebärfähigen Alter (19 - 21 Jahre). In der Literatur wird der Sulcus praeauricularis mit der Lockerung des Bänderapparates unter dem Geburtsvorgang assoziiert (Derry 1909, Bergfelder und Herrmann 1980). Über die Zeit hinweg haben sich etliche Untersuchungen mit dem Auftreten und der Aussagekraft dieses Merkmals hinsichtlich der Geschlechtsdiagnose beschäftigt (Breitinger 1989, Ubelaker 2012, Jugert et al. 2018), konnten jedoch keinen direkten Zusammenhang zwischen Geburt und Sulcus praeauricularis feststellen. Offenbar ist der Sulcus praeauricularis für die hier untersuchte Population aufgrund des seltenen Vorkommens kein zuverlässiges Merkmal für die Geschlechtsdiagnose zu sein.

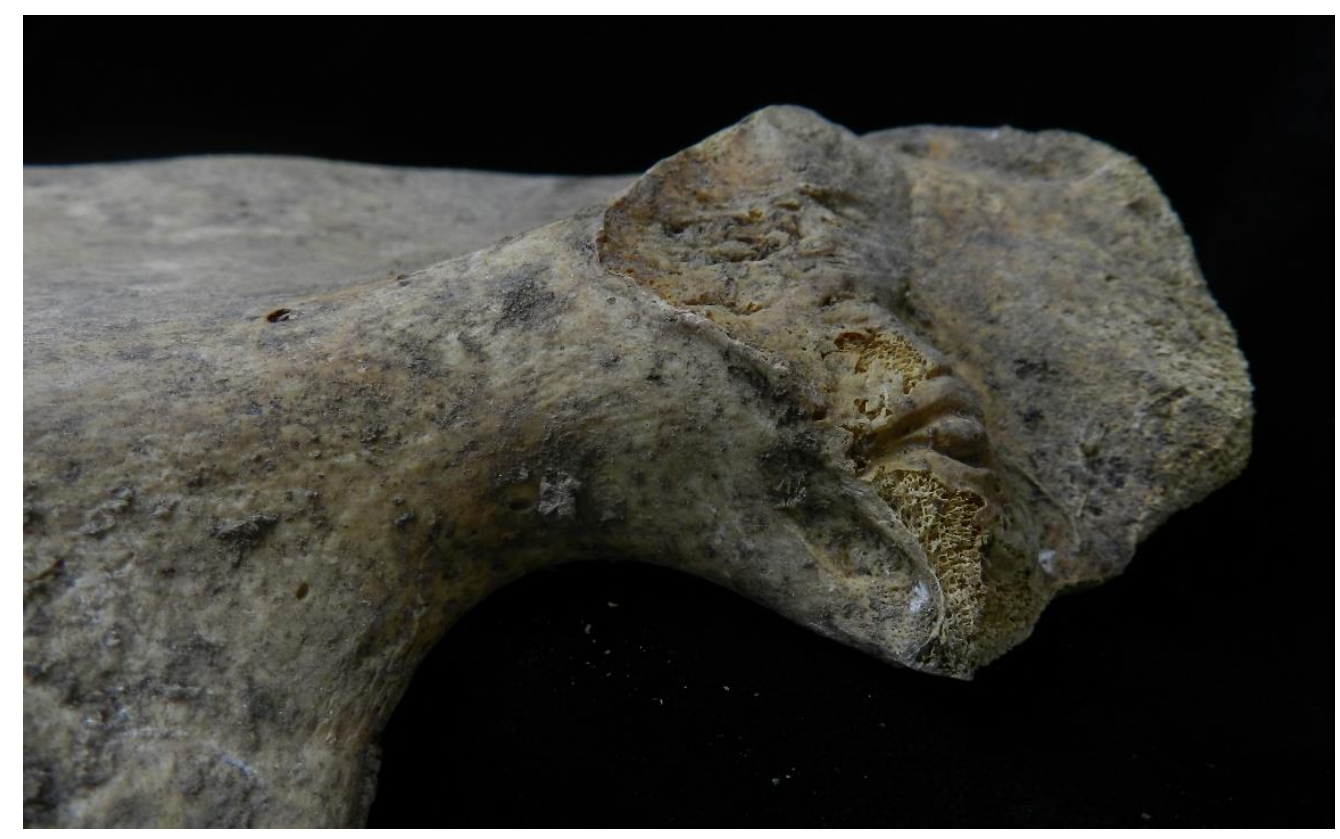

Abb. 79: Sulcus praeauricularis an dem rechten Os coxae, caudale Ansicht. Fundnummer 52, weiblich, 19 - 21 Jahre.

\subsubsection{Vergleich von Allelfrequenzen}

Für den Vergleich der Allelfrequenzen, um einen möglichen genetischen Unterschied beider Gruppen belegen zu können, wurde für jedes Individuum der genetische Fingerabdruck (siehe Anhang Kapitel 8.3) erstellt. Verglichen wurden die Daten von 14 Anatomieleichen und 31 regelbestatteten Individuen. Nur Allele, deren Amplifikation reproduzierbar war, wurden in die Berechnung aufgenommen. Der Exakte Test nach FISCHER ergab, dass es in keinem der untersuchten STR-Systeme Unterschiede zwischen den Gruppen bezüglich der Allelfrequenzen gab (siehe Anhang Tabelle 33). Offenbar gibt es keinen genetischen Unterschied zwischen den regelbestatteten Individuen und den Anatomieleichen. 


\subsection{Grabbeigaben, Beifunde und Sozialstatus}

In Tabelle 5 ist die Verteilung der Grabbeigaben und Beifunde erkennbar. Dabei wird deutlich, dass die meisten Grabbeigaben und Beifunde bei den Regelbestatteten zu finden sind. Lediglich bei fünf Individuen mit Sektionsspuren ließen sich Gegenstände im Grab finden. Die vier sezierten männlichen Individuen (7, 22, 60 und 102) hatten einen Rosenkranz, ein Holzkreuz und zwei Fingerhüte als Beigaben im Grab. Das nicht geschlechtsbestimmte Individuum (137A) ist ein Kind im Altersbereich Infans 2, welches einen Rosenkranz im Grab hatte.

Die häufigsten Grabbeigaben in der Gruppe der Regelbestattungen sind, unabhängig vom Geschlecht, Rosenkränze. Die Rosenkränze waren meist beim Auffinden der Skelette noch um die Unterarm- oder Handknochen geschlungen, teils lagen sie aber auch einfach im Bereich des Abdomens. Weitere typische Grabbeigaben und Beifunde waren Münzen, Zahnprothesen, Eheringe, Ohrringe, Statuetten, Porzellanpüppchen, Fingerhüte, Schreibtafeln und Griffel, Schüsseln und Kämme (Ströbl 2015). Die gefundenen Münzen ließen sich bei beiden Geschlechtern über jede Altersspanne hinweg finden. Sie sind eine typische Beigabe für Begräbnisse des 18 . bis 20. Jahrhunderts, allerdings gibt es unterschiedliche Interpretationsmöglichkeiten und diese Sitte ist nicht konfessionsgebunden (Kenzler 2015). Einige Kinder der katholischen St. Michael Gemeinde haben Puppen oder Heiligenbilder auf die Reise ins Jenseits mitbekommen.

Damit hatten $n=4 / 38$ der Anatomieleichen (10,53\%) und $n=45 / 121$ der Regelbestatteten $(37,19 \%)$ Beifunde im Grab.

Zwei Individuen wiesen Goldfüllungen in den Zähnen auf. Es wurde eine Goldfüllung bei einem Regelbestatteten, Individuum 9, Zahn 38, und einer Anatomieleiche, Individuum 123, Zähne 38, 47 und 48, gefunden.

Tab. 5: Grabbeigaben (Ströbl 2015), getrennt nach Geschlecht und Gruppe, nd = nicht determinierbar.

\begin{tabular}{|l|l|l|l|l|l|l|}
\hline & \multicolumn{2}{l|}{ Regelbestattungen } & \multicolumn{2}{l|}{ Anatomieleichen } \\
\hline Grabbeigabe & Männer & Frauen & nd & Männer & Frauen & nd \\
\hline \hline Rosenkranz & 6 & 15 & 5 & 1 & & 1 \\
\hline Holzkreuz & 4 & 1 & & 1 & & \\
\hline Münze & 5 & 2 & 4 & & & \\
\hline Puppe & & & 2 & & & \\
\hline Statuette & & & 1 & & & \\
\hline Heiligenbild & & & 1 & & & \\
\hline Samthaube & 1 & & & & \\
\hline \hline
\end{tabular}




\begin{tabular}{|l|l|l|l|l|l|l|}
\hline \hline Zum Körper gehörend & & & & & & \\
\hline \hline Zahnprothese & 1 & 1 & & & & \\
\hline Bruchband & 1 & & & & & \\
\hline \hline Persönlicher Schmuck & & & & & & \\
\hline \hline Ehering & & 1 & & & & \\
\hline Ohrringe & & 1 & 1 & & & \\
\hline \hline Persönlichkeit repräsentierend & & & & & & \\
\hline \hline Schreibgriffel und Schiefertafel & & 2 & & & & \\
\hline Kamm & & 1 & & & & \\
\hline Klappmesser & & & 1 & & & \\
\hline Fingerhut & & & & 2 & & \\
\hline Naturschwamm & 1 & & & & & \\
\hline \hline Sonstiges & & & & & & \\
\hline \hline Schüssel & & 1 & & & & \\
\hline
\end{tabular}

Die Schüssel wurde entweder zur Leichenwaschung genutzt oder beinhaltete die Organe nach einer Sektion. Allerdings weist das Individuum keine Sektionspuren auf, daher handelt es sich wahrscheinlich um Ersteres.

Die Fundsituation des Individuums 122A (1) ist ungewöhnlich, wie man in der Abbildung 80 erkennen kann. Bei dem sezierten Individuum 122A (1) wurden in der Bauchhöhle Tierknochen gefunden. Es handelt sich um Epiphysen von Langknochen eines Pferdes, welche eindeutig Sägespuren aufweisen.

Einem männlichen Individuum (60 - 80 Jahre) wurde im Rahmen der Bestattung eine Samthaube aufgesetzt (siehe Abbildung 81). Diese Samthaube besteht aus einem Textil, auf das mittels eines Fadens (vermutlich Kupfer) ein Ornament gestickt wurde. 


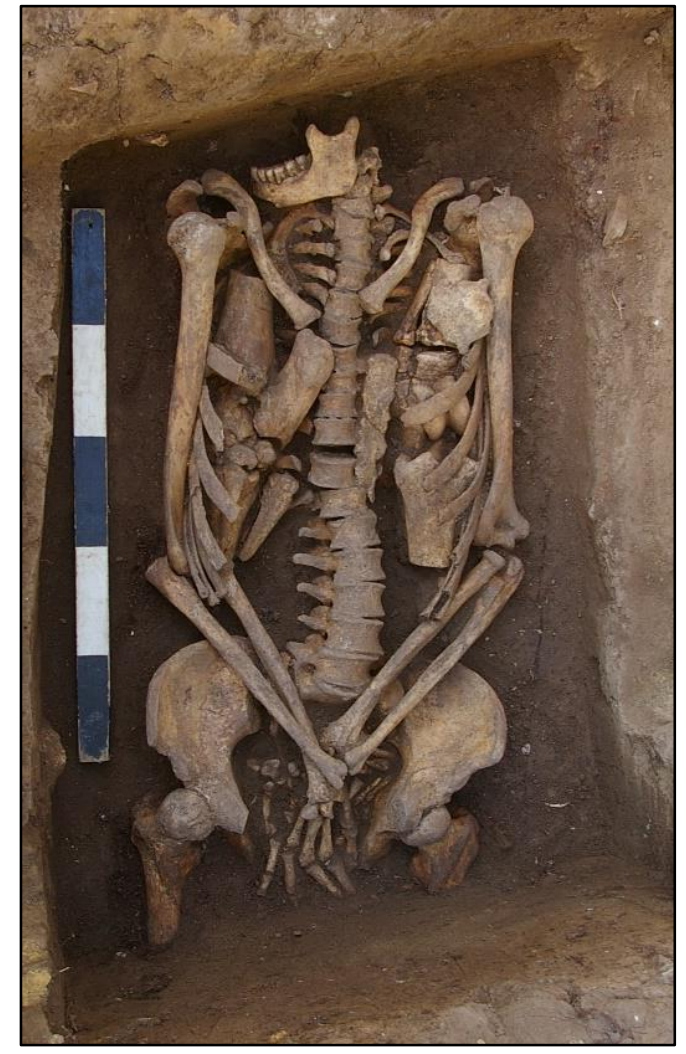

Abb. 80: Tierknochen im Bereich des Brustkorbs. Bild Firma Arcontor Projekt GmbH. Fundnummer 122A (1), männlich, 40 60 Jahre.

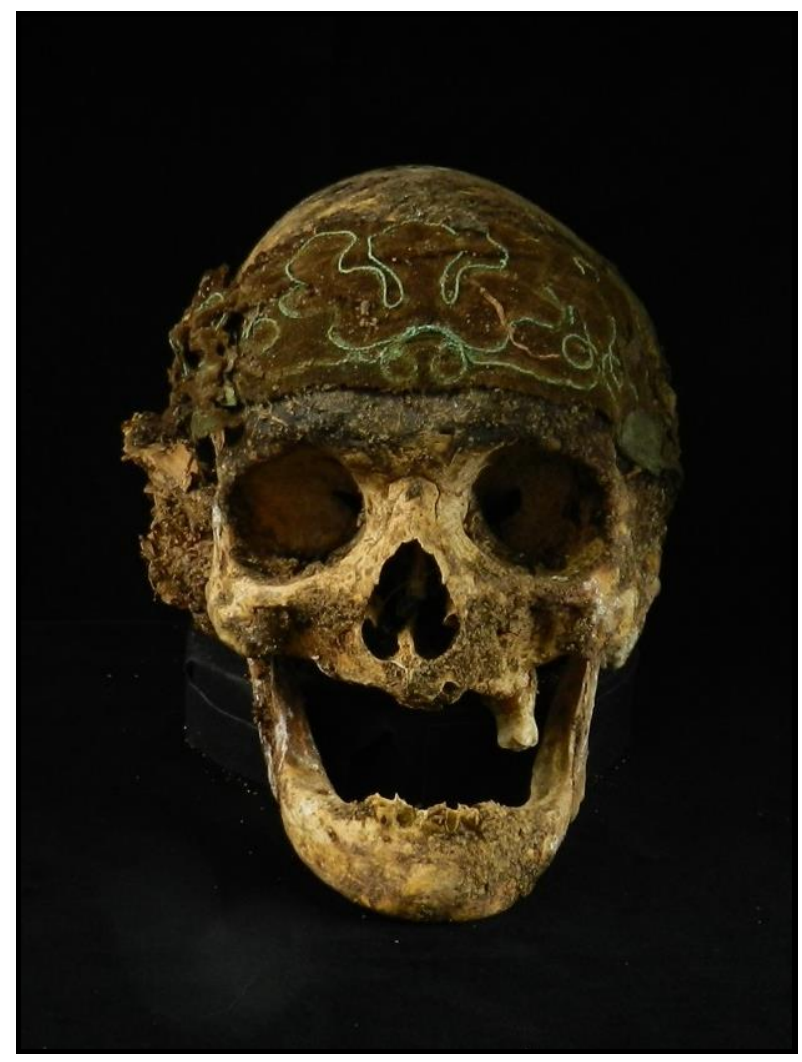

Abb. 81: Samthaube. Fundnummer 48, männlich, 60 - 80 Jahre.

In vielen Gräbern konnten Überreste von einfachen Holzsärgen, einfache- und kunstvoll verzierte Sarggriffe, Nägel, Schrauben, Sargfüße und Sargbeschläge (Ströbl 2015) gefunden werden. Ausgenommen sind fünf regelbestattete Individuen; sie wurden mit einem Innen- und Außensarg begraben. Eines dieser Individuen lag in einer Gruft (Individuum 18) und vier weitere Individuen (46, 48, 73 und 116) waren erdbestattet. Die restlichen vier Individuen waren alle männlich und verstarben bis auf ein adultes Individuum alle in der senilen Altersklasse. Das Individuum 116 war für eine morphologische Befundung zu stark degradiert.

Weitere Grabbeigaben und Beifunde werden von Ströbl (2015) beschrieben. 


\subsection{Historische Quellen und Daten}

Bereits im 5. Jahrhundert v. Chr. hat man im alten Griechenland über das Denken und Sein philosophiert sowie den menschlichen Körper auf seine Funktion hin analysiert. Berichte belegen, dass die ersten Sektionen in der „Schule von Alexandria“ stattfanden (ElizondoOmana et al. 2005). Während es zu jener Zeit als wissenschaftliche Errungenschaft galt, den menschlichen Körper zu untersuchen, änderte sich dessen Stellenwert im Mittelalter vollkommen. Den menschlichen Körper nach dem Tod zu öffnen wurde nicht nur als Blasphemie betrachtet, sondern auch streng verboten (Gregory und Cole 2002). Vielmehr galt das weltliche Dasein mit seinen materiellen Gütern als unwichtig. Die anatomische Lehre konnte daher ausschließlich über die Rezitation von Texten vermittelt werden. Erst mit der Renaissance rückte der menschliche Körper und dessen Aufbau wieder in den Focus der Wissenschaft. So führte beispielsweise Andreas Vesalius, Anatomieprofessor im 16. Jahrhundert, selbst Sektionen zu Lehrzwecken durch und verfasste mehrere neue Standardwerke für Studenten und Mediziner (Lenzen 2016). Im 17. und 18. Jahrhundert änderte sich mit der Aufklärung auch die Einstellung zur Leichenöffnung, sowohl in der Wissenschaft als auch mit der Zeit in der breiten Bevölkerung. Die menschlichen Leichen waren bedeutsames Forschungsmaterial für den medizinischen Unterricht. Medizinstudenten konnten ihr Wissen über Anatomie nun nicht mehr nur ausschließlich in der Theorie erwerben, sondern erhielten einen umfassenden Überblick über den Körperaufbau im Rahmen von medizinischen Sektionen.

\subsubsection{Anatomiepflichtige Leichen}

1736 wurde der Universität in Göttingen durch Georg II. das Privileg erteilt, dass alle Leichen von Hingerichteten im Umkreis von 6 Meilen an die Anatomie Göttingen verbracht werden müssen (Wagener 1995, Ude-Koeller 2010, Römling 2012). Damit sollte der ständige Nachschub an Leichen für die Lehrveranstaltungen der Medizinstudenten gesichert sein. Da die Leichen der Hingerichteten allein nicht den benötigten Bedarf an Lehrmaterial decken konnten, wurde zwischen 1737 und 1744 eine sukzessive Ausdehnung des betreffenden Personenkreises angeordnet (Stukenbrock 1997). Daraus entstand die Möglichkeit, zusätzlich die Leichen folgender Personengruppen für die Anatomie zu gewinnen: tödlich Verunglückte, tot Aufgefundene, durch Freitod Umgekommene, Leichen unehelicher Kinder und ihrer Mütter, Arme, „Vagabonden“, fremde Bettler, Menschen mit Behinderung und jene, welche sich keine Beerdigung leisten konnten (Wagener 1995, Stukenbrock 1997, Zimmermann 2009). Im 
angelsächsischen Raum gab es vergleichbare Gesetze, welche die Auslieferung von Leichen an die Universitäten regelten, z. B. Anatomy Act (1832), Poor Law Amendment Act (1834), Medical Act (1858). Das Versprechen der kostenlosen Bestattung von sezierten Leichen (Buklijas 2008) durch die Universität ist vermutlich einer der Gründe warum die Praxis der Leichensektion im deutschsprachigen Raum auf weniger Widerstand, als im englischsprachigen stieß. In den Verordnungen war genau festgeschrieben, welche Leichen sich eigneten, aus welchem Einzugsbereich sie zu stammen haben und aus welchem Personenkreis an Verstorbenen die Anatomieleichen bezogen wurden. An Göttingen wurde aus den Städten und Amtsbezirken der Fürstentümer Göttingen und Grubenhagen, aus dem Fürstentum Hildesheim (Außnahme: Goslar, Peine, Sarstedt, Hohenhameln, Ruthe), aus dem Bezirk der Bergbaumannschaft zu Clausthal, aus Ärzen, Coppenbrügge, Grohnde, Lauenstein, Polle, Bodenwerder und Hameln sowie dem Fürstentum Calenberg geliefert. Ebenso aus dem Strafarbeitshause Hameln und aus dem polizeilichen Werkhause zu Moringen (siehe Abbildung 82 aus dem Niedersächsischen Landesarchiv Wolfenbüttel (NLA WO)). Die Transportkosten waren dabei ebenso genau und streng geregelt wie die Transportmodalitäten selbst. Nicht jede Leiche konnte für den Sektionsunterricht genutzt werden. Ein Beschluss von 1857 (siehe Abbildung 82) schließt eine Ablieferung der Leichen aus, wenn:

1) „[...] dem Transport derselben gesundheitspolizeiliche Bedenken entgegenstehen oder die Leichen vorraussichtlich in dem Zustande der Verwesung an dem Bestimmungsort ankommen würden. Bedenken der gedachten Art sind vorhanden, wenn der Tod der Erkrankung an Menschenblattern, Faul- oder Nervenfieber, Ruhr, Cholera, Hundswuth, Milzbrand, Karbunkeln, höheren Graden der venerischen Krankheit oder besonders ansteckenden Hautkrankheiten war;

2) wenn nach dem Trachten der zuständigen Justizbehörde der Leichnam behus [bis zu Anm. d. Verf.] Einleitung eines Kriminalverfahrens zur Stelle bleiben muß.“ (Königlich Hannoversche Ministerien der Justiz und des Innern 1857, Abbildung 82)

Vereinzelt wurden den Bürgern bereits zu Lebzeiten bis zu 6 Reichstaler bezahlt, damit diese ihren Körper nach ihrem Tod der Anatomie zur Verfügung stellten (Römling 2012). Zum Vergleich, eine Standardlehrveranstaltung der Juristen kostete damals 6 Reichstaler im Semester und das übliche Jahresgehalt eines Professors mit Hofratstitel betrug in etwa 600 Reichstaler. Der Leichnam wurde mitunter lediglich als Ware angesehen (Gierl 1988). Dies schürte vor allem in den ärmeren Bevölkerungsschichten die Befürchtung, dass ihr Körper nach dem Tod seziert werden würde (Hurren 2008). 


\section{G.}

Die

2Ablicferung von seidnumen an Dic anatomiijden 2nittalten Des Rïnigrcidso betreffent.

(8)

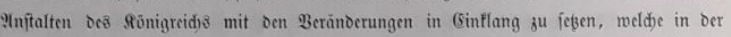

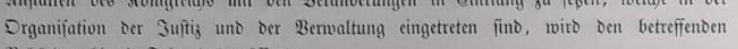

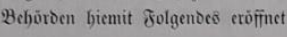

$$
\text { \$. } 1 .
$$

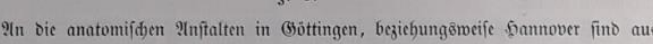

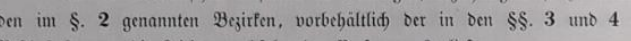

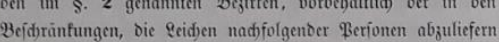

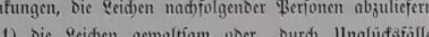

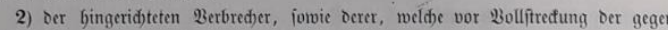

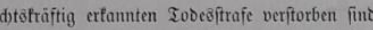

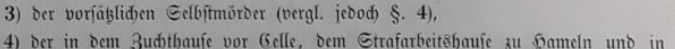

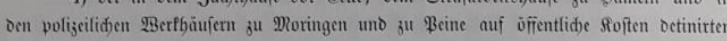
trafgefangenen,

5) Der in Den Gefanngnififen verfitorbenen Baganten und Bettler, infowecit die

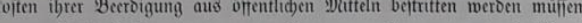

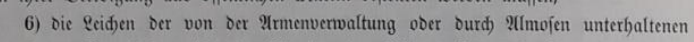

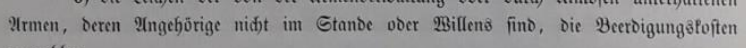
ju jablen.

$$
\text { \$ic s. }
$$

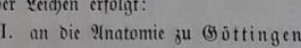

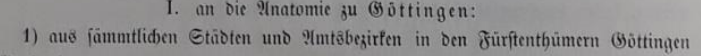
1) aus fäm

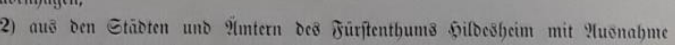

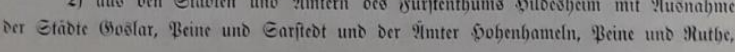

3.

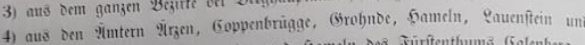

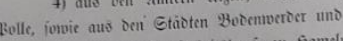

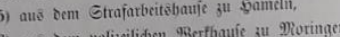

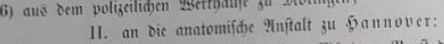

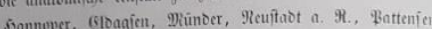

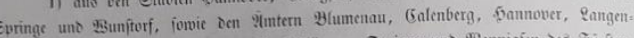

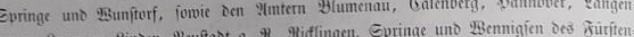

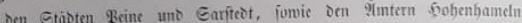

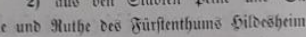

(3)

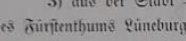

$$
\text { 4) aus been 3udththuic ;in sectle, }
$$

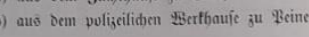$$
\text { Sic }
$$

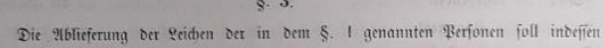
Etatt fintern:

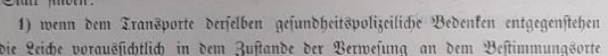

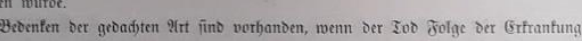

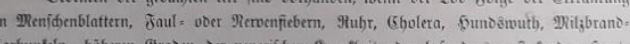

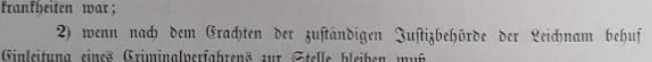

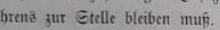$$
\text { 5. } 4
$$

Ginc Dispentation won der (a) sumathen

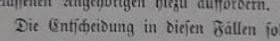

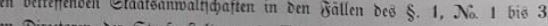
(a)

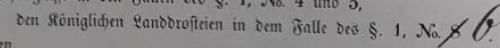

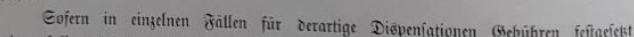

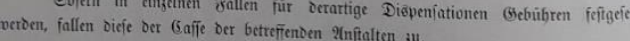
\&. 5

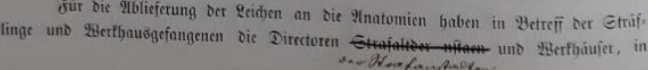

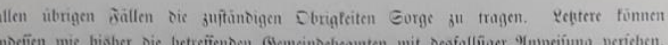

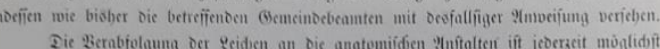

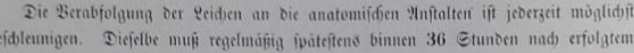
inoce Etatt finten.

$$
\text { s. } 6 .
$$

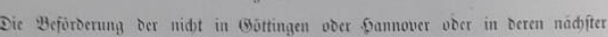

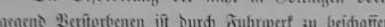

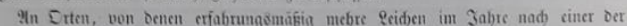

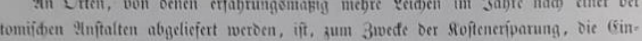
tidtumg 3u treficts:

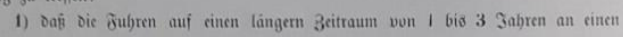

ter

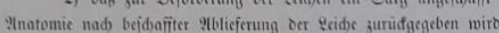

$$
\text { 5. } 7 \text {. }
$$

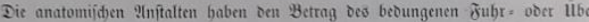

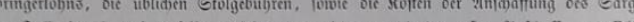

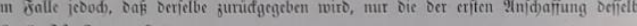

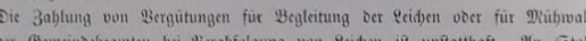

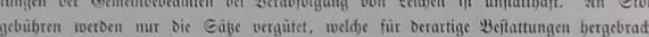
ober fertgeciest intor.

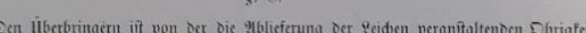

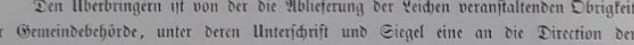

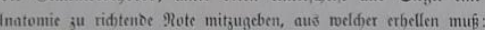

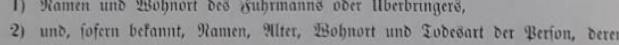
Pecidnam jugetulust wiro,

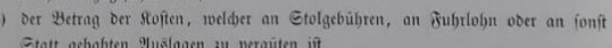

$$
\text { Jannourer, Den 31. 3uli } 1837
$$

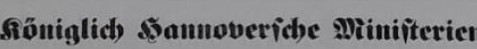

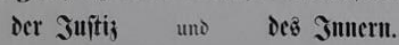

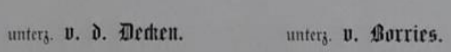

Abb. 82: Anweisung zur Ablieferung von Leichnamen an die anatomischen Anstalten des Königreichs betreffend vom 31. Juli 1857 (NLA WO, 26 A N, Nr. 1493 2017). 
Allerdings kam es trotz dieser sehr unmissverständlichen Verordnungen immer wieder zu Engpässen an „geeignetem Lehrmaterial“. Zum einen gab es einen Rückgang an exekutierten Häftlingen und oft wurden Leichen aus Angst und Abscheu in der Gesellschaft vor den Sektionen nicht von den Obrigkeiten an die Anatomie gemeldet. Zum anderen stiegen die Studentenzahlen mit den Jahren deutlich an. Somit mussten die Verantwortlichen in den Medizinischen Instituten immer wieder die Zuständigen der Städte aus den Einzugsgebieten daran erinnern sowie den König bitten, alle Leichen, die anfallen, an die anatomischen Abteilungen auszuliefern. Beschlüsse aus den Jahren 1773 und 1775 (siehe Abbildung 83 und 84 aus dem Niedersächsischen Landesarchiv Hannover (NLA HA)) zeigen, wie dringlich die Nachschubversorgung war und aus welchem Personenkreis sich die Gruppe der Anatomieleichen zusammensetzte.

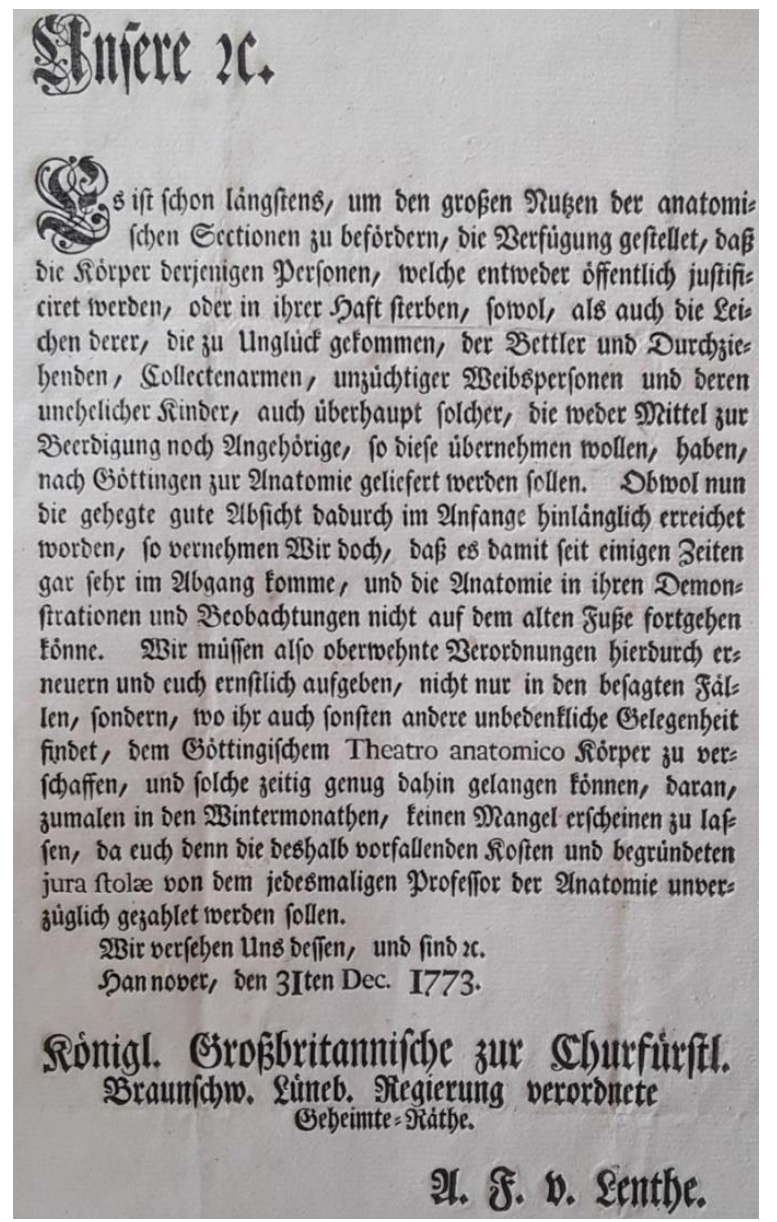

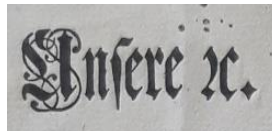

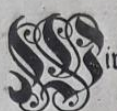
ir muißen ungern vetnebmen, Daf bie mebrmaligen Berorb: mungen, wegen Elefirung oer Leict)en auf Die (S̈òttingifd)e 2Inatomie, won senen Perfonen, rreldse entiveder óffentlid) juftificiret werben, ober in peinlid)er 5 naft verfterben, aud) zu Ungluaff

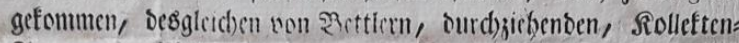
2(rmen, unjuid)tigen 2Seribsperionen, uno Seren uncblid)en Rin= bern, auch tiberbaupt fold)en, tere weser S)?ittel zur Vुcerbigung, nod) 2ngebórige baben, fo diefe ribernebmen mollen, gat wenig be= folyet werben, und befagter 2/nntomic co saburch) biefe Scit ber an Rórpern ju Seftionen felor gemangelt babe.

Da nun ber bierunter gebegte gute Entzived fo wenig von eud) misfennet wetien mag, als wegen ber befagten 2nftof ju vermutben ftebet; fo wicierbolen roir fotbane Berord=

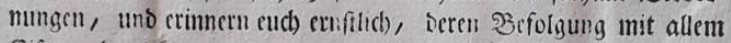
Eifer ju benitfen, wie icun atte Daber) vorfallende Roften, uno bie begruindeten Jura ftolæe von Dem \$rofeffor Der थmatomie, jeberzeit bejablet werben follen.

פBit werfeben uns deffen, und find 26 . Sannover ben $I 7^{\text {ten }}$ शovemb. 1775 .

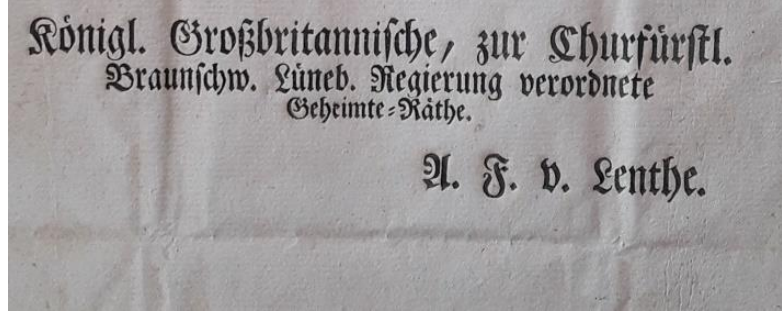

Abb. 83 und 84: Dokumente zur erneuten Aufforderung der Leichenabgabe und Erweiterung des Personenkreises aus den Jahren 1773 und 1775 (NLA HA, Hann. 74 Göttingen, Nr. 3630 2017).

Es wurde immer öfter darauf beharrt, dass jede anfallende Leiche möglichst effizient genutzt wird. In einem Schriftwechsel von 1796 wird ausdrücklich darauf bestanden, die nicht genutzten Leichen eines Bezirks in die Zuständigkeit eines anderen zu verlegen. In dieser 
Forderung wurde erstmals ein Mindestindividualalter der Individuen von zehn Jahren erwähnt (siehe Abbildung 85).
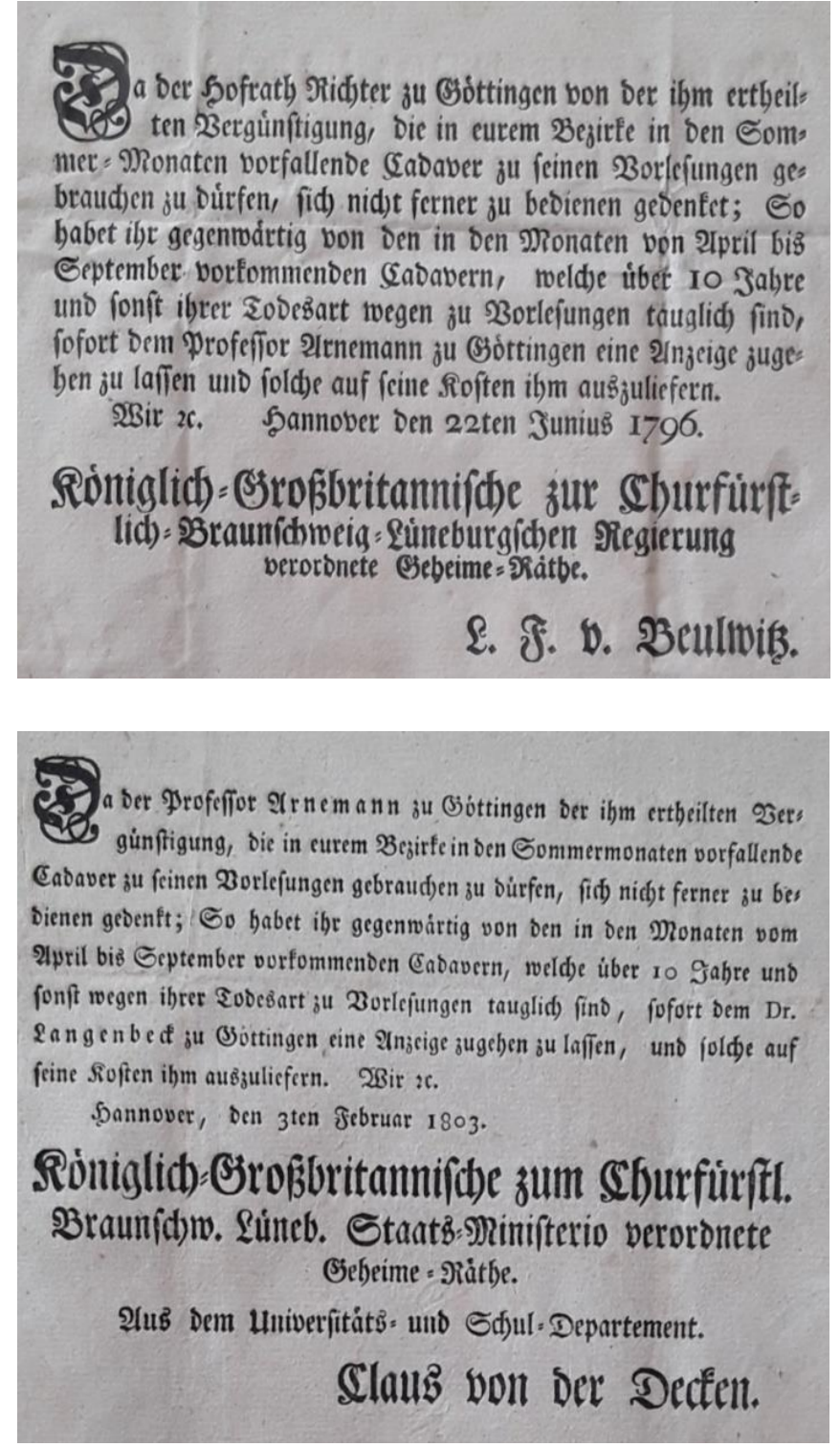

Abb. 85: Brief zur Umverteilung von Leichen für die Anatomie Göttingen aus dem Jahr 1796 (NLA HA, Hann. 74 Göttingen, Nr. 3630 2017).

Abb. 86: Brief mit der Bitte um Abgabe der Leichen an Prof. Langenbeck aus dem Jahr 1803 (NLA HA, Hann. 74 Göttingen, Nr. 3630 2017).

Die Abbildungen 85 und 86 zeigen: fielen an einer Institution übermäßig viele Leichen an, wurden diese auch von anderen Einrichtungen und Instituten für Lehrzwecke akquiriert.

Obwohl die Leichenöffnung im Rahmen der Lehre und Forschung bereits lange Zeit gängige Praxis war, verlor sie für viele Menschen nicht an Schrecken. In einem Brief (siehe Abbildung 87) durch die Behörden der Verwaltungsbezirke wird darauf hingewiesen, dass Gemeinden durch die universitäre Übernahme von Beerdigungskosten von der Leichenabgabe profitieren würden. Die Übernahme der Beerdigungskosten der sezierten Leichen ist für die katholische Gemeinde insofern interessant, als dass sie im 19. Jahrhundert immer noch eine kleine und nicht allzu wohlhabende Gemeinde bildete (Wehking 1992). Das würde auch erklären, warum sich die katholische Gemeinde dazu entschlossen hat, viele arme Menschen der Anatomie zu 
übergeben, obwohl der katholische Glauben besagt, dass der Körper nach dem Tod unversehrt in die Erde verbracht werden muss.

„Im Anschluss an unsere Circular-Verfügung vom 20. Octbr. 1870 (No 13,756) betreffend die Ablieferung von Leichen an die Anatomie zu Göttingen, theilen wir Eurer Hochwohlgeboren mit, daß der Herr Director des anatomischen Instituts, Professor OberMedicinat-Rath Dr. Henke, um dem auch jetzt noch fühlbaren Mangel an Leichen-Material nach Möglichkeit abzuhelfen, sich an den Herrn Minister der geistlichen, Unterrichtsund Medicinal-Angelegenheiten mir einer Vorstellung gewandt hat. In Letzterer ist die Vermuthung ausgesprochen, daß Die Gemeindebehörden des gesetzlichen LeichenAblieferungs-Bezirks sich bereitwilliger zeigen würden, die in der Anweisung vom 31. Juli 1857 bezeichneten Leichen, namentlich die von Armen, deren Angehörige nicht im Stande oder Willens sind, die Beerdigungs-

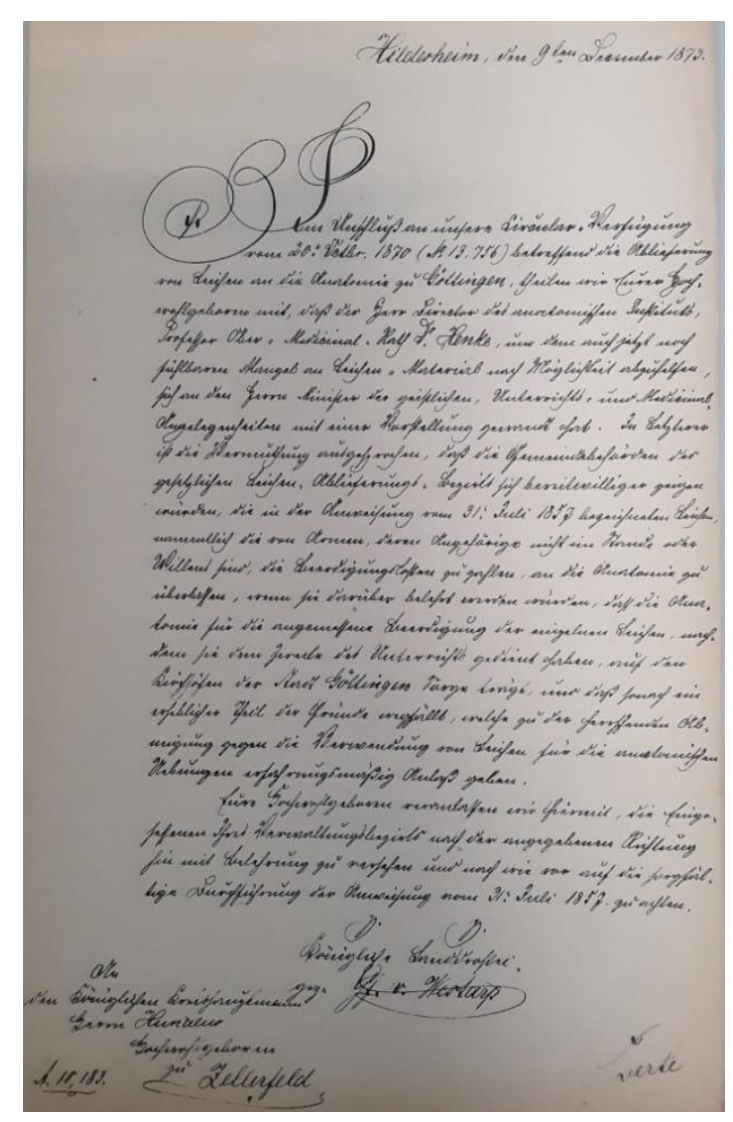

Abb. 87: Schreiben aus Hildesheim vom 9. December 1873 an den königlichen Kreishauptmann Herrn Hunaew Hochwohlgeboren zu Zellerfeld (NLA HA, Hann. 180 Hildesheim, Nr. 01221 2017).

kosten zu zahlen, an die Anatomie zu überlassen, wenn sie darüber belehrt werden würden, dass die Anatomie für die angemessene Beerdigung der einzelnen Leichen, nachdem sie dem Zwecke des Unterrichts gedient haben, auf den Kirchhöfen der Stadt Göttingen Sorge trägt, und daß sonach ein erheblicher Theil der Gründe wegfällt, welche zu der herrschenden Abneigung gegen die Verwendung von Leichen für die anatomischen Uebungen erfahrungsgemäßig Anlaß geben.

Eure Hochwohlgeboren veranlassen wir hiermit, die Eingesessenen Ihres Verwaltungsbezirks nach der angegebenen Richtung hin mit Belehrung zu versehen und nach wie vor auf die sorgfältige Durchführung der Anweisung vom 31. Juli 1857 zu achten.“ (Westarp 1857, Transkription durch die Sütterlinstube im Riebeck Stift Halle) 
Nicht nur die Beerdigungskosten, sondern auch die Transportkosten für die Anlieferung der Leichen wurden von der Universität bzw. den zuständigen Instituten übernommen, wie im Brief in Abbildung $88 \mathrm{zu}$ sehen ist.

„Für Überlieferung der Leiche Invalieden Fr. Denecke aus Lautenthal in die Anatomie zu Göttingen habe ich heute 13 Mark 50 Pfennig erhalten.“ (Uhse1891, Transkription durch die Sütterlinstube im Riebeck Stift Halle.)

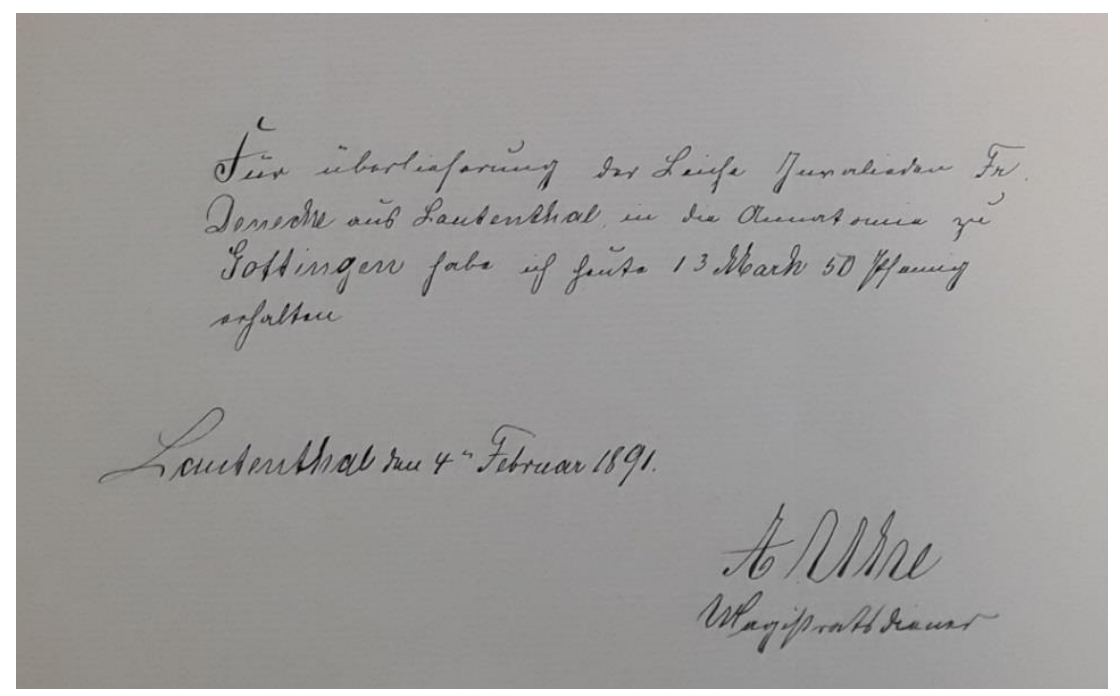

Abb. 88: Schreiben vom Magistrat aus Lautenthal vom 4. Februar 1891 (NLA WO, 26 A N, Nr. 1493 2017).

\section{Sammlungen}

Während der Präparationen wurden oft Körperteile (z. B. Knochen, Gewebe, Organe) aus dem Leichnam entnommen und für Lehr- bzw. Übungszwecke präpariert und aufbewahrt. Entweder wurden die Objekte zu einem späteren Zeitpunkt mit einer anderen Leiche bestattet oder weiterhin in der anatomischen Sammlung verwahrt. In zahlreichen deutschen Städten gibt es an Anatomischen Instituten der Universitäten anatomische, pathologische oder vergleichende Sammlungen für Lehre und Forschung. Bis auf wenige Ausnahmen, beispielsweise durch Zerstörung von Sammlungen im 2. Weltkrieg wie z. B. in Münster, lassen sich die Präparate dieser Sammlungen bis ins 17. oder 18. Jahrhundert zurückdatieren. Große bis mittelgroße Sammlungen befinden sich an den Universitäten in München, Heidelberg, Freiburg, Tübingen, Rostock, Halle, Jena, Greifswald, Marburg, Berlin und Göttingen.

In Göttingen wurden die ersten Präparate von dem Anatomen und Begründer der Anthropologie Johann Friedrich Blumenbach zusammengetragen und beschrieben. Diese Sammlungsstücke, zumeist Schädel, wurden 1840 von Langenbeck in die Göttinger Sammlung des Theatrum 
anatomicum aufgenommen und bildeten einen wichtigen Grundstock. Auch heute noch werden Knochen aus diesen Sammlungen untersucht und für weiterführende Fragestellungen, beispielsweise Isolierung von Humanpathogenen, herangezogen.

\subsubsection{Meldescheine bei Todesfällen}

Für Hunderte Personen sind im Archiv des Bistums Hildesheim Meldescheine hinterlegt, die nach deren Tod ausgestellt wurden. Die Meldezettel stammen aus dem Zeitraum 1855 - 1883. Auf den Meldescheinen befinden sich neben den Angaben zu Namen, Alter und Geschlecht auch Informationen über den Berufsstand, die Todesursache und deren Beerdigung beziehungsweise Ablieferung an die Anatomie Göttingen. Es konnten die Meldezettel zu 20 Individuen, welche nach ihrem Tod in die Anatomie Göttingen abgeliefert wurden, eingesehen werden. Bis auf eine Person sind alle im Ernst August Hospital Göttingen verstorben und kamen größtenteils aus dem Umfeld mit katholischer Glaubensrichtung (siehe Tabelle 6). Es gab eine direkte Zusammenarbeit zwischen der St. Michael Gemeinde in Göttingen und den Universitätseinrichtungen, die dazu führte, dass Prof. Henle während seiner Anstellung im Anatomischen Institut (1852 - 1885) stets mit neuen Leichen zu Sektionszwecken versorgt wurde (Droste 2015). Der Bau des Ernst August Hospitals wurde vom hannoverschen König angeordnet und es wurde 1851 offiziell eröffnet. Dieses neue Hospital sollte den Unterricht am Patienten vermitteln. Die Patienten kamen aus Göttingen und der unmittelbaren Umgebung. Es wurden arme Bürger unentgeltlich und bemittelte Bürger gegen Bezahlung aufgenommen (Schröder und Wojtkowiak 2015, nach „Bekanntmachung, [...]“ 1850). In unmittelbarer Umgebung befand sich das Pathologische Institut.

Abbildung 89 und 90 sind Beispiele für Meldezettel über Todesfälle von Menschen, die nach ihrem Tod an die Anatomie der Universität Göttingen geliefert wurden. 


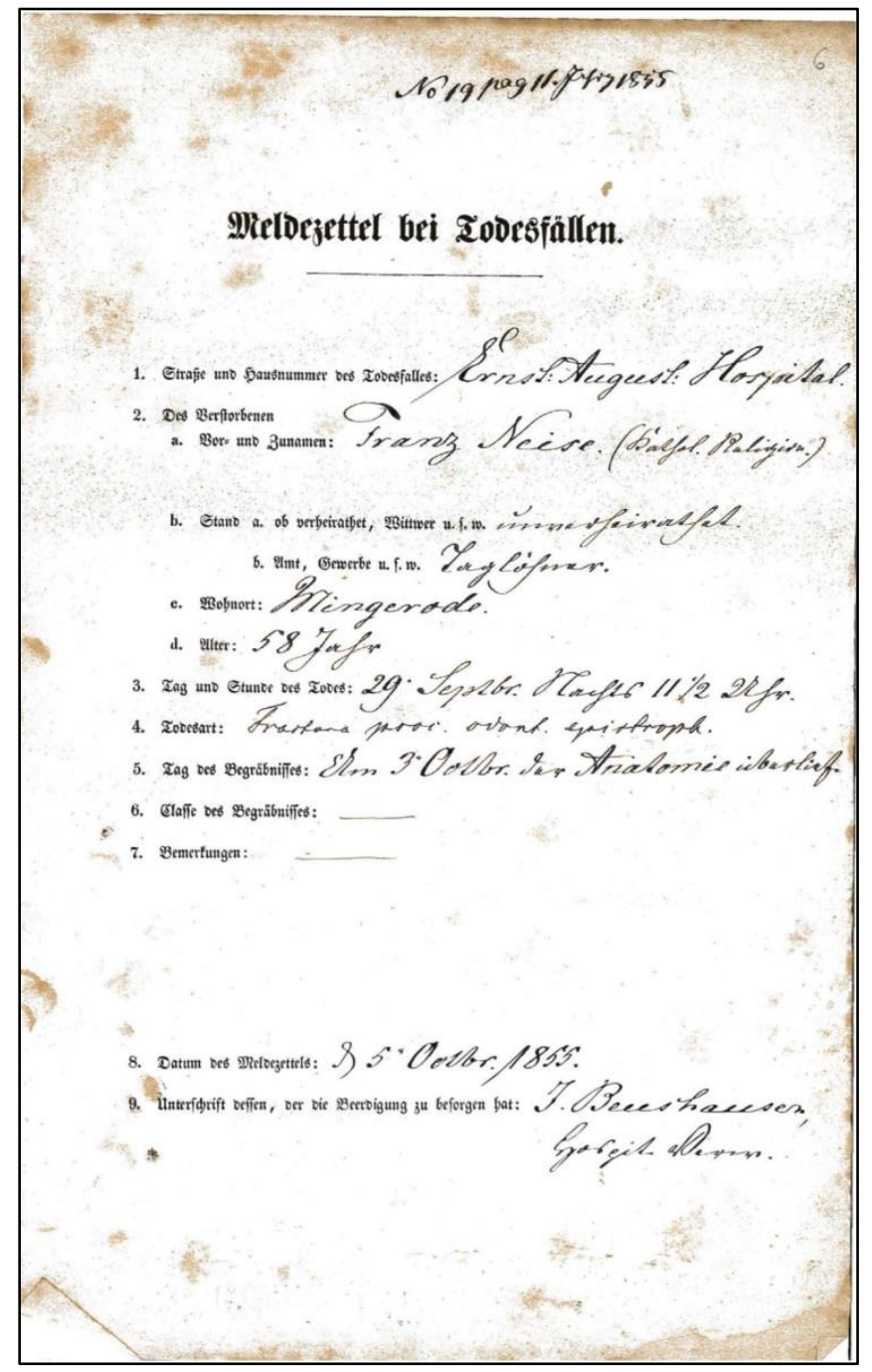

Abb. 89: Meldezettel: Franz Neise, starb im Alter von 58 Jahren an einer Fractura proc. odont. epistrophroph. (Genickbruch), Tagelöhner von Beruf (BAH, Pfarrarchiv [PfA] Göttingen, Sign. 56. 2018).

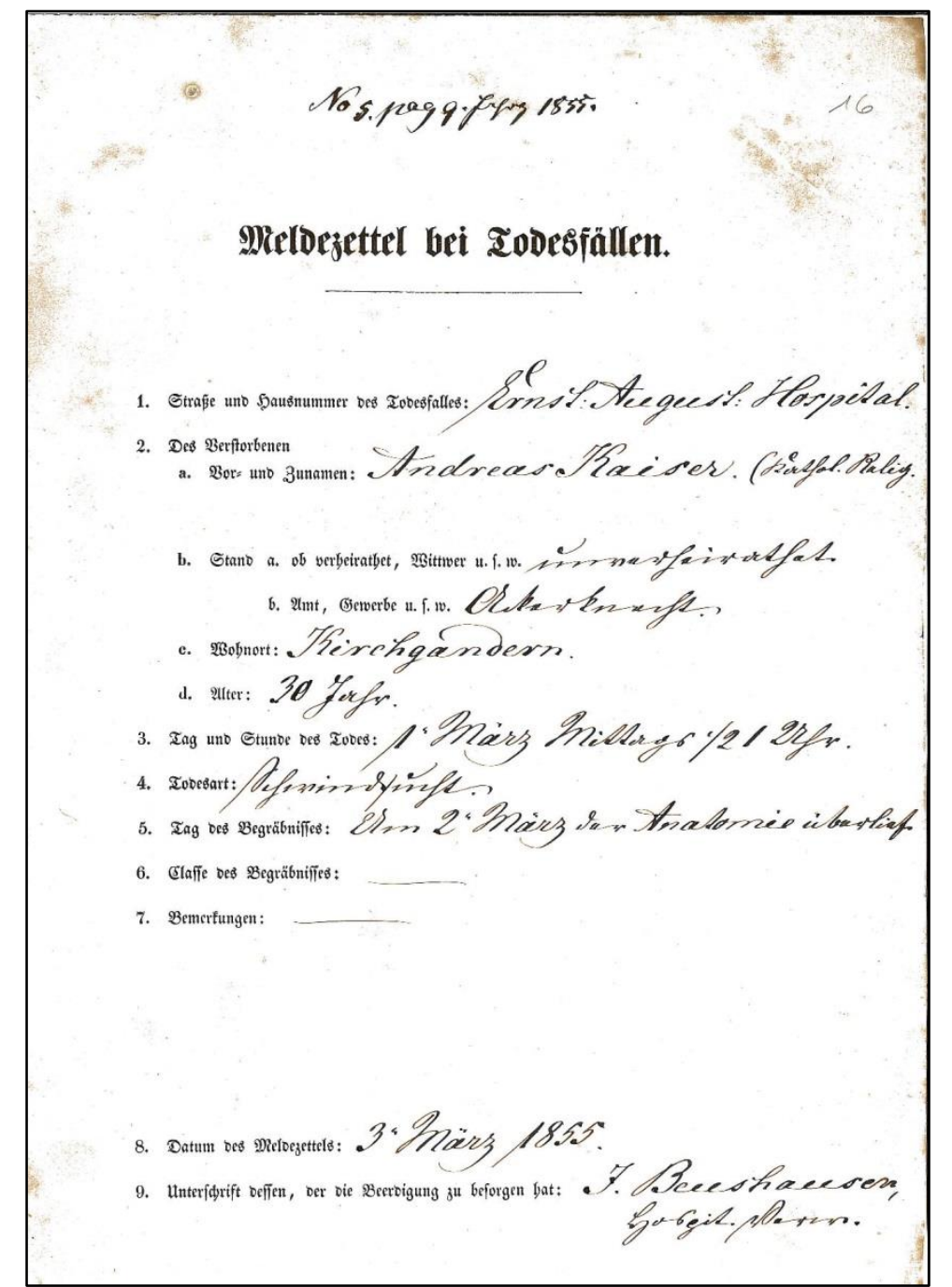

Abb. 90: Meldezettel: Andreas Kaiser, starb im Alter von 30 Jahren an Schwindsucht (Tuberkulose), Ackerknecht von Beruf (BAH, Pfarrarchiv [PfA] Göttingen, Sign. 56. 2018). 
Insgesamt sieht die Auswertung der Meldezettel wie folgt aus:

Tab. 6: Auswertung der Meldezettel bei Todesfällen. Kathol. = katholisch, n.l. = nicht lesbar; k.A. = keine Angabe.

\begin{tabular}{|c|c|c|c|c|c|c|}
\hline Geschl. & Alter & Religion & Stand & Gewerbe & Todesart & Wohnort \\
\hline $\mathrm{m}$ & 63 & Kathol. & - & Wollkämmer & Fleckenfieber & Fetterode \\
\hline $\mathrm{m}$ & 45 & k.A. & k.A. & Arbeiter & $\begin{array}{l}\text { Chron. } \\
\text { Nierenentzündung }\end{array}$ & Quedlinburg \\
\hline $\mathrm{m}$ & 64 & k.A. & k.A. & Färber & Lungenentzündung & $\begin{array}{l}\text { Rietberg in } \\
\text { Westphalen }\end{array}$ \\
\hline $\mathrm{m}$ & 58 & Kathol. & Unverheiratet & Tagelöhner & $\begin{array}{l}\text { Fractura proc. odont. } \\
\text { epistroph. } \\
\text { (Genickbruch) }\end{array}$ & Mingerode \\
\hline $\mathrm{m}$ & 27 & k.A. & Unverheiratet & Feldarbeiter & $\begin{array}{l}\text { Schwindsucht } \\
\text { (Tuberkulose) }\end{array}$ & Tyrol \\
\hline $\mathrm{m}$ & 43 & Kathol. & k.A. & Arbeiter & Lungenentzündung & Costine Kreis Posen \\
\hline $\mathrm{m}$ & 29 & Kathol. & k.A. & Maurer & $\begin{array}{l}\text { Lungenschwindsucht } \\
\text { (Tuberkulose) }\end{array}$ & $\begin{array}{l}\text { Westhausen bei } \\
\text { Duderstadt }\end{array}$ \\
\hline $\mathrm{m}$ & 18 & Kathol. & - & Malerlehrling & $\begin{array}{l}\text { Zuckerruhr } \\
\text { (Diabetes) }\end{array}$ & Duderstadt \\
\hline $\mathrm{m}$ & 73 & Kathol. & Verheiratet & Tagelöhner & $\begin{array}{l}\text { Marasmus senilis } \\
\text { (Altersschwäche) }\end{array}$ & Kella \\
\hline $\mathrm{m}$ & 50 & Kathol. & Unverheiratet & Stallknecht & Emphysema & $\begin{array}{l}\text { Dellbrück Westphalen } \\
\text { Kreis Paderborn }\end{array}$ \\
\hline $\mathrm{m}$ & 25 & Kathol. & Verheiratet & Arbeitsmann & Unterleibstyphus & $\begin{array}{l}\text { Burgwalde Kreis } \\
\text { Heiligenstadt }\end{array}$ \\
\hline $\mathrm{m}$ & 34 & Kathol. & Verheiratet & Tagelöhner & $\begin{array}{l}\text { Zuckerruhr } \\
\text { (Diabetes) }\end{array}$ & $\begin{array}{l}\text { Gerblingerode Kreis } \\
\text { Duderstadt }\end{array}$ \\
\hline $\mathrm{m}$ & 26 & Kathol. & - & Dienstknecht & Nierenentzündung & $\begin{array}{l}\text { Dieterode Kreis } \\
\text { Heiligenstadt }\end{array}$ \\
\hline $\mathrm{m}$ & 53 & Kathol. & Verheiratet & Ackerknecht & $\begin{array}{l}\text { Bruch des } \\
\text { Oberschenkels }\end{array}$ & Hebenshausen \\
\hline $\mathrm{W}$ & 30 & Kathol. & Unverheiratet & - & Beckenabbruch & Wollbrandshausen \\
\hline $\mathrm{m}$ & 28 & Kathol. & Unverheiratet & $\begin{array}{l}\text { Zigarren- } \\
\text { macher }\end{array}$ & Kopfgeschwüre & Bilshausen \\
\hline W & 21 & Kathol. & Unverheiratet & - & $\begin{array}{l}\text { Unterleibs- } \\
\text { entzündung }\end{array}$ & Espligerode \\
\hline $\mathrm{m}$ & 64 & k.A. & Unverheiratet & n.l.-arbeiter & Gemütskrankheit & unbekannt \\
\hline $\mathrm{m}$ & 30 & Kathol. & Unverheiratet & Ackerknecht & $\begin{array}{l}\text { Schwindsucht } \\
\text { (Tuberkulose) }\end{array}$ & Kirchgandern \\
\hline $\mathrm{m}$ & 58 & Kathol. & Verheiratet & Stellmacher & n.l. & $\begin{array}{l}\text { Käferhausen bei } \\
\text { Dingelstedt }\end{array}$ \\
\hline
\end{tabular}

Es konnte kein Skelett direkt mit einem der Meldezettel in Verbindung gebracht werden. Eine Übereinstimmung ist allerdings nicht gänzlich ausgeschlossen. Da es sich lediglich um eine Teilgrabung handelt, sind womöglich weitere Anatomieleichen im angrenzenden Bodenareal begraben. 
Sowohl der ausgeübte Beruf als auch die im Feld „Todesart“ aufgeführten Krankheiten, wie zum Beispiel Tuberkulose, sind häufig in den sozialen Unterschichten zu finden. Anhand der Tabelle 6 lässt sich erkennen, dass der Anteil an männlichen Individuen, welche an die Anatomie geliefert wurden, deutlich überwiegt. Damit entspricht die Geschlechterverteilung in den archivalischen Unterlagen den Ergebnissen der morphologischen Geschlechtsbestimmungen. Allerdings liegt laut den Dokumenten der Sterbegipfel eher im adulten Bereich, während er laut der morphologischen Altersbestimmung eher im maturen Altersbereich angesiedelt ist (siehe Abbildung 91). Diese Diskrepanz könnte an den unterschiedlichen Stichproben liegen. Keines der geborgenen Skelette konnte einem Individuum der Meldezettel sicher zugeordnet werden. Darüber hinaus handelt es sich bei der Grabung lediglich um eine Teilgrabung. Allerdings zeigen die Individuen, welche zusätzlich durch die Methode der Dentochronologie untersucht wurden, fast durchgehend eine Überschätzung des Sterbealters bei der morphologischen Methode. Die Stichprobe aus der Gruppe der Individuen, deren Zahnringe gezählt wurden, zeigt ebenfalls einen leichten Gipfel im adulten Altersbereich (siehe Kapitel 4.1.1). Es wurden keine Meldezettel gefunden für Individuen, die unter 18 Jahre alt waren und an die Anatomie geliefert wurden.

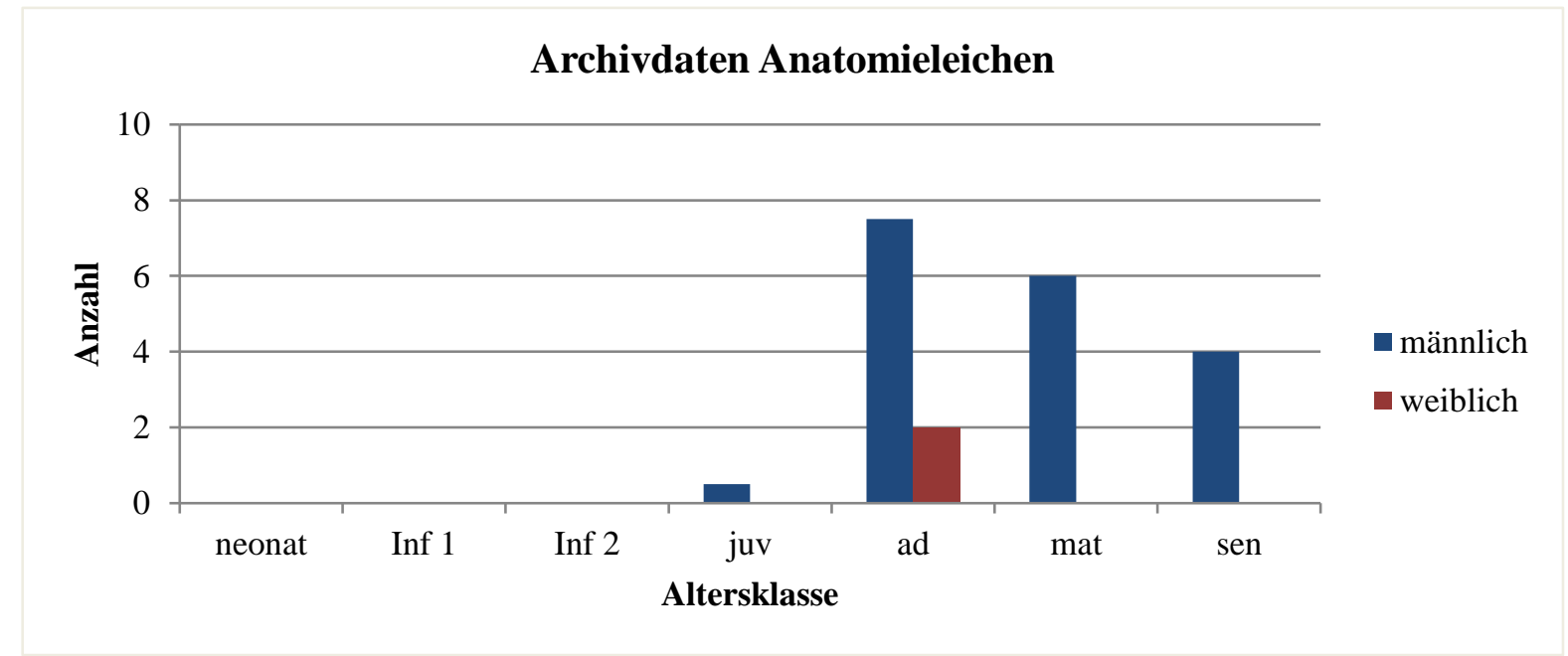

\footnotetext{
Abb. 91: Absolute Häufigkeit der Altersverteilung der Anatomieleichen $(n=20)$ in Abhängigkeit vom Geschlecht. Inf1 = Infans 1, Inf2 = Infans 2, juv = Juvenis, ad = Adultas, mat = Maturitas, sen = Senium.

Aufzeichnungen aus der Anatomie über Sektionen, Leicheneingangsbücher und Verbleib der katholischen Anatomieleichen konnten nicht gefunden werden. Das Gebäude der Anatomie wurde, aufgrund der unmittelbaren Nähe zum Bahnhof Göttingen, im Zweiten Weltkrieg 1945 durch Fliegerbomben zerstört. Damit sind die Unterlagen mehrerer Dekaden unwiederbringlich verloren gegangen.
} 


\section{Diskussion - Biologische Daten}

\section{Diskussion}

In dieser Arbeit wurde der Einfluss der sozialen Stellung in Form von Morbiditätsfrequenzen am Skelett untersucht. Die untersuchten Individuen mit Sägespuren am Skelett sind vermutlich in der Anatomie seziert worden und stammten, laut archivalischer Unterlagen, aus den niedrigsten sozialen Schichten. Problematisch für den Vergleich mit der Referenzserie ist, dass es sich bei den Regelbestattungen des ersten katholischen Friedhofs Göttingens vermutlich ebenfalls um Individuen handelt, die keiner hohen sozialen Schicht angehörten. Wehking (1992) beschreibt die katholische Gemeinde in deren Anfangszeiten als ärmliche Gemeinde, die in der protestantischen Region in und um Göttingen mit Anfeindungen zu kämpfen hatte. Es muss in Betracht gezogen werden, dass der Unterschied zwischen der sozialen Stellung der Regelbestatteten und der Anatomieleichen in Einzelfällen sehr gering ist.

\subsection{Biologische Daten}

\section{Demografie}

\section{Geschlechterverteilung}

Der hohe Männeranteil in beiden Gruppen ist sehr ungewöhnlich, zumal es keine Hinweise darauf gibt, dass zu dieser Zeit deutlich mehr Männer gestorben sind. Bei den Individuen vom ersten katholischen Friedhof handelt es sich um einen Teil der städtischen Bevölkerung Göttingens.

Der Männerüberhang ist vor allem in der Gruppe der Anatomieleichen sehr hoch. Häufig wurden die Leichen von Bettlern, hingerichteten Straftätern, Reisenden und Bedürftigen zu anatomischen Lehr- und Forschungszwecken genutzt. Vermutlich setzte sich diese Gruppe in erster Linie aus Männern zusammen. Für die geringe Anzahl an weiblichen und subadulten Individuen in dieser Gruppe gibt es zwei mögliche Erklärungen. Ein Grund ist, dass die im Accouchierhaus unter der Geburt verstorbenen Frauen nicht an die Anatomie übergeben, sondern bestattet wurden. Das Accouchierhaus galt vor allem als Geburtsklinik für mittellose und unverheiratete Frauen, die dort Unterkunft, Verpflegung und hygienisch-medizinische Versorgung erhielten. Allerdings stand bei der Einrichtung dieser Institution nicht das Wohl der Frauen im Vordergrund. Vielmehr galten die Schwangeren in erster Linie als Demonstrationsobjekte für die medizinische Forschung und Lehre (Kratz-Ritter 2016). Ein 


\section{$\underline{\text { Diskussion - Biologische Daten }}$}

weiterer denkbarer Grund ist, dass aus moralischen oder Pietätsgründen weitestgehend männliche Leichen von den männlichen Studenten seziert werden sollten.

Auch in der Gruppe der regelbestatteten Individuen der katholischen Gemeinde ist ein erhöhter Männeranteil erkennbar. Obwohl der Bergungsplan dafür keinerlei Hinweise zeigt (siehe Abbildung 25 Kapitel 4.1.1), könnte das Ungleichgewicht zwischen den Geschlechtern der Teilbergung des Friedhofs geschuldet sein. Eine weitere mögliche Erklärung für den hohen Männeranteil könnten die zugezogenen Professoren und Studenten sein, allerdings wird die Anzahl den Maskulinitätsindex nicht in dem Ausmaß beeinflusst haben. Durch die Gründung einer katholischen Gemeinde Mitte des 18. Jahrhunderts wurde die Universität attraktiver für Akademiker mit katholischem Glauben. Zu bedenken ist auf jeden Fall die kurze Belegdauer des Friedhofs. Möglicherweise sind in den knapp 30 Jahren tatsächlich viele Männer gestorben und die dazu gehörigen Ehefrauen starben erst, als der Friedhof bereits geschlossen war. Allerdings ist dieses Szenario eher unwahrscheinlich. Offenbar wurden tatsächlich weniger Frauen auf diesem Areal des Friedhofs bestattet. Ein hoher Anteil der subadulten Individuen konnte nicht geschlechtsbestimmt werden. Die starke Zersetzung von grazilen subadulten Knochen und die daraus resultierende Nichtbestimmbarkeit des Geschlechtes dürfte hierfür der Grund sein.

Zusammenfassend kann festgestellt werden, in der Gruppe der Anatomieleichen ist vermutlich die Auswahl des Lehrmaterials der Grund für den erhöhten Männeranteil, in der Gruppe der Regelbestattungen eventuell die Selektion aufgrund des unvollständig ergrabenen Areals.

\section{Altersverteilung}

Der geringe Anteil der subadulten Individuen in der Gruppe der Anatomieleichen könnte in der Auswahl des Lehrmediums begründet liegen. Möglicherweise sind aus ethischen Gründen seltener Kinderleichen für den Sektionsunterricht genutzt worden. Eventuell war aber auch das Interesse am ausgewachsenen Körper größer, zumal viele Strukturen mit dem Übergang ins Erwachsenenleben weiter und größer entwickelt sind. Aus dem Schriftwechsel von 1796 (siehe Abbildung 85) geht hervor, dass die abzuliefernden Leichen ein Mindestindividualalter von zehn Jahren haben sollen. Eine andere Begründung könnte sein, dass es tatsächlich weniger Kinder- als Erwachsenenleichen gab. Die Akquirierung von Anatomieleichen fand im großen Maße bei hingerichteten Verbrechern statt. Dabei handelt es sich ausschließlich um Erwachsene. Möglich ist, dass verstorbene Kinder, aus Ablehnung der Gesellschaft gegenüber Sektionen, lediglich dem Ordnungsamt gemeldet, nicht aber der Anatomie überliefert wurden. 
Aber auch in der Gruppe der Regelbestattungen ist der Anteil an subadulten Individuen, insbesondere derer im Altersbereich Infans 1, relativ gering. Dieser Lebensabschnitt unterliegt in der Regel einer erhöhten Mortalitätsrate, da das Immunsystem noch nicht vollständig ausgebildet ist und Kleinkinder den sogenannten Kinderkrankheiten schutzlos ausgesetzt sind. Des Weiteren findet in dieser Zeit eine Umstellung von der Muttermilch auf feste Nahrung statt, dies gestaltet sich gelegentlich problematisch. Da die medizinische Versorgung im 19. Jahrhundert bei Weitem nicht an die heutigen Standards heranreicht, konnten Infektionen und andere Krankheiten weniger erfolgreich behandelt werden. Dies führte vor allem im Kleinkindalter zu einer erhöhten Sterblichkeitsrate. Auf diesem Friedhof scheinen vor allem neonatale Individuen zu fehlen. Dies könnte unter anderem darin begründet liegen, dass Totgeburten, die im 1791 gegründeten Accouchierhaus geboren wurden, oft weder regulär begraben noch an die Anatomie verbracht wurden. „Verstorbene Embryos wurden als Anschauungsmaterial für die gynäkologische Ausbildung obduziert oder präpariert.“ (KratzRitter 2016).

Obwohl es aufgrund des Grabungsplanes keine Hinweise darauf gibt, besteht weiterhin die Möglichkeit, dass das Säuglings- und Kinderdefizit eine Art Artefakt sein könnte, zustande gekommen durch die Teilgrabung. Möglich ist auch, dass sich die Kinderknochen mit ihrer geringen Robustizität trotz Sargbestattung schneller im Erdboden zersetzt haben. Allerdings sind im Grabungsplan (siehe Abbildung 3) keine größeren Lücken zwischen den Reihengräbern zu erkennen, die darauf schließen lassen würden, dass sich dort weitere Kindergräber befunden haben.

In historischen Populationen zeigt sich für Frauen meist ein erster Sterbegipfel im adulten Altersbereich, da Frauen oft unter der Geburt oder deren Folgen verstarben. Der Sterbegipfel der in dieser Population untersuchten Frauen liegt im maturen Altersbereich. Möglicherweise führte die umfassende medizinische Ausbildung in der Frauenheilkunde der Universität Göttingen und im Accouchierhaus zu einer niedrigen Todesrate bei Frauen im gebärfähigen Alter während ihrer Schwangerschaft und der Niederkunft.

Zusammenfassend ist festzustellen, dass es aufgrund der selektiven Ergrabung des Friedhofareals ein Kleinkinder- und Kinderdefizit gibt. In beiden Gruppen liegt der Sterbegipfel unabhängig vom Geschlecht im maturen Altersbereich. 


\section{Diskussion - Biologische Daten}

\section{Körperhöhenverteilung}

Die mittlere Körperhöhe einer Population ist als Indikator für die Lebensumstände und daher indirekt für die Zugehörigkeit zu einem sozialen Stand zu verstehen. Die Grundannahme ist, dass Menschen, die nach ihrem Tod als Anatomieleichen genutzt wurden, einer sozial niederen Schicht angehörten und dies oft mit einer schlechten Nahrungsmittelversorgung einherging. Daher müssten folglich die Skelette dieser Personen geringere Körperhöhen aufweisen. Es ist bekannt, dass Wachstumsstillstand durch schwere Krankheiten in der Kindheit, aber auch durch massiven Nährstoffmangel hervorgerufen wird.

Da die durchschnittliche Körperhöhe beider Gruppen gleich ist, war offensichtlich die Nahrungsmittelversorgung während des Wachstums in der Kindheit und in der Jugend ähnlich gut. Der Schritt in die Armut oder das Abrutschen in eine niedrigere soziale Schicht fand möglicherweise erst im Erwachsenenalter statt. Eine weitere Möglichkeit ist, dass die von der Kirche und Stadt stark ausgeprägte Armenversorgung eine dramatische Unter- bzw. Fehlernährung in der armen Bevölkerung durch die Ausgabe von Nahrungsmitteln verhinderte. Es ist allerdings auch bekannt, dass eine ausreichende Erholungsphase reicht, um ein Wachstumsdefizit wieder aufzuholen. Erst lang anhaltende Perioden schwerer Unterversorgung resultieren in einer durchschnittlich geringeren Körperhöhe einer Population (Frisancho 1980, Haidle 1997). Frisancho et al. (1970) konnten an einer mittelamerikanischen Population zeigen, dass ein vermindertes Körperhöhenwachstum im Kindesalter später nicht mehr vollständig ausgeglichen werden kann.

Zusammenfassend ist festzustellen, dass es zwischen den beiden untersuchten Gruppen keinen Körperhöhenunterschied gibt.

\section{Diskrete Merkmale}

Zusammenfassend kann festgestellt werden, dass es in der katholischen Population diskrete Merkmale in Form anatomischer Varianten gibt. Allerdings sind keine auffälligen Häufungen bestimmter Merkmale zu finden, welche Rückschlüsse auf die Verwandtschaft zweier oder mehrerer Individuen zulassen. Hierbei ist zu bedenken, dass der Belegungszeitraum nur ca. 30 Jahre umfasst und daher eventuell nicht mehrere Individuen einer Familie auf diesem Friedhof begraben wurden. Keines der untersuchten Merkmale ist gehäuft bei einer der beiden untersuchten Gruppen anzutreffen. 


\section{Diskussion - Biologische Daten}

\section{Krankheiten}

\section{Unspezifische Stressmarker}

Da es in beiden Gruppen sehr viele Individuen mit Cribra orbitalia, aber keinen signifikanten Unterschied zwischen den Gruppen gibt, müssen hier Möglichkeiten diskutiert werden, welche über ein bloßes Auftreten von Mangelernährung hinausgehen. Die Cribra orbitalia könnte hier das Resultat einer Anämie in Folge von weitverbreiteten und wiederkehrenden Malariaausbrüchen in ganz Europa sein, welche bis in das 19. Jahrhundert auftraten. Die Krankheit wurde primär durch Söldner nach Europa eingeschleppt, später über die Handelswege aus Afrika, Indien und Ostasien (Dalitz 2005). Erst mit der Trockenlegung der Feuchtgebiete und weiteren Schutzmaßnahmen, z. B. verbesserte Wohnhygiene, wurden die Brutplätze für die Malaria übertragenden Mücken deutlich reduziert. In den gemäßigten Breiten handelt es sich hauptsächlich um die durch Plasmodium vivax verursachte Malaria tertiana (Dalitz 2005), auch bekannt als „Anderntagsfieber“. Eine Malariainfektion führt zu einer Blutarmut, da sich der Parasit für die Vermehrung in den roten Blutkörperchen einnistet und diese schlussendlich zerstört. Da der Körper bestrebt ist, wieder ein Gleichgewicht herzustellen, nimmt er eine flächenmäßige Vergrößerung der Blutbildungszentren vor. Um die Masse blutbildenden Knochens zu vergrößern, verdicken sich der Knochen und die Oberfläche am Orbitadach. In seltenen Fällen wird die Oberfläche im Bereich der Lamina externa des Os frontale porös in Form einer Cribra orbitalia beziehungsweise Cribra cranii externa (Schultz 2001). Weitere denkbare Endoparasiten wären Darmparasiten. Allerdings können außer der Anämie auch andere Krankheiten zu porösen Orbitadächern führen. Beispiele sind Skorbut, Rachitis, Entzündungen und Blutungsgeschehen die knöchern umgebaut werden (Schultz 2001, Wapler et al. 2004).

Schmelzhypoplasien konnten bei 19,2\% $(\mathrm{n}=14 / 73)$ der untersuchten Regelbestattungen und $30,6 \%(n=11 / 36)$ bei untersuchten Anatomieleichen beobachtet werden. Das gemeinsame Auftreten von Harris-Linien und transversalen Schmelzhypoplasien konnte lediglich bei 62 der 159 Individuen untersucht werden. Davon zeigten wiederum nur 12 Individuen (7 Regelbestattungen, 5 Anatomieleichen) beide unspezifische Stressfaktoren. Die transversalen linearen Schmelzhypoplasien entstehen während der Zahnontogenese im Kindesalter, weshalb ein Vorkommen im Erwachsenenalter darauf hindeutet, dass die Mangelphasen überlebt wurden. Die Mineralisationsstörungen aufgrund von Mangelernährung, (Stoffwechsel-) Erkrankungen oder lang anhaltenden schwerwiegenden Infektionen (Ogden et al. 2007) sind bei den Individuen, die nach ihrem Tod seziert wurden, geringfügig häufiger zu beobachten. 
Dies spricht sowohl für eine ausreichende Grundversorgung, als auch für eine ausreichende Nährstoffzufuhr im Kindesalter in beiden Gruppen, mit einer etwas besseren Versorgung zugunsten der Gruppe der Regelbestatteten.

Parallel zueinander verlaufende, im Röntgenbild strahlendichte Harris-Linien, können durch unterschiedliche Prozesse, wie physischen Stress, Mangelernährung oder schwere Erkrankungen entstehen. Wie schon Templin (1993) bei den Kindern der Population von Bettingen (Schweiz) feststellte, treten Harris-Linien nicht immer mit transversalen Schmelzhypoplasien gemeinsam auf. Wells (1967) meint, dass es für eine Wechselbeziehung nur geringe Anhaltspunkte gibt, sodass Harris-Linien und transversale lineare Schmelzhypoplasien unterschiedliche Antworten des Körpers auf Infektionen und Mangelernährung sein könnten.

Zusammenfassend kann gesagt werden, dass sowohl die Nährstoffversorgung als auch die medizinische Grundsicherung während der Kindheit der untersuchten Individuen gewährleistet war. Es gibt keinen signifikanten Unterschied zwischen den Regelbestatteten und den Anatomieleichen hinsichtlich der Häufigkeit von Cribra orbitalia und transversaler linearer Schmelzhypoplasien. Auffallend ist allerdings, dass das Vorkommen von unspezifischen Stressfaktoren in der Gruppe der Anatomieleichen immer etwas höher als in der Gruppe der Regelbestattungen ist. Zu bedenken ist allerdings, dass die Stichproben der sezierten Frauen und Kinder sehr gering waren.

\section{Mangelerkrankungen}

Eine Anämie kann durch Mangelerkrankungen verursacht werden. Ein Mangel an Eisen oder notwendigen Aminosäuren, z. B. Lysin und Tryptophan entsteht nutritiv durch eine einseitige Ernährung (Schultz 1982). Die Anämien durch Blutverlust infolge von großen Wunden, Menstruation oder Parasitenbefall verursacht zwar einen Mangel an roten Blutkörperchen und damit auch Eisen, muss aber gegen den nutritiven Eisenmangel abgegrenzt werden. In den untersuchten Gruppen gab es etliche Individuen mit einer für Anämie typischen Cribra orbitalia, allerdings konnten weitere Merkmale wie eine poröse Hyperostose, Knochenschwellungen oder ein sogenannter Bürstenschädel nicht gefunden werden.

Nur wenige Individuen ( $\mathrm{n}=5)$ weisen deutliche Anzeichen für chronische Mangelerkrankungen auf. Die fehlenden signifikanten Unterschiede zwischen der Gruppe der Regelbestatteten und der Gruppe der Anatomieleichen weisen darauf hin, dass die Versorgung mit Nährstoffen im Bereich der sozialen Randgruppen kaum schlechter ausgesehen hat als für 


\section{$\underline{\text { Diskussion - Biologische Daten }}$}

die durchschnittliche katholische Bevölkerung. Allerdings handelt es sich bei den Anzeichen für Mangelerkrankungen wie Skorbut, Osteomalazie und Anämie um Merkmale langwieriger und chronischer Prozesse. Individuen können kurz vor ihrem Tod durchaus an einem Nährstoffmangel gelitten haben, ohne dass dies morphologisch erkennbar ist.

Zusammenfassend kann festgestellt werden, dass es in der katholischen Bevölkerung in und um Göttingen offenbar wenige Fälle chronischer Mangelernährung (Vitamin C-, Vitamin D- oder Eisenmangel) gegeben hat.

\section{Infektionskrankheiten}

Meningeale Reaktionen, welche sich in Form entzündlicher und/oder hämorrhagischer Prozesse manifestieren, konnten in beiden Gruppen $(\mathrm{n}=15)$ gefunden werden. Allerdings zeichnet sich hier keine Tendenz für Gruppenunterschiede oder Geschlechterunterschiede ab. Da meningeale Reaktionen unterschiedlichste Ursachen haben können, ist es nicht möglich das Vorkommen ausschließlich mit dem sozialen Stand eines Individuums in Verbindung zu bringen. Vorstellbar ist allerdings, dass ein geschwächtes Immunsystem als Resultat einer Mangelernährung zu Infektionskrankheiten, z.B. Meningitis und Sinusitis, führt. Für alle untersuchten Kieferhöhlen wurden tendenziell mehr Fälle von Sinusitis in der Gruppe der Anatomieleichen $(n=14 / 18)$ als in der Gruppe der Regelbestattungen $(n=9 / 25)$ gefunden. Ebenfalls zeigten signifikant $\left(x^{2}(1 ; 75)=0,18 ; p=0,019\right)$ mehr Anatomieleichen $(n=24 / 29)$ Spuren einer chronischen Ostitis media als regelbestattete Individuen $(n=26 / 46)$. Die Ursache für das gehäufte Vorkommen beider Krankheiten in der Gruppe der Anatomieleichen könnte unter anderem in ungünstigen Lebensbedingungen in den vermutlich niedrigen Sozialklassen (Schultz 1979), dem regionalen Klima und/oder in einem geschwächten Immunsystem aufgrund von Mangelernährung liegen.

Mehr Regelbestattete zeigen Anzeichen einer chronisch entzündlichen Mundschleimhaut im Bereich des harten Gaumens. Der Grund hierfür könnte in einer unterschiedlichen Ernährung zwischen den Gruppen, Parodontopathien oder eine Mangelernährung wie Skorbut liegen. Eine Krankheit wie Skorbut verringert die Abwehrkräfte, was wiederum gehäuft zu Infektionskrankheiten, vor allem bei Kindern und alten Menschen, führt. Ebenso ist das Kariesvorkommen in der Gruppe der Regelbestattungen höher als bei den Anatomieleichen. Es wurden nur wenige Fälle $(n=4)$ von Knochenentzündungen in Form von Ostitis, Osteomyelitis und Periostitis in beiden Gruppen gefunden. Meist entstanden die Knochenentzündungen als Folge traumatischer Geschehen. Es konnten keine Gruppen- oder Geschlechtsunterschiede 
festgestellt werden. Eine Erkrankung, die allgemein mit Armut in Verbindung gebracht wird, ist die Tuberkulose. Allerdings konnte sie trotz Anfangsverdacht (Individuum 138) an keinem Skelett nachgewiesen werden. Dies steht im Kontrast zu den archivalischen Aufzeichnungen, welche in mehreren Fällen Tuberkulose als Todesursache in der Gruppe der Anatomieleichen auflistet. Typischerweise wäre eine Tuberkulose bei einfachen Arbeitern, die einem Beruf in einer Umgebung mit verdreckter Luft nachgehen, zu erwarten gewesen.

Die molekulargenetische Untersuchung der Knochen auf Erreger-DNA war lediglich teilweise erfolgreich. Da für die Individuen selbst ein guter DNA-Erhalt nachgewiesen wurde, erscheint es unwahrscheinlich, dass die Pathogen-DNA zu stark degradiert ist, um nachweisbar zu sein. Bei der Untersuchung der DNA ergaben sich komplette Sequenzen, jedoch ergab die BLASTSuche bei zwei von drei Proben keine Übereinstimmung mit bekannten Pathogen-DNASequenzen. Allerdings sind nicht alle Erreger, die es auf der Welt gibt, bereits sequenziert worden. Des Weiteren fand das Primerdesign immer mittels Referenzsequenzen von rezenten Bakterien statt. Es ist aber vorstellbar, dass sich die DNA der Pathogene im Verlauf der Zeit aufgrund von Mutationen und horizontalem Gentransfer verändert hat und deswegen bei einer BLAST-Suche nicht identifiziert werden konnte. Vorstellbar wäre hier eine weiterführende Untersuchung der Proteine, da Proteine in der Knochenmatrix eingebunden besser überdauern als aDNA (Schmidt-Schultz und Schultz 2004).

Mangelernährung und die Häufigkeit des Auftretens von Infektionskrankheiten hängen miteinander zusammen. Dies soll im Folgenden am Skelett der Anatomieleiche 105B gezeigt werden. Die Oberflächen beider Augendächer sind stark porös in Folge einer Cribra orbitalia, welche durch eine Anämie oder chronischen Skorbut etc. entstehen kann. Solch eine Mangelernährung führt zur Schwächung des Immunsystems, woraufhin die Abwehr des Körpers gegen Krankheitserreger heruntergesetzt ist. Das Skelett der Anatomieleiche zeigt Anzeichen einer chronischen Mittelohrentzündung, chronischer Entzündungen in den Sinus maxillaris und eine chronische Entzündung des harten Gaumens. In Folge einer Infektionskrankheit im Bereich des Craniums, z. B. Otitis media, kommt es gelegentlich zur Infektion der Meningen. Das Individuum zeigt in den Fossa cranii anterior beiderseits deutliche Impressiones digitatae als Folge intracranialen Drucks in Form einer Hirndrucksymptomatik. In der Abbildung 94 ist für das Individuum 105B dargestellt, wie eine Mangelernährung das Auftreten der oben beschriebenen Infektionskrankheiten begünstigt. 


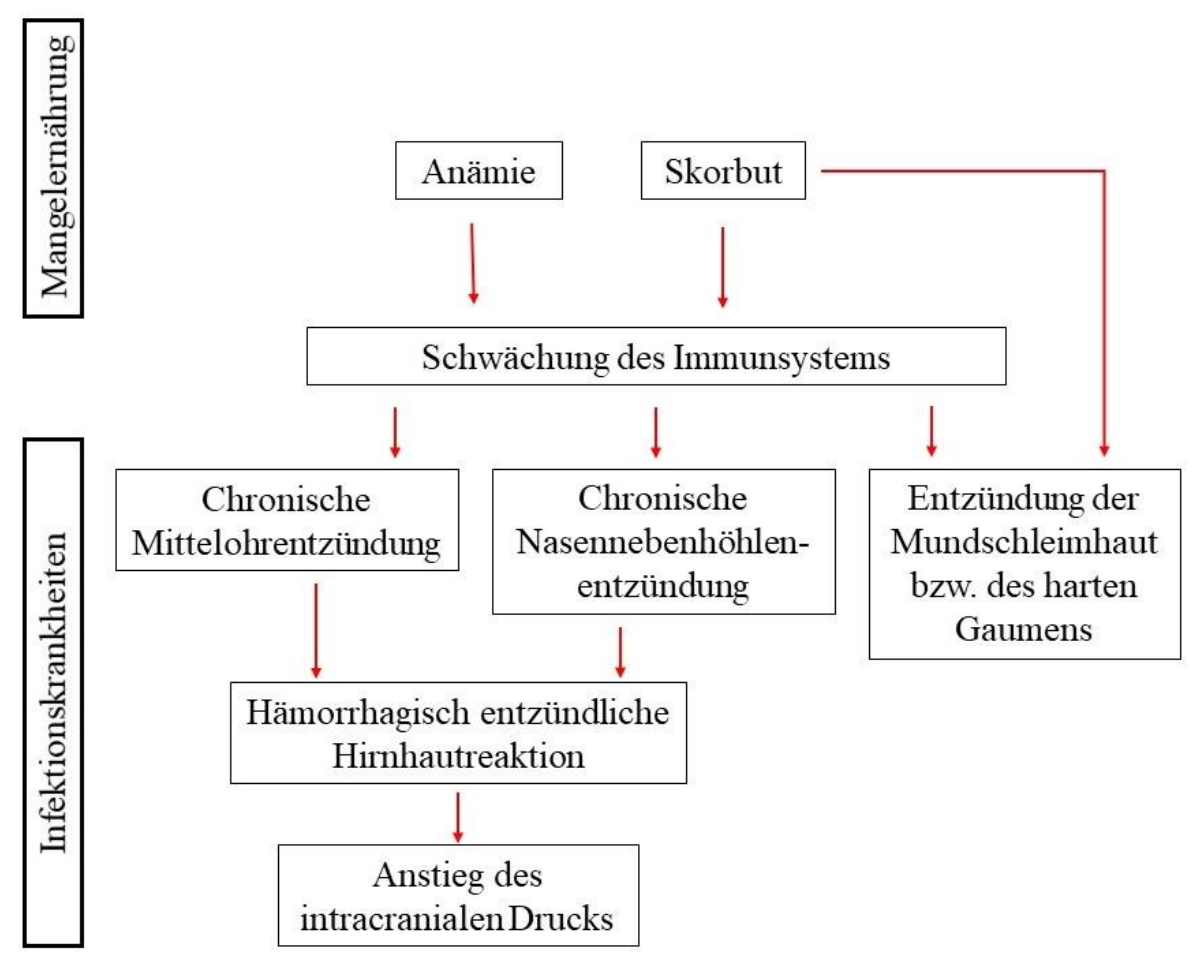

Abb. 94: Zusammenhang von Mangel- und Infektionskrankheiten anhand der pathologischen Veränderungen am Skelett des Individuums 105B, männlich, 40 - 60 Jahre.

Zusammenfassend ist festzustellen, dass Infektionskrankheiten wie Sinusitis und Otitis media häufiger bei den Anatomieleichen zu finden waren. Diese Erkrankungen werden durch ein geschwächtes Immunsystem infolge schwieriger Lebensumstände (z. B. Mangelernährung und problematische Wohnverhältnisse) in einer niedrigen sozialen Schicht begünstigt. Für die Stomatitis, ein Krankheitsbild, welches unter anderem durch die Ernährung begünstigt wird, wurden mehr Fälle unter den Regelbestatteten gefunden.

\section{Arthrose, Arthritis}

Arthrose und Arthritis kommen selten isoliert voneinander vor, da degenerative und proliferative Prozess meist aufeinanderfolgen. Umwelt und genetische Komponenten können während des Krankheitsverlaufes die Dauer und Intensität der Arthritis und Arthrose beeinflussen. Weder die regelbestatteten Individuen noch die Anatomieleichen zeigten ein erhöhtes einseitiges Krankheitsvorkommen. Dieser Umstand deutet darauf hin, dass es beiden Göttinger Gruppen weder im Alltag noch bei der Ausübung des Berufs zu dauerhaften einseitigen Belastungen gekommen ist.

Die Regelbestatteten weisen in allen Körperregionen geringfügig höhere Krankheitswerte auf, außer im proximalen und distalen Sprunggelenk. Dies widerspricht der Hypothese, dass Menschen, welche nach ihrem Tod seziert wurden, als Teil der sozial niedrigsten Schicht 
möglicherweise häufiger schwere körperliche Arbeit verrichtet haben als die Referenzserie des gleichen Friedhofsareals. Eine mögliche Interpretation der Daten ist, dass die regelbestatteten Individuen eventuell ebenfalls keinem sehr hohen sozialen Stand angehörten, denn die katholische Gemeinde war im 19. Jahrhundert sehr klein und wenig akzeptiert im protestantischen Göttingen. Eine weitere Interpretation ist, dass die Individuen der niedrigsten sozialen Schicht keinem Beruf oder nur teilweise einem Beruf nachgingen. Daher könnte die körperliche Belastung geringer gewesen sein. Möglich, aber eher unwahrscheinlich ist, dass Arme und Bettler durch eine Mangelernährung geschwächt und nicht zu harter körperlicher Arbeit in der Lage waren.

Arthrose entsteht allerdings sowohl bei Überlastung als auch bei Unterbelastung. Werden die ein Gelenk bewegenden Muskeln nicht genügend trainiert, wird der Knorpel stark abgenutzt und es kann zu einer Arthrose in den Gelenken kommen. Durch eine gut trainierte Muskulatur können selbst Krankheitswerte in Höhe einer Bewertungsziffer 4 problem- und schmerzlos kompensiert werden. Die höhere Arthroseintensität der regelbestatteten Individuen könnte daher paradoxerweise ebenso ein Hinweis für eine sehr geringe körperliche Belastung sein.

Im Vergleich mit anderen Skelettserien weisen die Skelette der katholischen Population von Göttingen eine geringe Arthroseintensität auf. Dieser Unterschied ist in der Lebensweise zu suchen. Die städtische katholische Population verrichtete tendenziell weniger körperliche Arbeit als zum Beispiel die Population aus Inden (Kr. Düren, Nordrhein-Westfalen), welche auf dem Land lebte. Dies wird durch den höheren Grad der Arthroseintensität in allen Altersgruppen deutlich.

In beiden Gruppen ist die Arthroseintensität der Wirbelsäulen im Durchschnitt doppelt so hoch wie die der Extremitätengelenke. Der Grund hierfür ist die Art der Lastenverteilung auf den Körper. Die Brust- und Lendenwirbelsäule trägt die Hauptlast, im Gegensatz dazu tragen die Extremitätengelenke lediglich eine Teillast. Zusätzlich wird die Wirbelsäule aufgrund ständigen Sitzens, einer schwachen Rumpfmuskulatur, Hohlkreuz oder Rundrücken stark belastet oder sogar fehlbelastet.

Die Gruppe der Anatomieleichen zeigt häufiger Myotendopathien bzw. Ligamentopathien im Bereich der Tuberositas deltoidea und der Befestigungsstelle des Ligamentum costoclaviculare als die Gruppe der Regelbestattungen. Die Myotendopathien äußern sich in Form mineralisierter Ausziehungen am Randbereich der Muskelansatzstellen (Osteophyten). In der Gruppe der Anatomieleichen sind vor allem Individuen ab der Altersklasse matur betroffen und bei den Regelbestattungen Individuen der Altersklassen matur und senil. Bei beiden betroffenen 
Arealen handelt es sich um Ansatzstellen der Muskulatur bzw. Bänder des Oberkörpers. Das Ligamentum costoclaviculare hat die Aufgabe die Clavicula am Thorax zu fixieren und gleichzeitig das Sternoclaviculargelenk zu stabilisieren gegenüber kranialen Zugkräften am Schlüsselbein. Das Ligamentum costoclaviculare ist sowohl bei der Bewegung in der Horizontalen als auch in der frontalen Ebene beteiligt. Sowohl an der Oberseite des Schlüsselbeins als auch am Humerus im Bereich der Tuberositas deltoideus ist der Deltamuskel (Musculus deltoidea) befestigt. Der Einsatz des Musculus deltoideus ist vielseitig je nach beanspruchtem Teil des Muskels. Er unterstützt die Abduktion und Adduktion des Oberarmes, die Ante- und Retroversion sowie die Außen- und Innenrotation. Andere Muskelansatzstellen bzw. - ursprünge wie die Crista tuberculi majoris und die Linea musculi solei sind überwiegend schwach ausgeprägt in beiden Gruppen. Dies spricht gegen eine sehr schwer körperlich arbeitende Bevölkerung.

Zusammenfassend ist zu sagen, dass die Gruppe der Anatomieleichen keine deutlich höhere Arthroseintensität gegenüber der Referenzserie aufweist. Beide Gruppen waren einer geringen körperlichen Belastung im Alltag ausgesetzt. Es konnten allerdings in beiden Gruppen gehäuft relativ deutliche Spuren von Myotendopathien und Ligamentopathien im Bereich der Oberextremitäten festgestellt werden.

\section{Erkrankungen der Zähne und Kiefer}

Die Anatomieleichen weisen mehr Zahnstein, aber weniger Karies und intravitale Zahnverluste auf als die Referenzserie.

In beiden Gruppen haben die Frauen häufiger Karies und intravitalen Zahnverlust, während bei den Männern häufiger Zahnstein vorkommt. Diese geschlechtsspezifische Verteilung der Zahnpathologien wurde schon oft beobachtet (Lendeckel 1990, Petersone-Gordina und Gerhards 2011, Schünemann 2014). Als mögliche Ursache für das gehäufte Vorkommen von Karies und intravitalen Zahnverlusten bei Frauen wird die stark kohlenhydratreiche Ernährung genannt. Durch diese Form der Nahrungszusammensetzung wird das saure Milieu in der Mundhöhle und das damit verbundene Wachstum der kariesverursachenden Bakterien begünstigt. Eine weitere Ursache könnte der gegenüber den Männern höhere Östrogenspiegel sein. Das Östrogen setzt die Speichelflussrate herab, schädliche Bakterien und Essensreste werden weniger gut durch den Speichel abgeführt und verweilen länger im Mundbereich. Petersone-Gordina und Gerhards (2011) erklären das erhöhte Vorkommen von Zahnstein bei Männern mit proteinreicher Nahrung. Oft wurde in der Vergangenheit dem Familienoberhaupt 


\section{$\underline{\text { Diskussion - Biologische Daten }}$}

gegenüber den restlichen Familienmitgliedern eine größere Portion Fleisch während der Mahlzeiten serviert. Die proteinreiche Ernährung führte zu einem eher basischen Mundmilieu und begünstigte die Bildung von Zahnstein. Allerdings ist dies keine Erklärung für das gehäufte Vorkommen von Zahnstein in der Gruppe der Anatomieleichen, da diese, zumindest jene Individuen, welche tatsächlich aus der sozialen Unterschicht stammen, wenig bis kein Fleisch konsumiert haben.

Für die Zunahme von intravitalen Zahnverlusten mit steigendem Alter in beiden Gruppen gibt es mehrere Erklärungen. Einer der wichtigsten Gründe für Zahnverlust ist die Gingivitis mit den daraus resultierenden Parodontopathien (Burt et al. 1990). Risikofaktoren für Gingivitis sind tiefe Zahnfleischtaschen, Zahnstein, Diabetes mellitus und Rauchen (Genco 1996). Auch fehlende orale Hygiene und sowohl sehr proteinreiche sowie säurehaltige Nahrung begünstigen den Zahnverlust (Eklund und Burt 1994). Sicherlich muss hier auch an Fälle von starker Abrasion bis zur Eröffnung der Pulpahöhle gedacht werden.

\section{Weitere Erkrankungen}

Die Gruppe der Anatomieleichen weist nicht häufiger schwere oder seltene Krankheiten am Skelettsystem auf als die Gruppe der Regelbestattungen. Allerdings worden die beiden Individuen, die unter einem Hydrocephalus litten, seziert. Es besteht die Möglichkeit, dass diese beiden Individuen aufgrund ihrer Hirndrucksymptomatik untersucht wurden.

\section{Traumata}

In beiden Gruppen sind wenige traumatische Verletzungsspuren zu finden. Dies spricht für eine städtische Population mit niedrigem Unfall- beziehungsweise Frakturrisiko.

Lediglich ein regelbestattetes Individuum (Individuum 48) wies Spuren längst verheilter massiver Verletzungen im Hüftbereich auf, wie sie zum Beispiel durch einen Sturz geschehen können. Eine Anatomieleiche (Individuum 61) zeigt Spuren eines längst verheilten Traumas im Schädelbereich. Die verheilten Verletzungen im Bereich des rechten Gonionwinkels und des rechten Gehörgangs lagen wahrscheinlich lange Zeit zurück. Denkbar ist, dass das Individuum im Kindesalter einen Sturz oder schweren Hieb erlitten hat, woraufhin rechtsseitig Unterkiefer und der Knochen um den Gehörgang Frakturen erlitten. Gleichzeitig weist das Individuum einen Hydrocephalus auf. Dieser entsteht durch intracranialen Druck aufgrund von meningealen Reaktionen. Der starke Druck von innen gegen die Schädelwände kann nur überlebt werden, wenn das Individuum zum Verletzungszeitpunkt noch im Kindesalter ist und 
die Schädelnähte noch nicht obliteriert sind. Aufgrund des Verheilungsgrades kann angenommen werden, dass die Ursache der Verletzung von Unterkiefer und Ohr und die Entstehung des Hydrocephalus dieselbe ist.

\section{Vergleich von Allelfrequenzen}

Es konnte kein genetischer Unterschied zwischen den Individuen verschiedener Sozialgruppen gefunden werden. Bei der katholischen Bevölkerung von Göttingen und aus der näheren Umgebung handelt es sich um eine homogene Gruppe, die trotz unterschiedlicher sozialer Schichten nicht untereinander divergiert.

Bereits in der Dissertation von Gerstenberger (2002) wurden ähnliche Vergleiche von Allelfrequenzen durchgeführt. Es handelte sich um das merowingische Gräberfeld Weingarten (Fr. Ravensburg), Baden-Württemberg. In der Merowingergemeinschaft gab es Gruppierungen nach sozialem Rang (Gerstenberger 2002). In der Dissertation wurde untersucht, ob die Population von Weingarten eine sozial durchlässige Bevölkerung war. Allerdings ergaben sich in der Arbeit von Gerstenberger ebenfalls keine Unterschiede bezüglich der Allelfrequenzen der untersuchten Individuen.

\subsection{Grabbeigaben, Beifunde und Sozialstatus}

Neben einem regelbestatteten Individuum wies auch eine Anatomieleiche Goldfüllungen im Gebiss auf. Dieser Fund ist erstaunlich angesichts der These, dass in der Anatomie in der Regel Individuen aus der sozialen Unterschicht seziert wurden. Allerdings ist die Zusammensetzung der Gruppe der Anatomieleichen recht heterogen. Neben Armen und Bettlern wurden auch hingerichtete Strafgefangene, die durchaus einem anderen sozialen Stand angehören konnten, in die Anatomie verbracht. Eine mögliche Erklärung ist, dass bei dem hochrangigen Individuum eine Obduktion im rechtmedizinischen Rahmen durchgeführt wurde. Zumal lediglich eine Craniotomie durchgeführt wurde und die Langknochen unversehrt geblieben sind. Craniotomien, z. B. beschrieben von Dr. Dieter Buhmann am Schädel von Fürst Wilhelm Heinrich von Nassau-Saarbrücken, wurden allerdings auch durchgeführt, um das Gehirn bedeutender Personen getrennt vom restlichen Körper zu beerdigen (persönliche Mitteilung von Prof. Dr. Dr. Schultz 16.01.2019).

Die einzelnen Beigaben und Beifunde können unterschiedliche Bedeutungen haben. Neben den häufig verbreiteten Rosenkränzen, die als Gebetskette für die Rosenkranzgebete genutzt wurden, sind Münzen und Schmuck häufig ein Zeichen für den sozialen Status. Verstorbene, 
welche zu Lebzeiten vermögend waren, wollten sich auch im Jenseits mit ihrem weltlichen Besitz, zum Beispiel Schmuck oder wertvolle Gegenstände, umgeben. Angehörige, die es sich leisten konnten, gaben den Verstorbenen häufig als Zeichen der Wertschätzung besondere Gaben mit ins Grab. Allerdings hat die Sitte, den Verstorbenen besonders wertvolle materielle Beigaben mit in das Grab zu geben, im 19. Jahrhundert stark abgenommen. Der Rosenkranz wurde am häufigsten sowie geschlechtsunabhängig beigegeben (Quelle: Brauchtum.de o. D.). Wie in Tabelle $4 \mathrm{zu}$ sehen, ist dies auch auf dem Friedhof der katholischen St. Michael Gemeinde Göttingen der Fall. Die Rosenkränze waren meist beim Auffinden der Skelette noch um die Unterarm- oder Handknochen geschlungen, teils lagen sie aber auch einfach im Bereich des Abdomens. Für Letzteres könnte der Grund im Verrutschen der Hände während der Bestattung oder der Verwesung der Weichgewebe liegen.

Die Grabbeigaben, die in den Gräbern des katholischen Friedhofs in Göttingen gefunden wurden, sind vergleichbar mit denen anderer Friedhöfe der gleichen Zeitstellung. Zum Beispiel sind auf dem ersten katholischen Friedhof von Berlin ebenfalls in erster Linie Rosenkränze, Holzkreuze und Münzen gefunden worden (Melisch et al. 2011).

Fünf regelbestattete Individuen wurden in einem Sarg, bestehend aus Innen- und Außensarg, bestattet, eines davon in einer Gruft. Die Bestattung in einem Sarg, bestehend aus Innen- und Außensarg, ist als ein Indiz für eine höhere soziale Stellung zu interpretieren. Insbesondere für das Individuum 48 wird dies sehr deutlich, da das Individuum zudem eine prachtvoll bestickte Samthaube trug (siehe Abbildung 30).

In den Gräbern der Anatomieleichen wurden Grabbeigaben nur in Ausnahmefällen gefunden. Es scheinen keine Beerdigungen mit zeremoniellen Grabbeigaben in Form von Rosenkränzen oder Kreuzen stattgefunden zu haben. Bei dem sezierten Individuum 122A (1) wurden im Thorax Tierknochen gefunden. Offensichtlich sind die tierischen Knochen vor der Beerdigung, eventuell im Rahmen einer Sektion der Leiche, in die offene Bauchhöhle geschoben worden. Es handelte sich vermutlich um einen studentischen Scherz (Grosskopf 2015).

Im Rahmen der Vorarbeiten wurden darüber hinaus in einer Abschlussarbeit (Breitung 2013) zur entomologischen Vielfalt 4705 Insekten, Insektenlarven und Puppen von den menschlichen Überresten des katholischen Friedhofs abgesammelt. Dabei war die Zusammensetzung der Spezies relativ ähnlich für alle untersuchten Skelette. Es wurden zwei Brachycera (Fliegen) Familien gefunden: Phoridae und Muscidae. Des Weiteren fanden sich sechs Coleoptera (Käfer) Familien: Rhizophagidae, Cryptophagidae, Staphylinidae, Curculionidae, Histeridae und Carabidae. Alle entdeckten und identifizierten Spezies können an verwesenden 
menschlichen Leichen gefunden werden. Die einzigen Ausnahmen sind Curculionidae wie Cossonus linearis, welche sich von totem Holzmaterial ernährt. Die morphologischen Untersuchungen wurden durch die Untersuchungen mit dem Elektronenmikroskop unterstützt und mittels genetischer Analysen verifiziert. Die gefundenen Insektenfamilien sind gleichmäßig auf das gesamte Gräberfeld verteilt und unterscheidet sich nicht zwischen den Gruppen.

Zusammenfassend ist festzustellen, dass die Gräber der Anatomieleichen kaum Grabbeigaben oder Beifunde aufweisen. Die Ausnahme bildet ein Individuum mit Goldfüllungen in den Zähnen. Die regelbestatteten Individuen sind, entsprechend ihrer Grabbeigaben und der Bestattungsform, einer höheren sozialen Schicht zuzuordnen als die Anatomieleichen.

\subsection{Historische Quellen und Daten}

Wie aus den königlichen Verordnungen hervorgeht, handelt es sich bei den Anatomieleichen um Personen, die zum einen aus der sozial schwachen Bevölkerungsschicht stammen und zum anderen um gesetzlich oder moralisch Verurteilte. Damit ergeben sich für die Auswertung der biologischen Daten folgende Probleme: Stammt eine Person aus der letzt genannten Gruppe, weist sie womöglich keine Anzeichen einer schlechteren Versorgung bzw. von schlechteren Lebensumständen auf. Ist eine Person nur kurz in Haft gewesen und verstorben, zeigt der Körper keine oder nur sehr geringe Anzeichen einer Mangel- oder Fehlernährung. Gleiches gilt sicherlich auch für die moralisch verurteilten Suizidenten. Bei Individuum 123 besteht zum Beispiel der Verdacht, dass es sich nicht um ein Individuum der niedrigsten sozialen Schicht handelt. Dieses Individuum hatte diverse Goldfüllungen in mehreren Molaren.

Die historischen Quellen geben einen Hinweis auf das Fehlen subadulter Individuen in der Gruppe der Anatomieleichen. In einem Schreiben aus dem Jahre 1796 (siehe Kapitel 4.3.1) steht der Zusatz, nach dem Leichen, die an die Anatomie abgeliefert werden sollen, mindestens 10 Jahre alt zu sein haben. Wenn dies regelmäßige Praxis war, erklärt dies das fast vollständige Fehlen subadulter Individuen.

Die historischen Unterlagen aus dem Archiv des Bistums Hildesheim zeigen, dass die Individuen, die nach ihrem Tod in die Anatomie überliefert wurden, ausnahmslos einfache berufliche Tätigkeiten ausgeführt haben. Für einige Individuen gab es in dieser Spalte keine Angaben, dies deutet auf eine fehlende berufliche Tätigkeit hin. Diese Beobachtungen entsprechen den historischen Quellen, nach denen die arme Bevölkerung einen Großteil derer ausmacht, die nach ihrem Tod als „Lehrmaterial“ in Anatomischen Instituten seziert wurden. 


\section{Diskussion - Methodenkritik}

Es konnten aufgrund eines fehlenden Belegungsplans des katholischen Friedhofs keines der Gräber einem bestimmten Meldezettel zugeordnet werden. Allerdings widersprechen die Daten auf den Meldezetteln den biologischen Daten der Skelette der Anatomieleichen auch nicht. Die Angabe von Beruf und Todesart in den Unterlagen unterstützt die Annahme, dass in erster Linie sozial schlechter gestellte Personen nach ihrem Tod in die Anatomie eingeliefert wurden.

Es gibt vergleichbare Funde von Anatomieleichen aus den letzten Jahrhunderten deutschlandweit. So wurden 2016 im Rahmen von Bauarbeiten Skelette auf dem städtischen Armenfriedhof Berlins freigelegt. Der Friedhof wurde von 1832 - 1884 genutzt. Unter den menschlichen Überresten befinden sich Skelette von zahlreichen Anatomieleichen, welche durch die Charité in Berlin untersucht wurden (Senatsverwaltung für Stadtentwicklung und Wohnen 2016). Da im Gegensatz zu Göttingen in Berlin die Stadt bzw. die Gemeinden das Begräbnis der Anatomieleichen zahlen mussten, sind oft mehrere Individuen gemeinsam bestattet worden, um Geld zu sparen (Senatsverwaltung für Stadtentwicklung und Wohnen 2016). 2007 wurden in unmittelbarer Nachbarschaft zum Clemenshospital in Münster 50 Skelette von „fremden, armen und nicht katholischen Männern“ (Prellert 2016) auf dem Friedhof der Barmherzigen Brüder geborgen. Bei den Barmherzigen Brüdern handelt es sich um einen katholischen Orden, dessen Mitglieder sich der Hilfe Armer und Kranker verschrieben haben (Höfling 2015). Es wird vermutet, dass diese Leichen im 18. Jahrhundert von den Ordensmitgliedern der Barmherzigen Brüdern zu Forschungs- und Lehrzwecken seziert und anschließend heimlich im Garten des Hospitals beigesetzt wurden (Winkler o. D.). 2013 wurden bei Bauarbeiten auf dem Friedhof vom Matzleinsdorfer Platz 25 (Wien, Österreich) Skelette und etliche dislozierte Knochen geborgen. Der Friedhof wurde von 1784 1879 belegt. Unter den 25 Individuen gab es drei, die Anzeichen einer Craniotomie zeigen. Auch hier wird davon ausgegangen, dass es sich um Sektionsleichen, die im Rahmen von Ausbildungs- und Übungszwecken in medizinischen Instituten seziert wurden, handelte (Binder 2016). Wie auch in den Gräbern der Anatomieleichen des katholischen Friedhofs von Göttingen konnten keine Grabbeigaben gefunden werden.

\subsection{Methodenkritik}

Da Knochen ein metabolisches Gewebe ist, d. h. ständig auf- und abgebaut wird, ist eine optimale Anpassung an die Lebensumstände gewährleistet. Mit zunehmendem Alter des Knochens wird der Geflechtknochen durch Lamellenknochen und Primärosteone durch Sekundärosteone umgebaut. Anhand der Dichte der Sekundärosteone im Knochen kann eine Alterseinschätzung stattfinden (Grosskopf 2004, Crowder 2016). Allerdings kann auch in 


\section{$\underline{\text { Diskussion - Methodenkritik }}$}

einem adulten Individuum Geflechtknochen gefunden werden. Das ist dann der Fall, wenn sich der Knochen im kindlichen bzw. jugendlichen Wachstum befindet oder die Muskeln im Bereich der Knochenansatzstelle unter physischen Stress geraten. Bei Krankheiten mit hoher Knochenumbaurate wie Morbus Paget (Osteodystrophia deformans), Hyperparathyreoidismus und Osteogenesis imperfecta (Schultz 2012) kann dieses Phänomen ebenfalls beobachtet werden.

\section{$\underline{\text { Altersbestimmung }}$}

Es gibt teilweise große Unterschiede zwischen den Ergebnissen der morphologischen Altersbestimmung am Knochen und denen der Bestimmung der Zuwachsringe im Zahnzement (siehe Kapitel 4.1.1). Die Diskrepanz zwischen den Ergebnissen der beiden Methoden fiel auch schon bei der Untersuchung des ersten katholischen Friedhofs von Berlin auf. Auch hier gab es eine häufige Überschätzung des Sterbealters bei Anwendung der komplexen Methode gegenüber dem Auszählen der Zahnzuwachsringe (Melisch et al. 2011).

Es ist bekannt, dass das morphologisch und lupenmikroskopisch bestimmte Sterbealter einer Person durch die Lebensbedingungen vom kalendarischen Alter abweichen kann. Dies ist zum Beispiel der Fall, wenn die Knochenumbaurate gesteigert oder verlangsamt ist, weil ein Individuum schwer körperlich arbeitet oder bettlägerig ist. Zudem liefert die Beurteilung der Facies symphysialis lediglich einen ,[...] ersten Anhaltspunkt dafür, ob das Lebensalters eines Individuums etwa um 50 Jahre oder wesentlich darunter bzw. darüber liegt.“ (Nemeskéri et al. 1960 S. 88).

Die Altersbestimmung durch Auszählung der Zuwachsringe im Zahnzement kann ebenfalls vom chronologischen Alter abweichen. Bei allen lupenmikroskopisch untersuchten Individuen wurden die Zuwachsringe an den Eckzähnen ausgezählt, um ein möglichst gleiches Durchbruchsalter annehmen zu können. Für einige Individuen stimmt das Ergebnis der Auszählung mit dem morphologisch bestimmten Alter überein. Bei anderen Individuen traten die im Folgenden beschriebenen Probleme auf. Das ausgezählte beziehungsweise errechnete Alter kann vom chronologischen Alter durch eine Varianz im Zahndurchbruchsalter $( \pm 24$ Monate) abweichen. Das Phänomen des „Doublings“ kann durch zusätzlich angelegte Ringe ein deutlich höheres Sterbealter suggerieren. Mikroorganismen oder ein gehäuftes Auftreten von Zementozyten können das Auszählen deutlich behindern. Grosskopf und McGlynn (2011) weisen eindringlich auf diagenetische Effekte sowie mechanische und pathologische Einflüsse auf das Hartgewebe hin. In der Literatur wird des Weiteren darauf hingewiesen, dass die Präzision mit dem zunehmenden individuellen Alter abnimmt (Bojarun et al. 2004). Eine 


\section{Diskussion - Methodenkritik}

durchschnittliche Abweichung von \pm 2,5 - 5,7 Jahre muss angenommen werden (Großkopf 1990, Kagerer und Grupe 2001, Bojarun et al. 2004 und Wittwer-Backofen et al. 2004). Pilloud (2004) wies für senile Individuen (57 - 90 Jahre) eine Abweichung von 12,7 Jahre nach und berichtet, dass für diese Individuen kein signifikanter Trend zwischen lichtmikroskopisch bestimmtem und chronologischem Alter gefunden werden konnte. „Die mit zunehmendem Alter größer werdenden Abweichungen zwischen ermitteltem und reallem Alter zeigt folglich ein Trend in ein niedrigeres histologisches Alter als erwartet.“ (Pilloud 2004). Das bedeutet, dass die Anzahl der Zahnringe im Zahnzement mit dem Alter zwar zunimmt, es während der Alterung aber auch zunehmend zu einer Abweichung zum chronologischen Alter nach unten kommen kann. In dieser Arbeit wurde eine Maximalabweichung von 17,2 Jahren erreicht. Dies entspricht den Maximalabweichungen anderer Studien, z. B. Großkopf (1990) mit 14,68 Jahren, Bojarun et al. (2004) mit 32,3 Jahren und Wittwer-Backofen et al. (2004) mit ca. 20 Jahren. Etliche Studien (Lucas und Loh 1986, Miller et al. 1988, Lipsinic et al. 1986) konnten allerdings nicht das korrekte Sterbealter anhand der Zuwachsringe bestimmen. Zwar scheint es auch in diesen Studien einen direkten Zusammenhang zwischen Alter und Anzahl der Ringe zu geben, allerdings konnte das konkrete Alter nicht bestimmt werden.

Das folgende Beispiel soll am Individuum 60 (Anatomieleiche) die Diskrepanzen zwischen den verschiedenen Methoden der Altersbestimmung verdeutlichen.

Nach der morphologischen Methode ist das Individuum anhand der strukturellen Veränderung der Schambeinsymphyse (50 - 70 Jahre) und Obliterationszustand der Schädelnähte (40 - 80 Jahre) in den Altersklassen mittelmatur bis mittelsenil (50 - 70 Jahre) einzuordnen. Die Knochenbinnenstruktur im lupenmikroskopischen Dünnschliff entspricht die eines Individuums im Altersbereich 35 - 45 Jahren. Es sind Reste einer äußeren Generallamelle zu finden. Das spricht für ein Individuum, dass nicht älter als frühmatur (40 - 45 Jahre) ist. Die Osteone sind kleinlumig und dicht gepackt. Das spräche für ein Individuum zwischen dem 40. und 50. Lebensjahr. Zwischen den Osteonen befinden sich lamelläre Strukturen, wahrscheinlich Tangentiallamellen (siehe Abbildung 92). Diese entstehen zum Beispiel in Knochen älterer Individuen durch Inaktivitätsatrophie. Endostal sind noch wenige Reste der Generallamelle zu finden, das spräche für ein Individuum, welches früh- bis mitteladult ist. Es gibt keine Resorptionslakunen. Eine Untersuchung (Hennies 2014) hat gezeigt, dass Individuen in der Altersklasse Maturitas zumeist auch anhand lupenmikroskopischer Untersuchungen dieser Altersklasse zugeordnet wurden. Für adulte Individuen fand häufig eine Überschätzung und für senile Individuen eine Unterschätzung des Alters statt, wenn die funktionellen Umstände nicht berücksichtigt wurden. Anhand der Zuwachsringe (siehe Abbildung 93) im Zahnzement 


\section{Diskussion - Methodenkritik}

entsteht ein berechnetes Alter (Anzahl der Zuwachsringe $17+$ Zahndurchbruchsalter im Unterkiefer für männliche Individuen 10,8 Jahre) von ca. 28 Jahren.

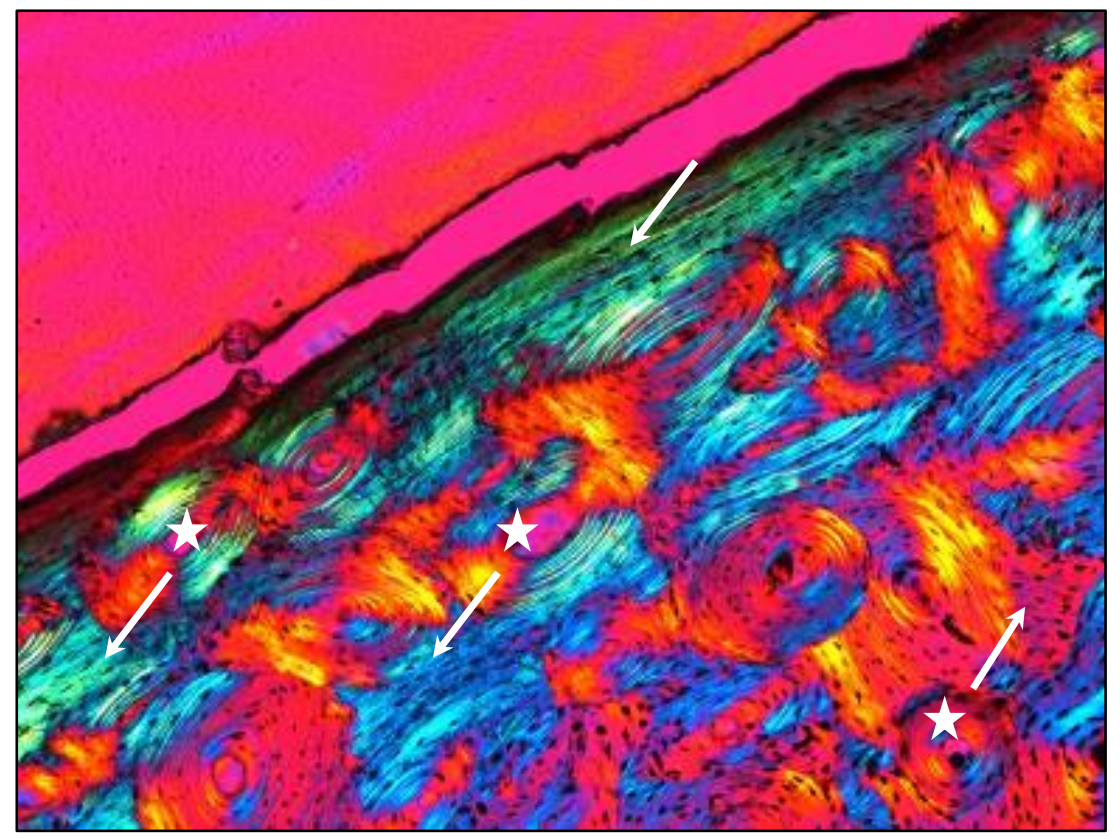

Abb. 92: Betrachtung mit dem Mikroskop, Femur rechts, $80 \mu \mathrm{m}, 100$-fache Vergrößerung, im polarisierten Licht unter Verwendung eines Hilfsobjekts Rot 1 . Ordnung (Quarz) als Kompensator. Reste einer Generallamelle (Pfeil). Zwischen den dichtgepackten Osteonen sind Tangentiallamellen $\mathrm{zu}$ erkennen (Pfeil mit Stern). Fundnummer 60, männlich.

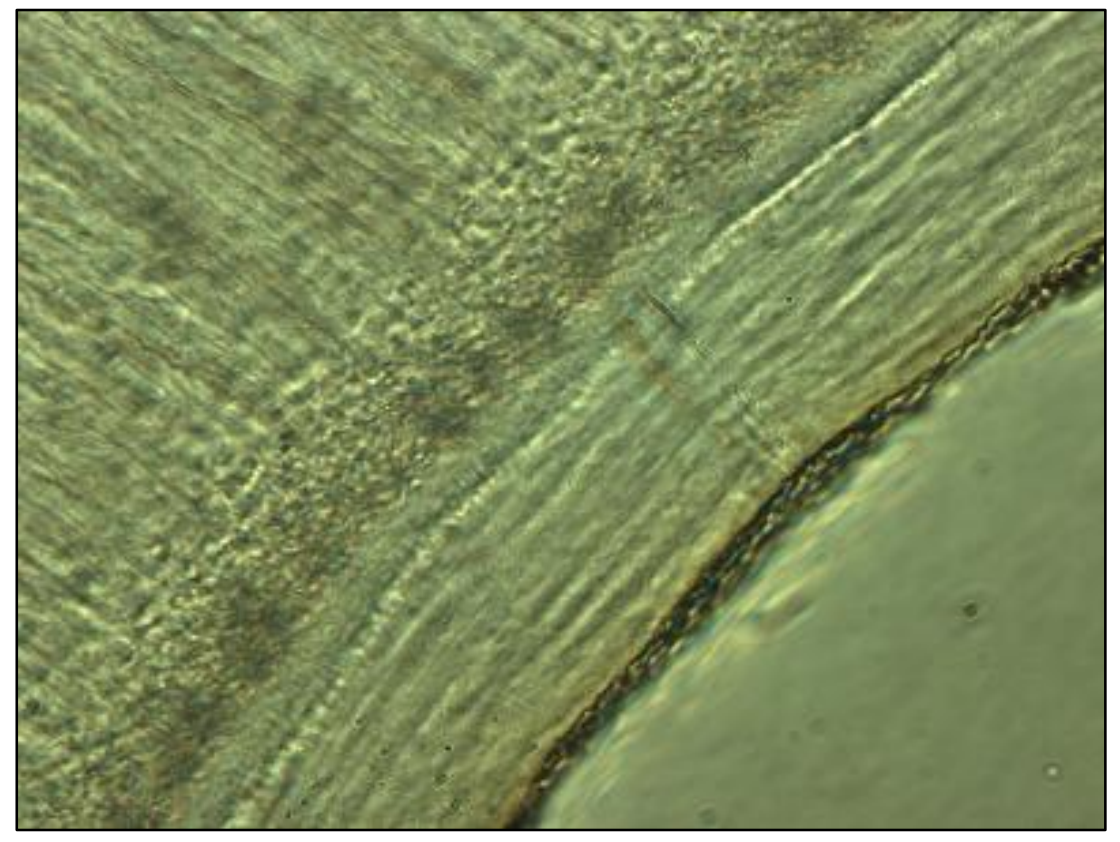

Abb. 93: Betrachtung mit dem Mikroskop, Zahn 33, $100 \mu \mathrm{m}, \quad 400$-fache Vergrößerung. Im Durchschnitt (mehrere Schliffe desselben Zahns an unterschiedlichen Stellen ausgezählt) 17 Zuwachsringe. Fundnummer 60, männlich.

Die Bildung der Zuwachsringe im Zahnzement ist immer noch nicht vollständig geklärt. Entstehen die Ringe hormonbedingt, könnte dies die Diskrepanz zwischen chronologischem Alter und ausgezähltem Alter erklären. Menschen haben unterschiedliche Hormonspiegel und der Spiegel wird außerdem stark durch äußere Faktoren beeinflusst. Die Zuwachsringe sind wie auch der Knochen anfällig für äußere Einflüsse, z. B. Umwelt, Ernährung, Belastung usw. Aber auch innere Einflüsse, wie zum Beispiel genetische Komponenten, können sich auf die Bildung der Zuwachsringe auswirken. Vorstellbar wäre ebenfalls eine Hypomineralisation durch einen Calciummangel bei Mangelernährung, Störung des Calciumstoffwechsels oder Mobilisierung 


\section{Diskussion - Methodenkritik}

des Calciumsvorrates aus Hartgewebe bei Schwangerschaften. Eine qualitative Veränderung bei Hypomineralisation konnte zumindest bei Kagerer und Grupe (2001) nachgewiesen werden. Es handelte sich um rezente Zähne.

\section{Körperhöhenbestimmung}

Generell unterliegt die maximale Körperhöhe eines Individuums natürlichen Schwankungen. Morgens ist die Körperhöhe größer, da sich im Laufe der Nacht die Bandscheiben mit Flüssigkeit füllen konnten. Im Verlauf des Tages tritt diese Flüssigkeit nach und nach aus, sodass der Mensch am Ende des Tages „kleiner“ ist. Im späten juvenilen bzw. frühen adulten Lebensalter gelangt der Mensch zu seiner maximalen Körperhöhe. Durch degenerative Prozesse wird die Knorpelschicht der Gelenke schmaler und die Menge der Gelenk- sowie Bandscheibenflüssigkeit nimmt ab. Allerdings bleibt die Langknochenlänge relativ konstant, sodass wir anhand des Skelettes zwar die maximal erreichte Körperhöhe eines Verstorbenen errechnen können, allerdings muss diese nicht der Körperhöhe zum Todeszeitpunkt entsprechen.

\section{$\underline{\text { Arthrose, Arthritis }}$}

Arthrose und Arthritis sind Begriffe, die erstens mehrere Problematiken umfassen und zweitens nicht getrennt voneinander betrachtet werden können. Die degenerativen und proliferativen Prozesse finden in unterschiedlicher Intensität, aber zur selben Zeit statt und betreffen neben dem knöchernen Anteil des Gelenkes auch das umliegende Weichgewebe wie Knorpel, Muskel, Bänder, Schleimhaut und Kapsel. Es ist bekannt, dass die Intensität der Arthrose nicht allein von der Belastung der körperlichen Arbeit in Form eines physisch anspruchsvollen Berufs abhängt. Auch alltägliche Belastungen hinterlassen mit der Zeit Spuren an den Gelenken und nehmen so mit steigendem Individualalter zu. So ist sowohl bei den Skeletten der katholischen Population aus Göttingen als auch bei denen der Population aus Inden (Kr. Düren, NordrheinWestfalen) eine Zunahme der Arthroseintensität mit zunehmendem Alter zu erkennen. 


\section{Zusammenfassung}

\section{Zusammenfassung}

Die hier vorgestellte Arbeit beschäftigt sich mit den Ergebnissen der Untersuchung zu den Morbiditätsfrequenzen einer Bevölkerungsgruppe des 19. Jahrhunderts

2011 wurden auf dem zentralen Campusgelände der Georg-August-Universität Göttingen in Folge von Bauarbeiten menschliche Überreste von 159 Individuen in Form einer Teilgrabung geborgen. Das ergrabene Areal gehört zur Friedhofsanlage der katholischen Pfarrgemeinde St. Michael Göttingen, Bistum Hildesheim, und ist zeitlich zwischen 1851 und 1888 einzuordnen. Ein besonderes Augenmerk in den Untersuchungen dieser Arbeit lag auf den menschlichen Überresten von 39 Individuen mit Sägespuren im Bereich des Craniums und/oder des postcranialen Skelettes. Diese Spuren sind vermutlich durch Sektionen in der Medizinischen Fakultät der Universität Göttingen, im Rahmen der Ausbildung von Studenten, entstanden.

Rezentstudien zeigen, dass sowohl die geistige als auch die körperliche Gesundheit stark durch den sozialen Stand eines Individuums in der Gesellschaft geprägt ist. In dieser Arbeit wurde überprüft, ob sich diese Ergebnisse auch am Skelettsystem historischer Populationen abbilden. Untersucht wurden die Skelette von sogenannten Anatomieleichen. Dabei handelt es sich um Menschen, deren Leichen der Anatomie für Lehr- und Forschungszwecke übergeben wurden, wenn sie sich keine Beerdigung leisten oder deren Angehörige nicht für die Kosten aufkommen konnten. Somit repräsentieren sie bis auf wenige Ausnahmefälle Menschen, die der sozialen Unterschicht angehörten. Als Referenz wurden die auf dem gleichen Areal geborgenen Skelette von regelbestatteten Individuen der gleichen Zeitstellung herangezogen.

Damit lautete die zentrale Fragestellung in dieser Arbeit, ob sich die durch den sozialen Status einer Person bedingten physischen Beanspruchungen und psychischen Belastungen auf ihr Skelett auswirkt. Aufgrund der Annahme, dass Menschen der sozial niedrigsten Schichten im 18. und 19. Jahrhundert nach ihrem Tod in der Anatomie bzw. Pathologie seziert wurden, wird erwartet, dass die Skelette dieser Leichen infolge der schlechteren Lebensbedingungen eine höhere Morbiditätsfrequenz aufweisen als die Vergleichsgruppe.

Das Methodenrepertoire umfasste in erster Linie medizinisch-naturwissenschaftliche Methoden wie die Makroskopie, Lupenmikroskopie, Endoskopie, Radiologie, Mikroskopie und die Molekulargenetik. Neben den rein naturwissenschaftlichen Untersuchungen wurden auch die Inhalte archivalische Quellen aus dem Niedersächsischen Landesarchiv, dem Stadtarchiv 


\section{Zusammenfassung}

Göttingen und dem Bistumsarchiv Hildesheim gesichtet und in die Diskussion der Untersuchungsergebnisse eingeflochten.

Es fand eine Erhebung von demografischen Daten, Körperhöhenrekonstruktion, Beschreibung diskreter Merkmale und Aufnahme über Art und Häufigkeit pathologischer Veränderungen am Knochenmaterial statt. Neben der statistischen Auswertung der biologischen Daten wurden auch die Grabbeigaben, Beifunde und das archivalische Quellenmaterial begutachtet und interpretiert.

Aufgrund der in dieser Arbeit erhobenen biologischen Daten kann davon ausgegangen werden, dass die soziale Stellung eines Individuums innerhalb der Gesellschaft einen Einfluss in Form statusbedingter Wirkungen auf das Skelettsystem haben kann. Allerdings konnten für die untersuchten Individuen lediglich erhöhte Morbiditätsfrequenzen für unspezifische Stressmarker und einige Infektionskrankheiten festgestellt werden, nicht aber für belastungsbedingte Gelenkserkrankungen oder chronische Mangelerkrankungen.

Die archivalischen Unterlagen unterstuitzen und komplettieren die Interpretation der Ergebnisse biologischer Daten, wie Alter, Geschlecht und Morbiditätsfrequenzen. So konnten Meldezettel Verstorbener im Bistumsarchiv Hildesheim eingesehen werden, welche belegen, dass alle an die Anatomie ausgelieferten Individuen einem niedrigen sozialen Stand angehörten. Die Dokumente zeigen, dass in erster Linie Tagelöhner, Knechte und einfache Arbeiter nach ihrem Tod seziert wurden. Meist sind diese Individuen an Krankheiten verstorben, welche mit Armut und schlechten Lebensbedingungen assoziiert werden können.

Einige Ergebnisse sind vor dem Hintergrund der selektiven Leichenauswahl für die anatomischen Lehrveranstaltungen und der Teilgrabung des Friedhofareals kritisch zu betrachten. Bei den angewendeten anthropologischen Methoden handelt es sich um Standardmethoden aus dem Fachbereich, die zu einem gewissen Anteil zu fehlerhaften Ergebnissen oder Interpretationen führen können, z. B. einer ungenauen Alterseinschätzung aufgrund pathologisch veränderter Knochenbinnenstrukturen. Daher mussten weiterführend Spezialmethoden, wie zum Beispiel die ausführliche Bewertung von Dünschliffpräparaten, angewendet werden.

Um weiterführende Perspektiven über die Unterschiede in der Quantität und der Qualität pathologischer Veränderungen zwischen Personen unterschiedlicher sozialer Schichten zu erhalten, ist es sinnvoll die hiesigen Daten mit Daten weiterer Gräberfelder zu komplettieren. 


\section{Literaturverzeichnis}

Acsádi G, Nemeskéri J (1970) History of Human Life Span and Mortality. Budapest, Akadémiai Kiadó.

Adler NE, Boyce T, Chesney MA, Cohen S, Folkman S, Kahn RL, Syme SL (1994) Socioeconomic status and health. The challenge of the gradient. American Psychologist 49(1): 15-24.

Adler P (1967) Die Chronologie der Gebißentwicklung. In: Harndt E und Weyers H: Zahn-, Mund- und Kieferheilkunde im Kindesalter. Verlag „Die Quintessenz“ Berlin.

Anatomie UMG (o. D.) Johann Friedrich Blumenbach. URL: http://www.anatomie.unigoettingen.de//pic/blumenbach.jpg [Stand 30.10.2018; 10:47].

Aufderheide AC, Rodriguez-Martin C (1998) The Cambridge encyclopedia of human paleopathology. Cambridge University Press.

Bamberger E (1989) Veränderungen der Röhrenknochen bei Bronchiektasie. Wiener klinische Wochenschrift 2: 226.

Bamberger E (1891) Über Knochenveränderungen bei chronischen Lungen- und Herzkrankheiten. Zeitschrift f. klin. Med. 18: 193.

„Bekanntmachung, die Benutzung des academischen Hospitals zu Göttingen betreffend“ vom 20.11.1850. Universitätsarchiv Göttingen: Kur. 5282, B1. 1.

Bellary SS, Steinberg A, Mirzayan N, Shirak M, Tubbs RS, Cohen-Gadol AA, Loukas M (2013) Wormian Bones: A Review. Clinical Anatomy 26(8): 922-927.

Bergfelder T, Herrmann B (1980) Estimating fertility on the basis of birth-traumatic changes in the pubic bone. Journal of Human Evolution 9(8): 611-612.

Binder M (2016) Der Friedhof vom Matzleinsdorfer Platz. In: Österreichisches Archäologisches Institut (Hrsg.) Wissenschaftlicher Jahresbericht des Österreichischen Archäologischen Instituts 2015.

Bojarun R, Jankauskas R, Garmus A (2004) Altersbestimmung mithilfe von Wachstumslinien des Zahnzementes. Rechtsmedizin 14: 405-408.

Bolk L (1914) Über überzählige Zähne in der Molarengegend des Menschen. Dtsch. Mschr. Zahnheilkde 32: 197-216.

Bramanti B (1999) Genetic characterization of the Goslar skeleton collective by aDNAanalysis. Arbeitsbericht, Biologische Fakultät der Georg-August-Universität, Göttingen.

Brauchtum.de (o. D.) Rosenkranz. Der ganze Glaube in einer Hand. URL: http://www.brauchtum.de/de/herbst/rosenkranz.html [Stand 26.10.2017; 11:44]. 
Breitinger E (1989) Sulcus praeauricularis und Sulcus praesymphysialis als Fertilitätszeichen. Ann. Naturhist. Mus. Wien 91A: 63-78.

Breitung M (2013) Morphological and genetic analysis of the entomological remains of the excavation from the first catholic graveyard in Göttingen. Masterarbeit, Biologische Fakultät der Georg-August-Universität, Göttingen.

Brossmann J, Czerny C, Freyschmidt J (1982) Freyschmidts Köhler/Zimmer: Grenzen des Normalen und Anfänge des Pathologischen im Röntgenbild des Skeletts. Georg Thieme Verlag Stuttgart New York.

Bryant JM, Grogono DM, Greaves D, Foweraker J, Roddick I, Inns T, Reacher M, Haworth CS, Curran MD, Harris SR, Peacock SJ, Parkhill J, Floto RA (2013) Whole-genome sequencing to identify transmission of Mycobacterium abscessus between patients with cystic fibrosis: a retrospective cohort study. Lancet. 381(9877): 1551-1560.

Buklijas T (2008) Cultures of Death and Politics of Corpse Supply. Anatomy in Vienna, 18481914. Bull Hist Med. 82(3): 570-607.

Burgerbibliothek Bern (o. D.) Schabkunstblatt 1745 von J. J. Haid nach dem Gemälde von J. R. Studer. URL: http://www.albrecht-von-haller.ch/medien/media/img-highres

/AvHStuderHaid.jpg [Stand 29.11.2018; 11:03].

Burt BA, Ismail AI, Morrison EC, Beltran ED (1990) Risk Factors for Tooth Locc Over a 28year Period. J Dent Res 69(5): 1126-1130.

Caffey J (1937) Skeletal changes in the chronic hemolytic anemias (erythroblastic anemia, sickle cell anemia and chronic hemolytic icterus. American Journal of Roentgenology and Radium Therapy.

Cronkite RC, Moos RH (1984) The Role of Predisposing Moderating Factors in the StressIllness Relationship. Journal of Health and Social Behavior. 25: 372-393.

Crowder CM (2016) Histological age estimation. In: Handbook of forensic anthropology and archaeology. Blau S and Ubelaker DH (editors). Left Coast Press.

Dalitz MK (2005) Autochthone Malaria im mitteldeutschen Raum. Dissertation, Medizinischen Fakultät der Martin-Luther-Universität Halle-Wittenberg.

Derry DE (1909) Note on the innominate bone as a factor in the determination of sex: with special reference to the sulcus preauricularis. J Anat Physiol 43: 266-76.

Dicks E (2012) Geschlechtsbestimmung isolierter Skelettelemente eines neuzeitlichen katholischen Friedhofs aus Göttingen mit einer Multiplex X/Y-PCR. Bachelorarbeit, Biologische Fakultät der Georg-August-Universität, Göttingen.

Dihlmann W (1987) Gelenke - Wirbelsäulenverbindungen. Klinische Radiologie einschließlich Computertomographie - Diagnose, Differentialdiagnose. 3. Überarbeitete und erweiterte Auflage. Georg Thieme Verlag Stuttgart, NewYork. 
Dittmar JM, Mitchell PD (2015) A new method for identifying and differentiating human dissection and autopsy in archaeological human skeletal remains. Journal od Archaeological Science: Reports 3: 73-79.

Dragano N (2007) Gesundheitliche Ungleichheit im Lebenslauf. Aus Politik und Zeitgeschichte 42: $18-25$.

Droste S (2015) Die Anatomieleichen und ihre Geschichte. In: Grosskopf B (Hrsg.) Der vergessene Friedhof. Kulturgeschichtliche und naturwissenschaftliche Ergebnisse zur Ausgrabung des neuzeitlichen katholischen Friedhofes in Göttingen. Universitätsverlag Göttingen.

Eklund SA, Burt BA (1994) Risk Factors for Total Tooth Loss in the United States; Longitudinal Analysis of National Data. J Public Health Dent 54(1): 5-14.

Elizondo-Omana R.E., Guzmán-López S, García-Rodríguez M (2005) Dissection as a teaching tool: Past, present, and future. The Anatomical Record (Part B: New Anat.) 285B: 11-15.

Fahlbusch O (1957) Göttingen im Wandel der Zeiten. 2. Aufl.

Fabig A (1999) Die Rekonstruktion der Ernährungsgrundlage als Möglichkeit der Differenzierung zwischen berufs- und ernährungsbedingten Elementeinträgen in das Skelett am Beispiel einer Bergbaubevölkerung. Arbeitsbericht, Biologische Fakultät der GeorgAugust-Universität, Göttingen.

Ferembach D, Schwindezky I, Stloukal M (1980) Recommendations for Age and Sex Diagnoses of Skeletons. Journal of Human Evolution 9: 517-549.

Fietz T, Schneider P, Knauf WU, Thiel E (1998) Trommelschlegelfinger und Arthralgien als reversibles paraneoplastisches Syndrom (Pierre-Marie-Bamberger-Syndrom) beim nichtkleinzelligen Bronchialkarzinom. Georg Thieme Verlag KG Stuttgart New York 123(50): 1507-1511.

Finke T (1999) Die Skelettfunde aus dem neuzeitlichen Gräberfeld Goslar, „Hinter den Brüdern“. Arbeitsbericht, Biologische Fakultät der Georg-August-Universität, Göttingen.

Finnegan M (1978) Non-metric variation oft he infracranial skeleton. J. Anat. 125(1): 23-37.

Flohr S, Schultz M (2009) Mastoiditis - Paleopathological Evidence of a Rarely Reported Disease. American Journal of Physical Anthropology 138: 266-273.

Flohr S, Kierdorf U, Schultz M (2009) Differenzialdiagnose an hypozellulären menschlichen Warzenfortsätzen - ein Beitrag zur Paläopathologie. Beiträge z. Archäozool. u. Prähis. Anthrop. VII.

Flux AL, Mazanec J, Strommenger B, Hummel S (2017) Staphylococcus aureus Sequences from Osteomyelitic Specimens of a Pathological Bone Collection from Pre-Antibiotic Times. Diversity 9(4): 43. 
Forestier J, Rotes-Querol J (1950) Senile Ankylosing Hyperostosis of the Spine. Ann Rheum Dis. 9(4): 321-330.

Friedmann I (1957) The pathology of otitis media (III) with particular reference to bone changes. J Laryng 71: 313-320.

Frisancho A, Guire K, Babler W, Borken G, Way A (1980) Nutritional influence on childhood development and genetic control of adolescent growth of Quechuas and Mestizos from the Peruvian Lowlands. American Journal of Physical Anthropology 52(3): 367-375.

Frischalowski M (2012) Befundung der Dentalpathologien einer Göttinger Skelettserie des 19. Jahrhunderts. Bachelorarbeit, Biologische Fakultät der Georg-August-Universität, Göttingen.

Frischalowski M (unveröffentlicht) Genetische Fingerabdrücke der Individuen des katholischen Friedhofs Göttingen. Zwischenbericht, Biologische Fakultät der GeorgAugust-Universität, Göttingen.

Frischalowski M, Seidenberg M, Grosskopf B, Wulf F-W, Hummel S (2015) Molekulargenetische Untersuchung des Verwandtschaftsverhältnisses von möglichen Mutter-Kind-Bestattungen aus dem frühneuzeitlichen Eldagsen. Nachrichten aus Niedersachsens Urgeschichte 84: 193-206.

Frisancho AR, Garn SM, Ascoli W (1970) Childhood Retardation Resulting in Reduction of Adult Body Size Due to Lesser Adolescent Skeletal Delay. Am J Phys Anthrop 33: 325-336.

Genco RJ (1996) Current View of Risk Factors for Periodontal Diseases. Journal of Periodontology 67(10S): 1041-1049.

Gerstenberger J (2002) Analyse alter DNA zur Ermittlung von Heiratsmustern in einer frühmittelalterlichen Bevölkerung. Dissertation, Biologische Fakultät der Georg-AugustUniversität, Göttingen.

Gierl M (1988) Vom Wühlen der Aufklärung in Gedärmen. In: Göttingen ohne Gänseliesel. Text und Bilder zur Stadtgeschichte. Hrsg. Duwe K., Gottschalk C. und Koerner M. i.A. der Geschichtewerkstatt Göttingen e.V. Wartberg Verlag.

Goodman AH, Rose JC (1990) Assessment of systematic physiological perturbations from dental enamel hypoplasias and associated histological structures. Yearbook of physical anthropology 33: 59-110.

Goodman AH, George J, Rose A, Rose J (1980) Enamel hypoplasias as indicators of stress in three prehistoric populations from Illinois. Human Biology 52(3): 515-528. Weyne State University Press.

Goodwin W, Linacre A, Hadi S (2011) An Introduction to Forensic Genetics. Wiley-Blackwell, Chichester, UK, 2nd. ed. 
Gregory SR, Cole TR (2002) The changing role of dissection in medical education. JAMA 287(9): 1180-1181.

Gresky J, Wagner M, Schmidt-Schultz T, Schwarz L, Wu X, Aisha A, Tarasov, Schultz M (2015) 'You must keep going' - Musculoskeletal system stress indicators of prehistoric mobile pastoralists in Western China. Quaternary International 405(Part B): 186-199.

Griffith DE, Brown-Elliott BA, Benwill JL, Wallace RJ Jr. (2015) Mycobacterium abscessus. „Pleased to meet you, hope you guess my name...“. Ann Am Thorac Soc. 12(3): 436-439.

Großkopf B (1990) Individualaltersbestimmung mit Hilfe von Zuwachsringen im Zement bodengelagerter menschlicher Zähne. Z Rechtsmed 103: 351-359.

Grosskopf B (2004) Leichenbrand. Biologisches und kulturhistorisches Quellematerial zur Rekonstruktion vor- und frühgeschichtlicher Populationen und ihrer Feudalpraktiken. Dissertation, Fakultät für Geschichte, Kunst- und Orientwissenschaften der Universität Leipzig.

Grosskopf B (2015) Die Bestatteten vom Michaelis Friedhof - Anthropologische Auswertung. In: Grosskopf B (Hrsg.) Der vergessene Friedhof. Kulturgeschichtliche und naturwissenschaftliche Ergebnisse zur Ausgrabung des neuzeitlichen katholischen Friedhofes in Göttingen. Universitätsverlag Göttingen.

Großkopf B (unveröffentlicht) Bestattungen vom katholischen Friedhof Göttingen Anthropologischer Katalog, Biologische Fakultät der Georg-August-Universität, Göttingen.

Grosskopf B, McGlynn G (2011) Age diagnosis based on incremental lines in dental cementum: A critical reflection. Anthropol Anz/J Biol Clinic Anthrop 68: 275-289.

v Hagens G (1979) Impregnation of soft biological specimens with thermostetting resins and elastomers. Anat Rec 194: 247-255.

Haidle MN (1997) Mangel-Krisen-Hungersnöte? Ein Beitrag der Physischen Anthropologie zur Geschichte der Ernährung und der Nahrungsversorgungssicherheit in vorindustriellen Zeiten. Beitr. z. Archäozool. u. Prähist. Anthrop. 1.

Hamperl H (1960) Lehrbuch der allgemeinen Pathologie und der pathologischen Anatomie. 24./25. Auflage. Springer Verlag Berlin Göttingen Heidelberg.

Hanihara T, Ishida H (2001a) Os incae: variation in frequency in major human population groups. J. Anat. 198(2): 137-152.

Hanihara T, Ishida H (2001b) Frequency variations of discrete cranial traits in major human populations. I. Supernumerary ossicle variations. J. Anat. 198(6): 689-706.

Harvey W (1628) Exercitatio Anatomica de Motu Cordis et Sanguinis in Animalibus.

Hennies A (2014) Age estimation by means of changes of microstructural features in different skeletal elements. Masterarbeit, Biologische Fakultät der Georg-August-Universität, Göttingen. 
Heptner L (2012) Untersuchungen der Osteopathien an Individuen eines frühneuzeitlichen, katholischen Friedhofs aus Göttingen. Bachelorarbeit, Biologische Fakultät der GeorgAugust-Universität, Göttingen.

Herrmann B (1981) Eine Möglichkeit der makroskopischen Fehlbeurteilung von Dekompositionserscheinungen des Knochens. Z Rechtsmed 87: 275-278.

Herrmann B (2010) Beiträge zum Göttinger Umwelthistorischen Kolloquium 2009 - 2010. Universitätsverlag Göttingen.

Herrmann B, Newesely H (1982) Dekompositionsvorgänge des Knochens unter langer Liegezeit 1. Die mineralische Phase. Anthropologisches Anzeiger 40(1): 19-31.

Herrmann B, Grupe G, Hummel S, Piepenbrink H, Schutkowski H (1990) Prähistorische Anthropologie. Leitfaden der Feld- und Labormethoden. Springer-Verlag Berlin Heidelberg.

Hoffmann R (1857) Anatom, Pathaloge, Lithographie von Rudolf Hoffmann, 1857. Nach einem Photo von Petri (Göttingen) Aus der Reihe "Gallerie ausgezeichneter Naturforscher" herausgegeben in Wien. URL: https://commons.wikimedia.org/wiki/File:Jakob_Henle_

Litho.jpg [Stand 29.11.2018; 11:40].

Höfling G (2015) Barmherzig und zupackend. URL: https://www.katholisch.de/aktuelles

/dossiers/bekannte-orden-benediktiner-dominikaner-und-mehr/barmherzig-und-zupackend [Stand 28.11.2018; 12:23].

Hrdlička A (1942) The adult scapula. Additional observations and measurements. American Journal of Physical Anthropology 29: 363-415.

Hummel S (2003) Ancient DNA Typing. Methods, Strategies and Applications. SpringerVerlag Berlin Heidelberg New York.

Hurren ET (2008) Whose Body Is It Anyway?: Trading the Dead Poor, Coroner's Disputes, and the Business of Anatomy at Oxford University, 1885-1929. Bulletin of the History of Medicine 82(4): 775-818.

Illsley R, Baker D (1991) Contextual variations in the meaning of health inequality. Social Science and Medicine 32(4): 359-365.

Jay P (1938) Lactobacillus Acidophilus and Dental Caries. Am J of Publ Health 28: 759-761.

Jesserer H (1971) Knochenkrankheiten. Urban \& Schwarzenberg, München Berlin Wien.

Jungklaus B (2010) Die Krankheitsbelastungen der mittelalterlichen und frühneuzeitlichen Kinderpopulation von Tasdorf (Ldk. Märkisch-Oderland). Dissertation, Fachbereich Biologie, Chemie und Pharmazie der Freien Universität Berlin.

Jugert F (2012) Deskriptiver Basisbefund der Göttinger Campusgrabung 50/10. Bachelorarbeit, Biologische Fakultät der Georg-August-Universität, Göttingen. 
Jugert F, Hummel S, Grosskopf B (2018) Investigations of the relation between birth trauma and pelvic size in females from a medieval gravesite from Lübeck. ANthropol. Anz. 75(2): 141-153.

Kagerer P, Grupe G (2001) Age-at-death diagnosis and determination of life-history parameters by incremental lines in human dental cementum as an identification aid. Forensic Science International 188: 75-82.

v Karolyi L (1971) Anthropometrie. Gustav Fischer Verlag, Stuttgart.

Kenzler H (2015) Religion, Status and Taboo. Changing Funeral Rites in Catholic and Protestant Germany. In: Tarlow S (Hrsg.). The Archaeology of Death in Post-Medieval Europe. De Gruyter Open Verlag.

Khan MA (2009) Ankylosing Spondylitis. OARL Oxford American Rheumatology Library. Oxford University Press.

Kiecolt-Glaser JK, McGuire L, Robles TF, Glaser R (2002) Emotions, Morbidity, and Mortality: New Perspectives from Psychoneuroimmunology. Annual Review Psychology 53: 83-107.

Klatt T (2012) Untersuchungen der Wirbelsäulenpathologien von Individuen eines frühneuzeitlichen, katholischen Friedhofs aus Göttingen. Bachelorarbeit, Biologische Fakultät der Georg-August-Universität, Göttingen.

Komlos J (1990) Height and Social Status in Eightteenth-Century Germany. The Journal of Interdisciplinary History 20(4): 607-621.

Koops T (2002) Gesellschaftlicher Wandel und soziale Frage. URL: https://www.bundesarchiv.de/imperia/md/content/dienstorte/rastatt/koops_katalogbeitrag_ b.pdf (21.02.17).

Kratz-Ritter B (2016) Das Accouchierhaus. Die Präsidentin der Universität Göttingen (Hrsg.).

Kreye A (2016) Pathological investigations on arthropathies in an Early Modern skeletal series from Inden. Masterarbeit, Biologische Fakultät der Georg-August-Universität, Göttingen.

Kroh M, Neiss H, Kroll L, Lampert T (2012) Menschen mit hohen Einkommen leben länger. DIW Wochenbericht 38.

Kuna E (2014) Das alte Handwerk in Vorpommern. Haff-Verlag.

Lamb DS (1890) The olecranon perforation. The American Anthropologist 111: 159-174.

Lampert T, Kroll LE (2010) Armut und Gesundheit. Hrsg. Robert Koch-Institut Berlin. GBE kompakt 5/2010.

Lampert T, Kroll LE (2014) Soziale Unterschiede in der Mortalität und Lebenserwartung. Hrsg. Robert-Koch-Institut, Berlin. GBE kompakt 5(2). 
Lampert T, Kroll LE, Dunkelberg A (2007) Soziale Ungleichheit der Lebenserwartung in Deutschland. Aus Politik und Zeitgeschichte 42: 11-18.

Lendeckel V (1990) Stomatologische Untersuchungen an Skeleten aus dem frühmittelalterlichen Gräberfeld von Barbing-Kreuzhof. Dissertation, Medizinische Fakultät der Georg-August-Universität Göttingen.

Lenzen M (2016) Anatomie lernt man vom Hinschauen: Andreas Vesalius ersetzt Autoritätsglaube durch Empirie, macht das Sezieren von Leichen gesellschaftsfähig und hinterlässt ein Meisterwerk der Buchkunst. URL: https://www.dasgehirn.info/entdecken

/meilensteine/andreas-vesalius-begruender-der-modernen-anatomie [Stand 04.12.2018; 11:24].

Lipsinic F, Paunovich E, Houston G, Robison S (1986) Correlation of Age and Incremental Lines in the Cementum of Human Teeth," Journal of Forensic Sciences 31(3): 982-989.

Lucas PW, Loh HS (1986) Are the incremental lines in human cementum laid down annually? Annals of the Academy of Medicine, Singapore 15(3): 384-386.

Manzi G, Gracia A, Arsuaga JL (2000) Cranial discrete traits in the middle pleistocene humans from Sima de los Huesos (Sierra de Atapuerca, Spain). Does hypostosis represent any increase in "ontogenetic stress" along the Neanderthal lineage? J Hum Evol. 38(3): 425-446.

Marie P (1980) De l'ostéo-anthropathie hypertrophiante pneumique. Rév Med, Paris, 10: 1-36.

Martin R (1928) Lehrbuch der Anthropologie in systematischer Darstellung mit besonderer Berücksichtigung der anthropologischen Methoden. 2. Band: Kraniologie, Osteologie. 2. Aufl. Verlag von Gustav Fischer Jena.

Mazanec J (unveröffentlicht) Untersuchungen von Pathogen-DNA in der Skelettserie des katholischen Friedhofs Göttingen. Zwischenbericht, Biologische Fakultät der GeorgAugust-Universität, Göttingen.

Melisch CM, Escher F, Jungklaus B (2011) Der erste katholische Friedhof Berlins. Archäologie, Anthropologie, Geschichte. Landesdenkmalamt Berlin (Hrsg.). Beiträge zur Denkmalpflege in Berlin Bd. 36. Michael Imhof Verlag.

Melikan M, Waldron T (2003) An examination of skulls from two British sites for possible evidence of scurvy. International Journal of Osteoarchaeology 13: 207-212.

Miller C, Dove S, Cottone J (1988) Failure of Use of Cemental Annulations in Teeth to Determine the Age of Humans," Journal of Forensic Sciences 33(1): 137-143.

Möller-Leimkühler AM (1999) Sozialer Status und Geschlecht. Zur Aktualität sozialer Ungleichheit bei psychiatrischen Erkrankungen. Der Nervenarzt 70: 970-980.

Morgulis A, Coulouris G, Raytselis Y, Madden TL, Agarwala R, Schäffer AA (2008) Database indexing for production MegaBLAST searches. Bioinform. Oxf. Engl. 24: 1757-1764. 
Nascimento FA, Gatto LAM, Lages RO, Neto HM, Zeferino Demartini Z Jr., Koppe GL (2014) Diffuse idiopathic skeletal hyperostosis: A review. Surg Neurol Int. 5(3): 122-125.

Nemeskéri J, Harsányi L, Acsádi G (1960) Methoden zur Diagnose des Lebensalters von Skelettfunden. Anthrop. Anz. Jg. 24(1): 70-95. Stuttgart.

Nothwang U (2008) Analyse von Osteopathologien zu Beginn der Röntgen-Ära (Fallbeispiele Annastift Hannover). Cuvillier Verlag.

Ogden AR, Pinhasi R, White WJ (2007) Gross enamel hypoplasia in molars from subadults in a 16th-18th Century London Graveyard. American Journal of physical anthropology 133: 957-966.

Ogden JA (1984) Growth slowdown and arrest lines. Journal of pediatric orthopedics 4: 409415, Raven Press, New York.

O'Loughlin VD (2004) Effects of different kinds of cranial deformation on the incidence of wormian bones. Am J Phys Anthropol. 123(2): 146-155.

Ortner DJ (2003) Identification of pathological conditions in human skeletal remains. Second Edition. Academic Press.

Ortner DJ, Putschar WGJ (1981) Identification of pathological conditions in human skeletal remains. Smithsonian Intitution Press.

Paraskevas GK, Papaziogas B, Tzaveas A, Giaglis G, Kitsoulis P, Natsis K (2010) The supratrochlear foramen of the humerus and its relation to the medullary canal: A potential surgical application. Med Sci Monit 16(4): 119-123.

Park EA (1954) Bone growth in health and disease. Archives of diseases in childhood 29(146): 269-281.

Pearson K (1899) Mathematical contributions to the theory of evolution. V. On the reconstruction of the stature of prehistoric races, Philosophical Transactions of the Royal Society of London Series A 192: 169-244.

Pereira MN, de Almeida LE, Martins MT, da Silva Campos MJ, Fraga MR, Vitral RWF (2011) Multiple hyperdontia: Report of an unusual case. American Journal of Orthodontics and Dentofacial Orthopedics. 140(4): 580-584.

Petersone-Gordina E, Gerhards G (2011) Dental Disease in a 17th-18th Century German Community in Jelgava, Latvia. Papers on Anthropology 20: 327-350.

Pilloud S (2004) Läßt sich mittels der Altersbestimmung anhand des Zahnzementes auch bei älteren Individuen ein signifikanter Zusammenhang zwischen histologischem und reellem Alter finden? Anthr Anzeiger Jahrg 62(2): 231-239.

Prellert J (2016) Mein Lieblingsobjekt - Die Anatomieleiche. URL: https://www.lwllandesmuseum-herne.de/blog/praktikanten-berichten-mein-lieblingsobjekt

[Stand 01.11.2018; 11:56]. 
Reimann F, Celik E (1978) Doppelkonturen und Begleitschatten am Schädel bei anämischen Erkrankungen. Fortschr Röntgenstr 129: 762-765.

Roberts C, Manchester K (2010) The Archaeology of Disease. Third Edition. The History Press UK.

Römling M. (2012) Göttingen: Geschichte einer Stadt. Tertulla-Verlag Soest.

Rösing FW, Graw M, Marré B, Ritz-Timme S, Rothschild MA, Rötzscher K, Schmeling A, Schröder I, Geserick G (2005) Arbeitsgemeinschaft für Forensische Altersdiagnostik der Deutschen Gesellschaft für Rechtsmedizin. Empfehlungen für die forensische Geschlechtsund Altersdiagnostik am Skelett. Rechtsmedizin 15: 32-38.

Sachse W (1987) Göttingen im 18. und 19. Jahrhundert: zur Bevölkerungs- und Sozialstruktur einer deutschen Universitätsstadt.

Schallmann J (2014) Arme und Armut in Göttingen 1860-1914. Vandenhoeck \& Ruprecht.

Schelzel M (2005) Degenerative Veränderungen an den Wirbelsäulen der menschlichen Skeletfunde aus dem Ostteil des frühbajuwarischen Gräberfeldes Straubigen (Niederbayern). Dissertation, Medizinische Fakultät der Georg-August-Universität, Göttingen.

Schmidt-Schultz TH, Schultz M (2004) Bone protects proteins over thousands of years: extraction, analysis, and interpretation of extracellular matrix proteins in archaeological skeletal remains. Am J Phys Anthropol 123(1): 30-39.

Schmidt-Schultz TH, Schultz M (2015) AG 85, a major secretion protein of Mycobacterium tuberculosis, can be identified in ancient bone. Tuberculosis 95 (Suppl.): S87-S92.

Schröder F (2012) Geschlechtsbestimmung subadulter Individuen eines neuzeitlichen katholischen Friedhofs aus Göttingen anhand einer Multiplex X/Y-PCR. Bachelorarbeit, Biologische Fakultät der Georg-August-Universität, Göttingen.

Schröder B, Wojtkowiak H (2015) Stiftsgeschichte(n). 250 Jahre Theologisches Stift der Universität Göttingen (1765-2015). Vandenhoeck \& Ruprecht.

Schultz M (1979) Zeichen akuter und chronischer Entzündungen des Mittelohres an frühgeschichtlichem Skelettmaterial. HNO 27: 77-85.

Schultz M (1982): Umwelt und Krankheit des vor- und frühgeschichtlichen Menschen. In: Wendt, H., \& Loacker, N. (Hrsg.): Kindlers Enzyklopädie der Mensch. Band 2, Kindler Verlag, Zürich, 259-312.

Schultz M (1988a) Methoden der Licht- und Elektronenmikroskopie. In: Knußmann R (Hrsg.). Anthropologie. Handbuch der vergleichenden Biologie des Menschen Bd I/1. Fischer, Stuttgart New York.

Schultz M (1988b) Paläopathologische Diagnostik. In: Knußmann R (Hrsg). Anthropologie. Handbuch der vergleichenden Biologie des Menschen Bd I/1. Fischer, Stuttgart New York. 
Schultz M (1993) Spuren unspezifischer Entzündungen an prähistorischen Schädeln. Ein Beitrag zur Paläopathologie. In: Anthropologische Gesellschaft Basel (Hrsg.), Anthropologische Beiträge Bd.4.

Schultz M (1999) Microscopic Investigation in Fossil Hominoidea: A Clue to Taxonomy, Functional Anatomy, and the History of Diseases. The anatomical record (new anat.) 257: 225-232.

Schultz M (2001) Paleohistopathology of bone: A new approach to the study of ancient diseases. Yearbook of physical anthropology 44: 106-147.

Schultz M (2012) Light microscopic analysis of macerated pathologically changed bones. In: Crowder C and Stout S (eds.) Bone Histology: An anthropological perspective. CRC Press, 253-296.

Schultz M, Schmidt-Schultz TH (2015) Is it possible to diagnose TB in ancient bone using microscopy?. Tuberculosis 95 (Suppl.): S80-S86.

Schultz M, Teschler-Nicola M (1987) Krankhafte Veränderungen an den Skeletten aus dem Karner der St. Martins-Kirche in Klosterneuburg, Niederösterreich Teil 1-4. Ann. Naturhist. Mus. Wien. Volume 89: 225-311.

Schumacher G-H, Schmidt H (1972) Anatomie und Biochemie der Zähne. Gustav Fischer Verlag Stuttgart.

Schumacher G-H, Schmidt H, Börnig H, Richter W (1990) Anatomie und Biochemie der Zähne. 4. überarbeitete Auflage. Gustav Fischer Verlag Stuttgart New York.

Schumpelick V, Arlt G, Conze J, Junge K (2015) Hernien. 5. vollständig überarbeitete und erweiterte Auflage. Thieme Verlag.

Schünemann MJ (2014) Paläodontologische Untersuchungen an Skeletresten aus der Wüstung Drudewenshusen im südniedersächsischen Eichsfeld. Dissertation, Medizinische Fakultät der Georg-August-Universität Göttingen.

Schünke M, Schulte E, Schumacher U, Voll M, Wesker KH (2011) Prometheus LernAtlas der Anatomie: Allgemeine Anatomie und Bewegungssystem. 3. überarbeitete und erweiterte Auflage.

Schüßler ST (2016) PCR based detection of Mycobacterium tuberculosis complex from skeletal material with osteological evidence of a tuberculosis infection. Masterarbeit, Biologische Fakultät der Georg-August-Universität, Göttingen.

Schwartz GT, Reid DJ, Dean MC, Zihlman AL (2006) A Faithful Record of Stressful Life Events Preserved in the Dental Developmental Record of a Juvenile Gorilla. International Journal of Primatology 27: 1201-1219. 
Seidenberg V, Schilz F, Pfister D, Georges L, Fehren-Schmitz L, Hummel S (2012) A new miniSTR heptaplex system for genetic fingerprinting of ancient DNA from archaeological human bone. Journal of Archaeological Science 39: 3224-3229.

Senatsverwaltung für Stadtentwicklung und Wohnen (2016) Pressemitteilung vom 05.12.2016. URL: https://www.stadtentwicklung.berlin.de/aktuell/pressebox

/archiv_volltext.shtml?arch_1612/nachricht6275.html [Stand 29.11.2018: 11:51].

Singhal S, Rao V (2007) Supratrochlear foramen of the humerus. Anatomical Science International 82: 105-107.

Starck D (1975) Embryologie. Ein Lehrbuch auf allgemein biologischer Grundlage. 3. Neubearbeitete und erweiterte Auflage. Georg Thieme Verlag Stuttgart.

Steckel R, Larsen CS, Sciulli PW, Walker PL (2005) Data Collection Codebook. The Global History of Health Project. Ohio State University; Columbus, $\mathrm{OH}$.

Steinbock RT (1976) Paleopathological Diagnosis and Interpretation. Bone Diseases in Ancient Human Populations. Thomas Books, Springfield, Illinois, U.S.A.

Ströbl A (2015) Engelskopf und Löwenfuß - Die Särge aus dem katholischen Friedhof. In: Grosskopf B (Hrsg.) Der vergessene Friedhof. Kulturgeschichtliche und naturwissenschaftliche Ergebnisse zur Ausgrabung des neuzeitlichen katholischen Friedhofes in Göttingen. Universitätsverlag Göttingen.

Stukenbrock K (1997) Die Rolle der Höfe bei der Beschaffung der Leichen für die anatomischen Sektionen an den Universitäten im 18. Jahrhundert. In: Mitteilungen der Residenzen-Kommission der Akademie der Wissenschaften zu Göttingen. (Hrsg.) Ewert U.C. and Selzer S. Sonderheft 2, Kiel.

Suckling GW (1989) Developmental defects of enamel - historical and present-day perspectives of their pathogenesis. Adv Dent Res 3(2): 87-94.

Szilvássy J (1977) Altersschätzung an den sternalen Gelenkflächen der Schlüsselbeine. Beitr gerichtl Med 35: 343-345.

Szilvássy J (1988) Altersdiagnose am Skelett. In: Knußmann R (Hrsg): Anthropologie Handbuch der vergleichenden Biologie des Menschen. Bd.I: Wissenschaftstheorie, Geschichte, morphologische Methoden. 4. Auflage, Gustav Fischer Verlag Stuttgart, New York.

Teegen W-R, Kreutz K, Schultz M (1997) Paläopathologische Untersuchungen der Skelette aus den Siedlungsbestattungen von der kaiserzeitlichen Wurt Feddersen Wierde. Vorbericht. Kokabi M (Hrsg.) Beitr. z. Archäozool. u. Prähist. Anthrop. I: 111-119.

Templin O (1993) Die Kinderskelette von Bettingen im Kanton Basel-Stadt (Schweiz). Eine paläopathologische Untersuchung. Dissertation, Fachbereich Medizin der Georg-AugustUniversität, Göttingen. 
Todd TW, Lyon DW Jr. (1925) Cranial suture closure. Its progress and agerelationship Part II. - Ectocranial closure in adult males of White Stock. Am. J. Phys. Anthrop. 8(1): 23-45.

Trede F (2016) Sonication-based extraction protocol for pathogenic DNA from skeletal material. Masterrarbeit, Biologische Fakultät der Georg-August-Universität, Göttingen.

Ubelaker DH (1989) Human skeletal remains: Excavation, analysis, interpretation. Second Edition. Smithsonian Institute.

Ubelaker DH (2012) Skeletal Indicators of Pregnancy and Parturition: A Historical Review. Journal of Forensic Sience 57(4): 866-872.

Ude-Koeller S (2010) “Geben Sie diese schönste Professur in Deutschland, nach welcher Viele die Hand ausstrecken nicht aus ihrer Hand“ - Jacob Henle in Göttingen 1852-1885. In: Sonderdruck aus Göttinger Jahrbuch. Band 58.

Vargová L, Horáčková L (2010) Notes to palaeopathological diagnostics of children's disease. Interdisciplinaria Archaeologica. Natural science in archaeology 1(1-2): 67-73.

Villotte S, Castex D, Couallier V, Dutour O, Knüsel CJ, Henry-Gambier D (2010) Enthesopathies as Occupational Stress Markers: Evidence from the Upper Limb. American Journal of Physical Anthropology 142: 224-234.

Wagener S. (1995) “...wenigstens im Tod der Welt noch nüzlich und brauchbar...” Die Göttinger Anatomie und ihre Leichen. In: Göttinger Jahrbuch. Band 43. Verlag Erich Goltze, Göttingen.

Waldron T (2009) Paleopathology. Cambridge University Press.

Wapler U, Crubézy E, Schultz M (2004) Is Cribra orbitalia synonymous with anemia? Analysis and Interpretation of cranial pathology in Sudan. Anerican Journal of Physical Anthropology 123: 333-339.

Wehking S (1992) „Ein jeder darf sich gleichen Rechts erfreue'n...“ - Die Geschichte der Katholischen Kirche in Göttingen 1746-1990.Studien zur Geschichte der Stadt Göttingen Bd. 17. Vandenhoeck und Ruprecht.

Wells C (1961) A New Approach to Ancient Disease. In: Discovery, Bd. 22.

Wells C (1967) A new approach to palaeopathology: Harris's Lines. In: Brothwell D \& Sandisons AT (Hrsg.): Disease in Antiquity. Charles C. Thomas Publisher, Springfield.

Welzl E (1985) Biochemie der Ernährung. De Gruyter, Berlin, New York.

Winkler S (o. D.) Der Friedhof der Barmherzigen Brüder. URL: https://www.muenster.de /stadt/ausgrabungen-stubengasse/Klarissenkloster_clemenshospital_friedhof_ barmh_brueder.html [Stand 01.11.2018; 12:58]. 
Wittwer-Backofen U, Gampe J and Vaupel J (2004) Tooth Cementum Annulation for Age Estimation: Results from a Large Known-Age Validation Study. American Journal of Physical Anthropology 123: 119-129.

Zaaijer T (1866) Untersuchungen über die Form des Beckens Javanischer Frauen. Naturrk Verhandel Holland Maatsch Ventensch Haarlem 24: 1-42.

Zhang Z, Schwartz S, Wagner L and Miller W (2000) A greedy algorithm for aligning DNA sequences. J. Comput. Biol, 7: 203-214.

Zimmermann V (2009) "Eine Medicinische Facultät in Flor bringen”: zur Geschichte der Medizinischen Fakultät der Georg-August-Universität Göttingen. 


\section{Anhang}

\subsection{Einheiten und Abkürzungen}

V. a. = Verdacht auf

ca. $=$ circa

z. T. = zum Teil

z. B. = zum Beispiel

bzw. $=$ beziehungsweise

max. $=$ maximal

min. $=$ minimal

u. a. = unter anderem

usw. $=$ und so weiter

u. v. m. = und viele mehr

etc. $=$ et cetera

et al. $=$ und Weitere

Abb. $=$ Abbildung

Tab. $=$ Tabelle

o. D. = ohne Datum

$\operatorname{Inf} 1=\operatorname{Infans} 1$

Inf $2=$ Infans 2

juv $=$ Juvenis

ad $=$ Adultas

mat $=$ Maturitas

sen $=$ Senium

STR $=$ Short Tandem Repeat

$\mu \mathrm{m}=$ Mikrometer

$\mathrm{nm}=$ Nanometer

$\mathrm{mm}=$ Millimeter

$\mathrm{cm}=$ Zentimeter

$\mathrm{m}=$ Meter

$\mathrm{m}^{2}=$ Quadratmeter

$1=$ Liter

$\mu \mathrm{l}=$ Mikroliter

$\mathrm{ml}=$ Milliliter

$\mathrm{rcf}=$ relative centrifugal force

$\mathrm{rpm}=$ rounds per minute

sek $=$ Sekunde

$\min =$ Minute

$\mathrm{h}=$ Stunde

$\mathrm{V}=\mathrm{Volt}$

$\mathrm{kV}=$ Kilovolt

${ }^{\circ} \mathrm{C}=$ Grad Celsius

$\mathrm{M}=$ molare Masse

$\mathrm{bp}=$ Basenpaare $\mathrm{m}=$ männlich

em $=$ eher männlich

$\mathrm{Tm}=$ Tendenz männlich

$\mathrm{M}=$ Mann

$\mathrm{w}=$ weiblich

ew $=$ eher weiblich

$\mathrm{Tw}=$ Tendenz weiblich

$\mathrm{F}=\mathrm{Frau}$

nd $=$ nicht determinierbar

$\mathrm{nb}=$ nicht befundbar

TVSH $=$ transversale lineare

Schmelzhypoplasien

$\mathrm{HL}=$ Harris-Linien

$\mathrm{BSG}=$ Bewegungssegment

UK = Unterkiefer

$\mathrm{OK}=$ Oberkiefer

EDTA $=$ Ethylendiamintetraacetat

SDS = Sodium dodecyl sulphate

PB-Buffer $=$ Binding Buffer

TBE $=$ Tris-Borat-EDTA-Puffer

$\mathrm{PCR}=$ polymerase chain reaction

$\alpha=$ Signifikanzniveau $\alpha$

$\mathrm{p}=\mathrm{p}$-Wert, Überschreitungs-

wahrscheinlichkeitswert

TM $=$ Trademark

(C) = Copyright

® = rechtlich geschützt 


\subsection{Formulare und Befundbögen}

\begin{tabular}{|l|l|}
\hline Fundnr. & \\
\hline Erhaltung & \\
\hline Alter Zahl & \\
\hline Alter Klasse & \\
\hline Geschlecht & \\
\hline Sek.spuren & \\
\hline Cranium & \\
\hline Zähne & \\
\hline Clavicula & \\
\hline Scapula & \\
\hline Sternum & \\
\hline Costae & \\
\hline Wirbel & \\
\hline & \\
\hline Humerus & \\
\hline Femur & \\
\hline Pibula & \\
\hline Oatella & \\
\hline Tibsa Pedis & \\
\hline Radius & \\
\hline Ossa Manus & \\
\hline Sacrum & \\
\hline Os Coxae & \\
\hline
\end{tabular}

Abb. 95: Befundbogen für allgemeine Auffälligkeiten und Abweichungen von der Regelanatomie. 


\begin{tabular}{|c|c|c|c|c|c|c|c|}
\hline \multirow{3}{*}{$\begin{array}{l}\text { Objekt: } \\
\text { Sign.: } \\
\text { Alter: }\end{array}$} & \multirow{3}{*}{$\begin{array}{l}\text { Grab-Nr.: } \\
\text { Geschlecht: }\end{array}$} & & & & \multicolumn{3}{|c|}{ Datum: } \\
\hline & & \multicolumn{3}{|c|}{ Rechle Korperseite } & \multicolumn{3}{|c|}{ Linke Körperseite } \\
\hline & & Rand & Flactie & Bewertuog & Rand & Fláche & Bewertung \\
\hline Schulter- & Cappor bumeri & & & & & & \\
\hline gelenk & Carvizs glenoidalis & & & & & & \\
\hline \multirow{4}{*}{$\begin{array}{l}\text { Ellentsogen- } \\
\text { gelenk }\end{array}$} & Caypitakm humeri & & & & & & \\
\hline & Capper radii & & & & & & \\
\hline & Trocitiea & & & & & & \\
\hline & Incisurz trochlearis & & & & & & \\
\hline \multirow{4}{*}{$\begin{array}{l}\text { Radio-UInar- } \\
\text { gelenk }\end{array}$} & Ciucuaferentia art. (Radius) & & & & & & \\
\hline & Ineinerz radialis (Ulina) & & & & & & \\
\hline & Incisuzz ulnaris (Rsalius) & & & & & & \\
\hline & Cincersferentia art. (Ulna) & & & & & & \\
\hline \multirow{3}{*}{$\begin{array}{l}\text { Froximales } \\
\text { Handgelenk }\end{array}$} & Proux. Reihe der Ylandwurzeliknochen & & & & & & \\
\hline & Faccies art. carpea (Radilts) & & & & & & \\
\hline & Comper ulnac & & & & & & \\
\hline \multirow{3}{*}{$\begin{array}{l}\text { Yüft- } \\
\text { gelenk }\end{array}$} & Capper fernoris & & & & & & \\
\hline & Fonvez tapitis femoris & & & & & & \\
\hline & Acerabolum & & & & & & \\
\hline \multirow{9}{*}{$\begin{array}{l}\text { Knic- } \\
\text { gelenk }\end{array}$} & Condyius med. femoris & & & & & & \\
\hline & Condyizs lat. femoris & & & & & & \\
\hline & Unterrend der Fassa intercomdylaris & & & & & & \\
\hline & Conctyus med. thise & & & & & & \\
\hline & Consciybus lat, tibiac & & & & & & \\
\hline & Facios pateliaris med, (Femex) & & & & & & \\
\hline & Famies patellaris lat, (Femur) & & & & & & \\
\hline & Farcies mod. (Patella) & & & & & & \\
\hline & Faries bit. (Fatella) & & & & & & \\
\hline \multirow{6}{*}{$\begin{array}{l}\text { Proximales } \\
\text { Sprunggelenk }\end{array}$} & Facies ark, inf. (Tibia) & & & & & & \\
\hline & Facies ar. sup. (Talus) & & & & & & \\
\hline & Faxies art. malieoli (Tibia) & & & & & & \\
\hline & Facies analleotaris med. (Taters) & & & & & & \\
\hline & Frocies aalteoli (Fibula) & & & & & & \\
\hline & Facies malleolaris lat. (Talus) & & & & & & \\
\hline \multirow{8}{*}{$\begin{array}{l}\text { Distales } \\
\text { Sprunggeienk }\end{array}$} & Fatres arr. calcan. post. (Taluss) & & & & & & \\
\hline & Farcis ant. tal. post. (Calcameus) & & & & & & \\
\hline & Facies aft. calcati. med. (Tahus) & & & & & & \\
\hline & Facies ant tal. ned. (Calcaneus) & & & & & & \\
\hline & Facies $2 \pi$. calcan. aur. (Taleas) & & & & & & \\
\hline & Fackes ar. tal an (Caicaneus) & & & & & & \\
\hline & Facres in. navicul. (Taiıs) & & & & & & \\
\hline & Fuciss $3 \pi$. prox. (Os naviculare) & & & & & & \\
\hline
\end{tabular}

Abb. 96: Befundbogen zur Dokumentation der Gelenksabnutzung (Schultz 1988). 


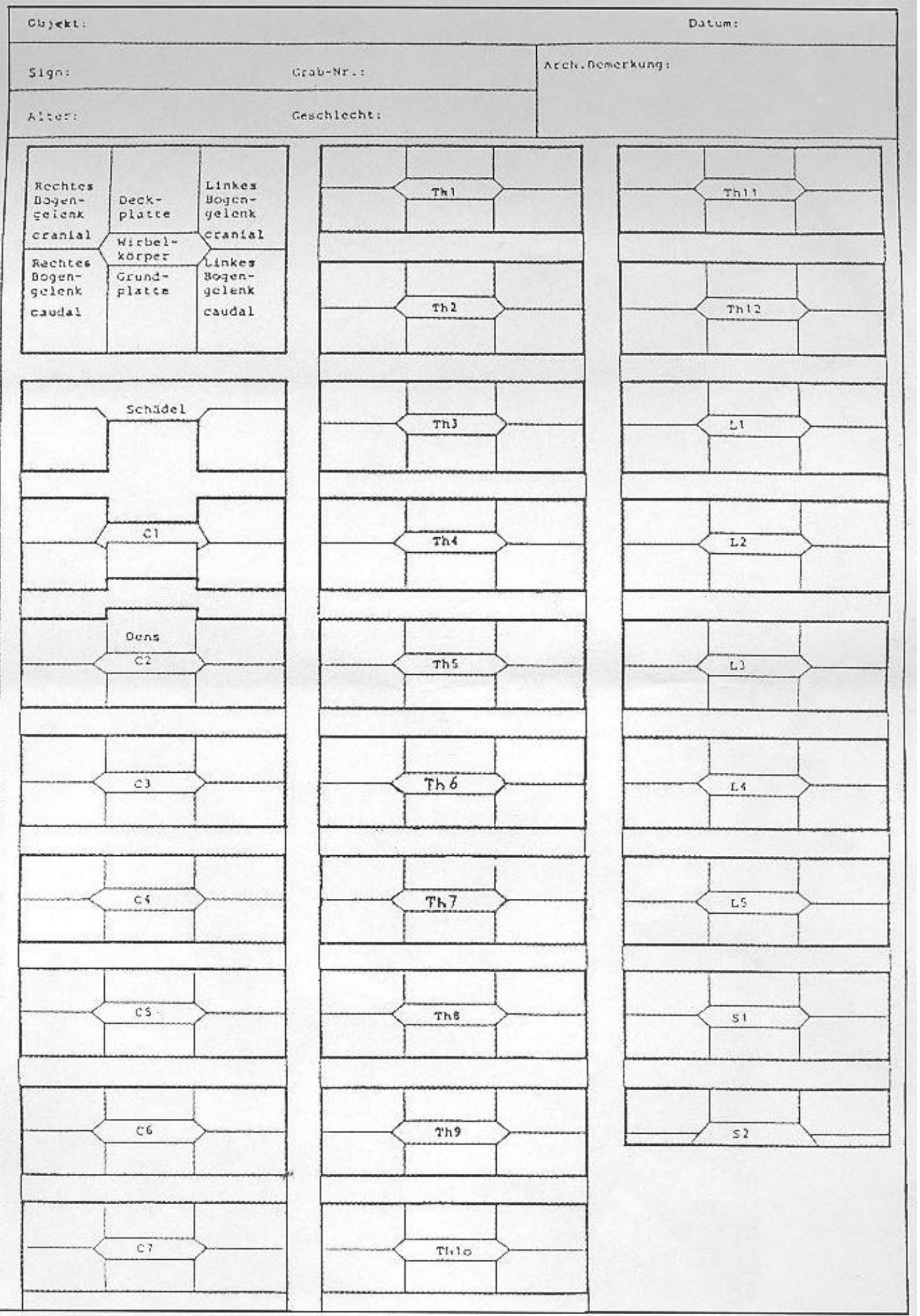

Abb. 97: Befundbogen zur Dokumentation der Wirbelsäulenveränderungen (Schultz 1988). 


\begin{tabular}{|c|c|c|}
\hline \multicolumn{2}{|l|}{ Objekt: } & \multirow{3}{*}{ Arch. Bemerk: } \\
\hline \multirow{2}{*}{\begin{tabular}{|l|} 
Sign.: \\
Alter:
\end{tabular}} & Grab-Nr.: & \\
\hline & Geschlecht: & \\
\hline \multicolumn{3}{|l|}{\begin{tabular}{|l|l|} 
& Lamina externa \\
$c$ & Lamina \\
$h$ & \\
$\hat{i}$ & \\
0 &
\end{tabular}} \\
\hline \multicolumn{3}{|l|}{ Lamina interna } \\
\hline \multicolumn{2}{|c|}{ Jochbeinaußenfläche re } & $1 \mathrm{i}$ \\
\hline Begr. Apertura pirif. & re & li \\
\hline \multicolumn{3}{|c|}{ Außenfläche } \\
\hline $\begin{array}{c}s \\
c \\
c\end{array}$ & re & li \\
\hline $\begin{array}{lll}0 & \text { Fossa cranii med. } \\
& \end{array}$ & re & Ii \\
\hline \begin{tabular}{l|l}
1 \\
$s$ \\
1 \\
$s$
\end{tabular} & re & ii \\
\hline \multicolumn{3}{|l|}{\begin{tabular}{|l} 
Sella \\
\end{tabular}} \\
\hline \multicolumn{3}{|l|}{ Clivus } \\
\hline \multicolumn{3}{|l|}{ Sinus sagitt. sup. } \\
\hline Sinus transversus & re & li \\
\hline Sinus sigmoideus & $\mathrm{re}$ & li \\
\hline Orbitadach & $\mathrm{re}$ & Ii \\
\hline Orbitaboden & re & li \\
\hline Mittelohr & $\mathrm{re}$ & li \\
\hline Meatus acust. ext. & $\mathrm{re}$ & Ii \\
\hline Meanus acust. int. & re & li \\
\hline Proc. mastoideus & re & Ii \\
\hline Sinus frontalis & $\mathrm{re}$ & ii \\
\hline Sinus maxillaris & re & ii \\
\hline Sinus sphenoidalis & re & $\mathrm{Ii}$ \\
\hline Cellulae ethmoidalis & re & ii \\
\hline Nasenhöhle & re & Ii \\
\hline \multicolumn{2}{|c|}{ Ductus nasolacrimal. re } & li \\
\hline Harter Gaumen & & Befunde: \\
\hline $\begin{array}{l}\text { Auflagerungen } \\
\text { Alveolarrand (auBen) }\end{array}$ & & $+:=$ krank \\
\hline $\begin{array}{l}\text { poröse Auskleidung } \\
\text { der Alveolen (innen) }\end{array}$ & & $-=$ gesund \\
\hline Karies & & $f=$ nicht befundbar \\
\hline Parodontopathien & & \\
\hline $\begin{array}{l}\text { Transv. Schmelzhyp. } \\
\text { Zahnstein }\end{array}$ & & $0=$ nicht vorhanden \\
\hline
\end{tabular}

Abb. 98: Befundbogen zur Dokumentation von Auffälligkeiten am Schädel (Schultz AG Paläopathologie UMG). 


\begin{tabular}{|c|c|c|}
\hline \multicolumn{2}{|l|}{ Objckt } & \multirow[t]{2}{*}{ Datum : } \\
\hline Signatur & Grab-Nr. : & \\
\hline Alter & Geschlecht: & \\
\hline
\end{tabular}
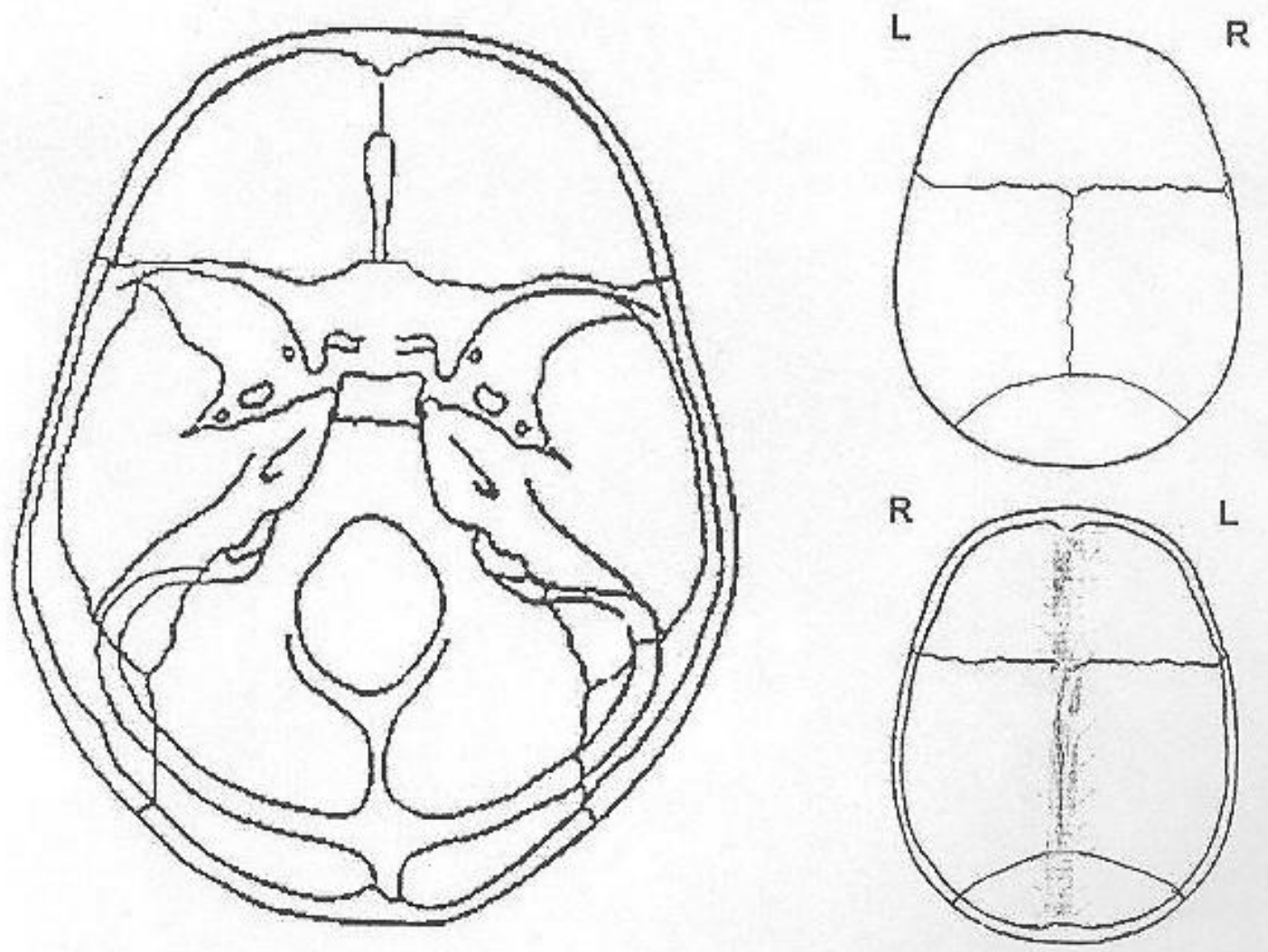

Abb. 99: Befundbogen zur Dokumentation von Auffälligkeiten am Schädel (Schultz AG Paläopathologie UMG). 


\subsection{Ergebnisse Molekulargenetischer Untersuchungen}

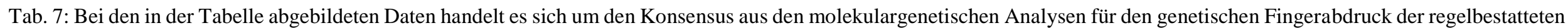
Individuen.

\begin{tabular}{|c|c|c|c|c|c|c|c|c|c|c|c|c|c|c|c|c|c|}
\hline Individuum & Skelettelement & \multicolumn{2}{|c|}{ Ameld } & \multicolumn{2}{|c|}{ D13S317 } & \multicolumn{3}{|c|}{ D21S11 } & \multicolumn{3}{|c|}{ D18S51 } & \multicolumn{2}{|c|}{ TH01 } & \multicolumn{2}{|c|}{ D5S818 } & \multicolumn{2}{|r|}{ FGA } \\
\hline $4 \mathrm{~A}$ & Dens 23 & $X$ & $\mathrm{Y}$ & 12 & 13 & 29 & 30 & 31 & 16 & - & & 9 & 9.3 & 11 & 13 & 19 & 23 \\
\hline 12 & Femur & $X$ & $\mathrm{Y}$ & 9 & 12 & 29 & 30 & & 14 & 21 & & 8 & 9 & 12 & - & 22 & - \\
\hline 17 & Prämolar & $X$ & - & 12 & 13 & 28 & - & & 14 & 15 & & 8 & 9 & 10 & 13 & 21 & 22 \\
\hline 24 & Pars petrosa li & $\mathrm{X}$ & - & 11 & 13 & 28 & 30 & & 15 & 17 & & 8 & 9 & 11 & 13 & 21 & 22 \\
\hline 31 & Tibia re & $X$ & - & 11 & - & - & - & & - & - & & 6 & $(9)$ & - & - & $(18)$ & - \\
\hline 36 & Metatarsus Ire & $X$ & - & 11 & 12 & 29 & $(30.2)$ & & (14) & 17 & & 9.3 & - & 11 & $(12)$ & 22 & - \\
\hline 44 & Dens 23 & $\mathrm{X}$ & $\mathrm{Y}$ & 8 & 11 & 29 & 32.2 & & 14 & 18 & & 6 & - & 11 & - & 22 & 24 \\
\hline 45 & Dens 13 & $X$ & $\mathrm{Y}$ & 11 & 13 & 30 & 32.2 & & 13 & 17 & & 7 & - & 11 & - & 21 & 24 \\
\hline 46 & Metatarsus I li & $\mathrm{X}$ & $\mathrm{Y}$ & 11 & 12 & (29) & 30 & & (13) & 16 & & 6 & 9 & 13 & - & $(20)$ & (23) \\
\hline 47 & Dens 43 & $\mathrm{X}$ & - & 9 & 10 & 28 & $(31)$ & & 14 & 19 & & 6 & 9.3 & 11 & - & 18 & 20 \\
\hline 48 & Clavicula re & $\mathrm{X}$ & $\mathrm{Y}$ & 9 & (13) & 30 & - & & (12) & 13 & (14) & 7 & 9.3 & (10) & 11 & 19 & 24 \\
\hline
\end{tabular}




\begin{tabular}{|c|c|c|c|c|c|c|c|c|c|c|c|c|c|c|}
\hline \multirow{2}{*}{$\begin{array}{lr} & \text { Individuum } \\
& \\
49 & \\
\end{array}$} & \multirow{2}{*}{ 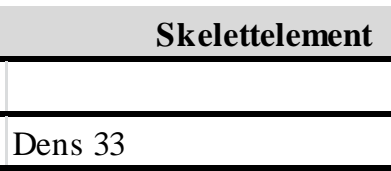 } & \multirow{2}{*}{\begin{tabular}{|l|} 
Ameld \\
$x-1$ \\
$x$
\end{tabular}} & \multicolumn{2}{|c|}{ D13S317 } & \multicolumn{2}{|c|}{ D21S11 } & \multicolumn{2}{|c|}{ D18S51 } & \multicolumn{2}{|r|}{ TH01 } & \multicolumn{2}{|c|}{ D5S818 } & \multicolumn{2}{|r|}{ FGA } \\
\hline & & & 10 & 11 & 29 & $(32.2)$ & 13 & - & 6 & 9 & 12 & 13 & 19 & 25 \\
\hline 66 & Dens 13 & \begin{tabular}{|ll|l}
$X$ & $Y$ \\
\end{tabular} & - & - & - & - & 13 & - & - & - & 12 & - & - & - \\
\hline 73 & Dens 13 & $\begin{array}{|ll|}\mathrm{X} & \mathrm{Y} \\
\end{array}$ & 12 & 13 & 28 & 33.2 & 15 & 18 & 6 & 7 & 11 & 12 & 22 & 26 \\
\hline $78 \mathrm{~B}$ & Dens 43 & $\begin{array}{|ll|}\mathrm{X} & \mathrm{Y} \\
\end{array}$ & 8 & 11 & 30 & 32.2 & 16 & 18 & 9.3 & - & 9 & 10 & 22 & - \\
\hline & & & & & & & & & & & & & & \\
\hline 91 & Dens 15 & $\mathrm{X}(\mathrm{Y})$ & - & - & - & - & - & - & 8 & - & - & - & - & - \\
\hline & & & & & & & & & & & & & 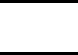 & 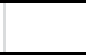 \\
\hline $92 \mathrm{C}$ & Tibia re & $\mathrm{X}(\mathrm{Y})$ & 10 & 12 & - & - & - & - & 6 & 7 & - & - & 21 & - \\
\hline & & & & & & & & & & & & & 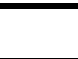 & \\
\hline 103 & Pars petrosa re & \begin{tabular}{|l|l|}
$X$ & $Y$ \\
\end{tabular} & 11 & 12 & 29 & 30 & 15 & 18 & 6 & 7 & 11 & 13 & 21 & 22 \\
\hline $104 \mathrm{~B}(3)$ & Metacarpus II re & $\begin{array}{|ll|}X & Y \\
\end{array}$ & 8 & 11 & (28) & (29) & 15 & 18 & 6 & 9.3 & 12 & _ & 19 & 21 \\
\hline $104 \mathrm{~B}(4)$ & Tibia (Osteomyelitis) & \begin{tabular}{|ll|l}
$X$ & $Y$ \\
\end{tabular} & 11 & 14 & 29 & 31.2 & 14 & 18 & 9 & 9.3 & 11 & 12 & 23 & 25 \\
\hline 118 & Dens 23 & $\begin{array}{|ll|}X & Y \\
\end{array}$ & 8 & 11 & 31.2 & 32.2 & 12 & (13) & 9 & 9.3 & 12 & 13 & 20 & 23 \\
\hline 137B & Metatarsus I re & $\mid \overline{X Y}$ & 11 & 12 & 30 & 31 & 15 & 16 & 9.3 & - & 11 & 12 & 21 & 25 \\
\hline
\end{tabular}




\begin{tabular}{|c|c|c|c|c|c|c|c|c|c|c|c|c|c|c|c|c|}
\hline Individuum & Skelettelement & \multicolumn{2}{|c|}{ Ameld } & \multicolumn{2}{|c|}{ D13S317 } & \multicolumn{2}{|c|}{ D21S11 } & \multicolumn{2}{|c|}{ D18S51 } & \multicolumn{2}{|c|}{ TH01 } & \multicolumn{2}{|c|}{ D5S818 } & \multicolumn{3}{|c|}{ FGA } \\
\hline 138 & 44 & $\mathrm{X}$ & - & 10 & 11 & 28 & 30 & 14 & 17 & 7 & 9.3 & 11 & - & 20 & 24 & \\
\hline 146 & Pars petrosa li + Proc. styloideus & $\mathrm{X}$ & $\mathrm{Y}$ & 10 & 12 & 28 & 29 & 12 & 18 & 7 & 9 & 11 & 12 & 21 & 23 & \\
\hline 153 & Metatarsus I li & $\mathrm{X}$ & $\mathrm{Y}$ & 11 & - & $(30)$ & $(31.2)$ & (13) & (14) & 7 & - & 11 & (12) & $(20)$ & 21 & \\
\hline 154 & Femur re & $\mathrm{X}$ & $\mathrm{Y}$ & 8 & 11 & 28 & - & 13 & 16 & 6 & 7 & 12 & 13 & 24 & 26 & \\
\hline Streufund 1 & Arcus vertebrae & $\mathrm{X}$ & $\mathrm{Y}$ & 9 & 14 & 29 & 31.2 & 14 & 19 & 9 & 9.3 & 11 & 12 & 22 & 24 & \\
\hline Streufund 3 & Humerus re (lang, dist. vollst.) & $\mathrm{X}$ & $\mathrm{Y}$ & 11 & 12 & 28 & 29 & 15 & 17 & 6 & 7 & $((12))$ & 13 & 20 & 23 & \\
\hline Streufund 3 & Humerus re (kurz, dist. gebrochen) & $\mathrm{X}$ & $\mathrm{Y}$ & 8 & 14 & 27 & $(30)$ & $(12)$ & 13 & 6 & 9.3 & 10 & (13) & 20 & $(22)$ & \\
\hline Streufund 3 & Femur & $X$ & $\mathrm{Y}$ & (8) & 13 & (30) & - & 14 & (15) & 6 & 9.3 & (11) & 12 & $((20))$ & $(22)$ & (24) \\
\hline Streufund 7 & Femur li & $X$ & $\bar{Y}$ & 8 & 9 & (30) & (33.2) & (13) & 15 & 9 & 9.3 & 11 & - & 22 & - & \\
\hline
\end{tabular}

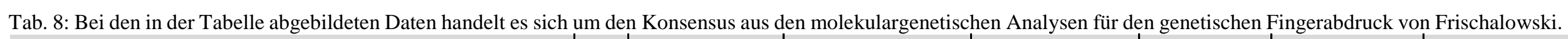

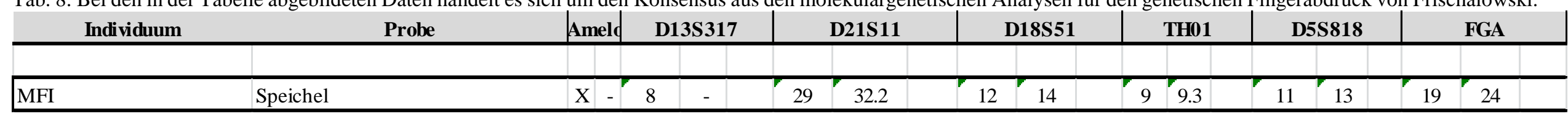




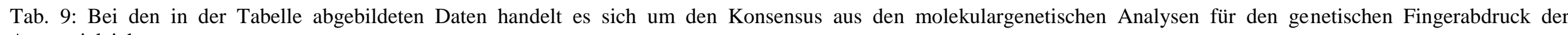
Anatomieleichen.

\begin{tabular}{|c|c|c|c|c|c|c|c|c|c|c|c|c|c|c|c|c|}
\hline Individuum & Skelettelement & \multicolumn{2}{|c|}{ Amelo } & \multicolumn{2}{|c|}{ D13S317 } & \multicolumn{3}{|c|}{ D21S11 } & \multicolumn{2}{|c|}{ D18S51 } & \multicolumn{2}{|r|}{ TH01 } & \multicolumn{2}{|c|}{ D5S818 } & \multicolumn{2}{|r|}{ FGA } \\
\hline $4 \mathrm{~B}$ & Tibia & $\mathrm{X}$ & $\mathrm{Y}$ & 9 & 11 & (28) & - & & (12) & (13) & 8 & $(9.3)$ & 12 & - & - & - \\
\hline 23 & Dens 35 & $\mathrm{X}$ & $\mathrm{Y}$ & 9 & 13 & 32.2 & - & & 10 & 20 & 8 & 9 & 11 & 12 & 21 & 24 \\
\hline $50(1)$ & Dens 15 & $\mathrm{X}$ & - & 8 & 11 & 30 & 33.2 & & 14 & 18 & 8 & 9.3 & 11 & - & 20 & 21 \\
\hline $50(2)$ & Femur re & $\mathrm{X}$ & $\mathrm{Y}$ & 11 & 12 & 29 & (30) & & 13 & 16 & 6 & 9 & 13 & - & 20 & 23 \\
\hline 61 & $\begin{array}{l}\text { Clavicula, Calcaneus, Dens, } \\
\text { Femur, Lumbalwirbel, } \\
\text { Metatarsus, Pars petrosa, } \\
\text { Phalanx, Rippe, Sternum, Tibia }\end{array}$ & $\mathrm{X}$ & $\mathrm{Y}$ & 11 & - & 29 & 31.2 & & 14 & 18 & 8 & 9.3 & 9 & 11 & 23 & 25 \\
\hline 62 & Dens 13 & $\mathrm{X}$ & $(\mathrm{Y})$ & 8 & (11) & (29) & $(32.2)$ & & (19) & - & (7) & 8 & 11 & - & (22) & 25 \\
\hline 82 & Metatarsus I li & $\mathrm{X}$ & $\mathrm{Y}$ & 12 & 13 & (28) & 30.2 & & (12) & 14 & 7 & 9 & 11 & (12) & 19 & 24 \\
\hline $104 \mathrm{~B}(1)$ & Dens & $X$ & $\mathrm{Y}$ & 8 & 11 & - & - & & - & - & 6 & 9.3 & 12 & - & - & - \\
\hline $105 \mathrm{~A}$ & Pars petrosa re, Dens & $\mathrm{X}$ & $\mathrm{Y}$ & 12 & 13 & 31 & $(31.2)$ & & 12 & 17 & 7 & - & 12 & - & (21) & (23) \\
\hline 105B & Dens & $\mathrm{X}$ & $\mathrm{Y}$ & 9 & 12 & - & - & & - & - & 6 & 9.3 & 12 & 13 & - & - \\
\hline $122 \mathrm{~A}(1)$ & Dens 34 & $\mathrm{X}$ & $\mathrm{Y}$ & 11 & 12 & 28 & 29 & 30 & 12 & 13 & 6 & 9.3 & 11 & 13 & 20 & 27 \\
\hline
\end{tabular}




\begin{tabular}{|c|c|c|c|c|c|c|c|c|c|c|c|c|c|c|c|c|}
\hline Individuum & Skelettelement & \multicolumn{2}{|c|}{ Amelo } & \multicolumn{2}{|c|}{ D13S317 } & \multicolumn{3}{|c|}{ D21S11 } & \multicolumn{2}{|c|}{ D18S51 } & \multicolumn{2}{|c|}{ TH01 } & \multicolumn{2}{|c|}{ D5S818 } & \multicolumn{2}{|c|}{ FGA } \\
\hline $122 \mathrm{~A}(2)$ & Tibia (großes Fragment) & $\mathrm{X}$ & $\mathrm{Y}$ & 10 & 12 & 30 & 31 & & 13 & 14 & 8 & 9 & 11 & 12 & 20 & 21 \\
\hline 131 & Dens 13 & $\mathrm{X}$ & $\mathrm{Y}$ & 12 & - & (32) & 33.2 & & 10 & (12) & 6 & - & 12 & - & 21 & - \\
\hline $142 \mathrm{~A}$ & Pars petrosa li & $\mathrm{X}$ & - & 8 & (12) & 28 & 29 & 30 & 14 & 18 & 6 & 9.3 & 10 & 12 & 22 & 25 \\
\hline
\end{tabular}




\subsection{Ergebnisse statistischer Untersuchungen pathologischer Veränderungen}

\section{Geschlechterverteilung}

Tab. 10: Ergebnisse des $\mathrm{Chi}^{2}$-Tests zur Verteilung der Geschlechter zwischen den Gruppen. Signifikanzniveau $\alpha=0,05$.

\begin{tabular}{|l|l|l|}
\cline { 2 - 3 } & $\mathrm{p}$-Wert & $\mathrm{x}^{\mathbf{2}}$ \\
\hline \hline Anatomieleichen gegen Regelbestattungen & 0,07 & 0,31 \\
\hline
\end{tabular}

\section{Altersverteilung}

Tab. 11: Ergebnisse des $\mathrm{Chi}^{2}$-Tests zur Verteilung der Geschlechter zwischen den Gruppen. Signifikanzniveau $\alpha=0,05$.

\begin{tabular}{|l|l|l|}
\cline { 2 - 3 } \multicolumn{1}{c|}{} & $\mathrm{p}$-Wert & $\mathrm{x}^{2}$ \\
\hline \hline Anatomieleichen gegen Regelbestattungen & 0,46 & 1,72 \\
\hline
\end{tabular}

\section{Mangelerkrankungen}

Tab. 12: Ergebnisse des $\mathrm{Chi}^{2}$-Tests zur Cribra orbitalia. Signifikanzniveau $\alpha=0,05$.

\begin{tabular}{|l|l|l|}
\cline { 2 - 3 } \multicolumn{1}{c|}{} & $\mathrm{p}$-Wert & $\mathrm{x}^{2}$ \\
\hline \hline Anatomieleichen gegen Regelbestattungen & 0,25 & 0,07 \\
\hline Anatomieleichen Männer gegen Regelbestattungen Männer & 0,43 & 0,05 \\
\hline Regelbestattungen Männer gegen Regelbestattungen Frauen & 0,44 & 0,08 \\
\hline
\end{tabular}

Tab. 13: Ergebnisse des Chi $^{2}$-Tests von Harris-Linien. Signifikanzniveau $\alpha=0,05$

\begin{tabular}{|l|l|l|}
\cline { 2 - 3 } \multicolumn{1}{c|}{} & $\mathrm{p}$-Wert & $\mathrm{x}^{\mathbf{2}}$ \\
\hline \hline Anatomieleichen gegen Regelbestattungen & 0,014 & 0,11 \\
\hline Anatomieleichen Männer gegen Regelbestattungen Männer & 0,052 & 0,01 \\
\hline Regelbestattungen Männer gegen Regelbestattungen Frauen & 0,50 & 0,11 \\
\hline
\end{tabular}

Tab. 14: Ergebnisse des $\mathrm{Chi}^{2}$-Tests von transversale lineare Schmelzhypoplasien. Signifikanzniveau $\alpha=0,05$.

\begin{tabular}{|l|l|l|}
\cline { 2 - 3 } \multicolumn{1}{c|}{} & $\mathrm{p}$-Wert & $\mathrm{x}^{\mathbf{2}}$ \\
\hline \hline Anatomieleichen gegen Regelbestattungen gesamt & 0,16 & 0,17 \\
\hline Anatomieleichen gegen Regelbestattungen nach Graden 0-VI & 0,52 & 5,85 \\
\hline Anatomieleichen Männer gegen Regelbestattungen Männer & 0,32 & 0,14 \\
\hline Regelbestattungen Männer gegen Regelbestattungen Frauen & 0,22 & 0,37 \\
\hline
\end{tabular}




\section{Infektionserkrankungen}

Tab. 15: Ergebnisse des Chi ${ }^{2}$-Tests von Infektionskrankheiten. K.A. = keine Angaben, denn aufgrund der geringen Datenmenge konnten nicht für alle Konstellationen statistische Tests ausgeführt werden. Signifikanzniveau $\alpha=0,05$.

\begin{tabular}{|l|c|c|c|c|c|c|c|c|}
\cline { 2 - 9 } & \multicolumn{2}{c|}{ Otitis media } & \multicolumn{2}{c|}{ Sinusitis max. } & \multicolumn{2}{c|}{ Sinusitis front. } & \multicolumn{2}{c|}{ Stomatitis } \\
\cline { 2 - 9 } & $\mathrm{p}-$ Wert & $\mathrm{x}^{2}$ & $\mathrm{p}$-Wert & $\mathrm{x}^{2}$ & $\mathrm{p}$-Wert & $\mathrm{x}^{2}$ & $\mathrm{p}$-Wert & $\mathrm{x}^{\mathbf{2}}$ \\
\hline \hline $\begin{array}{l}\text { Anatomieleichen gegen } \\
\text { Regelbestattungen }\end{array}$ & 0,019 & 0,18 & 0,007 & 0,04 & 0,07 & 0,09 & 0,14 & 0,51 \\
\hline $\begin{array}{l}\text { Anatomieleichen Männer } \\
\text { gegen Regelbestattungen } \\
\text { Männer }\end{array}$ & 0,025 & 0,12 & 0,032 & 0 & k.A. & k.A. & 0,047 & 0,45 \\
\hline $\begin{array}{l}\text { Regelbestattungen Männer } \\
\text { gegen Regelbestattungen } \\
\text { Frauen }\end{array}$ & 0,0065 & 0,93 & k.A. & k.A. & k.A & k.A. & k.A & k.A. \\
\hline
\end{tabular}




\section{Arthrotische Gelenksveränderungen}

\section{Seitenspezifische Gelenksarthrose}

Tab. 16: Ergebnisse des Wilcoxon-Man-Whitney-Tests für die unterschiedlichen Gruppen. Getestet wurde auf Unterschiede zwischen den Gelenken der linken und der rechten Körperseite. Signifikanzniveau p = 0,05.

\section{Anatomieleichen}

\begin{tabular}{|c|c|c|c|c|c|}
\hline & & \multicolumn{2}{|c|}{ Mittelwert } & \multicolumn{2}{|c|}{ U-Test } \\
\hline & Gelenkspaare & rechts & links & p-Wert & U-Wert \\
\hline Schulter & 27 & 1,42 & 1,40 & 0,8 & 350,5 \\
\hline Ellenbogen & 15 & 0,95 & 0,88 & 0,76 & 105 \\
\hline Radio-Ulnar & 14 & 1,07 & 1,09 & 0,89 & 95 \\
\hline Handgelenk & 15 & 1,38 & 1,38 & 0,93 & 110,5 \\
\hline Hüftgelenk & 19 & 1,63 & 1,68 & 0,60 & 162,5 \\
\hline Knie & 11 & 1,05 & 0,98 & 0,74 & 55,5 \\
\hline prox. Sprunggelenk & 17 & 1,01 & 0,94 & 0,52 & 126 \\
\hline dist. Sprunggelenk & 16 & 1,00 & 1,16 & 0,87 & 123,5 \\
\hline
\end{tabular}

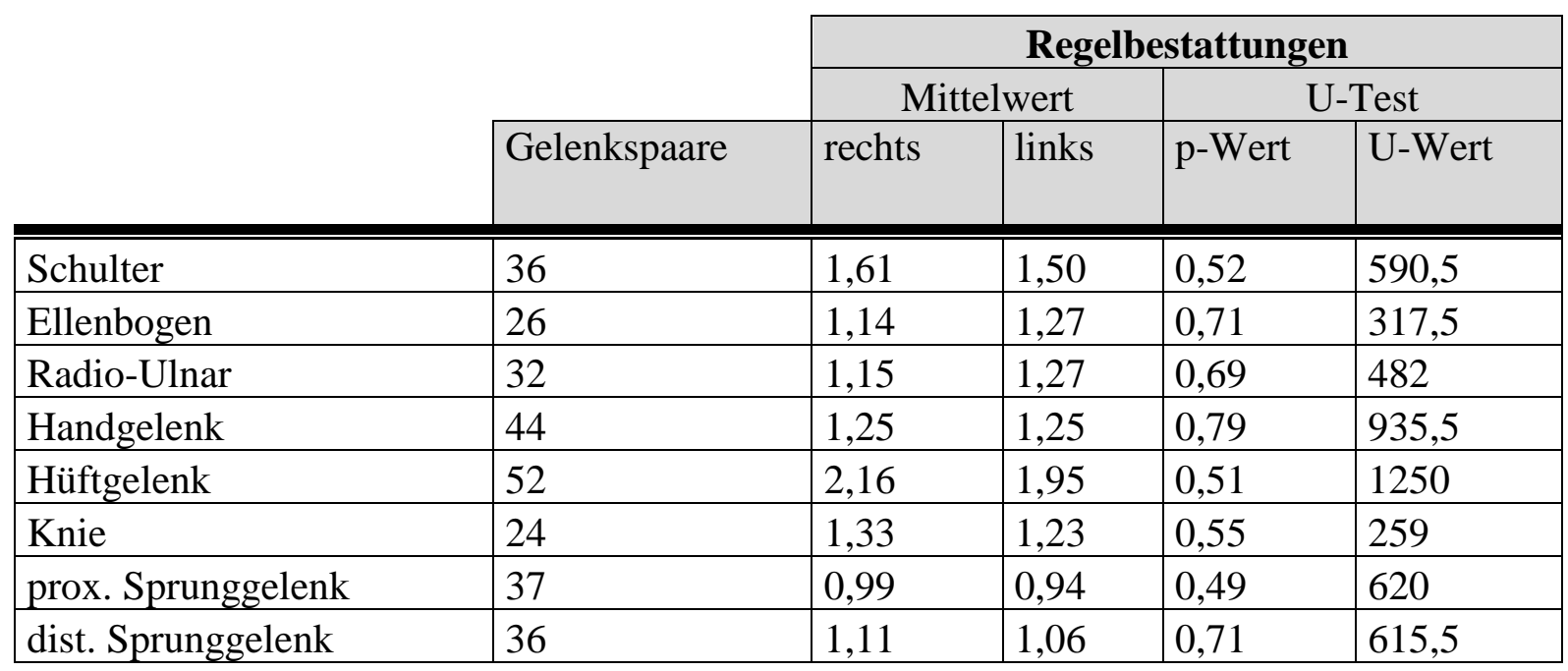

\begin{tabular}{|c|c|c|c|c|c|}
\hline & \multirow[b]{3}{*}{ Gelenkspaare } & \multicolumn{4}{|c|}{ Inden } \\
\hline & & \multicolumn{2}{|c|}{ Mittelwert } & \multicolumn{2}{|c|}{ U-Test } \\
\hline & & rechts & links & p-Wert & U-Wert \\
\hline Schulter & 97 & 2,02 & 1,94 & 0,43 & 4399 \\
\hline Ellenbogen & 126 & 1,88 & 1,78 & 0,18 & 7164,5 \\
\hline Radio-Ulnar & 111 & 2,00 & 2,00 & 0,89 & 6094,5 \\
\hline Handgelenk & 101 & 2,00 & 2,00 & 0,73 & 4959 \\
\hline Hüftgelenk & 153 & 2,30 & 2,28 & 0,47 & 11147 \\
\hline Knie & 132 & 2,01 & 2,00 & 0,33 & 8112,5 \\
\hline prox. Sprunggelenk & 131 & 1,66 & 1,69 & 0,29 & 7927,5 \\
\hline dist. Sprunggelenk & 137 & 1,89 & 1,91 & 0,47 & 8913 \\
\hline
\end{tabular}


$\underline{\text { Stärke der Gelenksarthrose }}$

Tab. 17: Mittelwerte und Ergebnisse des Kruskal-Wallis-Tests für die Körperregionen der Anatomieleichen. MW = Mittelwert, Signifikanzniveau $\mathrm{p}=0,05$.

\begin{tabular}{|l|l|l|}
\cline { 2 - 3 } \multicolumn{1}{c|}{} & Gelenkspaare & MW \\
\hline \hline Schultergelenk & 25 & 1,41 \\
\hline Ellenbogengelenk & 15 & 0,92 \\
\hline Radio-Ulnargelenk & 14 & 1,08 \\
\hline Handgelenk & 15 & 1,38 \\
\hline Hüftgelenk & 19 & 1,66 \\
\hline Kniegelenk & 11 & 1,02 \\
\hline prox. Sprunggelenk & 17 & 0,97 \\
\hline dist. Sprunggelenk & 16 & 1,08 \\
\hline
\end{tabular}

\begin{tabular}{|c|c|}
\hline p-Wert & H-Wert \\
\hline \hline 0,0005 & 21,96 \\
\hline
\end{tabular}

Tab. 18: Ergebnisse des Wilcoxon-Man-Whitney-Tests zwischen den Gelenken der oberen und unteren Extremitäten in der Gruppe der Anatomieleichen. Signifikanzniveau p =0,05.

\begin{tabular}{|l|l|}
\hline $\mathrm{p}$-Werte & U-Wert \\
\hline \hline 0,77 & 7 \\
\hline
\end{tabular}

Tab. 19: Mittelwerte und Ergebnisse des Kruskal-Wallis-Tests für die Körperregionen der Regelbestattungen. MW = Mittelwert, Signifikanzniveau $\mathrm{p}=0,05$.

\begin{tabular}{|l|l|l|}
\cline { 2 - 3 } \multicolumn{1}{c|}{} & Gelenkspaare & MW \\
\hline \hline Schultergelenk & 36 & 1,56 \\
\hline Ellenbogengelenk & 26 & 1,21 \\
\hline Radio-Ulnargelenk & 32 & 1,21 \\
\hline Handgelenk & 44 & 1,25 \\
\hline Hüftgelenk & 52 & 2,06 \\
\hline Kniegelenk & 24 & 1,28 \\
\hline prox. Sprunggelenk & 37 & 0,97 \\
\hline dist. Sprunggelenk & 36 & 1,08 \\
\hline
\end{tabular}

\begin{tabular}{|c|c|}
\hline p-Wert & H-Wert \\
\hline \hline $3,5^{*} 10^{-9}$ & 48,01 \\
\hline
\end{tabular}

Tab. 20: Ergebnisse des Wilcoxon-Man-Whitney-Tests zwischen den Gelenken der oberen und unteren Extremitäten in der Gruppe der Regelbestattungen. Signifikanzniveau $\mathrm{p}=0,05$.

\begin{tabular}{|l|l|}
\hline$p-W e r t$ & U-Wert \\
\hline \hline 0,77 & 7 \\
\hline
\end{tabular}

Tab 21: Ergebnisse des Wilcoxon-Man-Whitney-Tests zwischen den Gruppen auf Unterschiede hinsichtlich der Arthroseintensität. Signifikanzniveau $\mathrm{p}=0,05$.

\begin{tabular}{|l|l|}
\hline$p$-Wert & U-Wert \\
\hline \hline 0.12 & 87 \\
\hline
\end{tabular}


Gruppenspezifische Gelenksarthrose

Tab. 22: Prozentualer Verteilung der Bewertungsziffern der Arthroseintensität der einzelnen Körperregionen für die unterschiedlichen Gruppen. Grundlage sind die Mittelwerte der linken und rechten Körperseite für jede Körperregion.

\begin{tabular}{|l|l|l|l|l|l|l|l|}
\hline \multicolumn{1}{|c|}{ Anatomieleichen } & $0.0-0.9$ & $1.0-1.9$ & $2.0-2.9$ & $3.0-3.9$ & $4.0-4.9$ & $5.0-5.9$ & 6 \\
\hline \hline Ellenbogengelenk & 20.00 & 56.00 & 24.00 & 0.00 & 0.00 & 0.00 & 0.00 \\
\hline Radio-Ulnargelenk & 46.67 & 53.33 & 0.00 & 0.00 & 0.00 & 0.00 & 0.00 \\
\hline Handgelenk & 28.57 & 64.29 & 7.14 & 0.00 & 0.00 & 0.00 & 0.00 \\
\hline Hüftgelenk & 13.33 & 66.67 & 13.33 & 6.67 & 0.00 & 0.00 & 0.00 \\
\hline Kniegelenk & 15.79 & 31.58 & 52.63 & 0.00 & 0.00 & 0.00 & 0.00 \\
\hline prox. Sprunggelenk & 54.55 & 36.36 & 9.09 & 0.00 & 0.00 & 0.00 & 0.00 \\
\hline dist. Sprunggelenk & 52.94 & 41.18 & 0.00 & 0.00 & 5.88 & 0.00 & 0.00 \\
\hline Ellenbogengelenk & 43.75 & 50.00 & 6.25 & 0.00 & 0.00 & 0.00 & 0.00 \\
\hline
\end{tabular}

\begin{tabular}{|l|l|l|l|l|l|l|l|}
\hline Regelbestattungen & $0.0-0.9$ & $1.0-1.9$ & $2.0-2.9$ & $3.0-3.9$ & $4.0-4.9$ & $5.0-5.9$ & 6 \\
\hline \hline Ellenbogengelenk & 16.67 & 41.67 & 38.89 & 2.78 & 0.00 & 0.00 & 0.00 \\
\hline Radio-Ulnargelenk & 38.46 & 34.62 & 26.92 & 0.00 & 0.00 & 0.00 & 0.00 \\
\hline Handgelenk & 37.50 & 43.75 & 15.63 & 3.13 & 0.00 & 0.00 & 0.00 \\
\hline Hüftgelenk & 22.73 & 47.73 & 27.27 & 2.27 & 0.00 & 0.00 & 0.00 \\
\hline Kniegelenk & 11.54 & 30.77 & 34.62 & 23.08 & 0.00 & 0.00 & 0.00 \\
\hline prox. Sprunggelenk & 33.33 & 50.00 & 12.50 & 4.17 & 0.00 & 0.00 & 0.00 \\
\hline dist. Sprunggelenk & 54.05 & 37.84 & 8.11 & 0.00 & 0.00 & 0.00 & 0.00 \\
\hline Ellenbogengelenk & 33.33 & 58.33 & 8.33 & 0.00 & 0.00 & 0.00 & 0.00 \\
\hline
\end{tabular}

\begin{tabular}{|l|l|l|l|l|l|l|l|}
\hline \multicolumn{1}{|c|}{ Inden } & $0.0-0.9$ & $1.0-1.9$ & $2.0-2.9$ & $3.0-3.9$ & $4.0-4.9$ & $5.0-5.9$ & 6 \\
\hline \hline Ellenbogengelenk & 5.15 & 31.96 & 57.73 & 5.15 & 0.00 & 0.00 & 0.00 \\
\hline Radio-Ulnargelenk & 1.59 & 66.67 & 28.57 & 3.17 & 0.00 & 0.00 & 0.00 \\
\hline Handgelenk & 2.70 & 38.74 & 54.05 & 4.50 & 0.00 & 0.00 & 0.00 \\
\hline Hüftgelenk & 4.95 & 21.78 & 67.33 & 5.94 & 0.00 & 0.00 & 0.00 \\
\hline Kniegelenk & 3.92 & 11.76 & 70.59 & 13.07 & 0.65 & 0.00 & 0.00 \\
\hline prox. Sprunggelenk & 2.27 & 41.67 & 52.27 & 2.27 & 1.52 & 0.00 & 0.00 \\
\hline dist. Sprunggelenk & 0.76 & 90.84 & 8.40 & 0.00 & 0.00 & 0.00 & 0.00 \\
\hline Ellenbogengelenk & 1.46 & 49.64 & 48.91 & 0.00 & 0.00 & 0.00 & 0.00 \\
\hline
\end{tabular}


$\underline{\text { Geschlechtsspezifische Gelenksarthrose }}$

Tab. 23: des Wilcoxon-Man-Whitney-Test auf sign. Unterschiede zwischen regelbestatteten Männern und Frauen. Signifikanzniveau $\mathrm{p}=0,05$.

\begin{tabular}{|l|l|l|l|l|}
\cline { 2 - 5 } & \multicolumn{2}{|c|}{ Mittelwert } & \multicolumn{2}{c|}{ U-Test } \\
\cline { 2 - 5 } & Männer & Frauen & p-Wert & U-Wert \\
\hline \hline Schulter & 1.76 & 1.30 & 0.06 & 106,5 \\
\hline Knie & 1.07 & 1.44 & 0.21 & 45,5 \\
\hline
\end{tabular}

Tab. 24: des Wilcoxon-Man-Whitney-Test auf sign. Unterschiede zwischen männlichen Anatomieleichen und männlichen Regelbestattungen. Signifikanzniveau $\mathrm{p}=0,05$.

\begin{tabular}{|l|l|l|l|l|}
\cline { 2 - 5 } & \multicolumn{2}{|c|}{ Mittelwert } & \multicolumn{2}{c|}{ U-Test } \\
\cline { 2 - 6 } & $\begin{array}{l}\text { Männer } \\
\text { Regelbestattungen }\end{array}$ & $\begin{array}{l}\text { Männer } \\
\text { Anatomieleichen }\end{array}$ & p-Wert & U-Wert \\
\hline \hline Schulter & 1.76 & 1.37 & 0.07 & 163 \\
\hline Ellenbogen & 1.30 & 0.92 & 0.10 & 84,5 \\
\hline Hüftgelenk & 2.07 & 1.66 & 0.19 & 244 \\
\hline
\end{tabular}

\section{$\underline{\text { Altersspezifische Gelenksarthrose }}$}

Tab. 25: des Wilcoxon-Man-Whitney-Test auf sign. Unterschiede zw. Anatomieleichen und Regelbestattungen für jede Altersklasse einzeln pro Körperregion. K.A. = keine Angaben aufgrund zu geringer Datendichte. Signifikanzniveau $\alpha=0,05$.

\begin{tabular}{|c|c|c|c|c|c|c|c|c|}
\hline & \multicolumn{2}{|c|}{ subadult } & \multicolumn{2}{|c|}{ adult } & \multicolumn{2}{|c|}{ matur } & \multicolumn{2}{|c|}{ senil } \\
\hline & p-Wert & U-Wert & p-Wert & \begin{tabular}{|l|} 
U- \\
Wert
\end{tabular} & p-Wert & U-Wert & p-Wert & U-Wert \\
\hline Schultergelenk & k.A. & k.A. & 0,60 & 43 & 0,23 & 117 & 0,51 & 39 \\
\hline Ellenbogengelenk & k.A. & k.A. & 0,43 & 24,5 & 0,06 & 38,5 & k.A. & k.A. \\
\hline Radio-Ulnargelenk & k.A. & k.A. & 0,57 & 14 & 0,51 & 79,5 & 0,26 & 12 \\
\hline Handgelenk & k.A. & k.A. & 0,89 & 19 & 0,93 & 135,5 & 0,13 & 18 \\
\hline Hüftgelenk & k.A. & k.A. & 0,54 & 32,5 & 0,1 & 128,5 & 0,38 & 21,5 \\
\hline Kniegelenk & k.A. & k.A. & 0,41 & 9 & 0,07 & 17 & 0,93 & 13 \\
\hline prox. Sprunggelenk & 0,16 & 2 & 0,60 & 31,5 & 0,44 & 86,5 & 0,47 & 26 \\
\hline dist. Sprunggelenk & k.A. & k.A. & 0,75 & 31,5 & 0,51 & 72 & 0,51 & 25 \\
\hline
\end{tabular}

Tab. 26: Kruskal-Wallis-Test auf sign. Unterschied zw. den Altersklassen in beiden Gruppen $(\mathrm{AL}=$ Anatomieleichen; $\mathrm{R}=$ Regelbestattungen). Signifikanzniveau $\alpha=0,05$.

\begin{tabular}{|l|l|l|l|l|}
\cline { 2 - 5 } & \multicolumn{2}{c|}{ AL subadult adult matur senil } & \multicolumn{2}{c|}{ R subadult adult matur senil } \\
\cline { 2 - 5 } & \multicolumn{1}{c|}{ H-Wert } & \multicolumn{1}{c|}{ p-Wert } & \multicolumn{1}{c|}{ H-Wert } \\
\hline \hline Schultergelenk & 0,10 & 4,69 & 0,003 & 11,93 \\
\hline Radio-Ulnargelenk & 0,48 & 1,47 & 0,11 & 4,39 \\
\hline Handgelenk & 0,06 & 5,59 & 0,006 & 10,39 \\
\hline Hüftgelenk & 0,051 & 5,94 & 0,014 & 8,47 \\
\hline Kniegelenk & 0,43 & 1,69 & 0,055 & 5,79 \\
\hline $\begin{array}{l}\text { prox. } \\
\text { Sprunggelenk }\end{array}$ & 0,022 & 9,61 & 0,003 & 14,27 \\
\hline dist. Sprunggelenk & 0,08 & 5,11 & 0,075 & 5,17 \\
\hline
\end{tabular}




\section{Arthrotische Wirbelsäulenveränderungen}

\section{$\underline{\text { Seitenspezifische Wirbelbogenarthrose }}$}

Tab. 27: Ergebnisse des des Wilcoxon-Man-Whitney-Tests für die Anatomieleichen. Getestet wurde auf Unterschiede zwischen den Wirbelbogengelenken der linken und der rechten Körperseite. Signifikanzniveau $\alpha=0,05$.

\begin{tabular}{|l|l|}
\hline$p$-Wert & U-Wert \\
\hline \hline 0,65 & 289 \\
\hline
\end{tabular}

Tab. 28: Ergebnisse des des Wilcoxon-Man-Whitney-Tests für die Regelbestattungen. Getestet wurde auf Unterschiede zwischen den Wirbelbogengelenken der linken und der rechten Körperseite. Signifikanzniveau $\alpha=0,05$.

\begin{tabular}{|l|l|}
\hline$p$-Wert & U-Wert \\
\hline \hline 0,52 & 279 \\
\hline
\end{tabular}

\section{Gruppenspezifische Wirbelbogenarthrose}

Tab. 29: Ergebnisse des des Wilcoxon-Man-Whitney-Tests für die Regelbestattungen und Anatomieleichen. Getestet wurde auf Unterschiede zwischen den Gruppen. Signifikanzniveau $\alpha=0,05$.

\begin{tabular}{|l|l|l|l|}
\hline \multicolumn{2}{|c|}{ Mittelwert } & \multicolumn{2}{c|}{ U-Test } \\
\hline Regelbestattungen & $\begin{array}{l}\text { Anatomieleiche } \\
\mathrm{n}\end{array}$ & $\mathrm{p}$-Wert & U-Wert \\
\hline \hline 2,01 & 2,21 & $5,7 * 10^{-5}$ & 105 \\
\hline
\end{tabular}

\section{Altersspezifische Wirbelbogenarthrose}

Tab. 30: Ergebnisse des Kruskal-Wallis-Tests für die Regelbestattungen und Anatomieleichen. Getestet wurde auf Unterschiede zwischen den Altersklassen. Signifikanzniveau $\alpha=0,05$.

\begin{tabular}{|l|l|l|}
\cline { 2 - 3 } \multicolumn{1}{c|}{} & \multicolumn{2}{c|}{ subadult adult matur senil } \\
\cline { 2 - 3 } & $\mathrm{p}-$ Wert & H-Wert \\
\hline \hline Regelbestattungen Mann & $1.9 * 10^{-7}$ & 34,05 \\
\hline Regelbestattungen Frau & $3,8^{*} 10^{-11}$ & 51,50 \\
\hline Anatomieleichen Mann & $4,8^{*} 10^{-5}$ & 19,90 \\
\hline
\end{tabular}

\section{Gruppenspezifische Wirbelkörperarthrose}

Tab. 31: Ergebnisse des des Wilcoxon-Man-Whitney-Tests für die Regelbestattungen und Anatomieleichen. Getestet wurde auf Unterschiede zwischen den Gruppen. Signifikanzniveau $\alpha=0,05$.

\begin{tabular}{|l|l|l|l|}
\hline \multicolumn{2}{|c|}{ Mittelwert } & \multicolumn{2}{c|}{ U-Test } \\
\hline Regelbestattungen & $\begin{array}{l}\text { Anatomieleiche } \\
\mathrm{n}\end{array}$ & $\mathrm{p}$-Wert & U-Wert \\
\hline \hline 2,17 & 2,24 & 0.50 & 255 \\
\hline
\end{tabular}

\section{Altersspezifische Wirbelkörperarthrose}

Tab. 32: Ergebnisse des Kruskal-Wallis-Tests für die Regelbestattungen und Anatomieleichen. Getestet wurde auf Unterschiede zwischen den Altersklassen. Signifikanzniveau $\alpha=0,05$.

\begin{tabular}{|l|l|l|}
\cline { 2 - 3 } \multicolumn{1}{c|}{} & \multicolumn{2}{c|}{ subadult adult matur senil } \\
\cline { 2 - 3 } & p-Wert & H-Wert \\
\hline \hline Regelbestattungen Mann & $4 * 10^{-17}$ & 79,47 \\
\hline Regelbestattungen Frau & $1,3 * 10^{-10}$ & 45,52 \\
\hline Anatomieleichen Mann & $1,2 * 10^{-13}$ & 63,20 \\
\hline
\end{tabular}




\section{Vergleich der Allelfrequenzen}

Tab. 33: Ergebnisse des Exakten Fisher-Tests. Getestet wurde auf Unterschiede der Allelhäufigkeiten zwischen den Gruppen. Signifikanzniveau $\alpha=0,05$.

\begin{tabular}{|l|l|}
\hline STR-System & $p$-Wert \\
\hline \hline D13S317 & 0,87 \\
\hline D21S11 & 0,7 \\
\hline D18S51 & 0,16 \\
\hline TH01 & 0,31 \\
\hline D5S818 & 0,86 \\
\hline FGA & 0,54 \\
\hline
\end{tabular}

\subsection{Daten auf der beigelegten CD/Band 2}

Auf der der Arbeit beigelegten CD befindet sich die Datensammlung aus Kapitel 4.1.1 (Tabelle

3) und der ausführliche Fundkatalog zu den untersuchten Individuen der Skelette vom katholischen Friedhof Göttingens. 


\section{Danksagung}

In erster Linie möchte ich mich bei Prof. Dr. Peter Kappeler, Prof. Dr. Dr. Michael Schultz und Dr. Susanne Hummel recht herzlich für die hilfsbereite und wissenschaftliche Betreuung bedanken. Jeder hat mir mit seiner ganz eigenen Expertise sehr weitergeholfen. So durfte ich mich in der AG Paläopathologie genauso zu Hause fühlen wie in der Abteilung Historische Anthropologie und Humanökologie.

Dr. Birgit Großkopf bin ich dankbar für die guten Ratschläge und die Unterstützung während der Promotion. Ein großer Dank geht an Marthe Frischalowski, M.Sc. und Dipl. Biologin Janine Mazanec für die wissenschaftliche Unterstützung bei der Fragmentlängenanalyse der genetischen Fingerabdrücke und die Sequenzanalyse der Tuberkulose- bzw. Osteomyelitisproben. Danke auch an Anna Lena Flux, M.Sc. und Marion Knierim-Grenzebach für die Unterstützung im Labor.

Danken möchte ich außerdem dem Niedersächsischen Ministerium für Wissenschaft und Kultur (MWK), welche dieses Projekt im Rahmen des Programms Pro* Niedersachsen durch ihre finanzielle Unterstützung ermöglicht haben.

Des Weiteren bedanke ich mich beim Stadtarchiv Göttingen, Bistumsarchiv Hildesheim, Niedersächsischen Landesarchiv Standort Hannover und Wolfenbüttel für die Bereitstellung der archivalischen Unterlagen. Auch der Sütterlinstube im Riebeck Stift Halle sei gedankt für die Übersetzungen handschriftlicher Unterlagen.

Ein besonderer Dank gilt meinen Eltern und meiner Familie, die mich immer unterstützt und an mich geglaubt haben. Danke, dass ihr mir diesen Weg ermöglicht habt. Henning, deine unglaubliche Geduld und dein Verständnis haben mir in den vielen Stunden der Arbeit den Rücken gestärkt. Vielen Dank für die Kraft, den Rückhalt und die vielen lieben Worte. 


\section{Promovierenden-Erklärung der Georg-August-Universität Göttingen}

Name: Feicke, Maria, M.Sc.

Anschrift: Hannoversche Straße 133, Apt. 12, 37077, Göttingen

Ich beabsichtige, eine Dissertation zum Thema „Historische Anatomieleichen der Universität Göttingen - Zur Morbidität einer Bevölkerungsgruppe des 19. Jahrhunderts“ an der GeorgAugust-Universität Göttingen anzufertigen. Dabei werde ich von Prof. Dr. P. Kappeler, Prof. Dr. Dr. M. Schultz und Dr. S. Hummel betreut.

Ich gebe folgende Erklärung ab:

1. Die Gelegenheit zum vorliegenden Promotionsvorhaben ist mir nicht kommerziell vermittelt worden. Insbesondere habe ich keine Organisation eingeschaltet, die gegen Entgelt Betreuerinnen und Betreuer für die Anfertigung von Dissertationen sucht oder die mir obliegenden Pflichten hinsichtlich der Prüfungsleistungen für mich ganz oder teilweise erledigt.

2. Hilfe Dritter wurde bis jetzt und wird auch künftig nur in wissenschaftlich vertretbarem und prüfungsrechtlich zulässigem Ausmaß in Anspruch genommen. Insbesondere werden alle Teile der Dissertation selbst angefertigt; unzulässige fremde Hilfe habe ich dazu weder unentgeltlich noch entgeltlich entgegengenommen und werde dies auch zukünftig so halten.

3. Die Ordnung zur Sicherung der guten wissenschaftlichen Praxis an der Universität Göttingen wird von mir beachtet.

4. Eine entsprechende Promotion wurde an keiner anderen Hochschule im In- oder Ausland beantragt; die eingereichte Dissertation oder Teile von ihr wurden/werden nicht für ein anderes Promotionsvorhaben verwendet.

Mir ist bekannt, dass unrichtige Angaben die Zulassung zur Promotion ausschließen bzw. später zum Verfahrensabbruch oder zur Rücknahme des erlangten Grades führen können.

Göttingen, 22.01.2019 